\title{
Análise Multi-espeCtral dos Eventos Cíclicos de $\eta$ Carinae
}

\author{
Mairan Macedo Teodoro \\ Sob orientação do \\ Prof. Dr. Augusto Damineli Neto
}

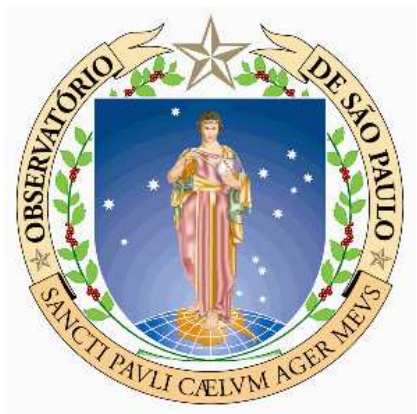

Instituto De Astronomia, Geofísica e Ciências Atmosféricas

Universidade de SÃo Paulo

Tese apresentada ao

Instituto de Astronomia, Geofísica e Ciências Atmosféricas da Universidade de São Paulo como requisito parcial para a obtenção do título de Doutor em Astronomia.

Outubro de 2009 
Mairan Macedo Teodoro

\section{Análise multi-espectral dos eventos cíclicos de $\eta$ Carinae}

Orientador:

Prof. Dr. Augusto Damineli Neto

Tese apresentada ao Instituto de Astronomia, Geofísica e Ciências Atmosféricas da Universidade de São Paulo, como requisito parcial para obtenção do título de Doutor em Astronomia.

São Paulo - Outubro de 2009 
À minha amada,

Pricila. 


\section{Agradecimentos}

Agradeço, em primeiríssimo lugar e de maneira muito especial, ao meu orientador, Prof. Augusto Damineli, por me acompanhar em mais uma jornada, cujo resultado está nesta tese.

Agradeço à minha esposa, Pricila, por me aguentar e entender as minhas ausências durante as frequentes e longas missões ao OPD/LNA. Também agradeço aos meus 'pequerruchos': Muque e Lua, por serem companheiros nas minhas (raras) horas de folga.

Agradeço aos meus colegas do Departamento de Astronomia do IAG/USP: Tatiana Laganá, Prof. Alex Carciofi, Aline Vidotto, Marcus Vinicius, Alessandro Moisés, Oscar Cavichia, Gustavo Rocha, Alberto Martins, Raimundo Lopes, Pedro Beaklini, Roberto Menezes a todos os T(h)iagos do Departamento e muitos outros que não pude citar aqui. Sem a ajuda de vocês esta tese não estaria completa.

Agradeço aos meus colaboradores, com os quais pude aprender muita coisa: Dr. José Groh, Dr. Theodore Gull e Dr. João E. Steiner.

Agradeço aos assistentes noturnos do OPD/LNA, que são imprescindíveis nas horas de apuros durante as noites de observação e que também ajudam a tornar agradáveis as nubladas.

Agradeço aos técnicos e analistas do Departamento de Astronomia do IAG/USP: Marcos, Luis, Ulisses e Patrícia. Sem a competência, disponibilidade e prontidão para resolver as questões de informática, típicas de cada um de vocês, esta tese não teria chegado ao fim.

Agradeço às secretárias do Departamento de Astronomia do IAG/USP: Marina, Regina, Cida e Conceição. Vocês formam o time de secretárias mais competente que eu já pude conhecer!

Agradeço a secretária da seção de pós-graduação, Rosemary F. da Silva, pela prontidão e competência em resolver os problemas que eu apresentei a ela.

Este trabalho teve auxílio financeiro da FAPESP através do processo 05/00190-8. 
"É melhor acender uma vela do que praguejar contra a escuridão"

Antigo provérbio oriental 


\section{Resumo}

Nesta tese foi feito um estudo dos eventos cíclicos em $\eta$ Carinae em diversas faixas espectrais. A presença de um buraco na região polar do Homúnculo foi confirmada pelos mapas de velocidade da linha do [Fe II] $\lambda 12567$. A componente em emissão da linha do He I $\lambda 10830$, detectada na linha de visada do lóbulo NW e que apresenta velocidades negativas, foi mapeada e está contida no plano equatorial. Foi observado que durante um período de 206 dias, centrado na fase zero, a linha do He i $\lambda 10830$ apresenta um aumento na velocidade máxima da componente em absorção, atingindo $-1800 \mathrm{~km} \mathrm{~s}^{-1}$. Tal comportamento favorece orientações orbitais onde a passagem pelo periastro ocorre próximo à oposição. O Pequeno Homúnculo apresenta a mesma distribuição espacial da emissão em rádio e, considerando que esta seja proveniente principalmente da secundária, o fluxo de fótons no contínuo de Lyman é compatível com uma estrela de tipo espectral O5.5-O7. A variabilidade das componentes largas e estreitas das linhas em diversas faixas espectrais apresenta um período bem definido (2022.1 \pm 0.6 dias) e extremamente estável ao longo dos últimos 60 anos, sendo que as variações observadas no período são devido aos erros nas medidas. Utilizando a componente estreita da linha do He I $\lambda 6678$ foi possível determinar a fase zero do ciclo \#11 $\left(T_{0}=2452819.8\right)$. Os eventos espectroscópicos são compostos de dois regimes: um de variações lentas e outro de colapso. A primeira é revelada por variações lentas no nível de ionização do meio circunstelar ao longo de todo o ciclo e está associada a variações graduais no cone de choque dos ventos (abertura angular e conteúdo). O regime de colapso é observado ao redor do mínimo e é causado por um colapso temporário do cone de choque. Os fenômenos de alta energia são sensíveis somente ao regime de colapso, enquanto os de baixa energia, ao de variação lenta. Os fenômenos que envolvem energias intermediárias, respondem aos dois regimes. Foi observado uma anti-correlação entre a linha do Fe II $\lambda 6455$ e a do He I $\lambda 7065$, indicando que a primeira é formada nas regiões mais externas do vento da primária e a segunda, na secundária ou no cone de choque dos ventos. A curva de luz do He II $\lambda 4686$ apresenta dois picos antes da fase zero e outro logo após. Os dois picos antes do mínimo apresentam uma correlação com os picos na faixa dos raios-X, porém estes ocorrem 16.5 dias antes daqueles. O mecanismo mais provável para explicar a luminosidade observada do He II $\lambda 4686$ é a produção de fótons com $\lambda \sim 1215 \AA$ através do fluxo de fótons na faixa do ultra-violeta extremo/raios-X moles produzidos na região próxima ao ápex do cone de colisão dos ventos. Como este mecanismo é extremamente sensível à densidade do meio, a região mais favorável para produzir a luminosidade observada do He II $\lambda 4686$ é a região do cone de choque voltada para a primária. 


\section{Abstract}

In this thesis, a multi-wavelength study on the cyclic events of $\eta$ Carine was performed. The presence of a hole in the polar region of the Homunculus was confirmed by the velocity maps of the [Fe II] $\lambda 12567$ line. The blue-shifted component of the He I $\lambda 10830$, detected towards the NW lobe, was mapped and it is in the equatorial plane. It was observed that within a short period of 206 days, centered on phase zero, the He I $\lambda 10830$ line shows an increase in the maximum velocity of the absorption component, which reaches up to $-1800 \mathrm{~km} \mathrm{~s}^{-1}$. Such behavior favors orbital orientation with periastron passage around oposition. The Little Homunculus shows the same spatial distribution as the radio emission and considering that the radio flux comes mainly from the secondary, then the photon flux in the Lyman continuum is comparable to a star with spectral type in the range O5.5-O7. The variability of the narrow and broad lines from many spectral regions shows a well-defined period (2022.1 \pm 0.6 days), which is also extremely stable along the last 60 years, during which the observed variations in the period are due to measurement errors. Using the narrow component of the He I $\lambda 6678$ it was possible to determine the phase zero of the cycle $\# 11\left(T_{0}=2452819.8\right)$. The spectroscopic events are a combination of two components: slow variation and collapse. The former is revealed by slow changes in the ionization level of circunstellar matter across the whole cycle and is associated to gradual changes in the wind-wind collision shock-cone (angular opening and gaseous content). The collapse component is restricted to around the minimum and is caused by a temporary collapse of the wind-wind collision shock. High-energy phenomena are sensitive only to the collapse component, while low-energy only to the slow variation component. Intermediate-energy phenomena are sensitive to both components. It was observed an anti-correlation between the Fe II $\lambda 6455$ and He I $\lambda 7065$, suggesting that the former is formed in the outer parts of the primary's wind, while the latter is associated to the secondary or to the wind-wind shock cone. The lightcurve of He II $\lambda 4686$ shows two peaks before phase zero and another one short after it. The two peaks before phase zero are correlated to the peaks seen in the X-rays. However, the X-ray peaks occur 16.5 days before those seen in the He II $\lambda 4686$ lightcurve. The most likely mechanism to explain the observed peak luminosity of the He II $\lambda 4686$ is the creation of $\lambda \sim 1215 \AA$ photons by the extreme ultra-violet/soft X-rays photons, which are produced near the apex of the wind-wind shock-cone. Since this mechanism is extremely sensitive to the density, the most likely region to form the observed peak luminosity of the He II $\lambda 4686$ is on the primary's side of the wind-wind shock-cone. 


\section{Lista de Figuras}

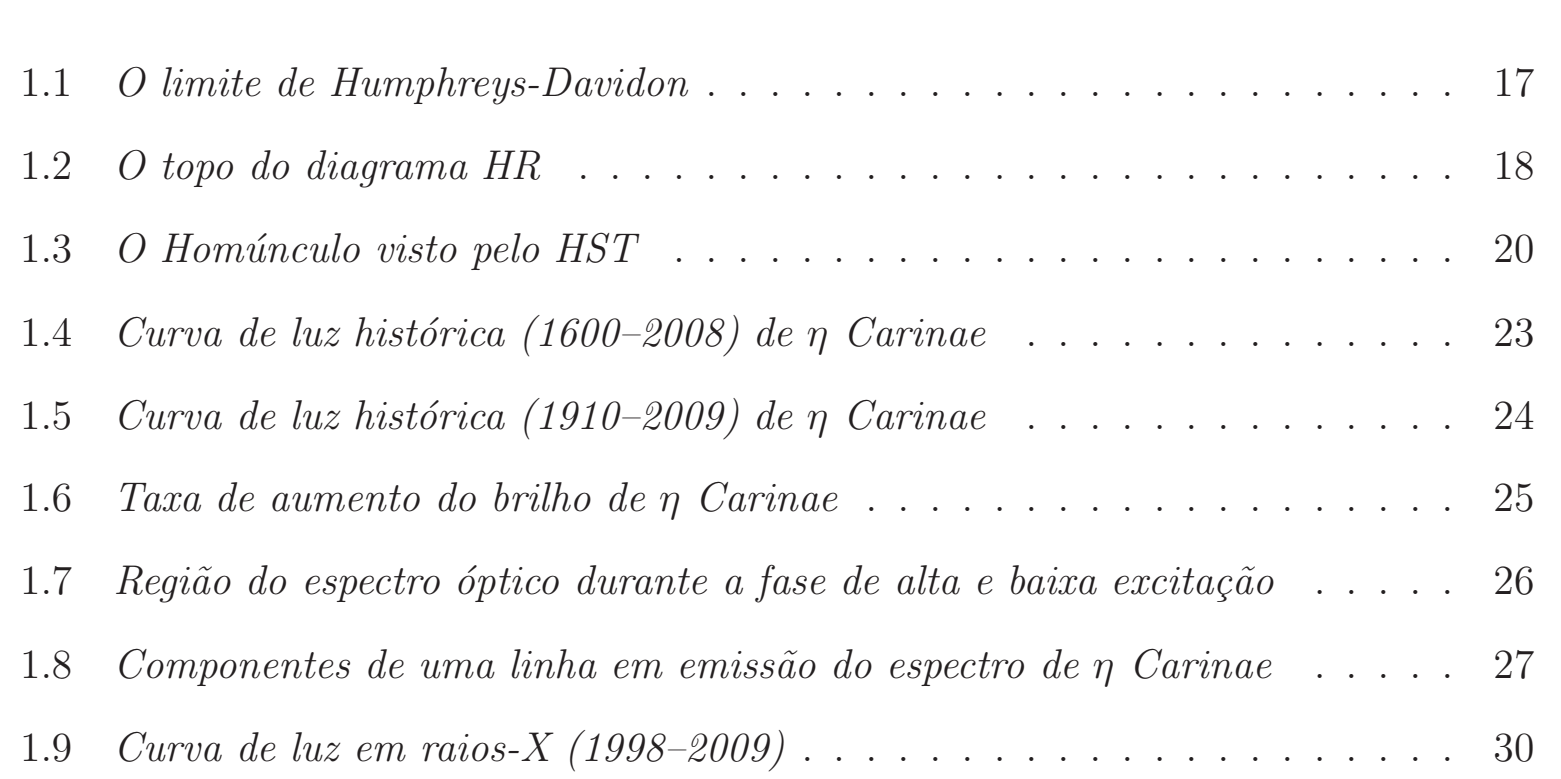

2.1 Espectro de $n$ Carinae obtido em 08/Mar/2009 com o Goodman . . . . . 39

2.2 Espectro de $\eta$ Carinae obtido em 18/Abr/2009 no OPD . . . . . . . . 40

2.3 Espectro de $n$ Carinae obtido em 04/Mai/2009 com o FEROS . . . . . . . 42

2.4 Espectro de $n$ Carinae obtido em 07/Mar/2009 com o REOSC ....... 43

2.5 Espectro de $n$ Carinae obtido em 09/Mar/2009 no CTIO . . . . . . . . . 44

2.6 Espectros de comparacão do Goodman: $\mathrm{Hq}$-Ar e Cu-Ar .......... 47

2.7 Solucão para o polinômio $\lambda$-pixel para cada lâmpada de calibracão _. . . . 48

2.8 Comparacão entre as solucões encontradas para o polinômio $\lambda$-pixel . . . . 49

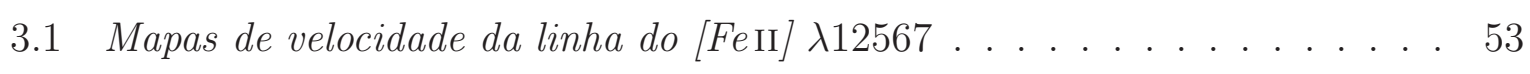

3.2 Determinacão da espessura dos lóbulos na reqião polar . . . . . . . . . . 54

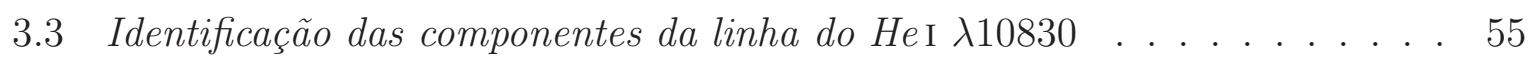

3.4 Perfil de velocidade da linha do He $\lambda 10830$ ao lonqo de P.A.=-41 . . 56

3.5 Comparacão entre o mapa rádio em $3 \mathrm{~cm}$ e o Pequeno Homúnculo . . . . . 58 


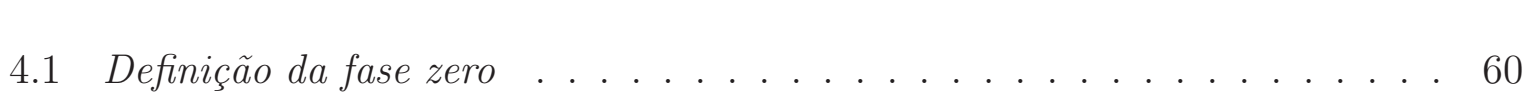

4.2 Determinacão do período através do deslocamento de curvas de luz . . . . 61

4.3 Determinacão do período através da laraura equivalente do He II $\lambda 4686$. . 63

4.4 Determinacão do período através da razão entre linhas _... . . . . . . . 65

4.5 Determinacão do período através da curva de luz do He II $\lambda 4686$. . . . . . 66

4.6 Intensidade relativa das linhas do [NII] $\lambda 5755$ e [Fe II] $\lambda 5745] \ldots \ldots$

5.1 A dupla composicão dos eventos . . . . . . . . . . . . . . . . . . . . 71

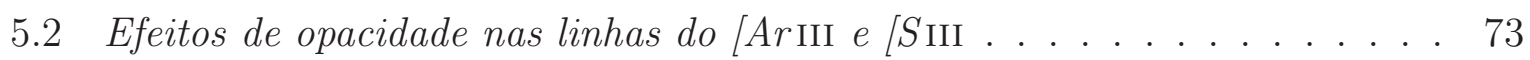

5.3 A componente estreita das linhas de alto potencial durante o evento . . . . 75

5.4 A componente estreita da linha do He I $\lambda 6678$ nos últimos 3 eventos . . . . 78

5.5 A componente laraa da linha do He I $\lambda 6678$ nos últimos 3 eventos . . . . . 79

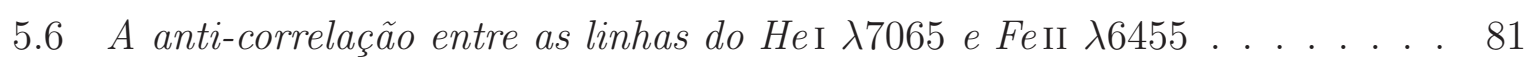

5.7 Perfil do He I $\lambda 10830$ ao lonqo de um ciclo . . . . . . . . . . . . . . . . . 83

5.8 Perfil do He $\lambda 10830$ durante a fase de alta e baixa excitacão . . . . . . . 84

5.9 Velocidade máxima da componente em absorcão do He I $\lambda 10830$. . . . . . 85

5.10 Uma visão do evento em vários comprimentos de onda . . . . . . . . . . 87

5.11 Velocidade radial de alqumas linhas espectrais durante o evento . . . . . . 89

6.1 A larqura equivalente do HeII $\lambda 4686$ durante os últimos \& eventos . . . . . 95

6.2 Determinacão do período através da larqura equivalente do He II $\lambda 4686$. . 96

6.3 Comparacão entre a larqura equivalente do He II $\lambda 4686$ e o fluxo em raios-X 98

6.4 Correcão da larqura equivalente pelo fluxo do contínuo para 2003.5 . . . . 99

6.5 Correcão da laraura equivalente pelo fluxo do contínuo para 2009.0 . . . . 101

6.6 Luminosidade da linha do He II $\lambda 4686 \ldots \ldots$. . . . . . . . . . . . . . . 102

6.7 Número de fótons por sequndo na linha do He $\mathrm{II} \lambda 4686$. . . . . . . . . . 103

6.8 Velocidade radial do pico e do centróide da linha do He II $\lambda 4686$. . . . . . 104

7.1 Espectro sintético intrínseco na faixa do UV extremo/raios-X . . . . . . . 115

A.1 Curva de luz histórica (1910-2009) de n Carinae . . . . . . . . . . . . 144 


\section{Lista de Tabelas}

2.1 Resumo das características de cada instrumento utilizado para obtenção dos espectros utilizados nesta tese. . . . . . . . . . . . . . . . . . . . . . 38

2.2 Comparacão dos parâmetros da solucão final encontrada pelo pacote IDENTIFY para as lâmpadas de calibração obtidas em 03 de Abril de 2009. . . . 50

4.1 Período dos eventos espectroscópicos determinado utilizando diversos métodos e em diferentes regiões espectrais. $P_{\text {pres }}$ representa o período médio

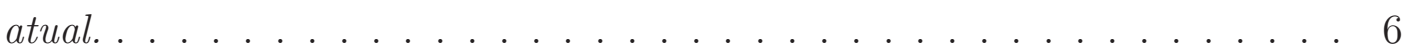

4.2 Limites para o período dos eventos espectroscópicos determinado utilizando as épocas previstas e observadas pana o mínimo. $P_{\text {med }}$ representa o valor médio do período entre 1948 e 1986.

5.1 Intervalo de tempo, a partir da fase zero, para desaparecimento da componente estreita dl linha indicada. $n_{\mathrm{c}}$ é a densidade crítica para formação da

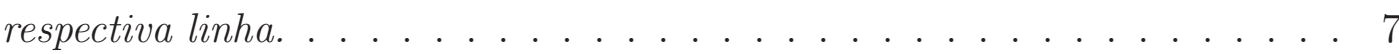




\section{Sumário}

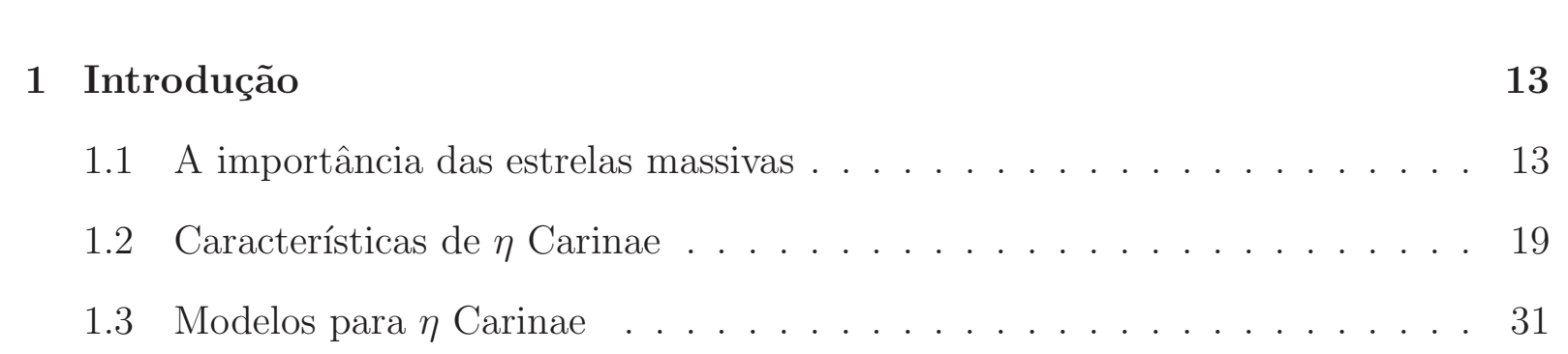

2 Observacões e reducão dos dados espectroscópicos $\quad 37$

2.1 Campanhas observacionais do evento de $2009.0(\# 12)$. . . . . . . . . . . . 37

2.2 Dados dos eventos de $1992.5(\# 9) .1998 .0(\# 10)$ e $2003.5(\# 11) \ldots 43$

2.3 Processamento dos dados do Goodman e do OPD . . . . . . . . . . . . . 46

3 Espectroscopia de campo integral do Homúnculo 51

3.1 Observacões e reducão dos dados . . . . . . . . . . . . . . . . . . . 51

3.2 Mapeamento espacial do $[\mathrm{Fe} \mathrm{II}] \lambda 12567 \ldots \ldots \ldots \ldots$. . . . . . . . . . 52

3.3 Mapeamento espacial do He I $\lambda 10830 \ldots \ldots \ldots \ldots$. . . . . . . . . . 54

3.4 A natureza da estrela secundária . . . . . . . . . . . . . . . . . 57

$4 \quad$ A periodicidade dos eventos em $\eta$ Carinae $\quad 59$

4.1 Definicão da fase zero . . . . . . . . . . . . . . . . . . . . . . . . . . . . . 59

4.2 Determinacão do período dos eventos . . . . . . . . . . . . . . 60

4.3 Outros métodos robustos para determinacão do período . . . . . . . . . . . 62

4.4 A estabilidade do período . . . . . . . . . . . . . . . . . . 67

5 Uma visão geral dos eventos periódicos em $\eta$ Carinae $\quad 70$

5.1 A morfologia composta dos eventos . . . . . . . . . . . . . . . 70 


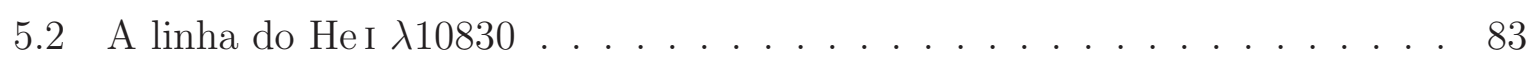

5.3 Uma visão multi-espectral do mínimo . . . . . . . . . . . . . . . . 86

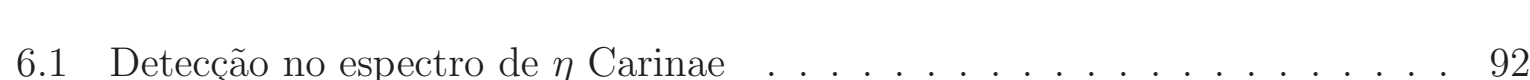

6.2 Comparacão da largura equivalente nos últimos 4 eventos . . . . . . . . . . 94

6.3 A largura equivalente do He II $\lambda 4686$ e o fluxo em raios-X $\ldots \ldots . . . .997$

6.4 A luminosidade observada do HeII $\lambda 4686 \ldots \ldots$. . . . . . . . . . . 99

6.5 Cinemática . . . . . . . . . . . . . . . . . . . . . . 104

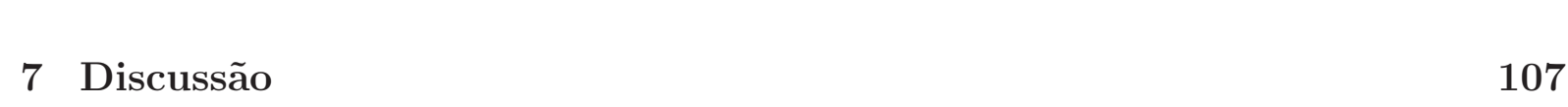

7.1 O período orbital e sua estabilidade . . . . . . . . . . . . . . . 107

7.2 Características do evento espectroscópico . . . . . . . . . . . . . . . . . . 109

7.3 Mapeamento espacial do Homúnculd . . . . . . . . . . . . . . . . . 112

7.4 Possíveis regiões e mecanismos de emissão do He II $\lambda 4686$. . . . . . . . . 114

7.5 Absorcão em altas velocidades na linha do HeI $\lambda 10830$. . . . . . . . . . 121

8 Conclusões e perspectivas 124

$\begin{array}{ll}\text { Referências bibliográficas } & 127\end{array}$

A $A_{\mathrm{V}}$ na direcão da fonte central 143

$\begin{array}{ll}\text { B Artigos } & 146\end{array}$ 


\section{Capítulo 1}

\section{Introdução}

\subsection{A importância das estrelas massivas}

O papel das estrelas massiva 1 na modificação das características físico-químicas do meio interestelar é fato conhecido há muitos anos: através de fortes ventos estelares e explosões de supernova, as estrelas massivas injetam energia e momentum no meio interestelar e também enriquecem-no quimicamente com uma grande quantidade de elementos pesados produzidos por estes objetos ao longo de sua vida e também durante sua morte.

Estrelas massivas (com massa entre 8 e $20 \mathrm{M}_{\odot}$ ) têm a sua física razoavelmente bem conhecida. Entretanto, o topo do diagrama HR2, onde se localizam as estrelas supermassivas, com massa superior a $20 \mathrm{M}_{\odot}$, é uma região povoada por estrelas peculiares, extremamente raras ou formando grupos desconexos, consideradas pouco atraentes para compreensão dos fenômenos estelares como um todo.

Entretanto, nas últimas décadas, com o advento dos telescópios espaciais capazes de obter dados nas regiões do ultra-violeta e raios-X, esta visão tem sido modificada radicalmente pela descoberta de um bom número de estrelas massivas em galáxias próximas como a Pequena e Grande Nuvem de Magalhães. Algumas galáxias foram, inclusive, denominadas galáxias Wolf-Rayet por apresentarem linhas em emissão muito intensas e

\footnotetext{
${ }^{1}$ Considera-se como estrela massiva aquelas com massa maior do que $8 \mathrm{M}_{\odot}$.

${ }^{2} \mathrm{O}$ diagrama Hertzprung-Russell é um gráfico da magnitude absoluta de uma estrela em função de sua temperatura efetiva ou da magnitude absoluta em função do índice de cor $B-V$, que está associado à temperatura da estrela.
} 
largas de íons como C IV, Si IV e He II, indicando que o espectro integrado é dominado por estrelas quentes (especialmente estrelas na fase Wolf-Rayet, que representam uma fase evolutiva, pós-sequência principal na vida das estrelas de tipo espectral O).

Devido ao estudo detalhado dos objetos do topo do diagrama HR, atualmente é possível o desenvolvimento de modelos de síntese evolutiva de populações estelares massivas que reproduzem razoavelmente bem detalhes do espectro na faixa do ultra-violeta e visível de galáxias dominadas por estes objetos. Especialmente no Universo distante, onde as galáxias não podem ser resolvidas espacialmente nem utilizando os maiores telescópios disponíveis, a síntese populacional é a única ferramenta disponível para o estudo do conteúdo estelar.

\section{As primeiras estrelas e a instabilidade de pares}

Aproximadamente 400 milhões de anos após o Big Bang, as primeiras estrelas começaram a se formar a partir do colapso de estruturas compostas essencialmente de hidrogênio e hélio. Conduzida pela matéria escura, a fragmentação produzia preferencialmente estrelas de grande massa $\left(100-1000 \mathrm{M}_{\odot}\right)$.Portanto, as primeiras estrelas do Universo, conhecidas também como estrelas de População III, eram extremamente massivas e, por isso, sua influência é muito maior em estágios primitivos das galáxias, como parecem indicar as explosões de gamma ray bursts (GRB) e supernovas. A título de exemplo, uma das supernovas de tipo II (SN II) 3 mais energética e duradoura já observada, denominada SN 2006gy (Ofek et al.,, 2007; (Smith et al., 2007), 2008; (Agnoletto et al.,, 2009), ocorreu em uma galáxia localizada a 238 milhões de anos-ludt. A energia liberada no pico de brilho correspondeu a 100 vezes a energia de uma SN II típica, que é $\sim 10^{51} \mathrm{erg}$, e por isso, esta explosão estelar foi classificada como uma hipernova. Além disso, a duração do pico de brilho também foi peculiar neste objeto, mantendo-se acima de $10^{53}$ erg durante alguns meses, enquanto uma SN II típica leva apenas alguns dias para diminuir seu brilho.

Outra SN II, classificada como a mais energética já observada, denominado SN 2005ap,

\footnotetext{
${ }^{3}$ Este tipo de supernova é o resultado do colapso gravitacional de uma estrela massiva.

${ }^{4} 1$ ano-luz corresponde à distância que a luz percorre, no vácuo, durante 1 ano, ou seja, aproximadamente $9.46 \times 10^{18} \mathrm{~cm}$.
} 
ocorreu em uma galáxia muito mais distante. a cerca de 4.7 bilhões de anos-luz (Quimby et al.,2007). Neste evento, a explosão foi 2 vezes mais luminosa do que o observado para SN 2006gy (ou 200 vezes maior do que uma SN II típica), porém, com uma duração do pico de brilho compatível com um evento de SN II típico. Apesar desta supernova ter sido observada antes de SN 2006gy, ela só foi reconhecida como a SN II mais energética recentemente (Quimbv et al., 2007).

Atualmente, acredita-se que o mecanismo por trás destes eventos ultra-energéticos seja a criacão de pares de partículas no interior de estrelas com massa superior a $90 \mathrm{M}_{\odot}$ (Fralev, 1968; Wooslev et al., 2007; Kasen et al., 2008). Acima de tal massa, a temperatura e densidade no interior da estrela é suficiente para produção de fótons na região dos raios- $\gamma$, que possuem uma profundidade óptica muito grande, e por isso, logo que são produzidos interagem com os íons ao redor e, eventualmente, são convertidos em pares elétron-pósitron, removendo energia do campo de radiação que sustenta a estrutura estelar contra o colapso gravitacional e favorecendo o surgimento de instabilidades que podem iniciar uma queima de combustível explosiva, como uma supernova de baixa energia. Dependendo da massa de He no núcleo estelar, a estrela pode passar por várias 'pequenas' ejeções de matéria (algumas dezenas de $\mathrm{M}_{\odot}$ ) causadas por este mecanismo antes de ser completamente destruída como SN II.

A principal característica dos modelos de instabilidade de pares é a recorrência de episódios de ejeção de matéria. O número de eventos é determinado, essencialmente, pela massa de He no núcleo: quanto menor a massa, maior é o número de eventos e vice-versa. Segundo o modelo de Wooslev et al. (2007), se a massa total da estrela no fim de sua vida estiver entre 95 e $130 \mathrm{M}_{\odot}$, ela pode apresentar pulsações, nas quais uma grande quantidade de material é ejetada em cada pulso, mimetizando uma SN II de baixa energia. Ao longo dos anos, cada ejeção de matéria expande-se e resfria, criando uma nebulosa ao redor da estrela. Além disso, dependendo da velocidade com que cada nebulosa é ejetada, podem acontecer choques entre elas, formando regiões com forte emissão de raios-X.

Desde o trabalho teórico de Fralev (1968) sobre as instabilidades causadas pela produção de pares, não existiam suportes observacionais para uma explosão de supernova 
induzida por tal mecanismo. No entanto, os dois casos de explosão estelar citados nesta seção, SN 2005ap e 2006gy, são exemplos extragaláticos de eventos que produziram energia muito acima daquela prevista pelos modelos atuais para uma explosão típica de SN II e, portanto, podem ter sido as primeiras evidências observacionais a favor do mecanismo de instabilidade por produção de pares.

\section{O limite de Humphreys-Davidson e a fase $L B V$}

De modo geral, a taxa de perda de massa varia de acordo com a massa da estrela. Para estrelas quentes, de tipo espectral $\mathrm{O}$ e B, esta relação é dada por

$$
\dot{M} \propto L^{1 / \alpha}
$$

onde $\dot{M}$ é a taxa de perda de massa, $L$ é a luminosidade da estrela e $\alpha$, uma constante cujo valor médio é de aproximadamente 0.6 para estrelas de tipo espectral O ou B (Howarth \& Prinja, 1989; Lamers \& Leitheren, 1993; Leitheren, 2009). Por isso, estrelas quentes sempre apresentam taxas de perda de massa elevadas, entre $10^{-5}$ e $10^{-6} \mathrm{M}_{\odot}$ ano ${ }^{-1}$, que são evidenciadas pelos perfis P Cygni presente em algumas linhas espectrais.

Hutchings (1976), estudando a taxa de perda de massa de estrelas quentes na Galáxia e na Pequena Nuvem de Magalhães, foi o primeiro a notar a existência de um limite superior para a luminosidade destes objetos. Posteriormente, Humphrevs \& Davidson (1979) e Garmany \& Fitzpatrick (1988) ampliaram esta análise para incluir a Grande Nuvem e confirmaram que, de fato, tanto na Galáxia quanto nas Nuvens de Magalhães, não existem estrelas de tipo espectral mais frio que B4 com luminosidade maior do que $\sim 10^{6} \mathrm{~L}_{\odot}$. Também foi constatado que, para estrelas mais quentes que B4, o limite superior de luminosidade depende da temperatura, sendo maior para tipos espectrais mais quentes, conforme pode ser visto na Fig. 1.1, que mostra o topo do diagrama HR para estrelas da Galáxia, segundo o estudo feito por Humphrevs \& Davidson (1979).

O limite superior para a luminosidade das estrelas massivas frias (como as supergigantes vermelhas e hipergigantes amarelas) é conhecido como limite de de Jager (de Jager), 1984) e aquele observado para estrelas massivas quentes, como limite de Humphreys- 


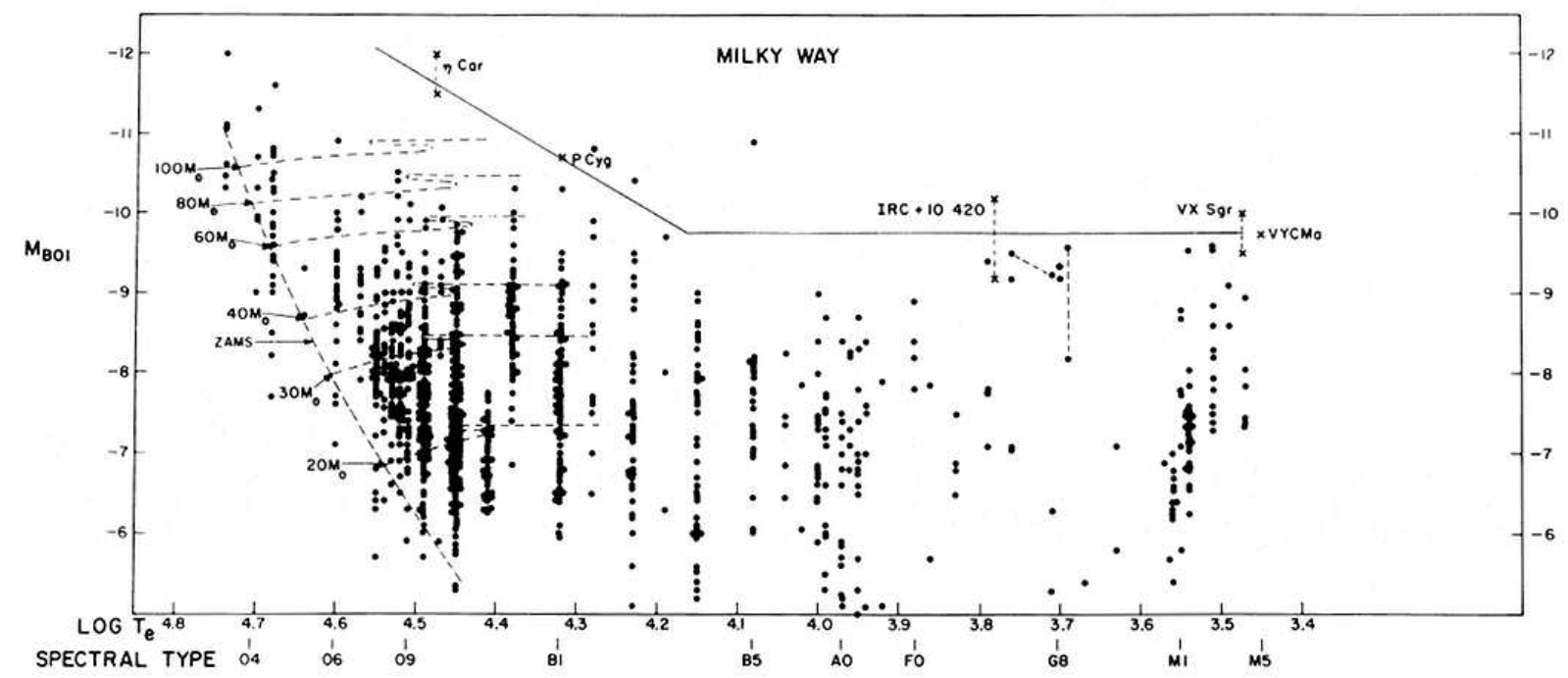

Figura 1.1: O limite de Humphreys-Davidson (HD) é definido pela linha contínua, que é constante $\left(\mathrm{M}_{\mathrm{BOL}} \approx-10\right)$ até o tipo espectral B4. Para tipos espectrais mais quentes o limite é dependente da temperatura e aumenta com ela. Nesta imagem estão somente as observações de estrelas localizadas na Galáxia, mas o limite HD é aproximadamente o mesmo para as Nuvens de Magalhães. Imagem extraída de Humphreus E Davidson 1979.

Davidson (HD). Ambos implicam em um limite superior para a massa de uma estrela, uma vez que a luminosidade de uma estrela depende fortemente de sua massa e varia conforme $M^{\alpha}$, onde $M$ é a sua massa e $\alpha$, uma constante que varia de 2 a 4 , dependendo da massa considerada (estrelas $\operatorname{com} M<1 \mathrm{M}_{\odot}$ tem $\alpha=2$; do tipo solar tem $\alpha \approx 4$ e estrelas massivas $\alpha \approx 3.5$ ).

Apesar do limite HD impor um limite superior de luminosidade, algumas estrelas poderiam violá-lo temporariamente. Tal comportamento está ilustrado na Fig.1.2, Algumas destas estrelas são quentes e estão passando por uma rápida fase conhecida como $L B V$ ou luminous blue variable (variável luminosa azul). Tais objetos são descendentes de estrelas que, segundo os modelos de evolução estelar, possuíam massa superior a $40 \mathrm{M}_{\odot}$ na sequência principal. Elas também são conhecidas como variáveis S Doradus e apresentam variações irregulares de brilho (geralmente entre 0.5 e 2 magnitudes) em escalas de tempo da ordem de dezenas de anos.

Durante as fases de menor brilho de uma $L B V$, ditas quiescente, a estrela é mais azul, tem um raio menor e apresenta linhas espectrais de excitação mais elevadas. Nas fases de máximo, ditas de erupção, a estrela ultrapassa o limite HD e torna-se mais vermelha, com raio maior e as linhas espectrais de alto potencial de excitação tornam-se fracas. 


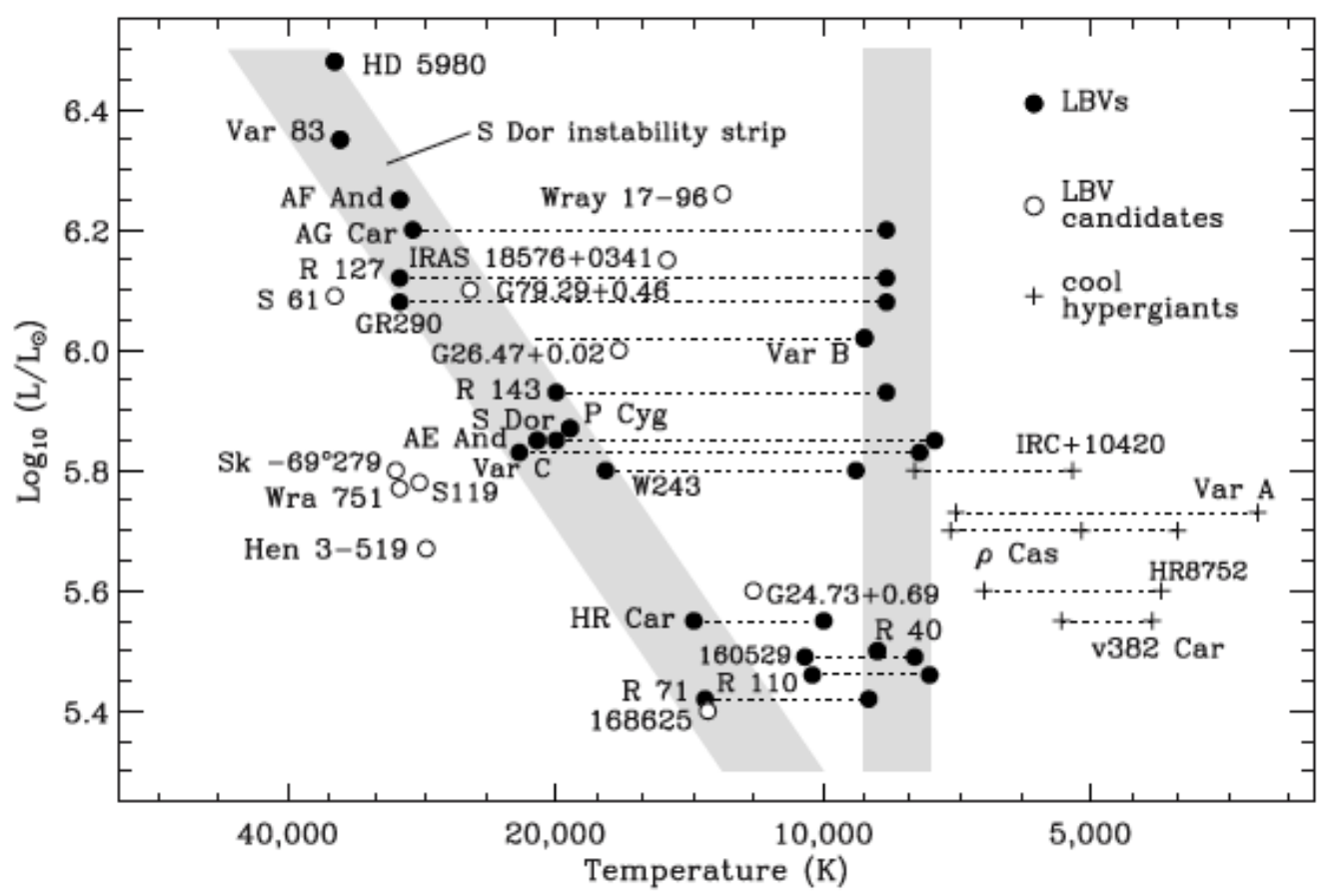

Figura 1.2: Topo do diagrama HR, mostrando a localização das estrelas confirmadamente na fase $L B V$, as candidatas à $L B V$ e as hipergigantes frias. As regiões cinza indicam onde as $L B V s$ são frequentemente observadas: na faixa diagonal, definida pelo limite de Humphreys-Davidson, ou na faixa vertical, com temperatura constante durante a fase de erupção. Gráfico extraído de Smith et al. (2004).

A magnitude bolométrica da estrela, neste ciclo, varia muito pouco, indicando que o fenômeno S Doradus é essencialmente um reprocessamento de energia, de fótons mais energéticos para menos energéticos.

Conforme pode ser visto na Fig. 1.2, na fase de quiescência, devido ao limite HD, a temperatura superficial de uma $L B V$ depende da sua luminosidade (faixa diagonal cinza), atingindo cerca de $40000 \mathrm{~K}$ para as mais luminosas e por volta de $10000 \mathrm{~K}$ para as menos luminosas. Na fase de erupção, entretanto, todas as $L B V s$ têm um limite inferior de temperatura que é, em média, de 8000 K (faixa vertical cinza da Fig. 1.2). Este comportamento é explicado pelo fato de que os ventos estelares densos encontram muita dificuldade de resfriarem-se abaixo de $7500 \mathrm{~K}$ (Davidson, 1987). Portanto, a variabilidade da temperatura superficial de uma $L B V$ está estritamente relacionada com sua luminosidade.

Durante a fase $L B V$, as estrelas mais luminosas apresentam períodos recorrentes de erupção com taxa de perda de massa extremamente elevada (da ordem de $10^{-2}$ a $10^{-3} \mathrm{M}_{\odot}$ ano $^{-1}$ ) durante um curto período de tempo (da ordem de anos), o que descarta 
mecanismos fotosféricos como origem das instabilidades. Algum outro mecanismo, além da transferência de energia do campo radiativo para o gás, se faz necessário. Uma possibilidade, já discutida anteriormente, é que a taxa de produção de pares elétron-pósitron aumente significativamente no interior de estrelas com massa superior a $90 \mathrm{M}_{\odot}$. Como os modelos de evolução preveem que objetos com tal massa passem pela fase $L B V$, as instabilidades de pares podem surgir durante este período, o que implica que as mais luminosas (mais massivas) podem explodir prematuramente por causa disso. Na Galáxia, o melhor exemplo de $L B V$ com erupções gigantescas recorrentes é $\eta$ Carinae.

\subsection{Características de $\eta$ Carinae}

$\eta$ Carinae (HD 93308; doravante $\eta$ Car) é um dos objetos mais intrigantes do Universo Local. A fonte central está envolta em duas nebulosas bipolares conhecidas como Homúnculo e Pequeno Homúnculo (Fig.1.3), que foram ejetadas em dois episódios eruptivos: o primeiro em 1843 e o segundo em 1890 (Thackerav, 1949; Gaviola, 1950; Ringuelet, 1958; Walborn et al., 1978; Currie et al., 1996; Ishibashi et al., 2003; (Smith et al., 2004). Seu comportamento fotométrico (van Genderen et al. . 2006) e espectroscópico (Davidson et al., 1982, 1986; Dufour, 1989; (Dufour et al., 1999) a classificam como uma $L B V$, que por sinal, é a mais luminosa da Galáxia. Sua classificação como $L B V$ é corroborada pela análise da composicão química das nebulosas eietadas, que são ricas em He e N (Smith \& Morse, 2004), indicando que a fonte central está próxima do fim da fase de queima do H no núcleo.

Além das duas nebulosas bipolares, $\eta$ Car também apresenta uma nebulosa mais extensa e antiga, conhecida como Outer Ejecta (cf. Fig.1.31). Os estudos sobre o movimento próprio de várias regiões ao longo da Outer Ejecta feito por vários autores (e.g. Walborn et al. 1978; Morse et al. 1998; Bohigas et al. 2000; Morse et al. 2001; Smith 2008) indicam que esta nebulosa tem uma idade cinemática estimada entre 500 e 1000 anos e, assim como as nebulosas bipolares do Homúnculo e Pequeno Homúnculo, também apresenta enriquecimento de elementos como o He e N. 


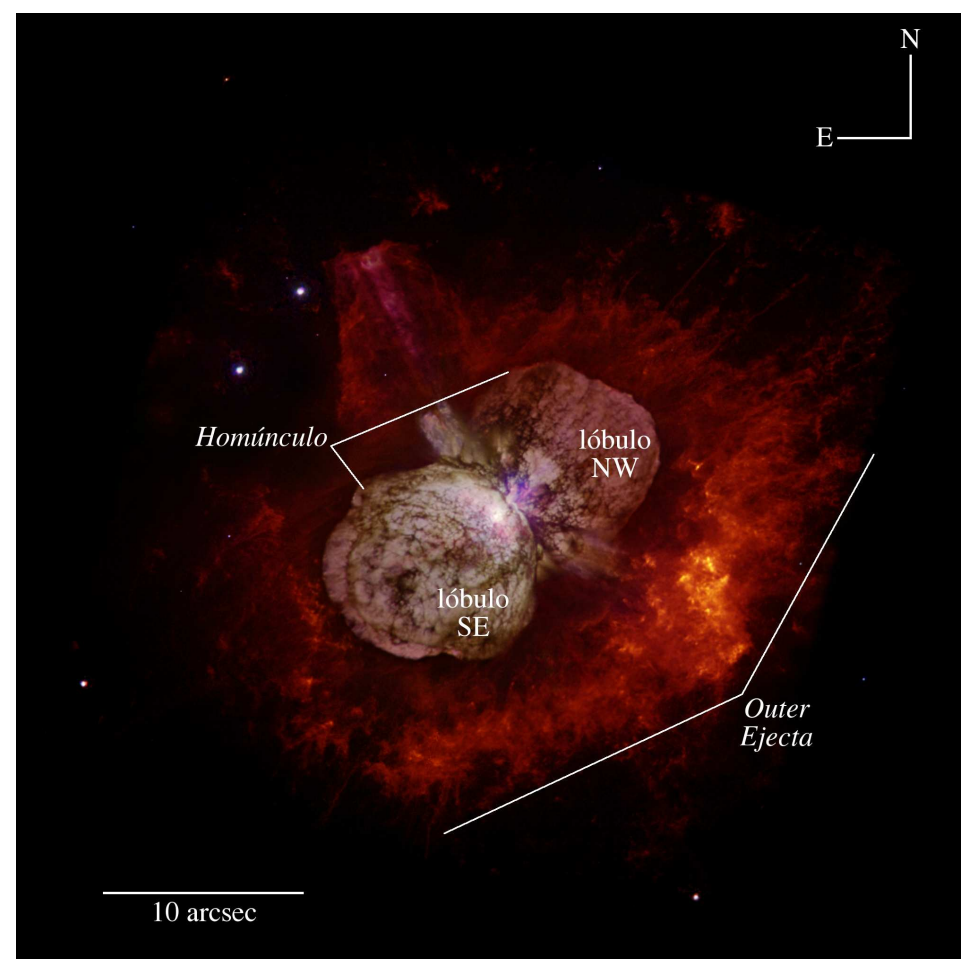

Figura 1.3: Imagem do Homúnculo obtida com o Hubble Space Telescope (HST). Nesta imagem é possivel ver também a nebulosa externa, mais antiga que o Homúnculo, conhecida como Outer Ejecta, cuja idade cinemática é estimada entre 500 e 1000 anos.

\subsubsection{Parâmetros físicos de $\eta$ Carinae}

A uma distância de 2300 pt5 (Allen \& Hillien, 1993; Davidson et al., 1997; Meaburn, 1999; Davidson et al., 2001), $\eta$ Car apresenta uma luminosidade de cerca de $10^{6.7} \mathrm{~L}_{\odot}$ (Westphal \& Neubebauer. 1969: Cox et al. . 1995) e massa da ordem de 100 M. (Hillier et al.,2001), o que sugere que sua massa inicial era de aproximadamente $120 \mathrm{M}_{\odot}$. Segundo a teoria de evolução estelar, objetos com tamanha massa duram cerca 3 milhões de anos. É importante ressaltar que a idade média das estrelas de tipo O pertencentes ao aglomerado Trumpler 14, ao qual pertence $\eta$ Car, é da ordem de 3.5 milhões de anos (Tapia et al., 2003).

A notável taxa de perda de massa elevada $\left(\sim 10^{-3}-10^{-1} \mathrm{M}_{\odot}\right.$ ano ${ }^{-1}$; White et al. 1994; Cox et al. 1995; Davidson et al. 1995; Hillier et al. 2001) é responsável por envolver a estrela em um vento extremamente denso e opaco, que, por sua vez, apresenta um campo de velocidade cuja intensidade depende da latitude estelar, sendo que, na direção polar, as

\footnotetext{
${ }^{5} 1 \mathrm{pc}=1$ parsec $\approx 3.09 \times 10^{18} \mathrm{~cm}$
} 
velocidades observadas são maiores $\left(600-1000 \mathrm{~km} \mathrm{~s}^{-1}, \mid\right.$ Smith et al.||2003) do que aquelas observadas na região equatorial $\left(400-500 \mathrm{~km} \mathrm{~s}^{-1}\right.$, Smith et al. 2003).

O perfil de densidade do vento estelar também varia latitudinalmente, sendo mais denso nos polos do que no equador. À primeira vista, isto pode parecer contra-intuitivo, uma vez que estrelas com alta taxa de rotação apresentam uma diminuição na força gravitacional efetiva na região equatorial, facilitando a ejeção de material pelo equador devido ao aumento da opacidade e produzindo densidades maiores na região equatorial do que nos polos, conforme é observado em supergigantes tipo $\mathrm{B}[\mathrm{e}]$, por exemplo. No entanto, em um vento produzido por absorção da radiação em linhas, como no caso das estrelas massivas, a deflexão do material superficial em direção ao equador pode ser inibida devido a outros fenômenos que começam a ser importantes em estrelas massivas, como por exemplo forças não-radiais (e.g. circulação meridional; Owocki et al. (1996).

De maneira geral, o aumento da gravidade polar é consequência direta do teorema de von Zeipel (von Zeipel, 1924), que mostra que em uma estrela em rotação, o fluxo radiativo $\left(F_{R}\right)$ é proporcional à gravidade efetiva $\left(g_{e f}\right)$ na superfície estelar. Este fenômeno - conhecido como escurecimento gravitacional (gravity darkening) - é mais evidente em estrelas com alta rotação, que geralmente é o caso das estrelas massivas, que apresentam $50 \mathrm{~km} \mathrm{~s}^{-1}<v \sin i<350 \mathrm{~km} \mathrm{~s}^{-1}$ (Mokiem et al., 2006; Pennv \& Gies, 2009). Entretanto, Owocki et al. (1996, 1998) mostraram que a taxa de perda de massa local $(\dot{M})$ em estrelas massivas com alta rotação pode ser relacionada ao fluxo luminoso e à gravidade efetiva através da seguinte relação

$$
\dot{M} \propto F_{R}^{\left(\frac{1}{\alpha}\right)} g_{e f}^{\left(1-\frac{1}{\alpha}\right)}
$$

onde $\alpha$ é o índice da lei de potência utilizada na teoria de ventos radiativos baseados no formalismo de Castor et al. (1975). Sendo assim, considerando que esta teoria seja aplicável à $\eta$ Car e levando em conta o teorema de von Zeipel $\left(F_{R} \propto g_{\text {ef }}\right)$, então a Eq. 1.2 fica da seguinte maneira

$$
\dot{M} \propto g_{e f}^{\left(\frac{1}{\alpha}\right)} g_{e f}^{\left(1-\frac{1}{\alpha}\right)} \Rightarrow \dot{M} \propto g_{e f}
$$

ou seja, a taxa de perda de massa será maior em latitudes onde a gravidade é mais intensa, 
que no caso de $\eta$ Car, ocorre nos polos. Além disso, o trabalho de Maeder \& Desiacques (2001) também mostrou que perdas de massa anisotrópicas surgem naturalmente em estrelas massivas com elevadas taxas de rotação e podem produzir ventos estelares com geometria bipolar e discos equatoriais, conforme observado em $\eta$ Carinae e em outras estrelas na fase de $L B V$. De fato, com as observacões interferométricas feitas por van Boekel et al. (2003) e Weigelt et al. (2007) foi possível medir diretamente a orientação e dimensões do vento da fonte central e concluir que ele apresenta altas velocidades na região polar, onde ele é mais denso. Portanto, o perfil de densidade/velocidade do vento de $\eta$ Car e a geometria bipolar de sua nebulosas podem ser resultados de uma elevada taxa rotação. Além disso, é importante salientar que a rotação elevada é uma componente importante para um GRB ou para uma hipernova.

\subsubsection{Variabilidade de longo termo e o aumento secular do brilho}

As primeiras observações de $\eta$ Car de que se tem notícia remontam ao início de 1600, quando sua magnitude oscilava entre 4 e 2 na banda $V$, comportamento observado até por volta de 1800, conforme pode ser visto na Fig.1.4. Antes de 1600, provavelmente $\eta$ Car tinha $V<4$, pois não aparece no catálogo Almagesto, compilado por Claudius Ptolomaeus no século II.

Em Fevereiro de 1827, John Burchell, em visita a São Paulo, alerta John Herschel, na África do Sul, que $\eta$ Argus (designação de $\eta$ Car na época) estava aumentando seu brilho de $V=4$ para $V=2$ (Lvnn, 1907). A partir de então, John Herschel começou o monitoramento fotométrico. Naquela época, entre 1820 e 1840, a taxa de aumento do brilho de $\eta$ Carinae era de aproximadamente -0.3 mag ano $^{-1}$ (cf. Fig.1.4) e culminou na Grande Erupção de 1843, responsável pela ejeção de cerca de $10 \mathrm{M}_{\odot}$, que formou a nebulosa bipolar do Homúnculo. Durante aquele evento, o brilho de $\eta$ Car atingiu $V \approx-1$, seguido de um rápido declínio até $V \approx 8$, causado pela absorção da luz da fonte central na nebulosa recém-formada. Foi durante o final deste período de declínio que Le

Sueur (1870) fez a primeira observação do espectro de $\eta$ Car, descrito como tendo fortes linhas espectrais em emissão de elementos como o H, He i e Fe II. 


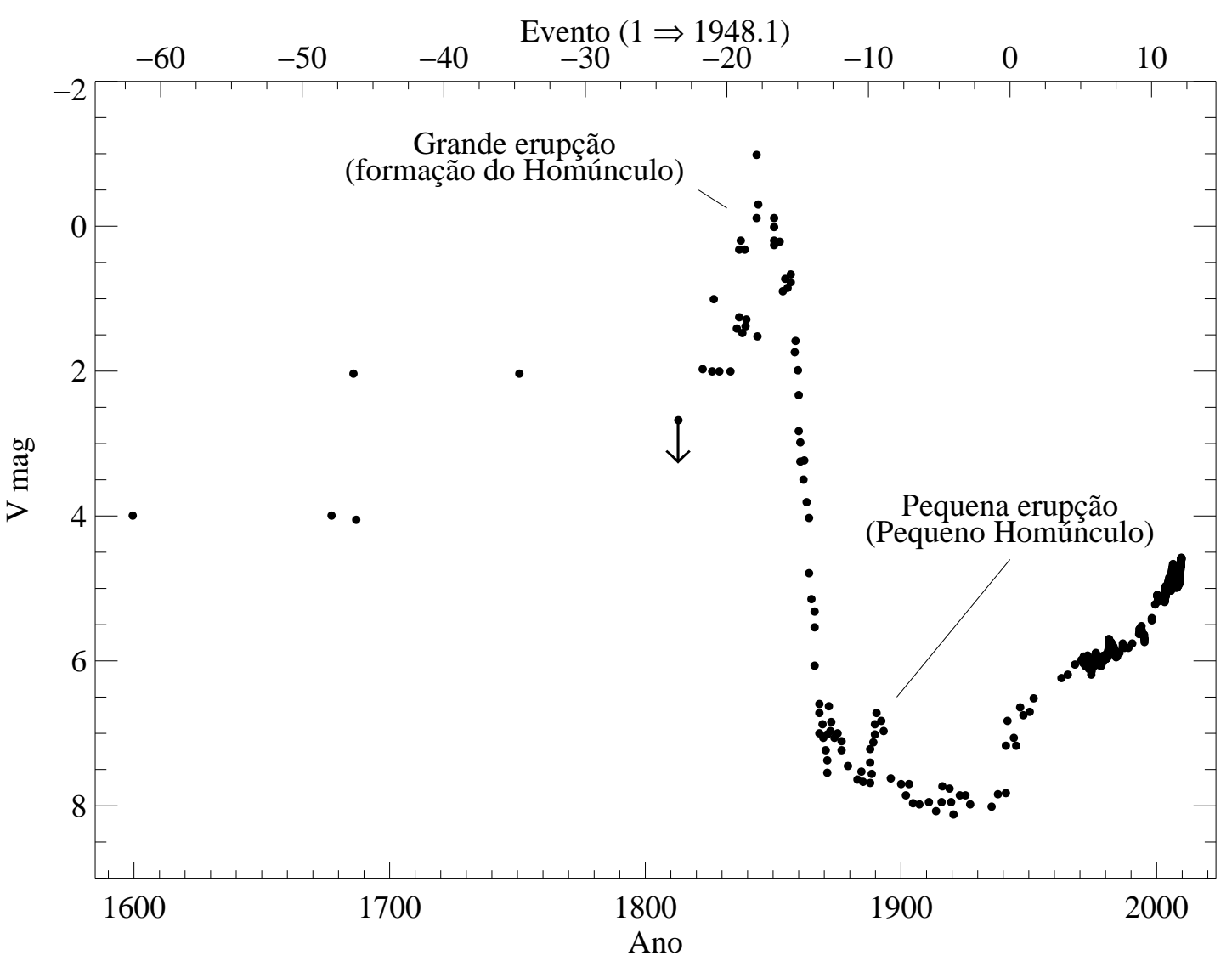

Figura 1.4: Curva de luz histórica de $\eta$ Car na banda $V$. A contagem dos ciclos é feita de maneira que o primeiro evento ocorreu em 1948.1. Os dois eventos eruptivos que formaram o Peaueno e Grande Homúnculo estão indicados. Dados extraídos de Feinstein E Marraco (1974); van Genderen et al. (1994, 2006).

Por volta de 1890, ocorreu uma segunda erupção, na qual foi ejetada cerca de $0.1 \mathrm{M}_{\odot}$ e que hoje é denominada Pequeno Homúnculo devido à sua semelhaça geométrica com Homúnculo. Nesta época, mais precisamente em Maio de 1892 (Humphrevs et al., 2008), que o primeiro espectro fotográfico foi obtido, utilizando um telescópio refrator de 13 polegadas $(33 \mathrm{~cm})$ montado em Arequipa, Peru. As características espectrais contidas nestes dados classificaram $\eta$ Car como sendo uma supergigante de tipo espectral F. Entretanto, a correção do obscurecimento pela poeira recém-formada elevaria o pico de luminosidade deste evento para valores próximos ao do evento de 1843.

Após a segunda erupção, o brilho de $\eta$ Car manteve-se constante até o início da década de 40, quando passou de $V \approx 8$ para $V \approx 7$ em menos de uma década. Foi também durante este período que foi observado pela primeira vez um 'evento espectroscópico', descrito por Gaviola (1953). Além desse evento, foram observados outros similares em 1965, 1981, 1987 


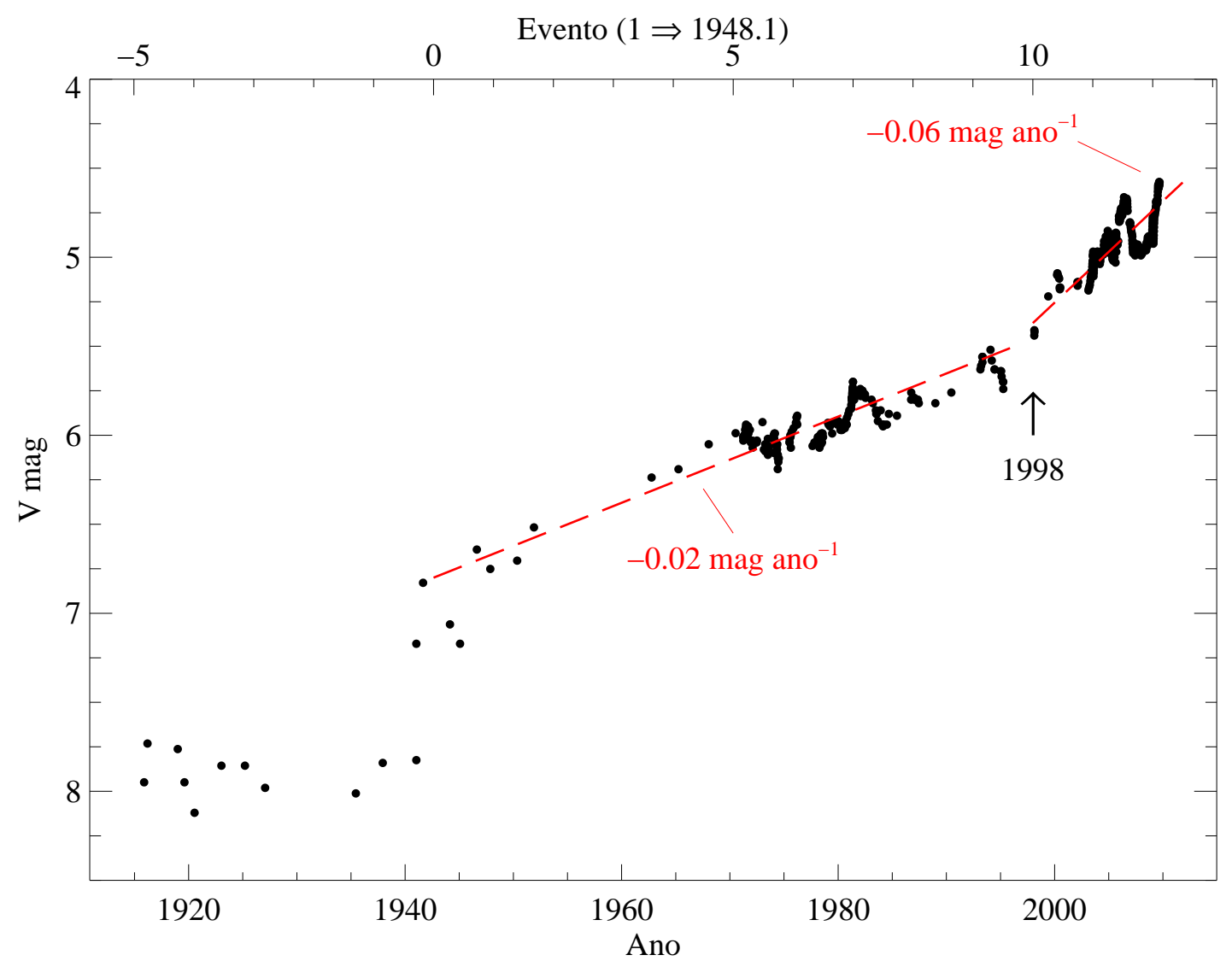

Figura 1.5: Curva de luz de $\eta$ Carinae na banda $V$ desde 1910. Após o evento 0, em meados de 1942, houve um aumento de $\approx 1$ magnitude no brilho da fonte central em menos de 5 anos (-0.2 magano $\left.{ }^{-1}\right)$. Depois disso, a taxa de aumento permaneceu constante em -0.02 mag ano $^{-1}$ até o evento de 1997.9, quando passou para -0.06 mag ano $^{-1}$.

e 1992. Damineli (1996) mostrou que tais eventos ocorrem a cada 5.54 anos e foi previsto que outro evento ocorreria em Dezembro de 1998, o que de fato aconteceu. Apesar do alerta ter sido dado previamente, não foram realizadas grandes campanhas observacionais e o evento foi monitorado por poucos observatórios. O primeiro evento espectroscópico devidamente monitorado foi o que ocorreu em 2003.5 (corroborando o período proposto), quando vários telescópios foram utilizados para realizar uma campanha observacional em diversas faixas espectrias, desde rádio até raios-X.

Além dos eventos de baixa excitação, observa-se que o brilho da fonte central tem aumentado continuamente durante os últimos 50 anos (van Genderen et al., 1994, 2006). Para ilustrar este comportamento, a Fig 1.5 mostra a curva de luz dos últimos 100 anos. Durante o período de 1952 a 1998, a taxa de aumento do brilho da fonte central (incluindo o Homúnculo) era linear na banda $V$, variando entre -0.02 e -0.03 mag ano $^{-1}$ (ver também 


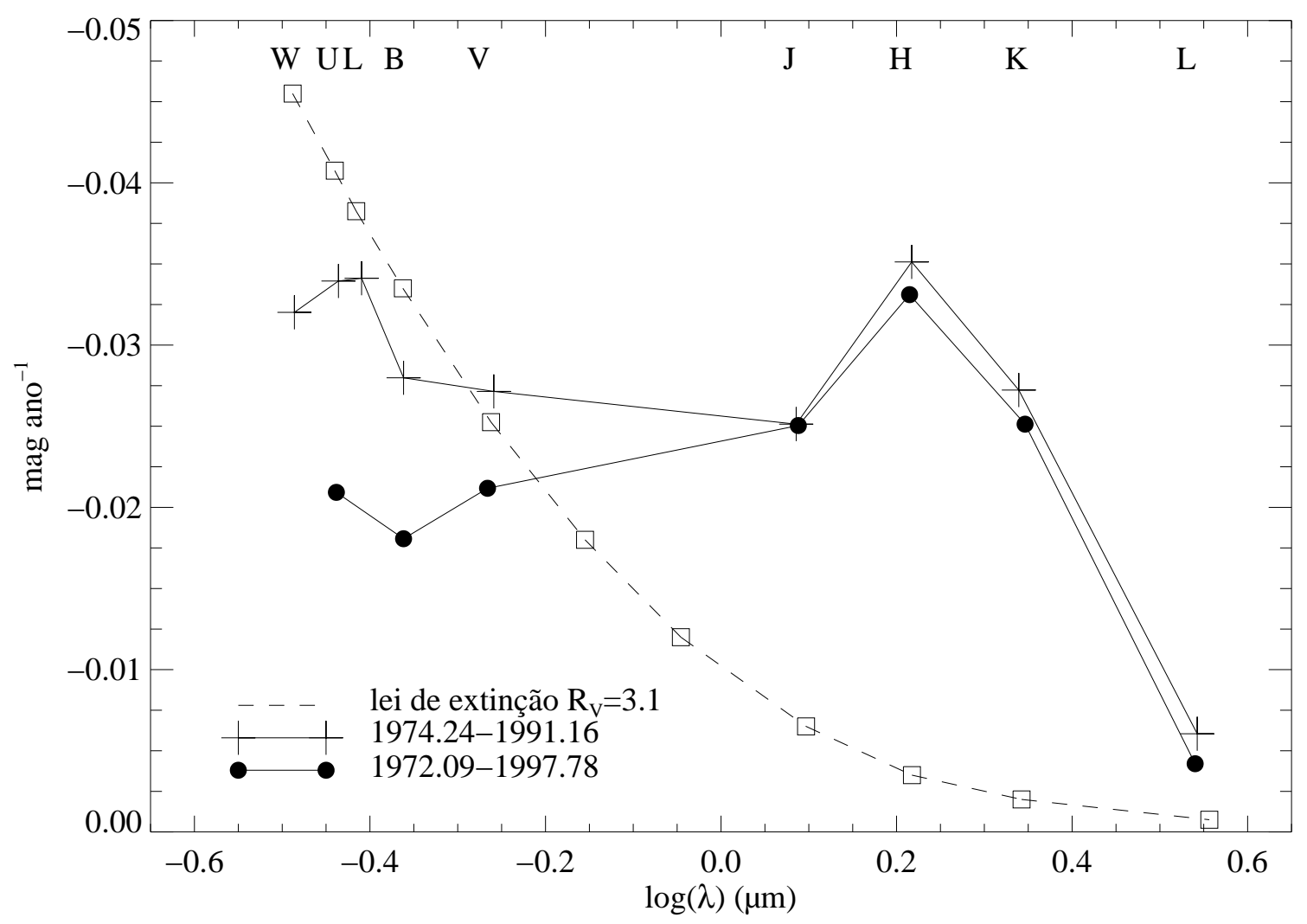

Figura 1.6: Taxa de aumento do brilho de $\eta$ Car (incluindo o Homúnculo) em função do comprimento de onda durante os períodos indicados na legenda. A curva tracejada corresponde ao comportamento esperado para uma lei de extinção a uma taxa de -0.025 magano ${ }^{-1} \mathrm{em} V$. Evidentemente, o aumento secular do brilho não é causado exclusivamente pela diminuição da extinção. Dados extraídos de van Genderen et al. (2006).

a Fig. 1.6, extraída de van Genderen et al.|2006). Depois do evento de 1998.0, o brilho da fonte central começou a aumentar a uma taxa maior do que a registrada até então. Por exemplo, na banda $V$ a taxa triplicou, passando de -0.02 para $-0.06 \mathrm{mag} \mathrm{ano}^{-1}$.

Na banda $V$, a variação na taxa de aumento do brilho deve-se principalmente ao Homúnculo. Porém no infra-vermelho próximo, cujo fluxo é oriundo da região central, o mesmo fator de aumento do brilho também foi observado após o evento de 1997.9, o que permite a conclusão de que a fonte principal da variabilidade é a estrela central e não o Homúnculo. Durante o período de 2000 até meados de 2006, a taxa de aumento do brilho manteve-se aproximadamente constante. Porém, no segundo semestre de 2006, o fluxo observado na banda $V$ diminuiu cerca de $30 \%$ em menos de um ano e permaneceu assim até meados de 2008, quando voltou a subir a uma taxa de aproximadamente -0.3 mag ano ${ }^{-1}$, 


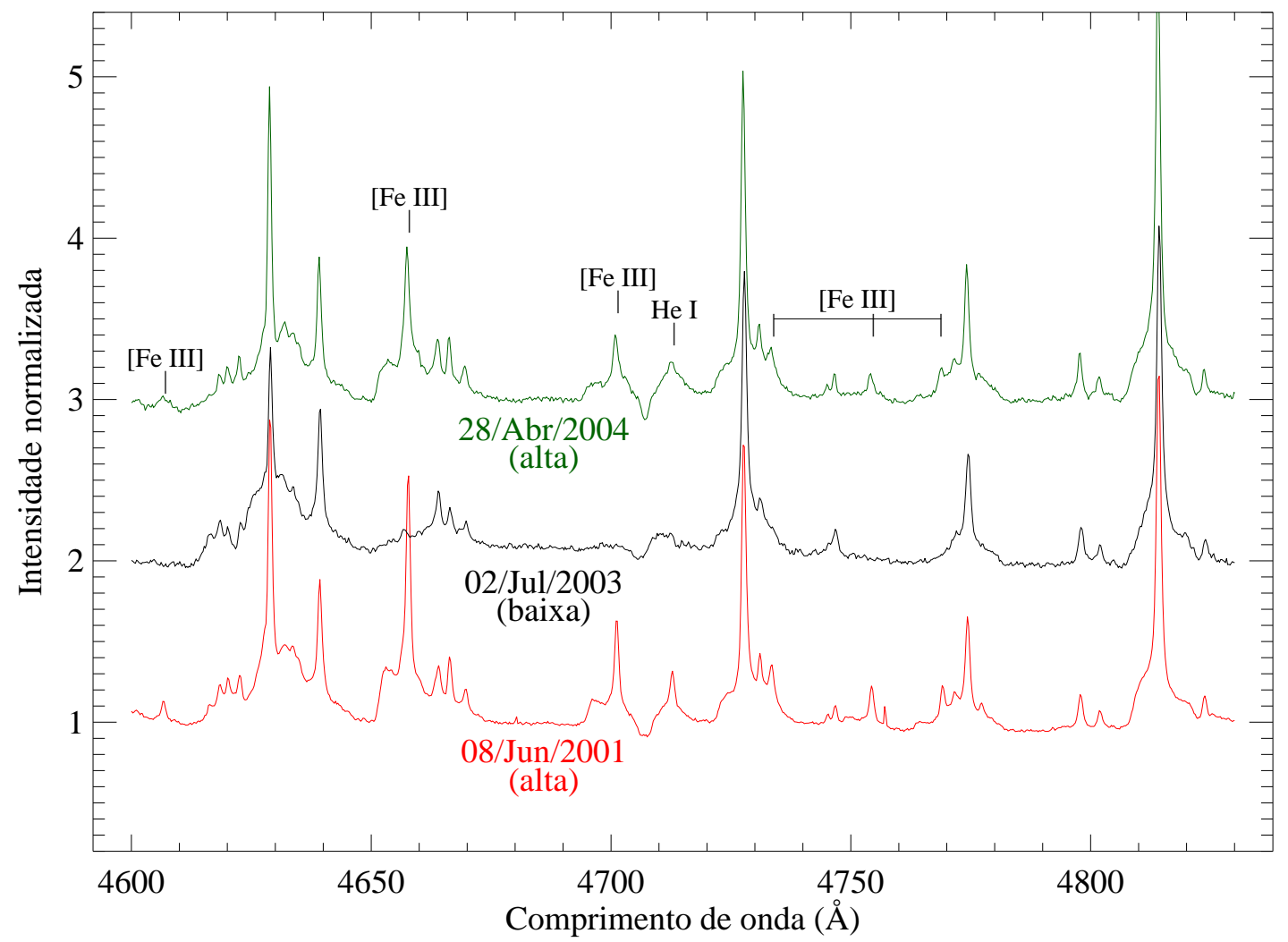

Figura 1.7: Comparação de uma região do espectro de média resolução de $\eta$ Car durante a fase de alta e baixa excitação. Nos espectros obtidos durante a fase de baixa excitação, a intensidade de todas as linhas diminui e as linhas de alto potencial de ionização desaparecem completamente, como por exemplo, as linhas do [Fe III], indicadas nesta figura.

ou seja, a uma taxa igual a observada antes da Grande Erupção! É importante salientar que, recentemente, o brilho voltou a diminuir, indicando que as variações não são devidas a mudanças na opacidade do Homúnculo.

\subsubsection{Variabilidade periódica}

Observações do espectro de $\eta$ Car ao longo dos anos indicam que a fonte central entra, ocasionalmente, em um estado de 'baixa excitação', no qual as linhas de alta excitação desaparecem temporariamente (Gaviola, 1953; Rodgers \& Searle, 1967; Thackerav, 1967; Zanella et al., 1984; Damineli et al., 1998). Este comportamento está ilustrado na Fig.1.7. onde pode ser visto que o espectro de 1995.0 - durante a fase de alta excitação - apresenta linhas proibidas de dupla ionização como o [Ne III] $\lambda 3868$ mais intensas do que o observado durante a fase de baixa excitação (espectros de 1970.38 e 1998.0). Os estudos feitos por 


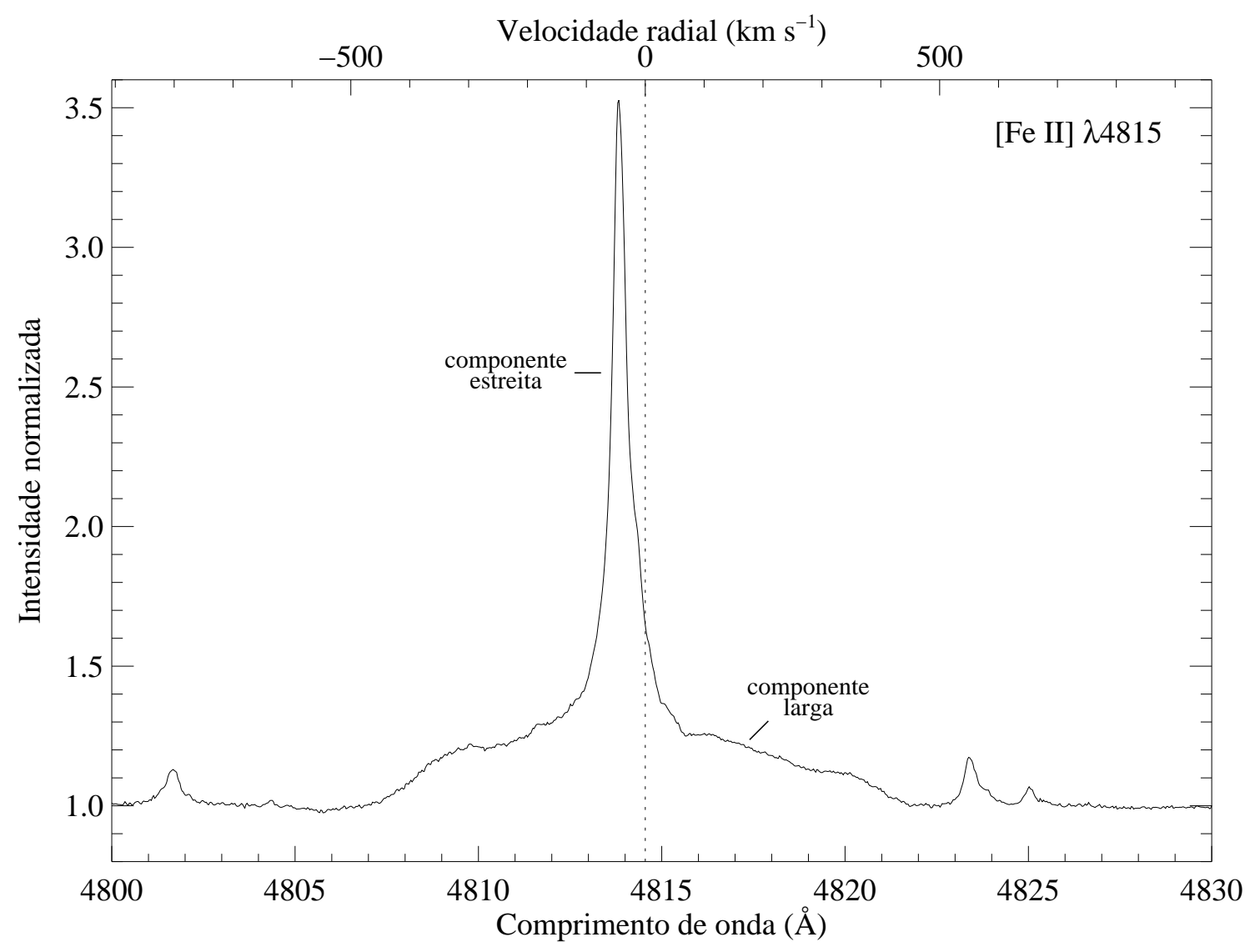

Figura 1.8: Linha do [Fe II] $\lambda 4815$ no espectro de $\eta$ Car. Esta linha espectral ilustra bem as duas componentes típicas da maioria das linhas no espectro de $\eta$ Car: uma estreita e outra larga. A primeira é formada nas nebulosidades circunstelares conhecidas como glóbulos de Weigelt, enquanto a componente larga é formada nas regiões mais externas do vento da estrela primária.

Damineli (1996) e Damineli et al. $(2000$, 2008) demonstraram que tal comportamento é periódico (com cerca de 5.54 anos) e poderia ser explicado considerando-se que a fonte central de $\eta$ Car fosse composta por um sistema binário, na qual a primária é mais massiva, luminosa e fria que a secundária. Desta maneira, as linhas de baixa excitação (com potencial de ionização $<20 \mathrm{eV}$, e.g.: H I, Fe II, [Fe II], [Ni II]) seriam excitadas pela primária, enquanto as de alta excitação (dupla ionização, e.g.: [NeIII], [Ar III], [S III], [Fe III]), pela secundária (Damineli et al., 2008).

Conforme mostrado na Fig.1.8 a maior parte das linhas em emissão observadas no espectro de $\eta$ Car é composta por duas componentes: uma larga e outra estreita. Elas se sobrepõem, resultando em uma linha com pico estreito e base larga. Esta é formada no vento denso da primária, enquanto a componente estreita tem origem nebular, isto é, ela 
é formada em uma região mais externa, ao redor do sistema, conhecida como objetos de Weigelt (Weigelt \& Ebersberger, 1986), que localizam-se a aproximadamente 0.25 arcsec NW da fonte central, e que são aglomerações densas de poeira e gás contidas no plano equatorial da primária, conforme o estudo feito por Davidson et al. (1995) utilizando espectros com resolução espacial obtidos com o telescópio espacial Hubble.

A componente estreita associada ao complexo de Weigelt apresenta velocidades típicas da ordem de -40 a $-50 \mathrm{~km} \mathrm{~s}^{-1}$, enquanto a componente larga estende-se de -400 até -1000 $\mathrm{km} \mathrm{s}^{-1}$, dependendo da latitude estelar de onde o espectro é extraído. Isso porque o vento da primária apresenta um campo de velocidades com dependência latitudinal (Smith et al., 2003), sendo que a região equatorial move-se mais lentamente que a região polar, que por sua vez é mais densa.

As observações espectroscópicas e fotométricas mostram que os eventos de baixa excitação em $\eta$ Car são recorrentes com um período de aproximadamente 5.54 anos. A característica mais importante destes eventos é que o período tem alta estabilidade. A taxa de mudança no período é menor do que 0.38 dias por ciclo, ao longo dos últimos 60 anos (Damineli et al., 2008). Segundo Khaliullin (1974), a taxa de variação do período devido à mudanças na taxa de perda de massa de um sistema binário (ignorando mudanças na excentricidade) é dado por

$$
\dot{P}=0.11 \alpha \frac{\dot{M}_{-3}}{M_{100}} \operatorname{dias~ciclo~}^{-1}
$$

onde $\alpha$ é uma constante da ordem da unidade, $\dot{M}_{-3}$ é a taxa de perda de massa da primária, em unidades de $10^{-3} \mathrm{M}_{\odot}$ ano ${ }^{-1}$, e $M_{100}$ é a sua massa, em unidades de $100 \mathrm{M}_{\odot}$.

No caso de $\eta$ Car, o valor esperado seria $\dot{P}=0.11$ dias ciclo $^{-1}$, mas o valor observado, porém, é quase 3 vezes maior, cerca de 0.27 dias ciclo ${ }^{-1}$. Considerando os dados do evento de 2009.0, o período atual passa a ser um pouco menor (conforme descrito mais adiante nesta tese), cerca de 2021.5 dias, e o limite superior para $P_{\text {med }}$ aumenta para 2023.6 dias, correspondendo a uma taxa de variação de 2.1 dias em 11 ciclos, ou seja, 0.38 dias ciclo $^{-1}$. Logo, a variação observada no período ao longo dos últimos 60 anos, é compatível com a taxa observada para a perda de massa da estrela primária. Em outras palavras, esta 
diferença entre o período atual e o valor médio, deve ser atribuído às incertezas nas medidas do período, e não a uma real variação do período devido a taxa de perda de massa.

Damineli et al. (2008) mostraram que cada evento é composto de duas componentes diferentes: uma de variação lenta e outra de colapso. A primeira ocorre durante a maior parte do período e são mudanças espectrais lentas e graduais no espectro que culminam com o mínimo do evento (Duncan \& White, 2003; Damineli, 1996; Damineli et al., 1999). Por outro lado, a componente de colapso gera mudanças significativas, do ponto de vista espectroscópico, cerca de 3 meses antes e depois do evento (ou passagem pelo periastro). Na faixa óptica, por exemplo, o monitoramento espectral mostra que, próximo a um evento, a taxa de diminuição (e recuperação após o evento) da intensidade das linhas que respondem ao evento espectroscópico parece ser dependente da energia da transição, isto é, as linhas com maior potencial de ionização desaparecem a uma taxa maior do que aquela observada para as linhas de menor potencial.

As linhas espectrais que apresentam um perfil P Cygni em absorção são de especial interesse porque elas permitem amostrar o gás em uma estreita região entre o observador e a fonte central. Os perfis mudam ao longo de todo o ciclo de 5.54 anos devido à mudanças no grau de excitação do material circunstelar. Muitas linhas apresentam um perfil P Cygni, que é extremamente variável ao longo do mínimo e até mesmo de ciclo para ciclo. Apesar de ainda não se ter certeza sobre a região exata onde é formada cada componente em absorção dos perfis P Cygni, o fato é que ela deve ser formado no material que encontra-se entre o observador e a fonte central.

A campanha conduzida por Mike Corcoran, desde 1996, indica que a curva de luz em raios-X (no intervalo de 2 a $10 \mathrm{keV}$ ) também apresenta um comportamento extremamente periódico (cf. Fig 1.9) . A emissão em raios-X, cuja origem será discutida na próxima seção, apresenta um aumento gradativo ao longo de todo o ciclo (Corcoran, 2005), culminando em um pico de emissão que acontece poucos dias antes do mínimo do evento espectroscópico, seguido de uma queda constante até desaparecer completamente. Uma das características mais intrigantes dos raios-X de 2 a $10 \mathrm{keV}$ é a duração do mínimo: cerca de 60 dias. 


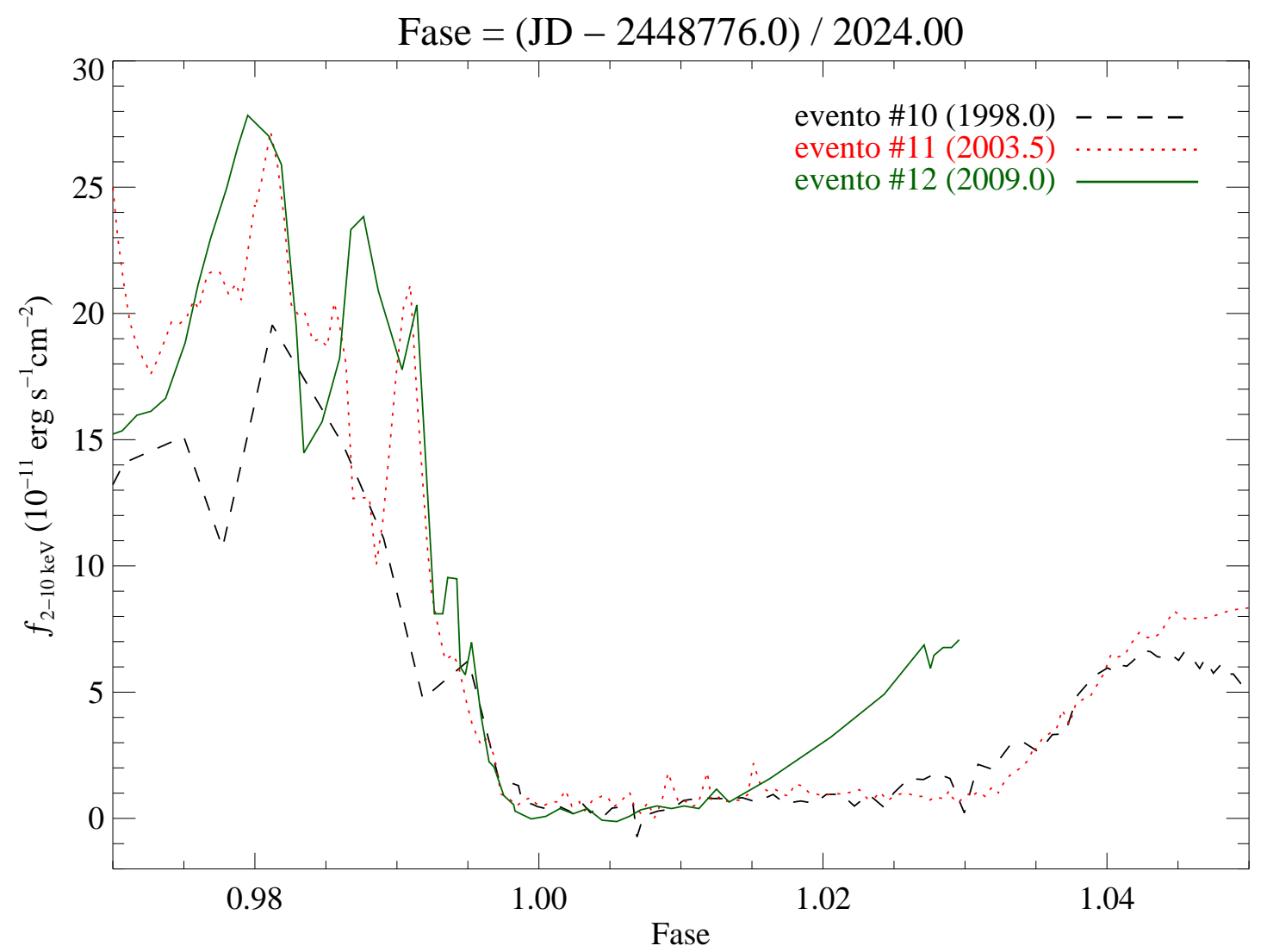

Figura 1.9: Curva de luz em raios-X extraída de Corcoran (2005). Cada curva corresponde ao comportamento observado durante os eventos indicados, utilizando a equação indicada no topo da figura para determinar a fase. As curvas foram deslocadas utilizando um período de 2024 dias.

Ainda não existe um consenso sobre o mecanismo físico por trás deste longo período de baixa emissão em raios-X.

A largura equivalente do perfil P Cygni da linha do Fe II $\lambda 6455$, que é formada no vento da primária, apresenta um comportamento muito semelhante ao observado para a densidade colunar $\left(N_{H}\right)$, reportado por Corcoran (2005), com base em observações na faixa dos raios-X. O máximo para ambas as medidas coincide com o centro do mínimo em raios-X, fato que pode ser interpretado como a verdadeira passagem da secundária pelo periastro. considerando que $n$ Car seia constituída de um sistema binário. Hamaguchi et al. (2007) mostraram que a temperatura do plasma responsável pela emissão de raios-X permanece constante durante o mínimo, em contraste com o comportamento esperado se o mínimo fosse devido exclusivamente ao colapso da estrutura formada na região de colisão dos ventos. Porém, Corcoran (2005) e Hamaguchi et al. (2007) mostraram que, durante 
o mínimo, existe uma diminuição na medida de emissão, significando que quase toda a região de colisão entre os ventos estaria atrás de uma região muito densa, responsável por absorver os fótons em raios-X.

A partir do estudo do perfil das linhas do Si XIV-XVI (formadas na região de colisão dos ventos), Henlev et al. (2008) encontraram indícios de mudanças significativas nas condições físicas da região emissiva. Esses autores mostraram que, durante o periastro, a profundidade óptica das linhas mencionadas acima aumenta consideravelmente (de 10 a 90 vezes) em relação ao apastro e concluíram que isso deve-se ao fato de que a extensão da região emissiva onde as linhas são formadas diminui durante o periastro, fazendo com que a linha de visada intercepte as regiões de aceleração do vento da secundária, onde as densidades são maiores e, consequentemente, a profundidade óptica também. Por isso, a curva de luz em raios-X de $\eta$ Car é provavelmente modulada tanto por parâmetros intrínsecos da colisão de ventos quanto orbitais.

\subsection{Modelos para $\eta$ Carinae}

Vários estudos já foram feitos com o intuito de tentar explicar o comportamento observado de $\eta$ Car, tanto fotométrica quanto espectroscopicamente. Os principais modelos propostos até hoje foram os seguintes:

- supernova lenta (Thackerav, 1956; Rodgers \& Searle, 1967)

- pulsar embebido em resto de supernova (Ostriker \& Gunn, 1971; Borgwald \& Friedlander, 1993)

- objeto compacto acumulando massa de uma estrela companheira (Bath, 1979; Warren-Smith et al., 1979; Tutukov \& Yungelson, 1980; Viotti et al., 1989; Gallagher, 1989; van Genderen et al., 1994)

- estrela massiva pré-sequência principal (Gratton, 1963) 
- estrela massiva na sequência principal com instabilidades

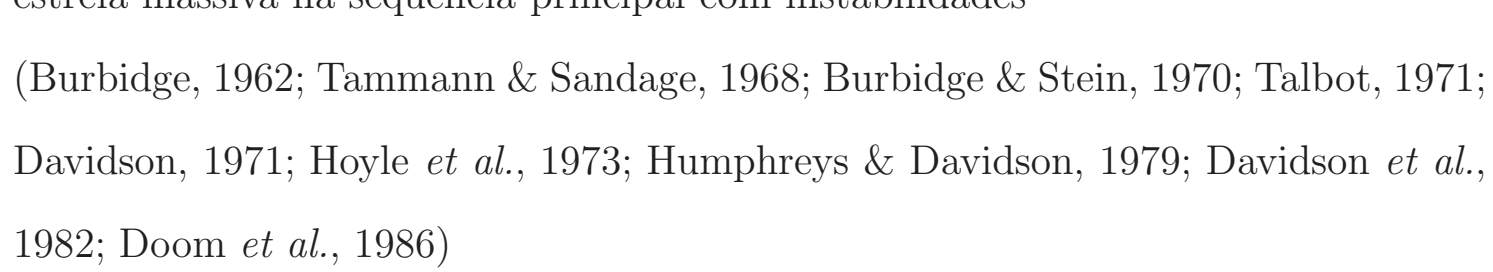

- estrela pós-sequência principal com instabilidades atmosféricas (Andriesse et al., 1981)

- instabilidade dinâmica em estrela com atmosfera extensa (Stothers \& Chin, 1983, 1993; Maeder, 1983; Maeder \& Mevnet, 1989; Maeder, 1992)

- binária com colisão de ventos e longo período orbital<smiles>[GeH3]</smiles>

De todos estes modelos, o mais aceito atualmente é o de um sistema binário com colisão de ventos, onde o choque entre o vento estelar das duas estrelas formaria uma região de alta densidade e temperatura, capaz de emitir radiação na faixa dos raios-X e cuja intensidade seria modulada tanto por parâmetros físicos (e.g. abertura do cone de choque, velocidade terminal dos ventos) quanto orbitais (e.g. ângulo de inclinação, longitude do periastro), conforme os estudos feitos por vários autores (Usov, 1992; Pittard \& Corcoran, 2003; Corcoran. 2005: |Hamaguchi et al..|2007: Okazaki et al... 2008: Henlev et al..|2008: Parkin et al., 2009).

O modelo de sistema binário com colisão de ventos explica a maioria dos fenômenos observados em $\eta$ Car e é praticamente um consenso entre muitos pesquisadores. Porém, apesar disso, ainda existem grandes divergências quanto aos parâmetros orbitais. Os principais cenários são discutidos a seguir.

\section{Cenário 1}

Este modelo é baseado no monitoramento de linhas no espectro óptico e também através do modelamento da curva de luz e de linhas espectrais em raios-X (Pittard \& Corcoran, 2002, 2003; Corcoran, 2005; Akashi et al., 2006; Hamaguchi et al., 2007; Henlev et al., 


\section{8; Damineli et al., 2008; Okazaki et al., 2008; Nielsen et al., 2009; Parkin et al., 2009; Gull et al., 2009).}

- inclinação orbital: $i \approx 41^{\circ}$;

- $\operatorname{argumento~do~periastro:~} 240^{\circ} \lesssim \omega \lesssim 270^{\circ}$ (próximo à oposição);

- excentricidade: $0.90 \lesssim e \lesssim 0.95$.

Nesta configuração, durante a maior parte do ciclo, a secundária estaria iluminando diretamente os glóbulos de Weigelt e durante a passagem pelo periastro, o seu fluxo ionizante seria completamente absorvido nas paredes do cone de choque por causa da estrutura espiralada formada devido ao movimento orbital, ou seja, durante a passagem pelo periastro, a velocidade orbital é maior do que a do material escoando ao longo da superfície do cone de choque. Isto faz com que, a grandes distâncias, o cone se deforme criando uma estrutura espiral, como as observadas em sistemas binários massivos no aglomerado do Quintupleto (Tuthill et al., 2006). Desta maneira, praticamente toda linha de visada até a secundária interceptaria a parede do cone de choque e toda a radiação ficaria 'presa' por esta estrutura.

Alguns autores encontraram evidências de que o periastro não fica exatamente em oposicão. mas sim. a cerca de $30^{\circ}$ à leste da primária. isto é. no sentido horário (Okazaki et al., 2008; Gull et al., 2009). Sendo assim, durante o apastro, a abertura do cone de choque estaria apontando diretamente na direção NW, onde estão localizados os glóbulos de Weigelt.

O estudo do perfil cinemático de linhas proibidas feito por Gull et al. (2009), com dados obtidos pelo telescópio espacial Hubble de 1998 a 2004, sugere a existência de uma região paraboloidal - onde seriam formadas as linhas proibidas de alta excitação no espectro óptico - que foi interpretada como sendo o cone de choque. Apesar de reproduzir razoavelmente bem o perfil cinemático observado ao longo do eixo maior do Homúnculo, a configuração orbital deste modelo não reproduz completamente o perfil cinemático observado quando a fenda está a um ângulo de posição P.A $=-28^{\circ}$. 


\section{Cenário 2}

Este modelo baseia-se na curva de luz na faixa rádio e raios-X e na modelagem de perfis de linhas espectrais na faixa óptica (Abraham et al., 2005; Falceta-Goncalves et al., 2005; Abraham \& Falceta-Goncalves, 2007; Falceta-Goncalves \& Abraham, 2009). Os principais parâmetros orbitais para este modelo são os seguintes:

- inclinação orbita $6: i=120^{\circ}$;

- argumento do periastrd7: $\omega=50^{\circ}$ (próximo à conjunção);

- excentricidade: $0.93 \lesssim e \lesssim 0.95$.

Este modelo reproduz bem a curva de luz na faixa rádio (Abraham et al.., 2005) e a fase pré-mínimo do evento em raios-X (Falceta-Goncalves et al., 20051), assim como alguns perfis de linhas espectrais, como He II $\lambda 4686$ e Pa-8 $\lambda 9540$ (Abraham \& Falceta-Goncalves, 2007; Falceta-Goncalves \& Abraham, 2009). Entretanto, ainda existem dificuldades em explicar algumas características observacionais, como as listadas a seguir.

Os glóbulos de Weigelt, situados no plano equatorial do Homúnculo, respondem às variações no fluxo ionizante proveniente da secundária. Isto pode ser visto nos espectros obtidos com o telescópio espacial Hubble (Davidson et al.., 2001: Gull et al.., 2001: Verner et al., 2005), que possui resolução espacial suficiente para separar o espectro da fonte central e dos glóbulos de Weigelt.

Durante um evento, o fluxo total que chega aos glóbulos diminui e todas as linhas de alta excitação desaparecem (Damineli et al., 1998). Depois do evento, o fluxo visto pelos glóbulos volta a aumentar, assim como as linhas de alta excitação, e permanecem assim durante a maior parte do ciclo. Se a secundária é responsável pelos fótons mais energéticos, seria muito difícil a sua visualização direta pelos glóbulos de Weigelt com a configuração orbital sugerida por este modelo. Isto porque a secundária passa a maior parte do ciclo no apastro que, segundo este modelo, ocorre em oposição. Porém, nesta

\footnotetext{
${ }^{6}$ Definido de maneira que, se $i=0^{\circ}$, a órbita é vista ao longo do eixo do plano orbital (face-on), e se $i=90^{\circ}$, a linha de visada do observador está contida no plano orbital (edge-on). Com esta definição, o eixo maior do Homunculus tem $i=41^{\circ}$ (Davidson et al., 2001).

${ }^{7}$ Medido no plano orbital e definido de maneira que, considerando $i=90^{\circ}$, se $\omega=0^{\circ}$, o periastro ocorre em quadratura à Oeste da primária e se $\omega=90^{\circ}$, o periastro ocorre na conjunção inferior.
} 
configuração, as paredes do cone de choque absorveriam a radiação ionizante, impedindo que os fótons mais energéticos alcançassem os glóbulos de Weigelt.

A principal característica deste modelo, é que o eixo orbital não está alinhado com o de rotação da primária. Portanto, neste caso, é natural esperar que o plano orbital apresente variações devido à precessão, cuja amplitude é diretamente proporcional à razão entre o momento angular rotacional e o orbital (Alexander, 1976). Entretanto, a precessão geraria uma variabilidade cíclica com período menor que o orbital, o que não é confirmado pelas observações.

\section{Cenário 3}

- inclinação orbital: $i \approx 42^{\circ}$;

- argumento do periastro: $\omega=90^{\circ}$ (exatamente em conjunção);

- excentricidade: $0.90 \lesssim e \lesssim 0.95$.

Segundo este modelo, durante a passagem pelo periasto, a aproximação das duas estrelas seria tão pequena que toda a região de colisão dos ventos (cone de choque) colapsaria e, desta maneira, uma quantidade significativa de massa $\left(\sim 10^{-4} \mathrm{M}_{\odot}\right)$ seria acretada pela secundária durante um curto período de tempo (Soker, 2003, 2005; Soker \& Behar, 2006; Soker, 2007; Kashi \& Soker, 2008a, b, 2009). Durante esta fase, o material seria acretado no plano equatorial da secundária, o que aumentaria a opacidade nesta região, causando a colimação do vento da secundária na direção polar.

Este modelo apresenta dificuldades geométricas quando comparado com observações na faixa ultra-violeta obtidas pelo telescópio espacial Hubble: Smith et al. (2004) mostrou que a direção do excesso de fluxo ultra-violeta (UV) durante um evento é tal que, 1 mês antes do mínimo, o excesso começa a desaparecer a partir da direção NE e, depois, durante o mínimo, desaparece em toda a região NW (mas ainda permanece um excesso de fluxo na direção SE), seguida de um apagão geral no fluxo UV (em todas as direções). Depois do mínimo, o excesso de fluxo UV volta a ser detectado na direção NE. 
Se $\omega=90^{\circ}$, então durante o periastro não existiria razão aparente para o desaparecimento completo do excesso de fluxo UV, uma vez que a secundária estaria entre o observador e a primária e, portanto, considerando $i=42^{\circ}$, o fluxo UV deveria estar iluminando a região na direção $\mathrm{N}$ ou NW. Mesmo que durante esta fase a região equatorial da secundária esteja obstruída pelo material sendo acretado, ainda seria possível a observação do fluxo UV proveniente do vento colimado na direção polar. Porém, isto também não é observado.

Para finalizar este capítulo, é importante ressaltar que, atualmente, o único consenso que existe entre os diversos cenários é de que $\eta$ Car é composta de um sistema binário massivo com alta excentricidade. 


\section{Capítulo 2}

\section{Observações e redução dos dados}

\section{espectroscópicos}

Os resultados mostrados nesta tese foram obtidos através da análise de dados obtidos por nós e por nossos colaboradores em vários espectrógrafos, com várias configurações diferentes. Além disso, a grande quantidade de dados obtida exigiu que o processo de redução fosse feito de maneira confiável e consistente.

Neste capítulo, são apresentadas as principais características de cada instrumento utilizado e também o procedimento de redução dos dados coletados no Southern Astrophysical Research Telescope (SOAR) e no Observatório do Pico dos Dias (OPD), utilizando um script específico para eles.

\subsection{Campanhas observacionais do evento de 2009.0 (\#12)}

A Tabela 2.1] reúne todas as principais características de cada instrumento utilizado na coleta de dados que aparecem ao longo desta tese. Vários destes instrumentos tem sua própria metodologia de processamento e redução dos dados.

As campanhas observacionais realizadas por colaboradores produziram dados que foram processados, reduzidos e calibrados pelos mesmos, utilizando os pacotes pertinentes 
Tabela 2.1: Resumo das características de cada instrumento utilizado para obtenção dos espectros utilizados nesta tese.

\begin{tabular}{|c|c|c|c|}
\hline Instrumento & $\begin{array}{l}\text { Dispersão } \\
\left(\AA \operatorname{pix}^{-1}\right)\end{array}$ & $\begin{array}{l}\text { Cobertura espectral } \\
\qquad(\AA)\end{array}$ & Resolução espectral \\
\hline Goodman & 0.65 & $4150-6850$ & $2800\left(3\right.$ pixels $\left.^{a}\right)$ \\
\hline FEROS $^{b}$ & 0.03 & $3500-9200$ & 24000 (2 pixels) \\
\hline $\mathrm{OPD}^{c}$ & 0.25 & variável & 10000-15000 (2 pixels) \\
\hline $\mathrm{MSSSO}^{d}$ & 0.03 & $3868-11000$ & 60000 (2 pixels) \\
\hline $\mathrm{UVES}^{e}$ & 0.02 & $3000-11000$ & $80000-110000$ (2 pixels) \\
\hline $\mathrm{REOSC}^{f}$ & 0.19 & $3600-6500$ & 12500 (2.5 pixels) \\
\hline $\mathrm{CTIO}^{g}$ & 0.06 & $4600-7300$ & 50000 (2 pixels) \\
\hline $\begin{array}{l}{ }^{a} \text { Elemento de r } \\
{ }^{b} \text { Fiber-fed exter } \\
{ }^{c} \text { Observatório d } \\
{ }^{d} \text { Mount Stromlc } \\
{ }^{e} \text { Ultraviolet anc } \\
{ }^{f} \text { Complejo Astr } \\
{ }^{g} \text { Cerro Tololo I }\end{array}$ & $\begin{array}{l}\text { esolução, medi } \\
\text { aded range opt } \\
\text { lo Pico dos Di } \\
\text { o and Siding } S \\
\text { visual échelle } \\
\text { onómico El Le } \\
\text { nteramerican }\end{array}$ & $\begin{array}{l}\text { do no espectro da lâmpad } \\
\text { ical spectrograph - ESO/C } \\
\text { as - LNA/Brasil. } \\
\text { pring Observatories - Au } \\
\text { spectrograph - ESO/Chil } \\
\text { oncito - Argentina. } \\
\text { Observatory - NOAO/Ch }\end{array}$ & $\begin{array}{l}\text { la de calibração. } \\
\text { thile. } \\
\text { strália. } \\
\text { le. }\end{array}$ \\
\hline
\end{tabular}

a cada instrumento. Estes dados não foram re-processados pelo autor desta tese e foram tomados como válidos após uma inspeção visual para determinar se o espectro apresentava algum problema grave. Portanto, neste capítulo, serão discutidos somente os procedimentos de redução referentes aos dados coletados com o telescópio do SOAR e do OPD.

\subsubsection{Dados do telescópio do SOAR}

Localizado nos Andes chilenos, no Cerro Pachón, a 2700 m acima do nível do mar, o telescópio SOAR tem um espelho primário de 4,2 m de abertura e foi construído pelo consórcio formado pelo NOAO (National Optical Astronomy Observatory), pela Universidade da Carolina do Norte (UNC), pela Universidade Estadual de Michigan (MSU) e pelo Brasil (representado pelo $\mathrm{CNPq}$ ).

Os espectros do SOAR apresentados nesta tese foram obtidos utilizando o espec- 


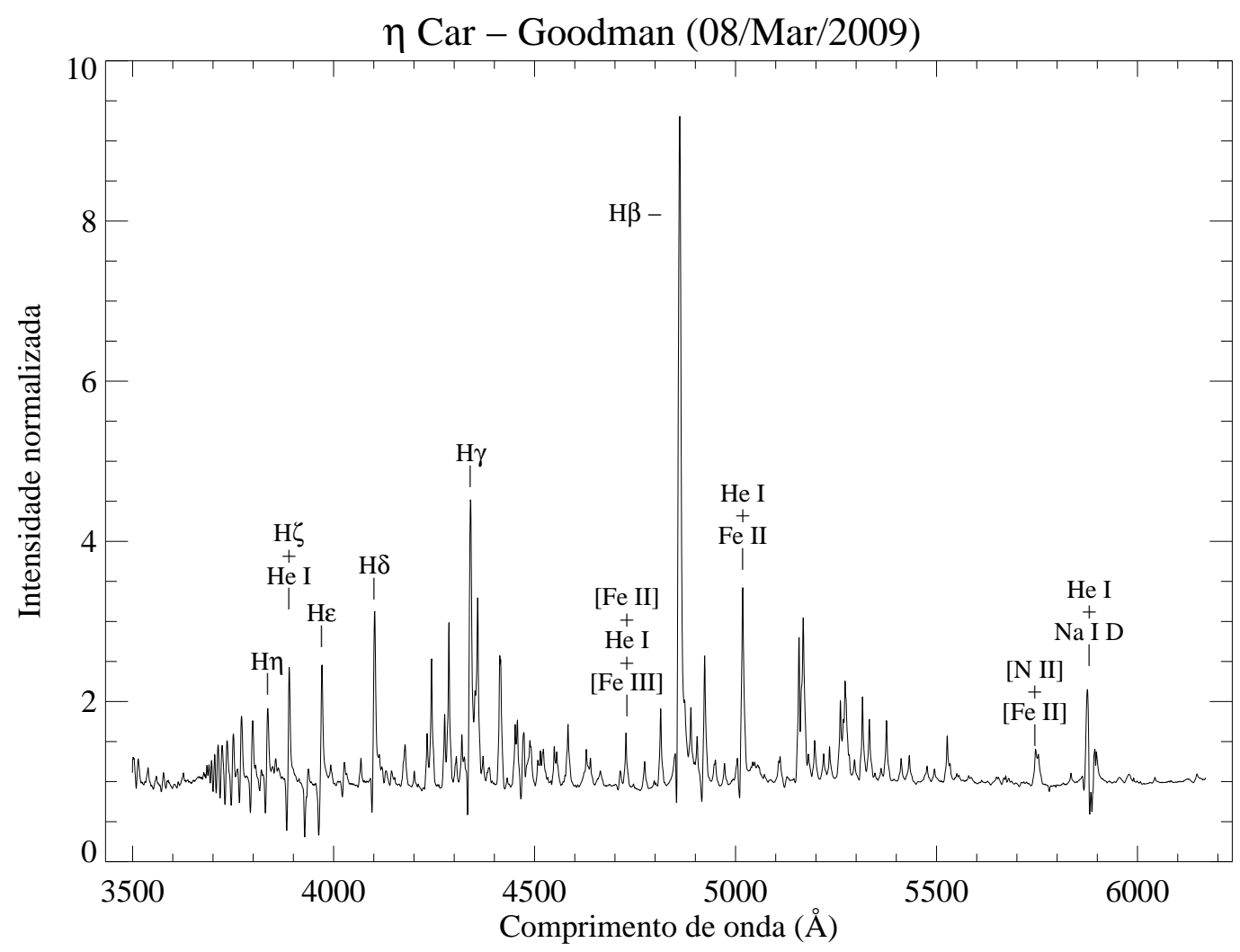

Figura 2.1: Espectro de $\eta$ Car obtido em 08 de Março de 2009, com o espectrógrafo Goodman, no SOAR, utilizando a rede de 600 linhas $\mathrm{mm}^{-1}$. Algumas linhas espectrais estão identificadas. O sinal de + significa que as linhas estão muito próximas entre si.

trógrafo Goodman 1 com a rede de 600 linhas $\mathrm{mm}^{-1}$. Isso permitiu obter espectros na faixa óptica de 3500 a $9000 \AA$, divididos em duas partes: azul (3500-6100 A) e vermelha (6400-9000 Å). Além disso, foram obtidos espectros com tempo de exposição curto e longo para permitir o monitoramento tanto das linhas mais intensas (e.g. $\mathrm{H} \alpha, \mathrm{H} \beta$ ) quanto as mais fracas (e.g. He II $\lambda 4686$ ). Os dados do Goodman foram coletados utilizando a fenda de 0.45 arcsec, que fornece um elemento de resolução de cerca de 3 pixels (ou $\approx 1.8 \AA$, em torno de $5000 \AA$, medido no espectro das lâmpadas de calibração). Isso representa uma resolução espectral de aproximadamente 2800. Um espectro típico, não-saturado, de $\eta$ Car (processado, reduzido e calibrado em comprimento de onda) tomado com o espectrógrafo Goodman é mostrado na Fig. 2.1.

Os espectros foram processados por um script desenvolvido especificamente para os dados do Goodman. Depois do processamento, os espectros apresentavam um contínuo 


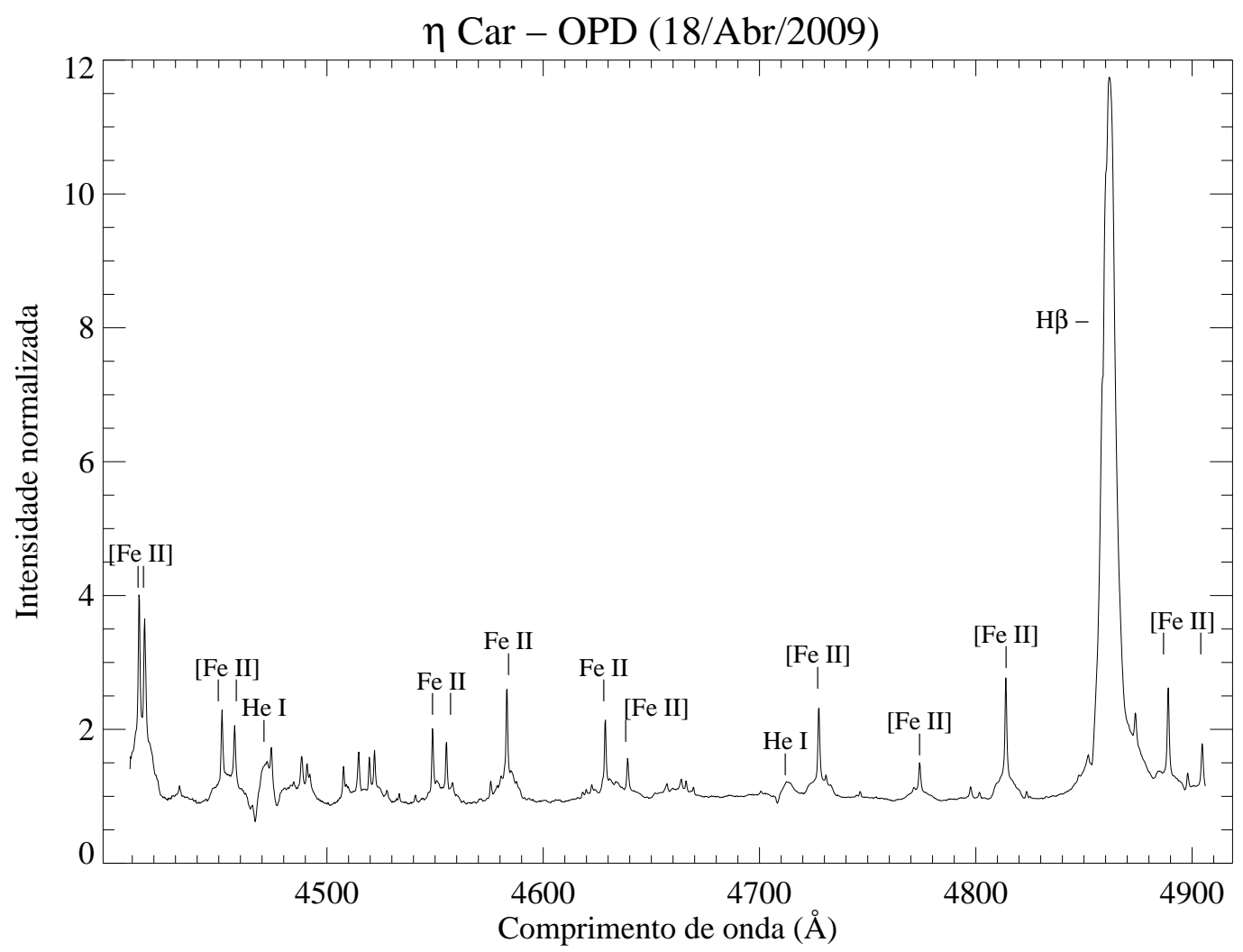

Figura 2.2: Espectro de $\eta$ Car obtido no OPD em 18 de Abril de 2009, utilizando o foco Coudé do telescópio de $1.60 \mathrm{~m}$ e a rede de $600 \mathrm{l} / \mathrm{mm}$.

razoavelmente plano, facilmente normalizado por um polinômio Chebyshev de ordem 2 ou 3.

\subsubsection{Dados do telescópio de $1.60 \mathrm{~m}$ do OPD}

Situado em Brasópolis, a cerca de 250 km de São Paulo, no sul de Minas Gerais, este observatório, com 1890 m de altitude, abriga o maior telescópio profissional em solo brasileiro, com 1.6 m de diâmetro, e é operado pelo Laboratório Nacional de Astrofísica, instituto do Ministério de Ciências e Tecnologia.

Infelizmente, o evento de 2009.0 aconteceu em um período do ano em que o tempo no OPD é muito instável, e, portanto, poucas noites geraram dados aproveitáveis. De fato, só foi possível coletar dados em quatro ocasiões ao longo da campanha no OPD: 12 e 13 de Janeiro, 20 de Fevereiro e 18 de Abril. Para processar estes dados, também foi criado um script semelhante ao descrito na seção anterior.

A largura da fenda utilizada para coleta de dados no OPD foi mantida em aproxima- 
damente 1 arcsec durante todas as campanhas observacionais, desde 1992.5 até 2009.0. O detector utilizado na coleta dos dados na campanha observacional dos eventos de 1992.5 até 2003.5 foi o CCD $098\left(4096 \times 4096\right.$ pixels e $0.25 \AA$ pixel $\left.^{-1}\right)$, com uma cobertura espectral de $1000 \AA$ e elemento de resolução de aproximadamente $0.5 \AA$, correspondendo a $R \approx 10000$.

Para o evento de 2009.0 foi utilizado o CCD $105\left(2048 \times 2048\right.$ pixels e $0.25 \AA$ pixel $\left.^{-1}\right)$, que cobre metade da faixa espectral do CCD 098, porém ambos possuem pixels do mesmo tamanho.

Devido à pequena cobertura espectral, os dados coletados com o CCD 105 apresentaram um contínuo muito plano e sem grandes oscilações, conforme pode ser visto na Fig. 2.2, que mostra um espectro típico do OPD depois de processado, reduzido e calibrado. Além disso, a lâmpada de calibração utilizada, Th-Ar, contem muitas linhas ao longo do espectro, o que possibilitou a utilização de um polinômio de baixa ordem (geralmente $\leq 3)$ para determinar a solução da correlação $\lambda$-pixel, com bastante precisão e acurácia, conforme discutido mais adiante, na seção 2.3 .

\subsubsection{Dados obtidos com outros instrumentos}

\section{FEROS (ESO/Chile)}

Em todas as noites, durante o período de 21 a 31 de Dezembro de 2008, foram coletados dados com este espectrógrafo. De maneira geral, o contínuo da maioria dos espectros obtidos com o FEROS não apresentou grandes oscilações nas regiões onde as ordens são sobrepostas para formar um único espectro, conforme ilustra a Fig. 2.3. Isto facilitou bastante a tarefa de determinação de um contínuo local para medição de larguras equivalentes das linhas.

\section{REOSC (CASLEO/Argentina)}

Os dados obtidos com o espectrógrafo échelle REOSC são difíceis de serem normalizados para uma correta medida da largura equivalente das linhas. Provavelmente, isto é decorrente de uma pobre correção de flat field em cada uma das ordens do espectro. De 


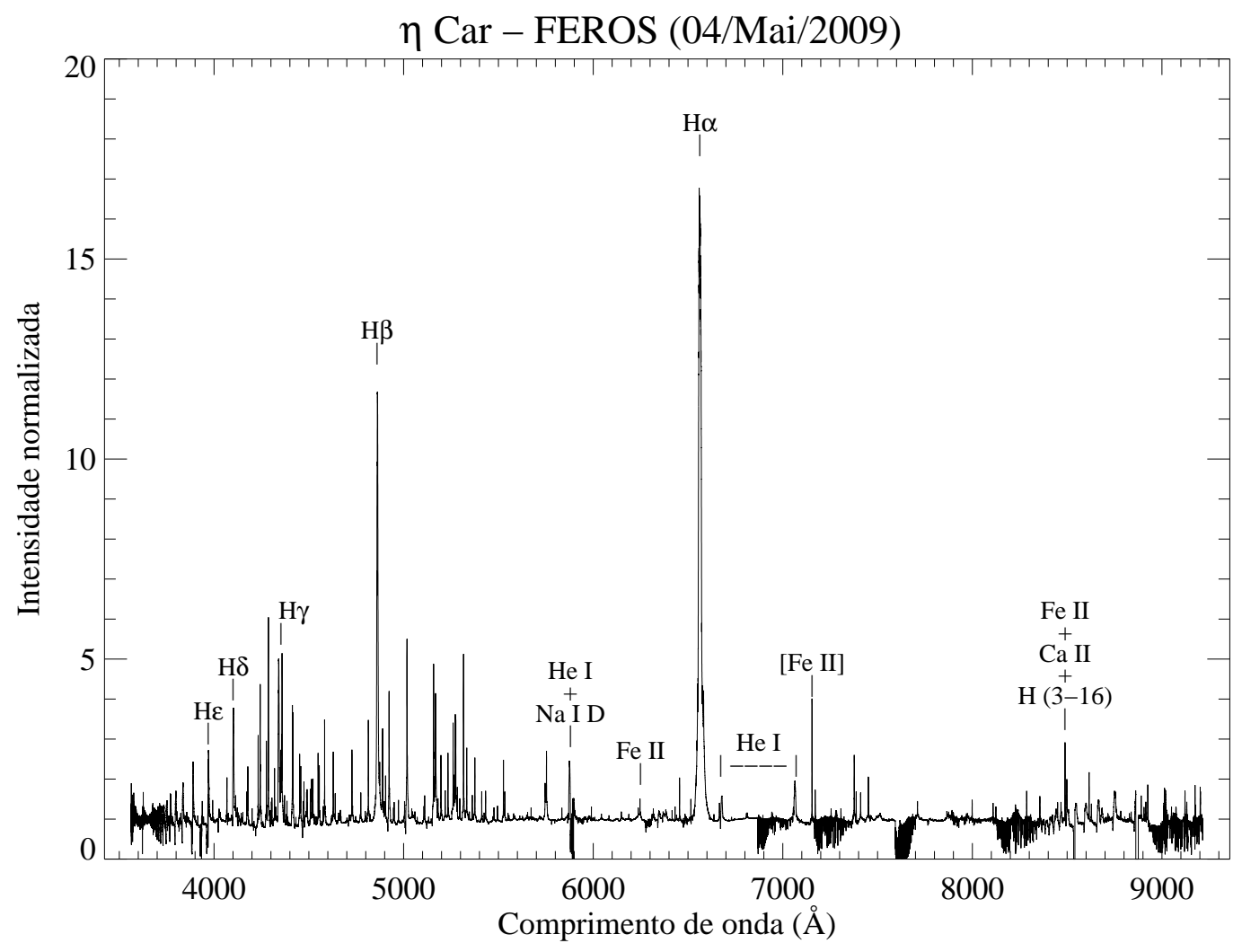

Figura 2.3: Espectro de $\eta$ Car obtido em 04 de Maio de 2009, com o espectrógrafo FEROS, no ESO. As linhas em absorção além de 6500 A são linhas telúricas.

fato, quando o perfil espectral de cada ordem não é devidamente corrigido pela resposta instrumental, o processo de combinação das ordens para formar um único espectro resulta em um contínuo cheio de ondulações, conforme pode ser visto na Fig. 2.4.

Devido ao fato de o contínuo não ser facilmente normalizado, os espectros obtidos com o REOSC não foram utilizados para medir a largura equivalente da linha do He II $\lambda 4686$, já que tal medida toma por base o contínuo local do espectro. É importante ressaltar que este problema não afeta a medição da razão entre as intensidades de linhas contíguas e, por isso, estes espectros puderam ser utilizados na determinação da razão entre o pico das linhas do [N II] $\lambda 5755$ e [Fe II] $\lambda 5747$.

\section{CTIO (NOAO/Chile)}

Os dados do espectrógrafo echélle, acoplado ao telescópio de $4.0 \mathrm{~m}$ do CTIO, foram obtidos em três ocasiões: 09, 16 e 17 de Março de 2009. Apesar de não possuir cobertura na região azul da faixa óptica, estes espectros são similares em qualidade aos obtidos pelo 


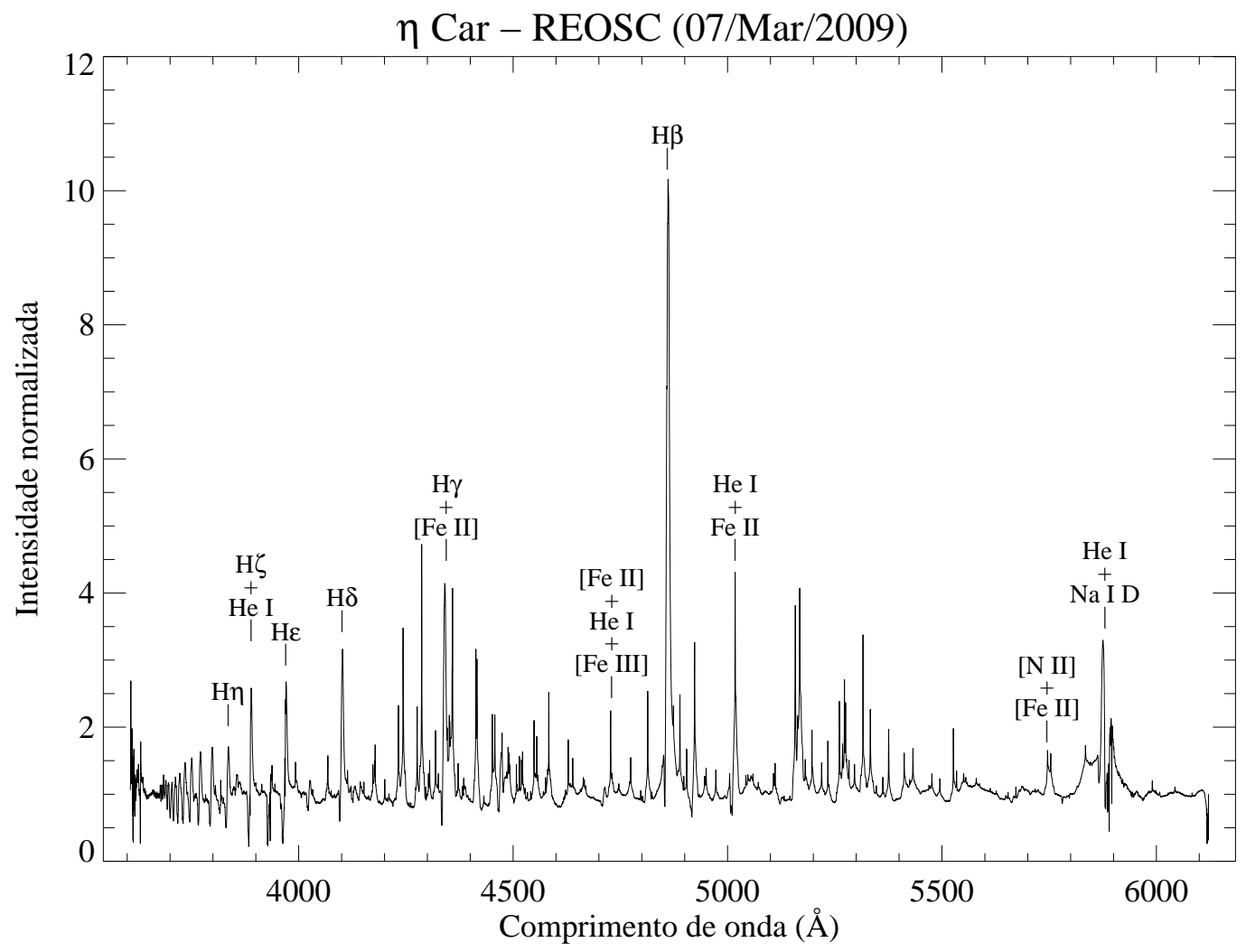

Figura 2.4: Espectro de $\eta$ Car obtido em 07 de Março de 2009, com o espectrógrafo échelle REOSC, instalado no telescópio de $2.15 \mathrm{~m}$ do CASLEO. Note as oscilações do contínuo espectral, que no lado vermelho é mais evidente que no azul. Este efeito é um fator complicante na determinação de um contínuo local para realizar as medidas de largura equivalente.

FEROS, ou seja, o espectro final apresenta um contínuo muito bem corrigido pela resposta instrumental, conforme visto na Fig. 2.5.

\subsection{Dados dos eventos anteriores: $1992.5(\# 9)$, $1998.0(\# 10), 2003.5(\# 11)$}

Assim como os dados do evento de 2009.0 (\#12), os dados referentes aos eventos de 1992.5, 1998.0 e 2003.5 também foram obtidos com a utilização de diversos instrumentos em diversos observatórios. Os dados dos 3 eventos anteriores (evento \#9, \#10 e \#11), utilizados nesta tese, foram coletados com os instrumentos listados a seguir. 


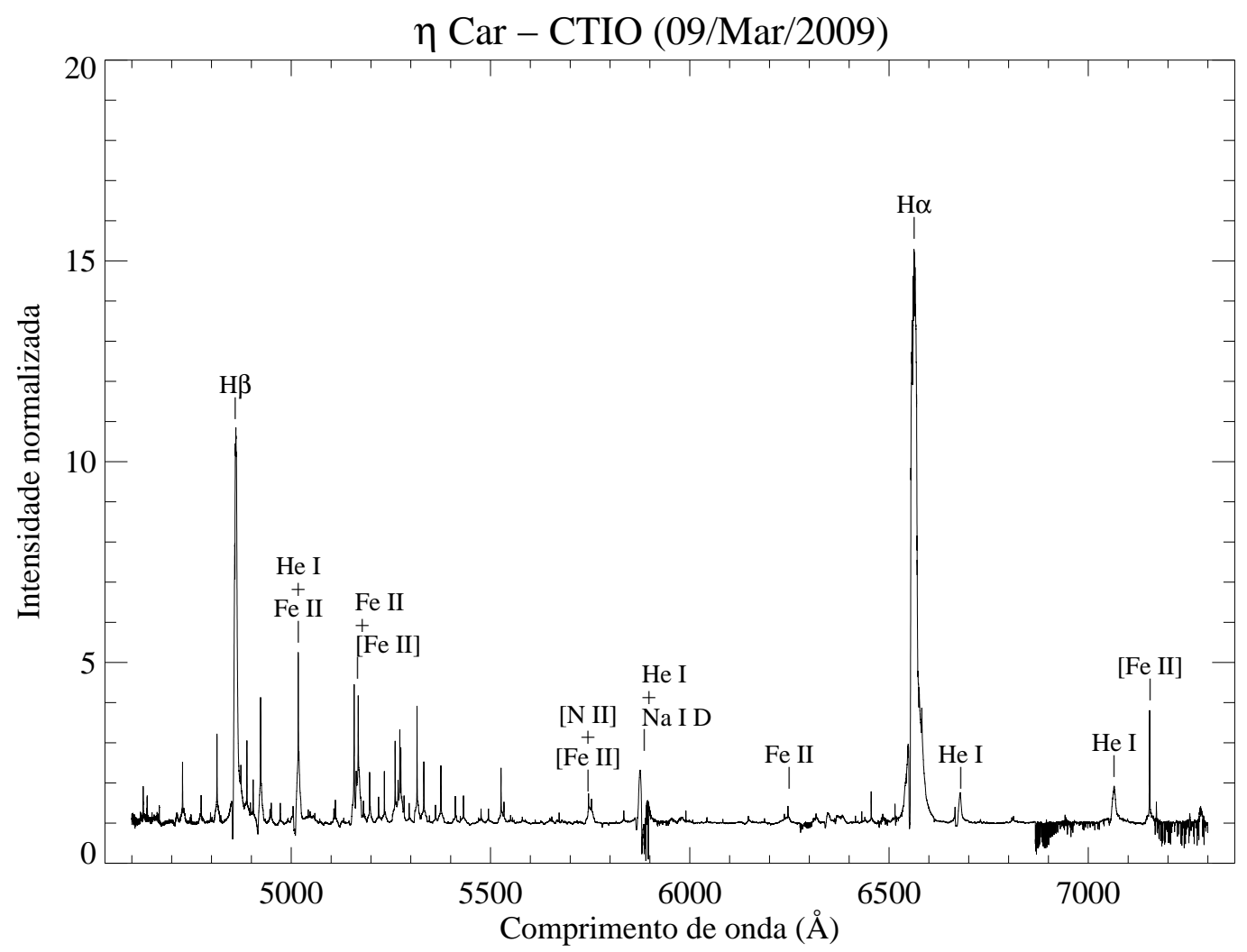

Figura 2.5: Espectro de $\eta$ Car obtido em 09 de Março de 2009, com o espectrógrafo echélle, instalado no telescópio de $4.0 \mathrm{~m}$ do CTIO.

\section{OPD (1992.5 e 2003.5)}

Foram coletados espectros durante os eventos de 1992.5 e 2003.5, utilizando o foco Coudé do telescópio de $1.60 \mathrm{~m}$ e um detector de $4096 \times 4096$ pixels que fornecia dados com a mesma dispersão dos dados de 2009.0, porém com o dobro de intervalo espectral. A largura da fenda utilizada para coleta dos dados de 1992.5 e 2003.5 foi a mesma utilizada na coleta de 2009.0. As datas de observação foram as seguintes:

- 1992: 02/Jun;

- 2003: 13/Mai, 12/Jun, 20-30/Jun, 01-07/Jul, 09/Jul, 20/Jul e 13/Dez.

\section{UVES (2003.5)}

Os dados do UVES foram coletados durante o evento de 2003.5 como parte de uma campanha observacional no ESO, liderada por Otmar Stahl, da Universidade de Heidelberg, Alemanha. Foram obtidos dados com o UVES durante 34 noites entre Dezembro de 1999 
e Março de 2004, com observações mais frequentes próximo ao evento, ou seja, durante Maio, Junho e Julho de 2003. Entrentanto, a intenção da campanha observacional com o UVES era estudar as variações espectrais que ocorrem durante um evento na região conhecida como FOS4 (localizada a 4 arcsec ao leste e 6 arcsec ao sul da fonte central), e por isso, para os objetivos desta tese, só foram aproveitadas 6 noites de observação:

- 2002: 07 e 12/Dez;

- 2003: 14/Fev, 29/Mai, 03/Jun e 05/Jul.

\section{MSSSO (1998.0)}

Durante o evento de 1998, Peter McGregor, da Universidade Nacional da Austrália, conseguiu coletar dados utilizando um espectrógrafo echélle montado no foco coudé do telescópio de 74 polegadas do MSSSO, localizado na Austrália. Entretanto, estes dados apresentaram o mesmo problema encontrado nos espectros do REOSC, isto é, um contínuo difícil de ser normalizado para medições de largura equivalente. Porém, é importante ressaltar que nos espectros do MSSSO, a intensidade das oscilações eram muito menor do que aquelas presentes nos dados do REOSC.

As datas de observação de $\eta$ Car com o espectrógrafo do MSSSO são as seguintes:

- 1997: 18/Nov e 25/Dez;

- 1998: 25/Fev e 23/Mar.

Tendo em vista a importância destes dados, uma vez que são praticamente os únicos obtidos deste evento, foi feito um esforço na tentativa de realizar a correção da resposta instrumental dos espectros através do ajuste simples de um polinômio de baixa ordem (primeiro um de ordem 3 e depois outro de ordem 2), cujo resultado mostrou-se satisfatório para a normalização do contínuo.

\section{FEROS (1992.5)}

Durante o evento de 1992.5, também foram obtidos dados com o espectrógrafo FEROS. As características deste espectrógrafo já foram discutidas anteriormente. As datas de 
observação foram as seguintes:

- 1992: 20/Jun, 21/Jul, 26/Jul, 03/Ago e 08/Ago.

\subsection{Processamento dos dados do Goodman e do OPD}

Devido ao grande volume de dados obtido, foi necessária a criação de um script de redução de dados específico para o espectrógrafo Goodman e outro para os dados coletados no telescópio do OPD. Este script faz uso de pacotes conhecidos e largamente utilizados do IRAF 2 para processar, reduzir e calibrar todos os dados obtidos com a mesma configuração instrumental, em uma dada faixa espectral. Esta metodologia é extremamente importante pois os resultados finais tornam-se homogêneos, mesmo que as observações sejam feitas em épocas distintas.

O processamento dos dados do Goodman e do OPD foi feito da maneira padrão: subtração das contagens geradas pela leitura do detector (bias), correção da resposta pixel a pixel (flat field), extração espectral e calibração em comprimento de onda. O pacote CCDPROC foi utilizado para aplicar as correções de bias e flat field, e o pacote DOSLIT foi utilizado para extrair e calibrar o espectro em comprimento de onda. Além disso, foi calculado, para cada espectro, a correção a ser aplicada para que o sistema de velocidades passasse de topocêntrico para o heliocêntrico. Para isso, foi utilizado o pacote RVCORRECT, que utiliza as informações contidas no cabeçalho das imagens sobre o sítio do telescópio (longitude, latitude e fuso horário) e também das informações sobre as coordenadas do objeto e a hora da observação.

\section{Identificação das linhas espectrais}

Depois da extração do espectro, o script de redução utiliza a observação de uma lâmpada de calibração para determinar uma solução para a relação entre posição do pixel e comprimento de onda. Isto foi feito utilizando o pacote IDENTIFY.

A lâmpada de calibração utilizada na coleta dos dados do OPD é a de Th-Ar, que é frequentemente utilizada por conter uma grande quantidade de linhas espectrais conspí-

\footnotetext{
${ }^{2}$ Image Reduction and Analysis Facility (www.iraf.noao.edu).
} 


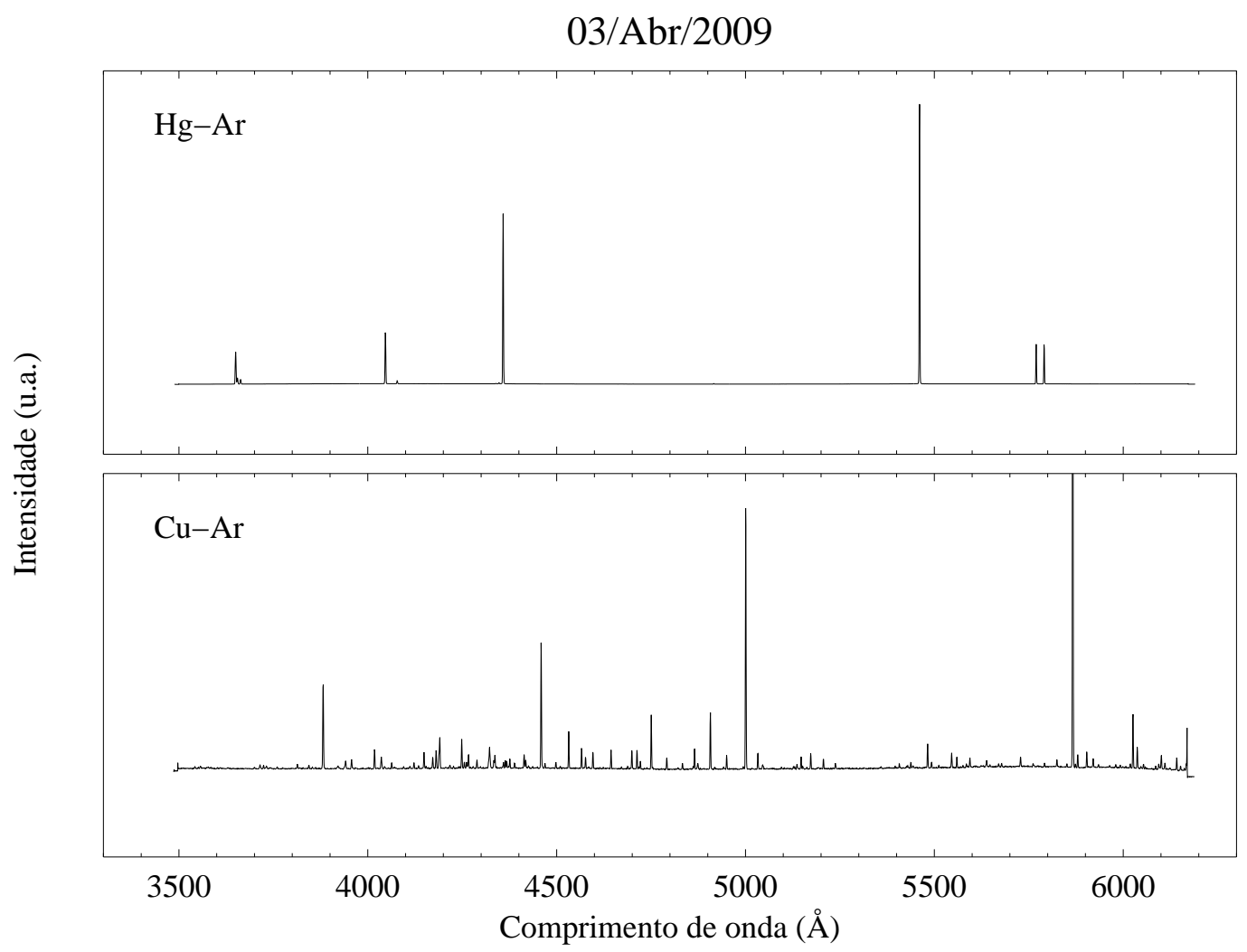

Figura 2.6: Espectro das lâmpadas de comparação do Goodman, obtidos em 03 de Abril de 2009. No painel superior está o espectro do Hg-Ar e no inferior, o do Cu-Ar. Note a diferença no número de linhas entre os dois espectros. A escala vertical está em unidades arbitrárias.

cuas ao longo de toda a faixa óptica. Desta maneira, para os dados do OPD, a correlação $\lambda$-pixel foi obtida através do uso de um polinômio Chebyshev de ordem 3 ou 4 , dependendo da configuração utilizada, o que resulta, em média, em um r.m.s $3<0.01 \AA$. De maneira geral, os espectros do OPD são relativamente fáceis de serem processados, calibrados e normalizados.

No caso específico dos dados do Goodman, ao longo de todo o espectro tomado com a rede de 600 linhas $\mathrm{mm}^{-1}$, existem pouquíssimas linhas da calibração claramente visíveis ao utilizar a lâmpada padrão de Hg-Ar, conforme visto na Fig. 2.6. De fato, existem somente 6 linhas espectrais passíveis de serem utilizadas na calibração em comprimento de onda quando se utilza a lâmpada de $\mathrm{Hg}$-Ar. Inicialmente, este fato foi preocupante porque na região de $4686 \AA$ (região de interesse desta tese) não havia sequer uma linha espectral da

\footnotetext{
${ }^{3}$ Root mean square (valor quadrático médio), dado por $\sqrt{\frac{1}{n} \sum_{i=1}^{n} \Delta \lambda_{i}^{2}}$, onde $\Delta \lambda_{i}$ é a diferença entre o comprimento de onda calculado pelo polinômio e o teórico e $n$ é o número de linhas identificadas.
} 


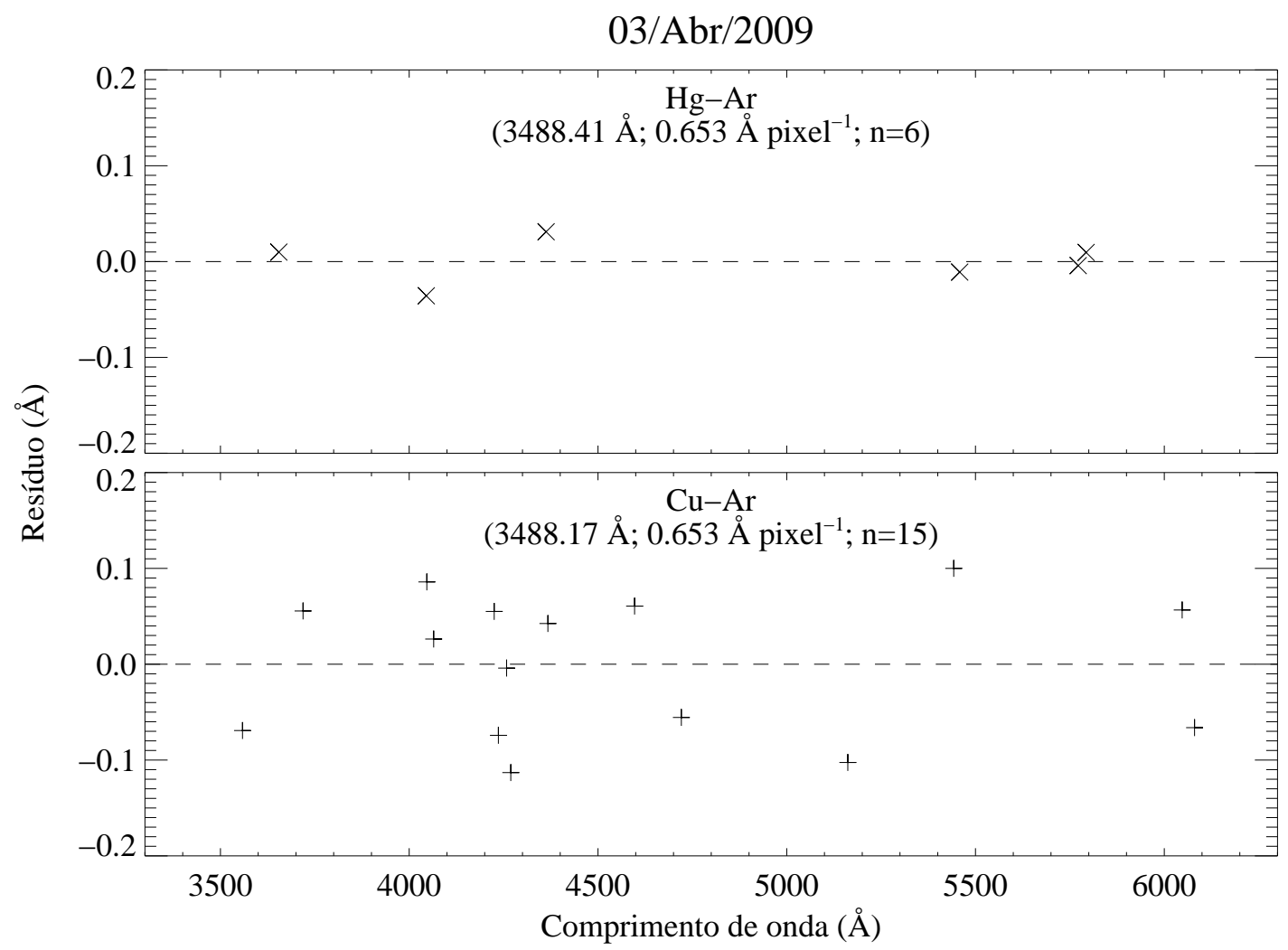

Figura 2.7: Esta figura mostra a diferença entre o comprimento de onda da linha identificada no espectro da lâmpada de calibração e o valor calculado ao aplicar um polinômio Chebyshev de ordem 4 ao espectro. A lâmpada de Hg-Ar apresenta o menor r.m.s (0.02 A), embora a de Cu-Ar (r.m.s. $\approx 0.07 \AA$ ) tenha muito mais linhas espalhadas ao longo do espectro. Porém, ambas convergem para soluções muito semelhantes, que estão mostradas, nesta figura, entre parênteses e na Tabela 2.2.

lâmpada de calibração para garantir a qualidade da solução encontrada nesta região. Por isso, foi necessário fazer uma comparação entre o resultado obtido ao aplicar a solução derivada da lâmpada de Hg-Ar (que tem somente 6 linhas conspícuas) e aquele obtido com Cu-Ar (que apresenta muito mais linhas, cf. Fig. 2.6, painel inferior) para garantir que todos os dados calibrados com Hg-Ar não fossem descartados por má qualidade da solução encontrada para a correlação $\lambda$-pixel.

A Fig. 2.7 mostra os resíduos e a Tabela 2.2 resume as soluções encontradas para a correlação $\lambda$-pixel ao utilizar as duas lâmpadas de calibração obtidas no dia 03 de Abril de 2009. Ajustando um polinômio Chebyshev de ordem 4 às 6 linhas do espectro de calibração da lâmpada de Hg-Ar, a solução encontrada é muito semelhante àquela obtida utilizando 15 linhas da lâmpada de $\mathrm{Cu}$-Ar, distribuídas de maneira mais homogênea ao 
Espectro de $\eta$ Car em 03/Abr/2009

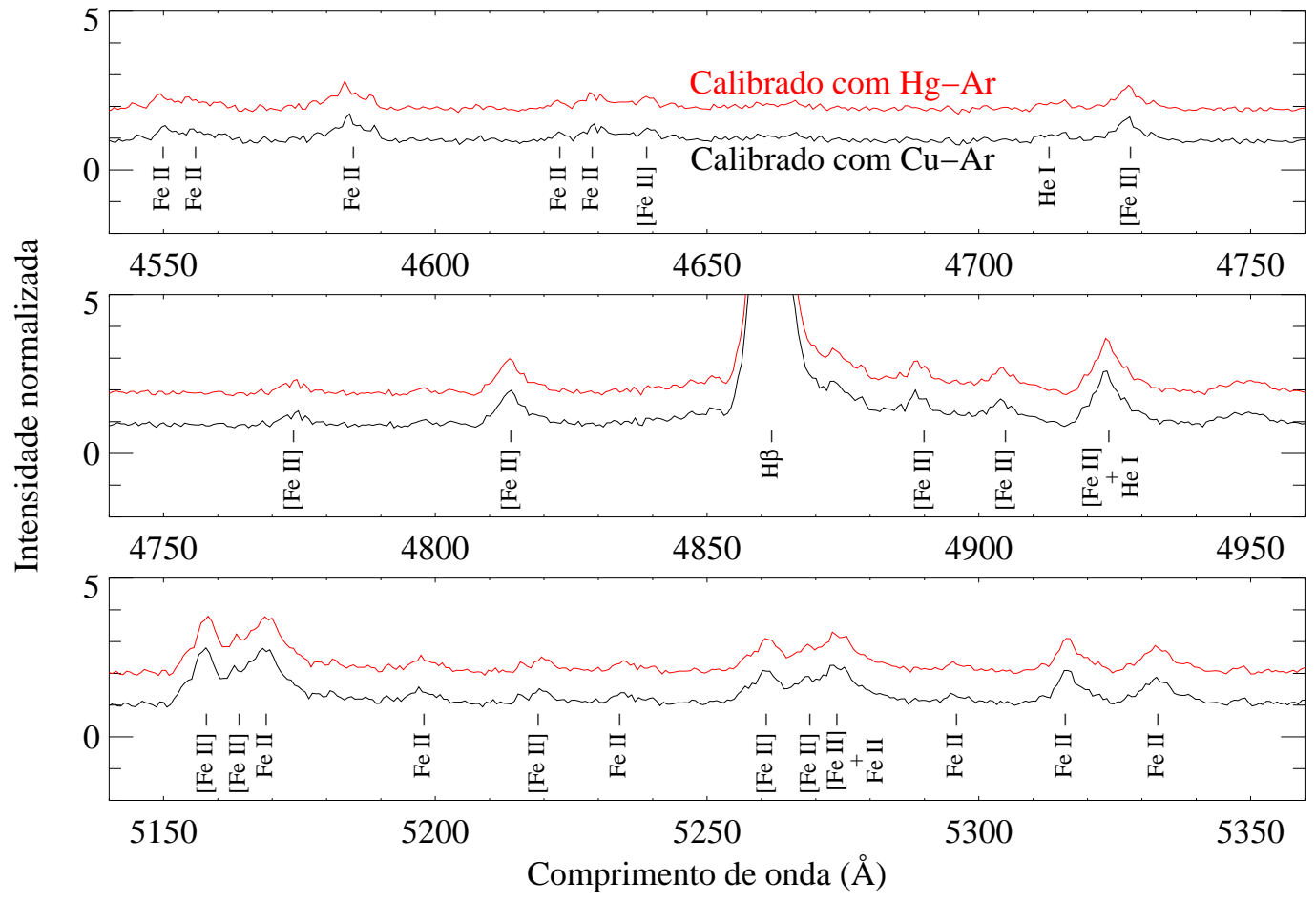

Figura 2.8: Espectro de $\eta$ Car obtido com o espectrógrafo Goodman, em 03/Abr/2009. Para comparação das soluções encontradas para as duas lâmpadas de comparação, o mesmo espectro foi calibrado em comprimento de onda aplicando o polinômio encontrado para a lâmpada de $\mathrm{Hg}$ - $\mathrm{Ar}$ (espectro em vermelho) e o encontrado para $\mathrm{Cu}$-Ar (espectro em preto). Esta figura confirma que as soluções são compativeis entre si, apesar da escassez de linhas no espectro de $\mathrm{Hg}$ - $\mathrm{Ar}$ em relação ao $\mathrm{Cu}$-Ar.

longo do espectro. De fato, aplicando a solução ao espectro de $\eta$ Car, observado no mesmo dia, a diferença entre o valor da solução encontrada para o primeiro e o último pixel do detector utilizando as lâmpadas de $\mathrm{Hg}$ - $\mathrm{Ar}$ e $\mathrm{Cu}$-Ar é de apenas $0.24 \AA$, o que corresponde a aproximadamente $1 / 3$ da dispersão dos dados do Goodman.

A Fig. 2.8 mostra, de maneira direta, a comparação entre as soluções encontradas por ambas as lâmpadas de calibração. O espectro de $\eta$ Car, observado em 03 de Abril de 2009, foi calibrado utilizando a solução encontrada com a lâmpada de Hg-Ar e, depois, com aquela encontrada com a lâmpada de Cu-Ar. A Fig 2.8 mostra 3 regiões ao longo do espectro de $\eta$ Car: $\lambda \lambda 4550-4750$ (começo do detector), $\lambda \lambda 4750-4950$ (meio) e $\lambda \lambda 5150-5350$ (fim). É possível notar que, ao longo de todo o espectro, as calibrações em comprimento de onda obtidas através da utilização de ambas as lâmpadas são completa- 
Tabela 2.2: Comparação dos parâmetros da solução final encontrada pelo pacote IDENTIFY para as lâmpadas de calibração obtidas em 03 de Abril de 2009.

\begin{tabular}{ccccc}
\hline \hline Lâmpada de calibração & $\mathrm{n}^{a}$ & CRVAL1 $^{b}(\AA)$ & CDELT1 $^{c}\left(\AA_{\text {pixel }}^{-1}\right)$ & r.m.s. $(\AA)$ \\
\hline Hg-Ar & 6 & 3488.41 & 0.6525 & 0.02 \\
$\mathrm{Cu}-\mathrm{Ar}$ & 15 & 3488.17 & 0.6525 & 0.07 \\
\hline
\end{tabular}

\footnotetext{
${ }^{a}$ Número de linhas utilizadas para determinação do polinômio.

${ }^{b}$ Comprimento de onda do primeiro pixel.

${ }^{c}$ Dispersão.
}

mente compatíveis entre si. Este resultado mostra que a calibração com a lâmpada de Hg-Ar, apesar de apresentar poucas linhas, é satisfatório. Portanto, todos os espectros do Goodman apresentados nesta tese foram calibrados em comprimento de onda utilizando a lâmpada de $\mathrm{Hg}-\mathrm{Ar}$, com r.m.s. $\approx 0.02 \AA$ A, em média. 


\section{Capítulo 3}

\section{Espectroscopia de campo integral do}

\section{Homúnculo}

Este capítulo é resultado do trabalho publicado em Teodoro et al. (2008), que foi, essencialmente, os resultados obtidos ao longo do mestrado. Entretanto, a finalização do trabalho e sua publicação tomaram parte do tempo de doutorado e, durante este período, novos resultados - que não puderam ser incluídos na dissertação - foram obtidos.

\subsection{Observações e redução dos dados}

Os dados foram coletas em 14, 15 e 18 de Março de 2003, utilizando o espectrógrafo de campo integral CIRPASS (Cambridge InfraRed Panoramic Survey Spectrograph), que na época era um instrumento visitante do telescópio de $8 \mathrm{~m}$ do Gemini Sul. A matriz de lentes (unidade de campo integral) colocada no foco do telescópio é composta de 490 lentes em formato hexagonal, onde cada lente coleta a luz de uma região de $0.25 \times 0.22 \operatorname{arcsec}^{2}$ no céu, resultando em um campo de visão total de $9.0 \times 3.3 \operatorname{arcsec}^{2}$. Os espectros obtidos com o CIRPASS cobrem o intervalo espectral de 10620 a $12960 \AA$ A com resolução espectral de $\sim 3200$.

Para mapear toda a nebulosa do Homúnculo, foi feito um mosaico composto de 44 posições ao longo da nebulosa, onde, em cada posição, foram feitas duas exposições para melhorar a relação sinal-ruído (que nos espectros reduzidos e calibrados era de $\sim 25$ ). 
Cada posição do mosaico foi deslocada cerca de 0.88 arcsec em relação à posição anterior ao longo do eixo Norte-Sul. Desta maneira, foram obtidos espectros de 6299 posições ao longo de toda a nebulosa do Homúnculo.

A redução foi feita utilizando as técnicas padrões de redução de dados no infravermelho. Os sinais espúrios foram removidos utilizando o pacote COSMICRAYs do IRAF e, posteriormente, os dados foram corrigidos pelas variações na resposta pixel-a-pixel e o espectro foi extraído utilizando o algorítmo de extração ótima para minimizar o efeito de sobreposição dos espectros vizinhos ao longo da direção espacial. A calibração em comprimento de onda foi feita aplicando um polinômio de baixa ordem às linhas espectrais identificadas em uma lâmpada de calibração com o pacote IDENTIFY, também do IRAF. Além disso, as linhas telúricas foram removidas utilizando o espectro de uma estrela padrão quente (HD 303308, O3 V) observada logo após o objeto de ciência.

\subsection{Mapeamento espacial do [Fe II] $\lambda 12567$}

Esta linha espectral foi utilizada para mapear as regiões de excitação colisional ao longo da nebulosa do Homúnculo utilizando a seguinte relação

$$
\frac{I_{[\mathrm{FeII}] \lambda 12567}}{I_{P a \gamma}}=0.41 \frac{I_{[\mathrm{FeII}] \lambda 16435}}{I_{B r \gamma}}
$$

onde $I$ é a intensidade da linha indicada pelo subscrito. A razão de linhas mostrada no lado direito desta equação é frequentemente utilizada como indicador do mecanismo de excitação da região onde é formada. Por exemplo, remanescentes de supernova (onde as linhas são formadas por colisão) apresentam $I_{F e I I \lambda 16435} / I_{B r \gamma} \gtrsim 30$, enquanto as regiões H II

(linhas formadas por recombinação) têm esta razão tipicamente $\leqslant 1$ (McKee et al.., 1984; Seab et al., 1984; Shull \& Draine, 1987; Graham et al., 1987; Smith et al., 2003). Portanto, a Eq. 3.1] foi utilizada para transferir as propriedades da razão entre o [Fe II] $\lambda 16435$ e Br $\gamma$ (banda $H$ e $K$, respectivamente) para a região coberta pelo CIRPASS (banda $J$ ). Além disso, a utilização das linhas do [Fe II] $\lambda 12567$ e Pa $\gamma$ tem a vantagem de ser menos afetada pelo avermelhamento do que a razão entre uma linha na banda $H$ e outra na banda $K$. 


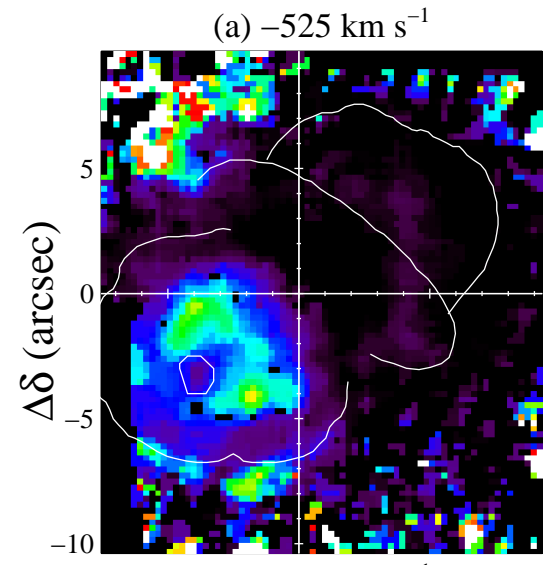

(d) $+401 \mathrm{~km} \mathrm{~s}^{-1}$

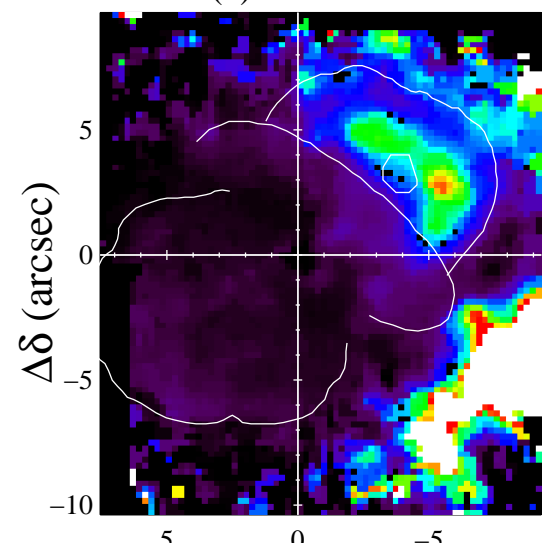

(b) $-471 \mathrm{~km} \mathrm{~s}^{-1}$

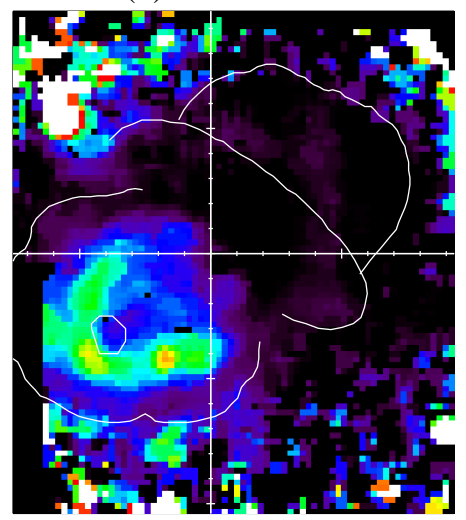

(e) $+455 \mathrm{~km} \mathrm{~s}^{-1}$

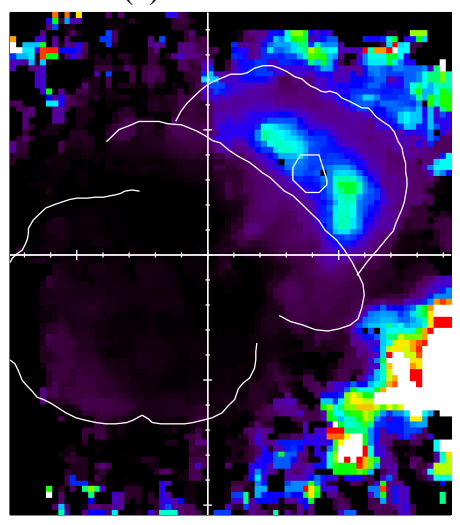

$\Delta \alpha(\operatorname{arcsec})$ (c) $-416 \mathrm{~km} \mathrm{~s}^{-1}$

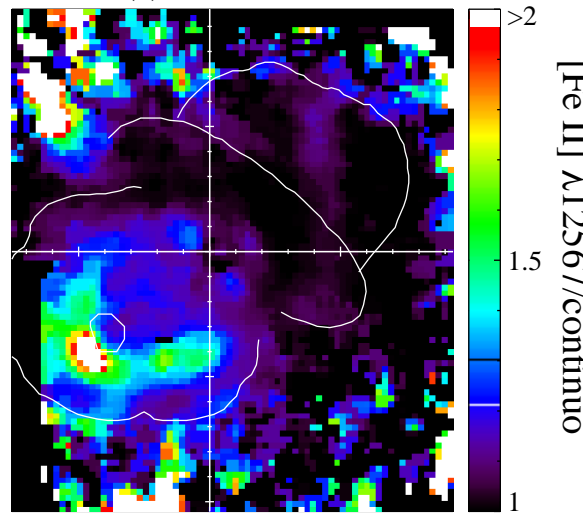

(f) $+510 \mathrm{~km} \mathrm{~s}^{-1}$

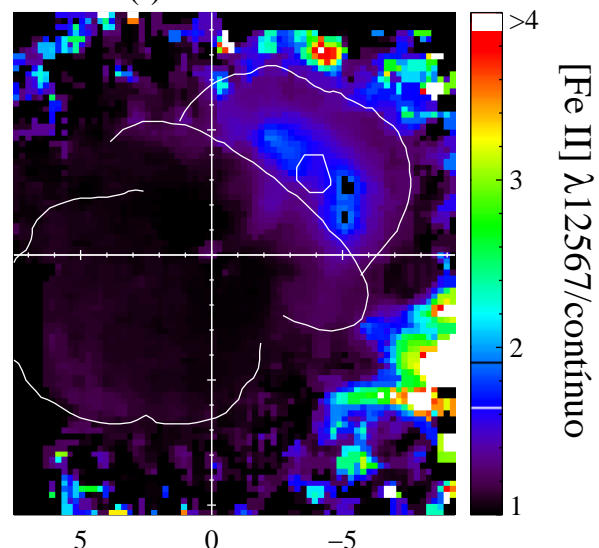

Figura 3.1: Mapas de velocidade da linha do [FeII] $\lambda 12567$. Nestes mapas é possível ver a posicção dos buracos em ambos os lóbulos (círculo branco).

A utilização da Eq. 3.1 nos dados do CIRPASS confirmou a presença de um buraco na parede do Homúnculo, na região do lóbulo SE conhecida como SE hole (Smith et al.), 1998), conforme pode ser visto na sequência de imagens mostrada na Fig. 3.1, que mostra cortes na direção espectral (em velocidade) do cubo de dados. Além disso, também foi confirmada a presença de uma região correspondente no lóbulo NW, cujas coordenadas foram obtidas pela rotação de $180^{\circ}$ (em torno da fonte central) da posição do SE hole.

É importante ressaltar que as emissões proibidas intrínseca:11 (incluindo a do [Fe II] $\lambda 12567$ ) são oriundas das colisões que ocorrem na parede interna dos lóbulos e, por isso, modelos geométricos do Homúnculo baseados em emissões proibidas são sempre menores quando comparados com as imagens obtidas com filtros largos, como os obtidos pelo telescópio espacial Hubble (Davidson et al., 2001). Por outro lado, o modelo baseado nas emissões de $\mathrm{H}_{2}$ feito por Smith (2006), é representativo da parede externa do lóbulos, onde as

\footnotetext{
${ }^{1}$ Emissões que não são produzidas na fonte central e, posteriormente, refletidas nos lóbulos.
} 


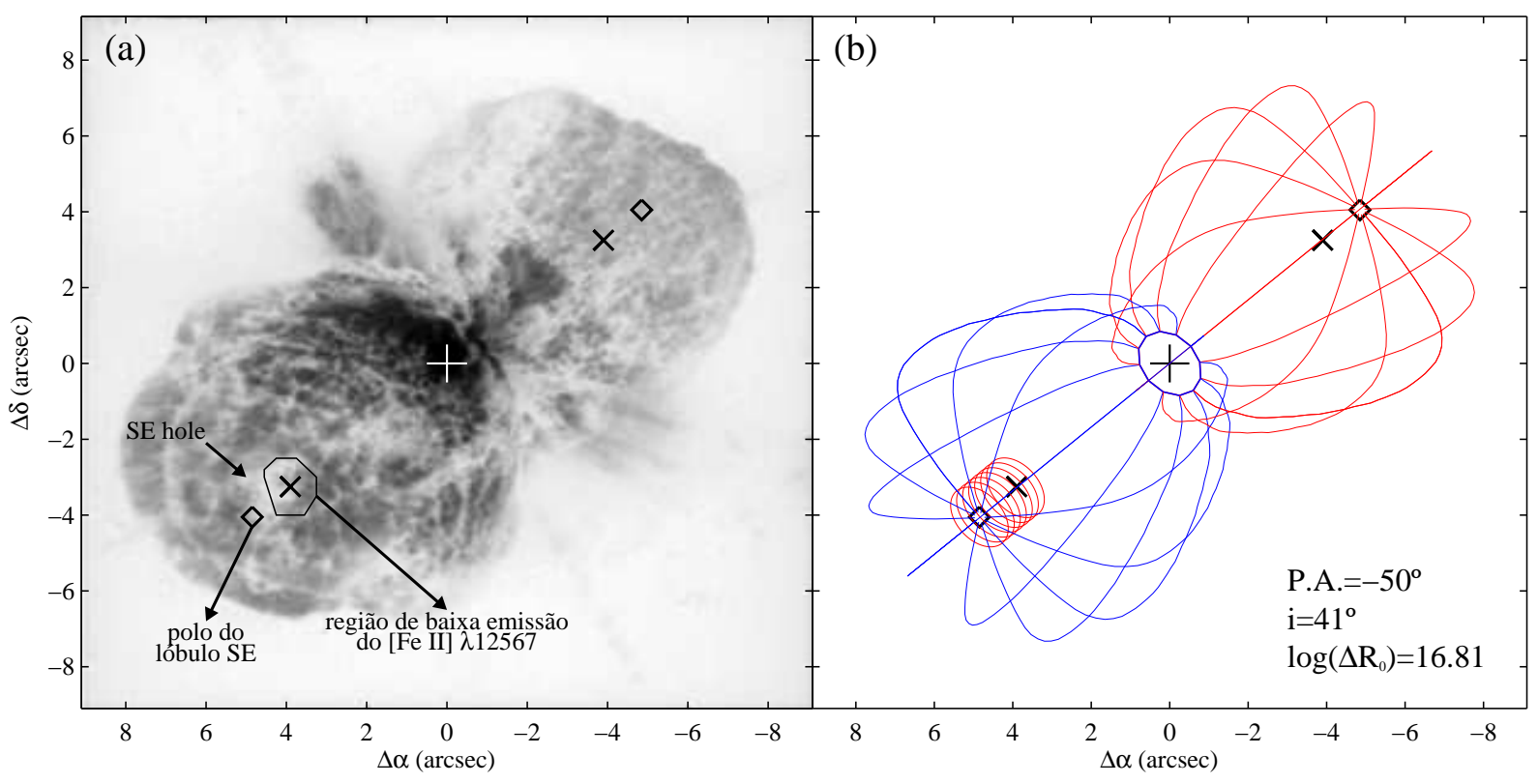

Figura 3.2: Determinação da espessura dos lóbulos na região polar do Homúnculo. O losango marca a posição do polo segundo o modelo obtido por Smith (2006) e o símbolo $\times$ mostra a posição do centro da região que não apresenta emissão na linha do [Fe II] $\lambda 12567$.

temperaturas são menores e as densidades maiores do que o interior dos mesmos, criando as condições ideais para a existência de espécies moleculares.

Conforme ilustra a Fig. 3.2, combinando a posição do buraco nos lóbulos obtida através da linha do [Fe II] $\lambda 12567$ e a posição do pold2 2 prevista pelo modelo cinemático baseado na emissão do $\mathrm{H}_{2}$ feito por Smith (2006), foi possível determinar a espessura dos lóbulos na região polar, cujo valor é de aproximadamente $7 \times 10^{16} \mathrm{~cm}$, assumindo que o Homúnculo esteja inclinado de $41^{\circ}$ em relação à linha de visada e a uma distância de 2300 pc. Além disso, o raio dos buracos, determinado através da mesma metodologia, é de $\approx 6 \times 10^{16} \mathrm{~cm}$.

\subsection{Mapeamento espacial do He I $\lambda 10830$}

Foram observadas estruturas de emissão desta linha, na linha de visada do lóbulo NW, que estendem-se a distâncias muito maiores do que os próprios lóbulos. Inicialmente, isto pode parecer estranho, tendo em vista que esta é uma linha que deve ser formada na fonte central e depois refletida nos lóbulos. Além do mais, na direção do lóbulo NW, onde tais estruturas foram observadas, o perfil cinemático das linhas em emissão (tanto intrínsecas

\footnotetext{
${ }^{2}$ Local nos lóbulos onde a latitude estelar é $90^{\circ}$.
} 


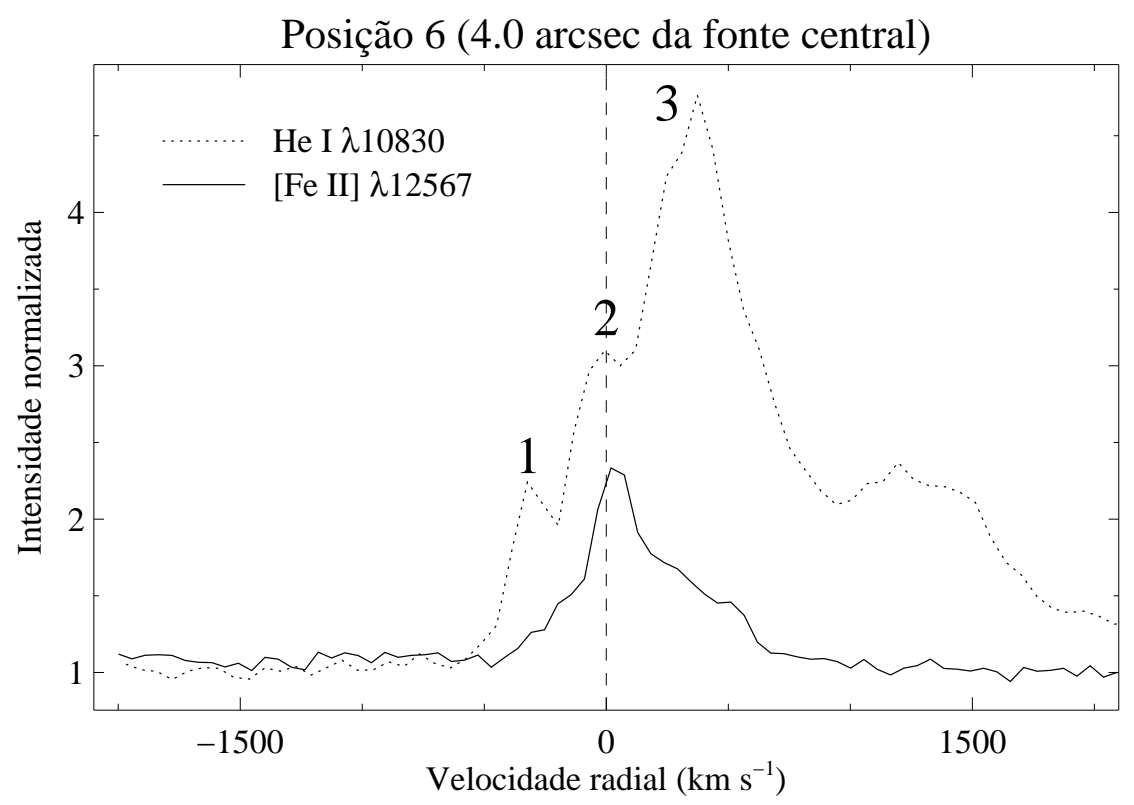

Figura 3.3: Componentes identificadas na linha do He I $\lambda 10830$. As componentes 1 e 2 correspondem a emissões intrínsecas enquanto a componente 3 é emissão refletida no lóbulo NW. Este espectro foi extraído da posição 6, mostrada na Fig. 3.4.

quanto refletidas) é de recessão, ou seja, só são observadas emissões com velocidades positivas, se afastando do observador. Portanto, a única explicação é que estas estruturas em emissão sejam formadas no gás contido no plano equatorial (que estende-se a distâncias muito maiores do que aquelas observadas nas imagens do HST) e, consequentemente, são emissões intrínsecas.

A Fig. 3.3 mostra as componentes cinemáticas identificadas na linha do He I $\lambda 10830$ e comparado à emissão do [Fe II] $\lambda 12567$. Ambos os espectros foram extraídos da posição 4 , indicada na Fig. 3.4. É possível notar a existência de pelo menos 3 componentes cinemáticas da linha do He I $\lambda$ 10830: duas associadas a emissões intrínsecas (componente 1 e 2) e uma associada à emissão refletida no lóbulo NW (componente 3). É interessante notar que a componente 1 é a única que se desloca para velocidade mais negativas em espectros extraídos em regiões cada vez mais distantes da fonte central. Tal comportamento corrobora a ideia de que ela seja uma emissão intrínseca formada no material contido no plano equatorial.

O ângulo de posição no qual a emissão do He I 10830 é observada é P.A. $=-48^{\circ}$, levemente menor do que o observado para o eixo maior do Homúnculo, que é de cerca de $-50^{\circ}$ (Smith, 2002). Considerando que a componente 1 seja, realmente, uma emissão 


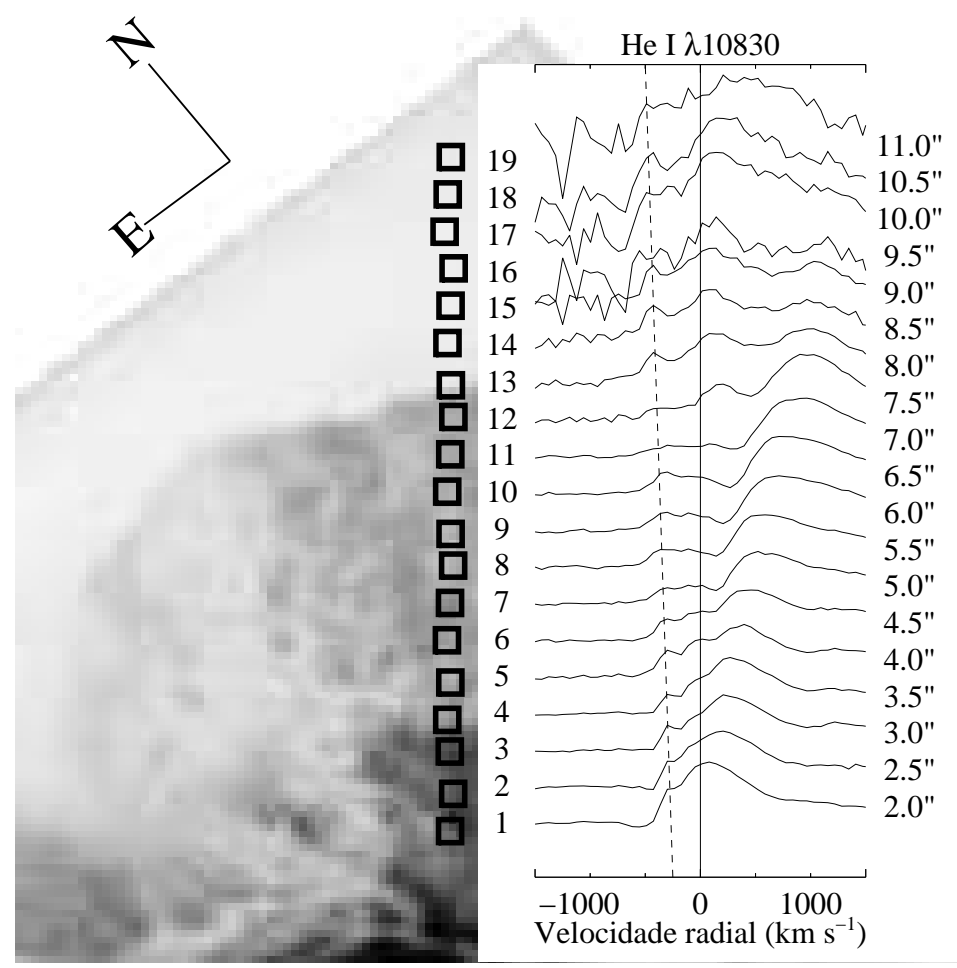

Figura 3.4: Perfil de velocidade da linha do He I $\lambda 10830$ ao longo do ângulo de posição P.A. $=-41^{\circ}$, ilustrando o comportamento cinemático de cada componente da Fig. 3.3. O espectro mostrado à direita nesta figura foi extraído da região delimitada pelos quadrados.

intrínseca proveniente do gás na região equatorial, a variação de sua velocidade em função da distância da fonte central pode ser utilizada para estimar o ângulo de inclinação em que o material responsável por esta componente se encontra em relaç̃o à linha de visada. Isto foi obtido utilizando a seguinte equação (Davidson et al., 2001; Smith, 2002)

$$
\tan \left(i_{\mathrm{He}}\right)=\frac{t}{4.74 D} \frac{V}{\omega}
$$

onde $t$ é a idade (em anos) do disco equatorial, $D$ é a distância (em pc) até $\eta$ Car, $V$ é a velocidade (em $\mathrm{km} \mathrm{s}^{-1}$ ) da componente 1 a uma distância de $\omega$ arcsec da fonte central e $i_{H e}$ é o ângulo de inclinação do plano que contém o material responsável pela emissão de maneira que, se $i_{H e}=0^{\circ}$, o disco equatorial é visto de frente (face-on) e se $i_{H e}=90^{\circ}$, ele é visto de lado (edge-on). O valor médio observado para $|V / \omega|$ foi de aproximadamente $68 \mathrm{~km} \mathrm{~s}^{-1} \operatorname{arcsec}^{-1}$, o que corresponde a $i_{H e} \approx 134^{\circ}$ (ou $44^{\circ}$ a partir do plano do céu na direção do observador). Apesar do valor determinado utilizando medidas feitas em espectros obtidos com fenda longa ser de cerca de $131^{\circ}$, o erro na medida das velocidades 
nos dados do cubo de dados corresponde a aproximadamente $\pm 3^{\circ}$, cujo limite inferior é consistente com a localização no plano equatorial do material responsável pela emissão da componente 1.

\subsection{A natureza da estrela secundária}

A Fig. 3.5 mostra que o mapa de emissão em rádio na faixa de $3 \mathrm{~cm}$ tem a mesma distribuição espacial que o Pequeno Homúnculo, que pode ser visto integrando-se o perfil da linha do [Fe II] $\lambda 12567$ entre $-1000 \mathrm{e}+1000 \mathrm{~km} \mathrm{~s}^{-1}$. Portanto, o fluxo em rádio parecer estar contido completamente dentro da região delimitada pelo Pequeno Homúnculo.

Aproveitando a semelhança com uma região H II, foi possível utilizar o fluxo em rádio para determinar o número de fótons no contínuo de Lyman produzidos pela fonte ionizante e, consequentemente, estimar o seu tipo espectral. Para isso, foi utilizada a seguinte equação (Mezger et al.., 1974; Carpenter et al., 1990; Filipovic et al., 2003; Morgan et al., 2004)

$$
N_{\mathrm{Ly}}=\phi a\left(\nu, T_{e}\right)^{-1}\left(\frac{\nu}{\mathrm{GHz}}\right)^{0.1}\left(\frac{T_{e}}{\mathrm{~K}}\right)^{-0.45}\left(\frac{S_{\nu}}{\mathrm{Jy}}\right)\left(\frac{D}{\mathrm{kpc}}\right)^{2},
$$

onde $\phi$ é uma constante numérica $\left(=4.76 \times 10^{48}\right)$ que varia lentamente de acordo com Mezger \& Henderson (1967), $\nu$ é a frequência na qual a densidade de fluxo, $S_{\nu}$ foi medida, $T_{e}$ é a temperatura eletrônica do gás emissor e $D$ é a distância até $\eta$ Carinae. Utilizando a densidade de fluxo de $\approx 39 \mathrm{Jy}$, observada no contínuo rádio em $1.3 \mathrm{~mm}$ durante a fase de alta excitação, (quando a secundária está fora do vento denso da primária) reportada por Zulema Abraham (comunicação privada) e adotando $T_{e}=10^{4} \mathrm{~K}$ (para a qual $a\left(\nu, T_{e}\right) \sim 1$ ), foi obtido $\log \left(N_{\mathrm{Lv}}\right) \approx 49.4\left(\mathrm{~s}^{-1}\right)$, que corresponde a uma estrela de tipo espectral entre O5.5 III a O7 I (Martins et al., 2005). No entanto, com base somente neste resultado, não se pode excluir a possibilidade de uma companheira Wolf-Rayet, pois esta também $\operatorname{apresenta} \log \left(N_{\mathrm{Ly}}\right) \gtrsim 49.4$ (Crowther, 2007$)$.

Uma estrela com tipo espectral O7 I tem parâmetros físicos compatíveis com aqueles derivados por outros trabalhos. A temperatura efetiva é de cerca de $35000 \mathrm{~K}$, que é um valor que está dentro dos limites (34000-38000 K) determinados por Verner et al. (2005), 


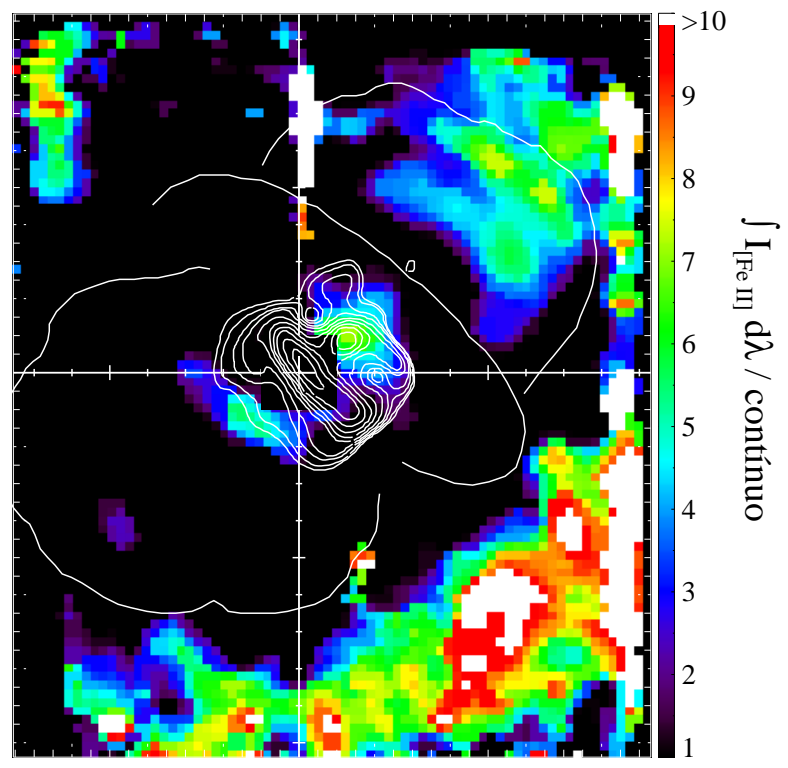

Figura 3.5: Sobreposição do mapa de emissão em rádio na faixa de $3 \mathrm{~cm}$ (Duncan et al., 1997) sobre a imagem (normalizada) integrada de $-1000 a+1000 \mathrm{~km} \mathrm{~s}^{-1}$ da linha do [Fe II] $\lambda 12567$.

baseado na razão entre o [Ar III $] \lambda 7135$ e o [Ne III $] \lambda 3868$. Além disso, os resultados de Iping et al. (2005) também indicam uma temperatura de aproximadamente $35000 \mathrm{~K}$, com base em espectros obtidos com o Far Ultraviolet Spectroscopic Explorer (FUSE). Embora os modelos (Hillier et al., 2001) prevejam que o fluxo da companheira domine o espectro observado pra comprimentos de onda menores do que $1200 \AA$ A uma análise quantitativa é extremamente complexa (Hillier et al., 2006).

Por outro lado, uma estrela de tipo espectral O5.5 III apresenta uma temperatura efetiva de aproximadamente $39250 \mathrm{~K}$, ou seja, um valor acima do limite superior derivado por Verner et al. (2005). Entretanto, tal temperatura não pode ser descartada, pois entre os glóbulos de Weigelt e a fonte ionizante deve haver material que absorva os fótons mais energéticos, diminuindo a temperatura efetiva vista pelos glóbulos.

Finalmente, é interessante notar que Prinia et al. (1990) mostraram que estrelas de tipo espectral quente na faixa de O5.5 a O7 apresentam ventos com velocidades terminais entre 1100 e $3000 \mathrm{~km} \mathrm{~s}^{-1}$, que é compatível com os valores propostos por Davidson (1999) e Pittard \& Corcoran (2003), com base em cálculos hidrodinâmicos. 


\section{Capítulo 4}

\section{A periodicidade dos eventos em $\eta$ Carinae}

\subsection{Definição da fase zero}

Durante um evento espectroscópico, as componentes estreita e larga das linhas de alta excitação desaparecem. A determinação da época exata em que isso acontece é um dos métodos de se restringir o valor do período entre os eventos. No entanto, para isso é necessário uma densa amostragem temporal ao redor do evento, o que nem sempre é possível. Além disso, cada linha tende, assintoticamente, a um mínimo em épocas diferentes, levando até 1 semana para desaparecer completamente.

Para minimizar esses problemas, a análise feita neste capítulo foi restringida à fase de rápido declínio das linhas, que começa aproximadamente 3 semanas antes do desaparecimento completo das linhas. A determinação da fase zero foi feita através da regressão linear e extrapolação à zero da curva da largura equivalente observada para a componente estreita da linha do He I $\lambda 7065$ e do He I $\lambda 6678$, conforme pode ser visto na Fig. 4.1. A utilização deste método permite contornar a necessidade de uma amostragem temporal densa. A época do mínimo para a componente estreita do He I 26678 - escolhida para definição da fase zero - obtida por este método foi MJD=52819.8 (29 de Junho de 2003). Obviamente, a escolha da linha utilizada para definição da fase zero foi arbitrária, mas 

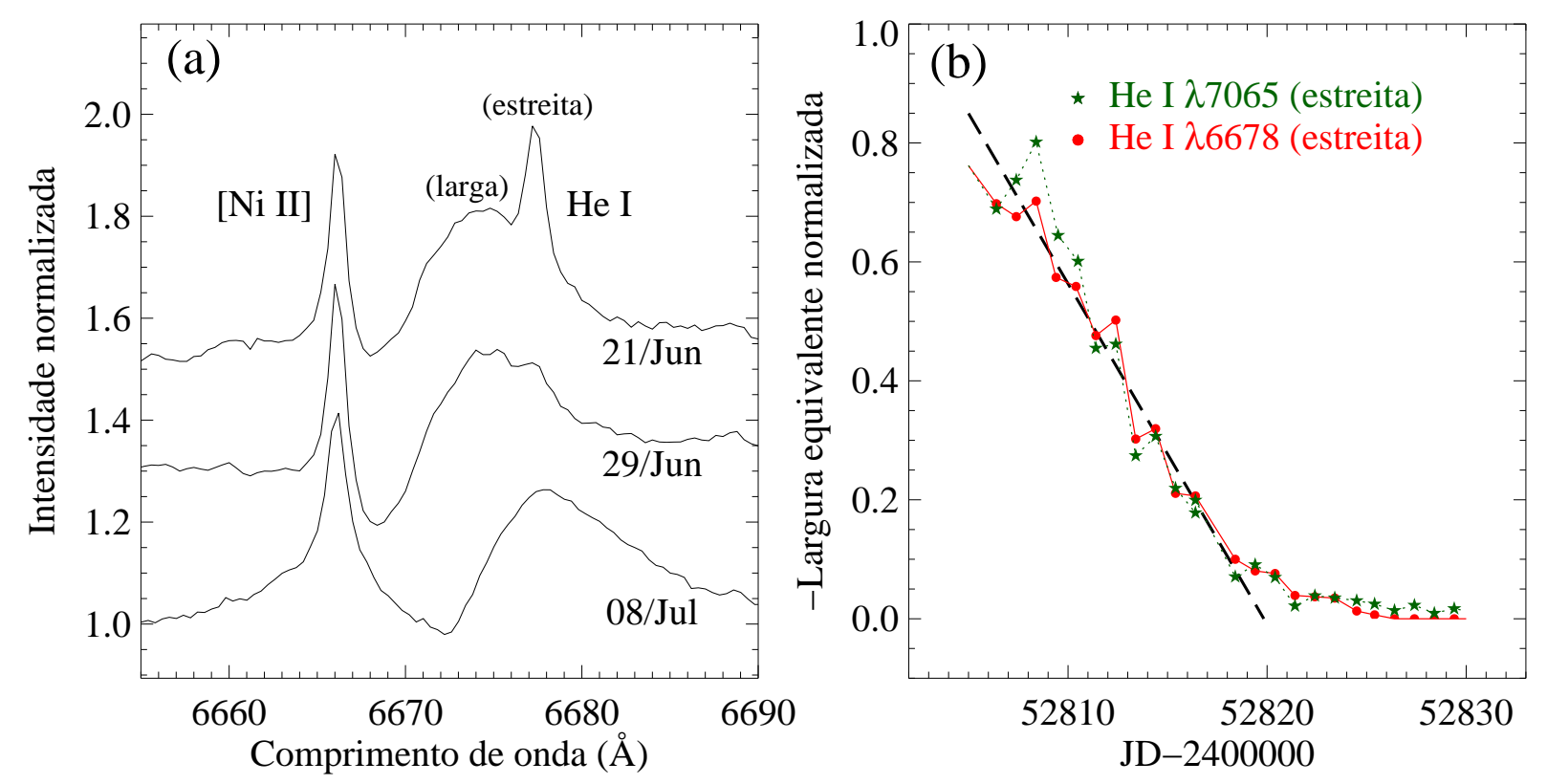

Figura 4.1: Definição da fase zero. (a) Perfil do He I $\lambda 6678$ observado ao longo de 17 dias, em 2003. Note o desaparecimento completo de sua componente estreita. (b) Utilizando a largura equivalente das duas linhas indicadas do He I, foi possivel extrapolar seu comportamento durante a fase de queda e determinar a época em que a linha desapareceu completamente (considerada a fase zero).

sua utilização neste estudo deve-se ao fato de apresentar um longo histórico de observações e também por ser uma linha relativamente livre de blends como a maioria das linhas observadas no espectro de $\eta$ Carinae.

\subsection{Determinação do período dos eventos}

Utilizando a linha do He I $\lambda 6678$, também foi possível determinar o período do ciclo \#10 e \#11. Novamente, a análise ficou restrita à fase de rápido declínio e foi feita aplicando o seguinte procedimento: deslocando as medidas da largura equivalente e da velocidade radial observadas durante os eventos \#9 (1992.5) e \#10 (1998.0) foi possível encontrar um valor que minimizasse as diferenças quando comparados com o evento \#11 (2003.5). O resultado pode ser visto na Fig. 4.2. Este método é semelhante ao utilizado por Corcoran (2005) com a curva de luz na faixa dos raios-X.

O período obtido utilizando a largura equivalente e velocidade radial da linha do He I $\lambda 6678$ foi de $2022 \pm 1$ dias, valor compatível ao obtido por outros métodos, conforme mostrado na Tabela 4.1. Naquela tabela, estão listados os períodos determinados através 

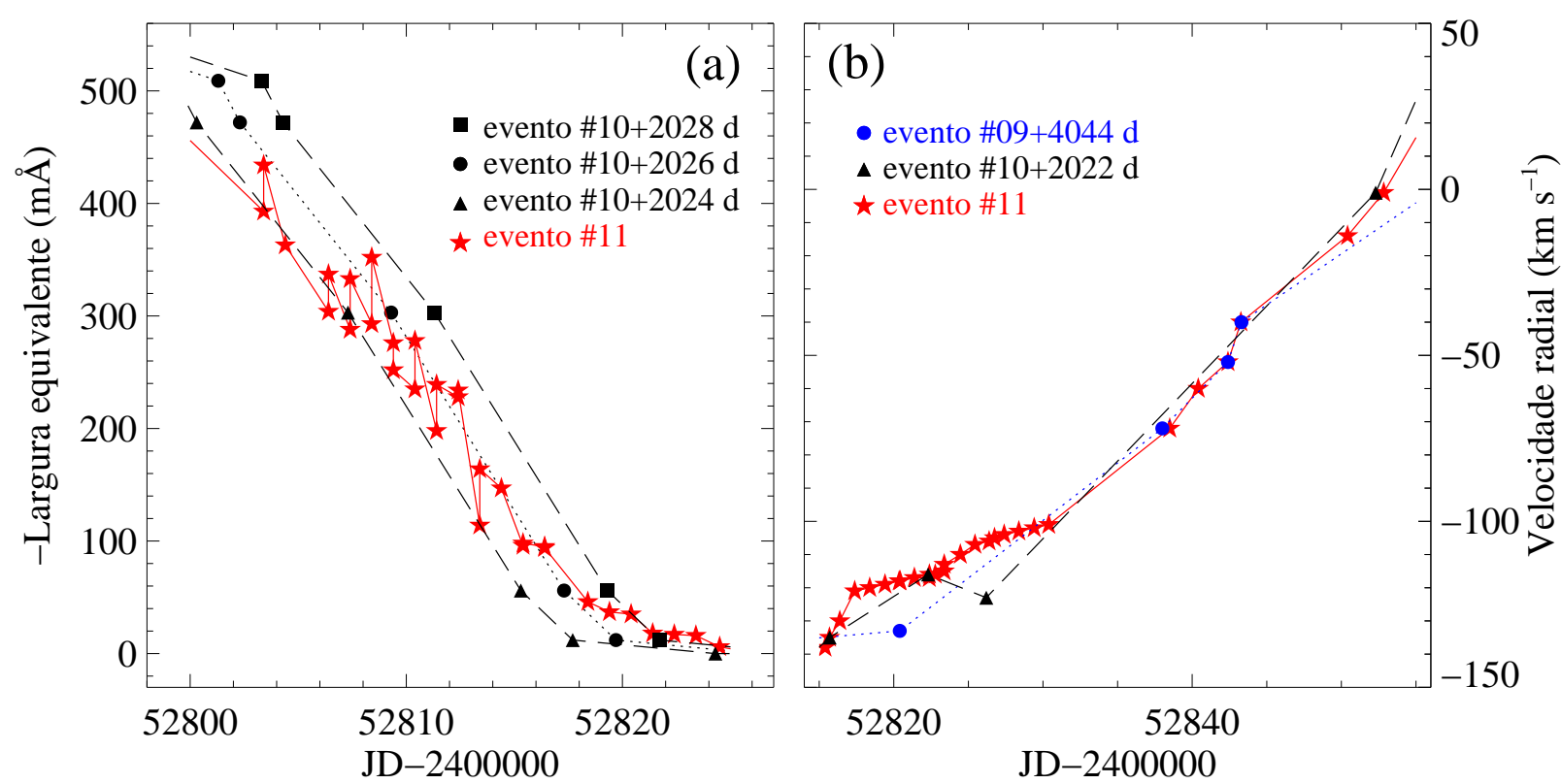

Figura 4.2: Determinação do período através do deslocamento da curva de luz de duas características espectrais: (a) a largura equivalente do He I $\lambda 6678$, durante os eventos de 1998.0 e 2003.5, e (b) a velocidade radial da componente larga da mesma linha espectral durante os eventos de 1992.5, 1998.0 e 2003.5. Os períodos testados estão indicados na legenda.

da medida de certas características espectrais, como largura equivalente da componente estreita da linha em emissão ou da componente em absorção do perfil P Cygni, em épocas próximas à fase zero.

Não existem, entretanto, razões para acreditar que o período dependa da técnica utilizada e, portanto, pode-se determinar um valor médio a partir da combinação dos períodos obtidos utilizando as diversas técnicas descritas na Tabela 4.1. Este período médio foi denominado período atual $\left(P_{\text {pres }}\right)$ de maneira a diferenciá-lo daquele obtido através de observações históricas.

Evidentemente, também não existem motivos para que cada característica espectral apresentem a mesma fase zero, pois cada linha espectral é formada em uma região diferente (e.g. no vento estelar da primária ou na região de colisão dos ventos). No entanto, pelos motivos já discutidos anteriormente, nesta tese, a fase zero foi definida pelo desaparecimento da componente estreita da linha do He I $\lambda 6678$, o que resulta na seguinte equação para as efemérides

$$
\mathrm{JD}(\text { fase zero })=2452819.8 \pm 0.5+(2022.7 \pm 1.3) E
$$


Tabela 4.1: Período dos eventos espectroscópicos determinado utilizando diversos métodos e em diferentes regiões espectrais. $P_{\text {pres }}$ representa o período médio atual.

\begin{tabular}{cc}
\hline \hline Período \pm erro & Característica ou banda espectral utilizada \\
\hline $2026 \pm 2$ & He I $\lambda 6678$ \\
$2024 \pm 2$ & raios-X \\
$2023 \pm 1$ & banda $J$ \\
$2023 \pm 1$ & banda $H$ \\
$2023 \pm 1$ & banda $K$ \\
$2023 \pm 2$ & banda $L$ \\
$2022 \pm 2$ & Velocidade radial do P Cygni do Fe II $\lambda 6455$ \\
$2022 \pm 1$ & Largura equivalente do Si II $\lambda 6347$ \\
$2022 \pm 1$ & Velocidade radial da comp. larga do He I $\lambda 6678$ \\
$2022 \pm 1$ & Largura equivalente do He I $\lambda 10830$ \\
$2021.5 \pm 2$ & banda $V$ \\
$2021 \pm 2$ & Largura equivalente do P Cygni do Fe II $\lambda 6455$ \\
\hline &
\end{tabular}

É importante ressaltar que as incertezas na fase zero e no período correspondem a apenas $0.07 \%$ do valor do período.

\subsection{Outros métodos robustos para determinação do período}

Foi aplicado o método de menor dispersão para determinar o período dos eventos à luz dos novos dados. Para isso, foi utilizada a parte de monitoramento mais denso de 2009.0 e 2003.5, ou seja, a fase de entrada e o começo da saída do mínimo. 

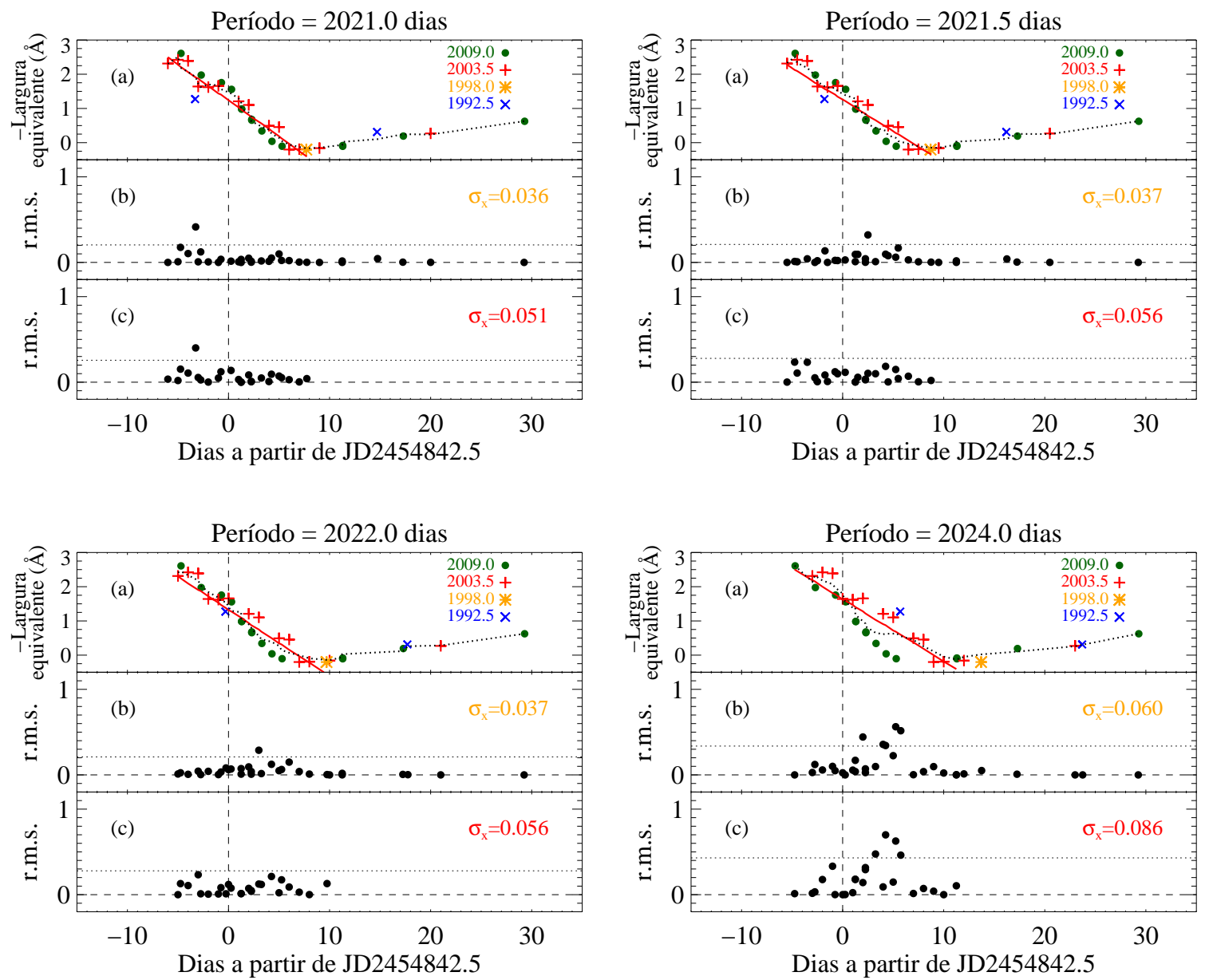

Figura 4.3: Determinação do período utilizando a linha do He II $\lambda 4686$. Em (a) estão apresentados os dados e os ajustes. Em (b) nota-se o desvio padrão do modelo que ajusta toda a curva de luz, desde a entrada até o começo da saída (linha preta pontilhada). Já em (c), o mesmo é mostrado, mas o ajuste é feito apenas na fase de entrada no mínimo (linha vermelha). Utilizando os dados dos 4 últimos eventos, ambos os métodos são consistentes com um período entre 2021 e 2022 dias. A linha horizontal pontilhada nos gráficos (b) e (c) de cada painel representa o limite de $1 \sigma$.

\section{A largura equivalente do He II $\lambda 4686$}

Para obter o período mais adequado para a linha do He II $\lambda 4686$, foram feitos dois ajustes linear aos dados dos 4 eventos combinados: um durante a fase de entrada no mínimo (ajuste parcial) e outro durante a entrada e começo da saída (ajuste completo). A Fig.4.3 mostra o resultado para 4 períodos de teste: 2021, 2021.5, 2022 e 2024 dias. Para cada painel daquela figura, são apresentados os dados e os ajustes (Fig. 4.3(a)), os resíduos da subtração do ajuste completo (Fig. 4.3(b)) e os resíduos do ajuste parcial (Fig. 4.3(c)). O ajuste parcial foi feito no intervalo de $-7 \mathrm{a}+8$ dias em torno do mínimo, enquanto o ajuste completo, de $-7 \mathrm{a}+29$ dias. 
De maneira geral, os testes indicaram que os períodos (para a linha do He II $\lambda 4686$ ) que apresentaram o melhor ajuste estão entre 2021 e 2022 dias. O período de 2021 dias apresenta o menor erro absoluto, mas apresenta 1 ponto acima de $1 \sigma$ para os dois ajustes, parcial e completo. Este ponto corresponde à única observação feita no LNA, nesta faixa espectral, em 2 de Junho de 1992. Ele apresenta uma boa relação sinal/ruído - da ordem de 200 - e sua normalização não apresenta qualquer distorção no contínuo adjacente à região de $4686 \AA$ A. Pela qualidade deste espectro, ele deve ter um peso maior nos ajustes dos dados do evento de 1992.41.

Utilizando um período de 2021.5 e 2022 dias, todos os pontos correspondentes ao ajuste parcial apresentaram uma dispersão dentro do limite de $1 \sigma$ e um erro absoluto relativamente pequeno para ambos ajustes (parcial e completo). O painel inferior direito da Fig. 4.3 apresenta o resultado obtido para um período de 2024 dias. O erro absoluto obtido com este período é o maior de todos, assim como a dispersão do pontos para ambos ajustes. Mesmo sem ajuste algum, visualmente os pontos não são coerentes entre si.

\section{A razão entre [N II] $\lambda 5755$ e [Fe II] $\lambda 5745$}

Durante todo o período de alta excitação de $\eta$ Car, os glóbulos estão diretamente expostos à radiação ultra-violeta da fonte central. No cenário binário, durante um evento, a companheira aproxima-se tanto da primária que o seu fluxo UV é quase que completamente 'abafado' pelo vento opticamente espesso da primária, reduzindo drasticamente o fluxo UV nos glóbulos de Weigelt e, consequentemente, diminuindo o estado de excitação dos íons. Isso faz com que as linhas de alta excitação praticamente desapareçam.

Por outro lado, os íons com potencial de excitação intermediário, como [N II], também respondem à queda no fluxo UV, mas não desaparecem completamente porque sua população, nos glóbulos de Weigelt, ainda pode ser mantida pela radiação da primária. Desta maneira, o período do evento pode ser determinado através da razão entre uma linha de alta/média excitação e outra de baixa excitação. Neste estudo, foi utilizada a razão entre a linha [N II] $\lambda 5755$ e a [Fe II] $\lambda 5745$ como indicadores do período dos eventos. A primeira

\footnotetext{
${ }^{1}$ Os outros pontos do evento de 1992.4 correspondem aos dados do FEROS. Estes espectros apresentam pequenas distorções no contínuo nesta faixa espectral, provenientes da normalização do espectro.
} 

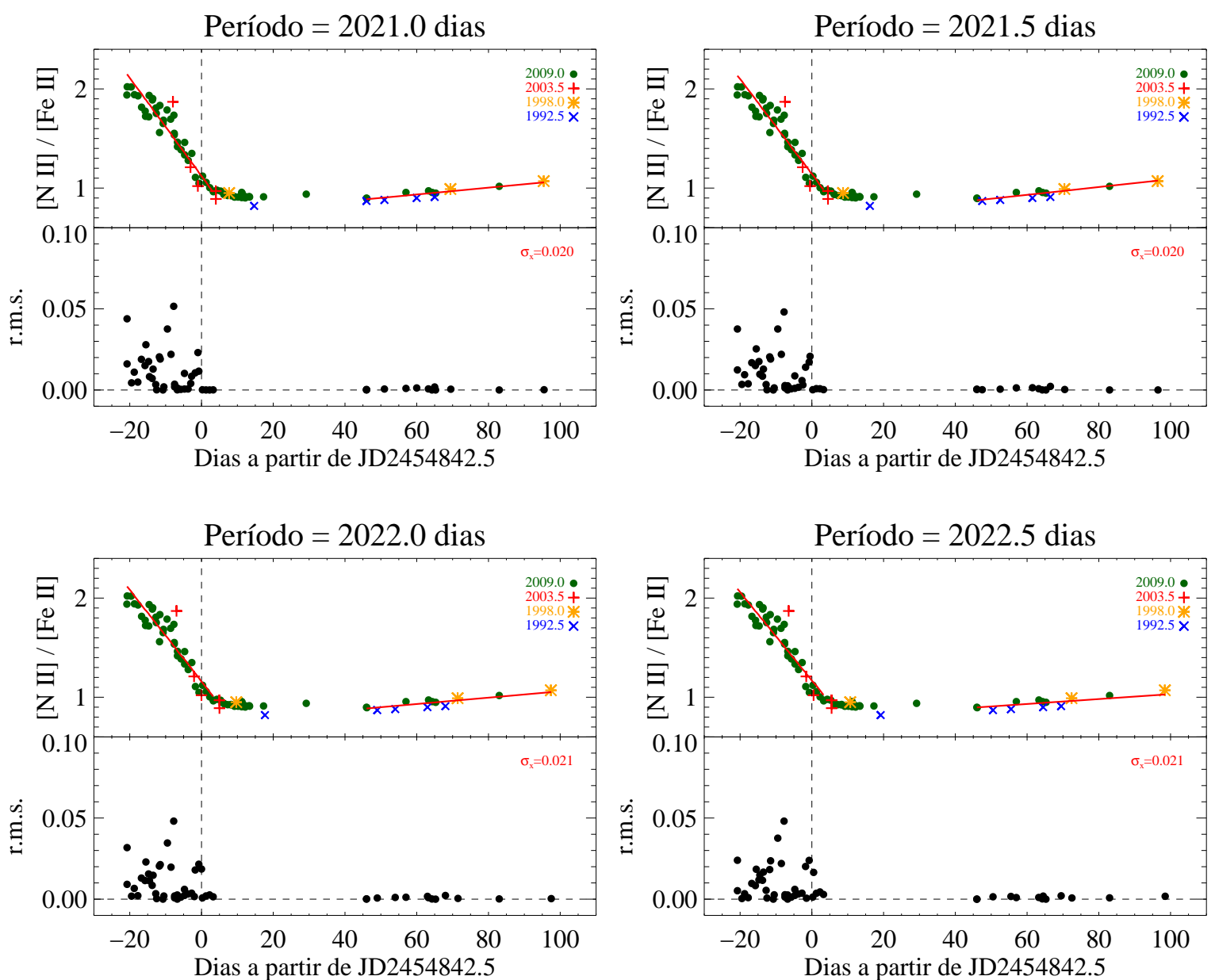

Figura 4.4: O mesmo que na Fig. [4.3. mas utilizando a razão entre a linha do [N II] $\lambda 5755$ $e$ [Fe II] $\lambda 5745$. Todos os dados foram degradados para R 2800. Neste caso, o melhor período está entre 2021 e 2021.5 dias.

é uma linha de excitação intermediária $(h \nu>14.5 \mathrm{eV})$ e a segunda, de baixa excitação $(h \nu>7.9 \mathrm{eV})$. Ambas são formadas nos glóbulos de Weigelt. Este método é robusto porque tem a vantagem de ser independente da definição de um contínuo local.

No entanto, para que os dados sejam corretamente analisados, é necessário que todos estejam com a mesma dispersão, pois as medidas são feitas utilizando a intensidade do pico das componentes estreitas, que tem o seu perfil espectral melhor amostrado em um espectrógrafo com alta resolução do que em um com baixa resolução. Por isso, nesta tese todos os espectros de alta resolução foram degradados para serem compatíveis com os dados de maior elemento de resolução que, neste caso, são os do Goodman (com cerca de $1.8 \AA$ A). A Fig. 4.4 mostra o resultado para a razão entre as linhas mencionadas acima, considerando todos os dados disponíveis para os 4 últimos eventos.

Utilizando a razão de linhas como indicador do período dos eventos, o melhor ajuste foi 


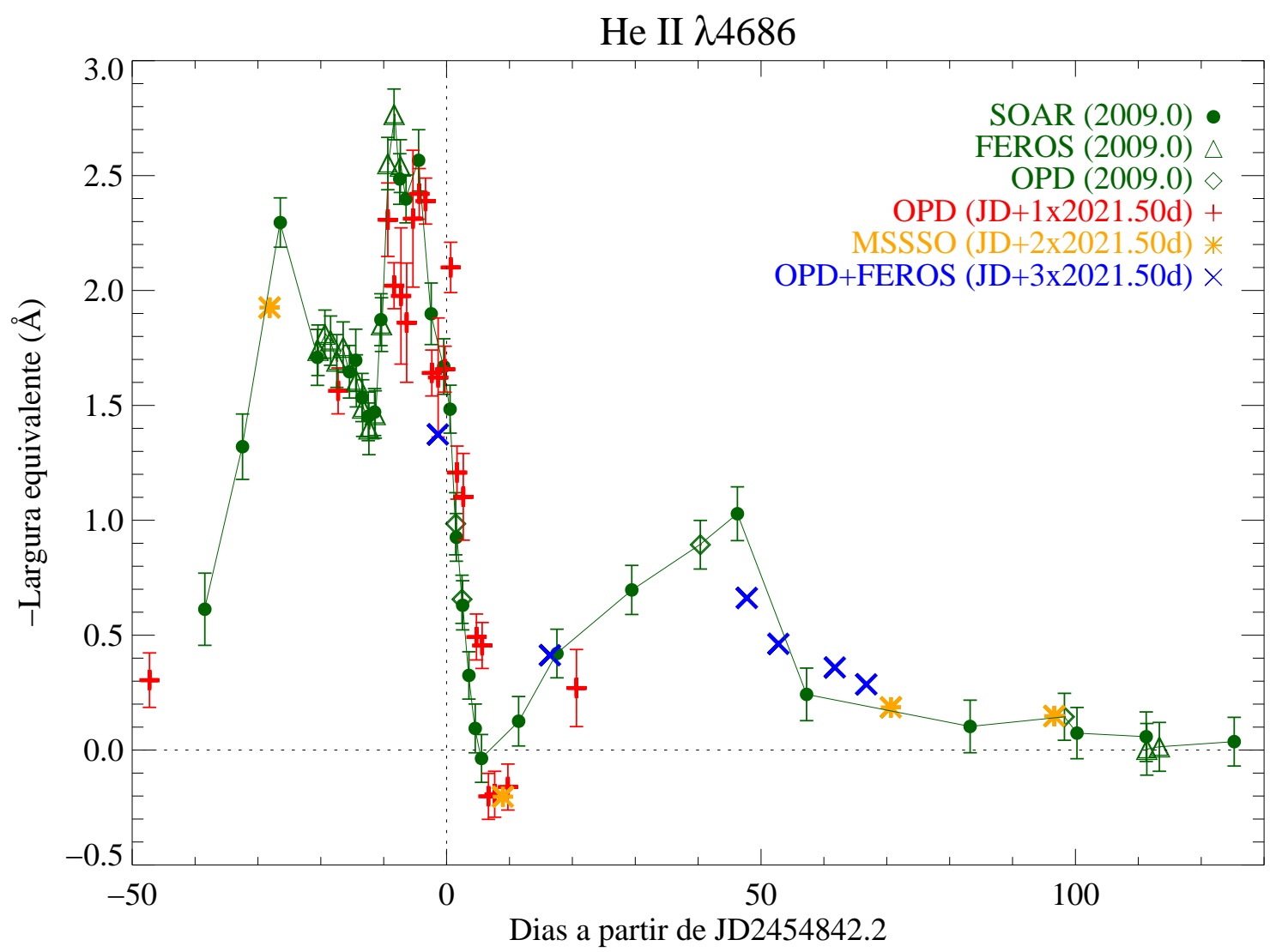

Figura 4.5: Determinação do período dos eventos de $\eta$ Car utilizando a linha do HeII $\lambda_{4} 686$. Os dados foram deslocados por 2021.5 dias. Note que, com este período, existe uma maior compatibilidade entre as medidas de 2003.5 e 2009.5 (monitoramentos mais densos).

obtido com um período entre 2021 e 2021.5 dias. Estes valores apresentaram os menores erros absolutos para ambos ajustes (parcial e completo).

Um período de $2021.5 \pm 1$ dia parece ser o mais adequado aos dados apresentados nesta tese, combinando os resultados obtidos pelos dois métodos descritos anteriormente. Além disso, este valor é perfeitamente compatível com os resultados obtidos em diversas faixas espectrais, cujo valor médio tem sido 2022.7 \pm 1.3 dias (Damineli et al., 2008). A Fig. 4.5 mostra o resultado da aplicação do período de 2021.5 dias aos dados dos 4 últimos eventos. Como os testes realizados com este método foram feitos com intervalos de 0.5 dias, o ajuste fino realizado posteriormente mostra que este é o período que melhor ajusta todos os dados. 

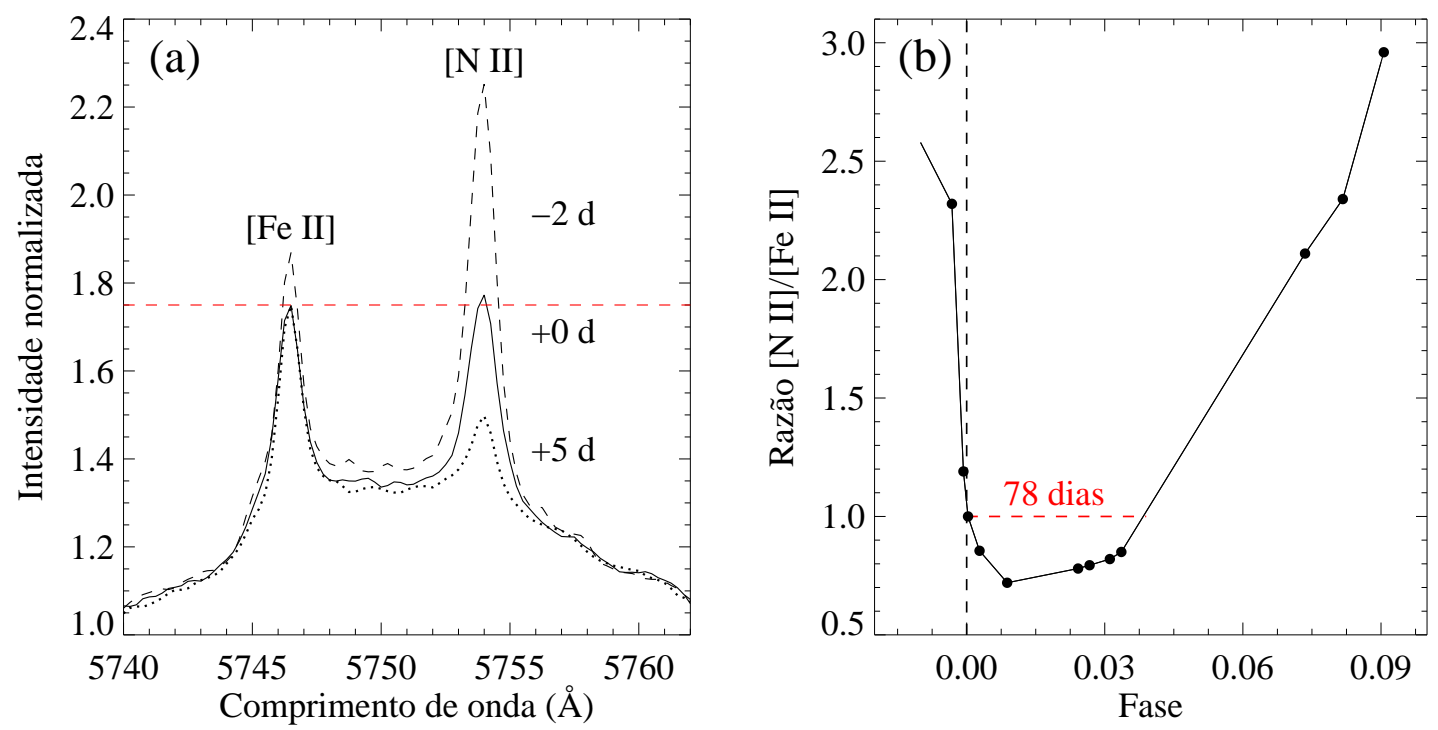

Figura 4.6: Intensidade relativa das linhas do [N II] $\lambda 5754$ e do [Fe II $] \lambda 5746$. (a) Variação do perfil espectral e (b) razão entre o pico das duas linhas. Note que a razão passa a ser menor que a unidade na fase zero e permanece assim durante um período de 78 dias.

\subsection{A estabilidade do período}

Uma questão levantada naturalmente é sobre a estabilidade do período. Devido à elevada taxa de perda de massa do sistema e às interações via força de maré durante as passagens pelo periastro, o período pode apresentar variações. A única maneira de verificar se existe alguma variação no período é comparando o valor atual, $P_{\text {pres }}$, com o valor médio, $P_{\text {med }}$ determinado a partir de dados tomados ao longo dos últimos 60 anos.

Com base nos dados publicados por Feast et al. (2001) - onde são reportados as épocas de alta e baixa excitação de $\eta$ Carinae desde 1948 até 1978 - e nas observações do evento de 1992.5 e 1998.0, foi possível definir limites para o período médio, $P_{\text {med }}$, cujos valores estão listados na quarta coluna da Tabela 4.2. Naquela tabela, a primeira coluna indica o ciclo considerado; a segunda coluna, a data prevista para o mínimo e a terceira coluna, a data observada em que, de fato, ocorreu o mínimo. Os eventos de 1992.5, 1998.0 e 2003.5 não estão incluídos naquela tabela porque estes foram utilizados para obter o período atual $\left(P_{\text {pres }}\right)$.

Analisando os dados mostrados na Tabela 4.2. pode-se notar que o período médio $\left(P_{\text {med }}\right)$ durante os últimos 60 anos está contido no intervalo de 2018.6 a 2029.3 dias. 
Tabela 4.2: Limites para o período dos eventos espectroscópicos determinado utilizando as épocas previstas e observadas para o minimo. $P_{\text {med }}$ representa o valor médio do período entre 1948 e 1986.

\begin{tabular}{|c|c|c|c|}
\hline Ciclo & Data prevista $^{a}$ & Data observada & Período \\
\hline$\# 1$ & $11 / \mathrm{Fev} / 48$ & 19/Abr/48 & $>2015.9$ \\
\hline$\# 2$ & 26/Out/53 & $28 / \mathrm{Jun} / 53^{b}$ & $<2029.3$ \\
\hline$"$ & $"$ & 30/Dez/53 & $>2009$ \\
\hline$\# 3$ & 11/Mar/59 & 14/Mai/59 & $>2014.4$ \\
\hline$\# 4$ & $23 /$ Set/64 & $15 /$ Fev/65 & $>2001.9$ \\
\hline$\# 5$ & 07/Abr/70 & 17/Mai/70 & $>2016.0$ \\
\hline$\# 7$ & 04/Mai/81 & 21/Mai/81 & $>2018.6$ \\
\hline$\# 8$ & $17 / \operatorname{Nov} / 86$ & $15 / \operatorname{Jan} / 87$ & $>2003.1$ \\
\hline \multicolumn{4}{|c|}{$2029.3>P_{\text {med }}>2018.6$ dias } \\
\hline
\end{tabular}

Porém, as observações espectroscópicas feitas por Gaviola (1953) fornecem um limite superior para $P_{\text {med }}$, de maneira mais quantitativa, com base na razão entre as linhas do [N II] $\lambda 5754$ e [Fe II] $\lambda 5746$. Gaviola (1953) reportou que a linha do nitrogênio mencionada apresentava uma intensidade menor do que a do ferro. Conforme pode ser visto na Fig. 4.6, tal comportamento ocorre durante uma fase muito específica durante um evento.

Portanto, adotando um período de 2022.7 dias, a fase zero prevista para o evento de 1948 reportado por Gaviola deveria acontecer em 11 de Fevereiro daquele ano, conforme indicado na Tabela 4.2. No entanto, a fase zero real poderia ter ocorrido em qualquer momento entre 11 de Fevereiro e 29 de Abril de 1948 (intervalo de 78 dias).

Adotando o dia 9 de Março de 1948 (JD 2432619.8) - que corresponde a metade do intervalo de 78 dias contado a partir de 11 de Fevereiro - como a data para a fase zero daquele ano, e combinando com aquela observada para o mínimo de 2003.5 (ocorrido em JD 2452819.8), tem-se que, ao longo de 10 ciclos, o limite superior para o período médio 
seria de

$$
P_{\text {med }}=\frac{(2452819.8-2432619.8)}{10}=2020 \text { dias. }
$$

A estabilidade do período pode ser obtida da diferença entre o período atual e o período médio, que é de 2.7 dias em 10 ciclos. Porém, como $P_{\text {med }}$ é o valor médio do período em 10 ciclos, deve-se considerar apenas metade deles, pois a variação pode ter sido para mais ou para menos. Sendo assim, o período não pode ter variado mais do que 1.5 dias ciclo $^{-1}$ durante os últimos 60 anos.

Segundo Khaliullin (1974), a taxa de variação do período devido à mudanças na taxa de perda de massa de um sistema binário (ignorando mudanças na excentricidade) é dado por

$$
\dot{P}=0.11 \alpha \frac{\dot{M}_{-3}}{M_{100}} \operatorname{dias} / \text { ciclo, }
$$

onde $\alpha$ é uma constante da ordem da unidade, $\dot{M}_{-3}$ é a taxa de perda de massa da primária, em unidades de $10^{-3} \mathrm{M}_{\odot}$ ano ${ }^{-1}$, e $M_{100}$ é a sua massa, em unidades de $100 \mathrm{M}_{\odot}$. No caso de $\eta$ Carinae, o valor esperado seria $\dot{P}=0.11$ dias ciclo ${ }^{-1}$, mas o valor observado,

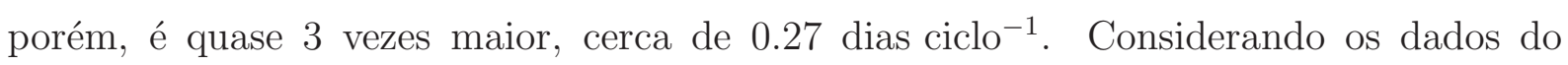
evento de 2009.0 na análise descrita acima, o período atual passa a ser um pouco menor (conforme descrito mais adiante nesta tese), cerca de 2021.5 dias, e o limite superior para $P_{\text {med }}$ aumenta para 2023.6 dias, correspondendo a uma taxa de variação de 2.1 dias em 11 ciclos, ou seja, 0.38 dias ciclo $^{-1}$. Logo, a variação observada no período ao longo dos últimos 60 anos, é maior que o efeito produzido pela taxa de perda de massa da estrela primária. Em outras palavras, esta diferença entre o período atual e o valor médio, deve ser atribuído ao erro nas medidas do período, e não a uma real variação do período devido a taxa de perda de massa. A situação é diferente para as erupções de 1843 e 1890, quando uma considerável quantidade de massa foi removida da primária em curtos períodos de tempo. 


\section{Capítulo 5}

\section{Uma visão geral dos eventos periódicos em $\eta$ Carinae}

\subsection{A morfologia composta dos eventos}

Há até pouco tempo, os eventos de baixa excitação em $\eta$ Car eram tidos como breves, afetando somente as linhas espectrais de alta excitação. Entretanto, uma análise cuidadosa do evento de 2003.5 revelou que os eventos são compostos pela combinação de duas componentes: uma componente de variação lenta e outra de colapso.

\section{A componente de variação lenta}

A Fig. 5.1(a) mostra o comportamento da razão entre as intensidades da componente estreita das linhas do [Ar III] $\lambda 7135$ e [Fe II] $\lambda 7155$ ao longo de um ciclo, normalizado em intensidade para a fase 0.5. Ambas as linhas são formadas nos glóbulos de Weigelt, mas somente a primeira é uma linha de alto potencial de ionização e, portanto, sua intensidade é muito mais sensível às variações no fluxo de fótons energéticos do que a linha do ferro.

Em vez de apresentar somente a intensidade da linha do [Ar III] em função da fase, foi escolhida a razão entre a intensidade desta linha e aquela observada para uma linha vizinha, neste caso a do [FeII], para compensar qualquer variação na intensiade da linha devido à mudanças no contínuo local, uma vez que a intensidade da componente estreita da linha do argônio apresenta variações assimétricas ao longo do ciclo (causadas, em parte, 

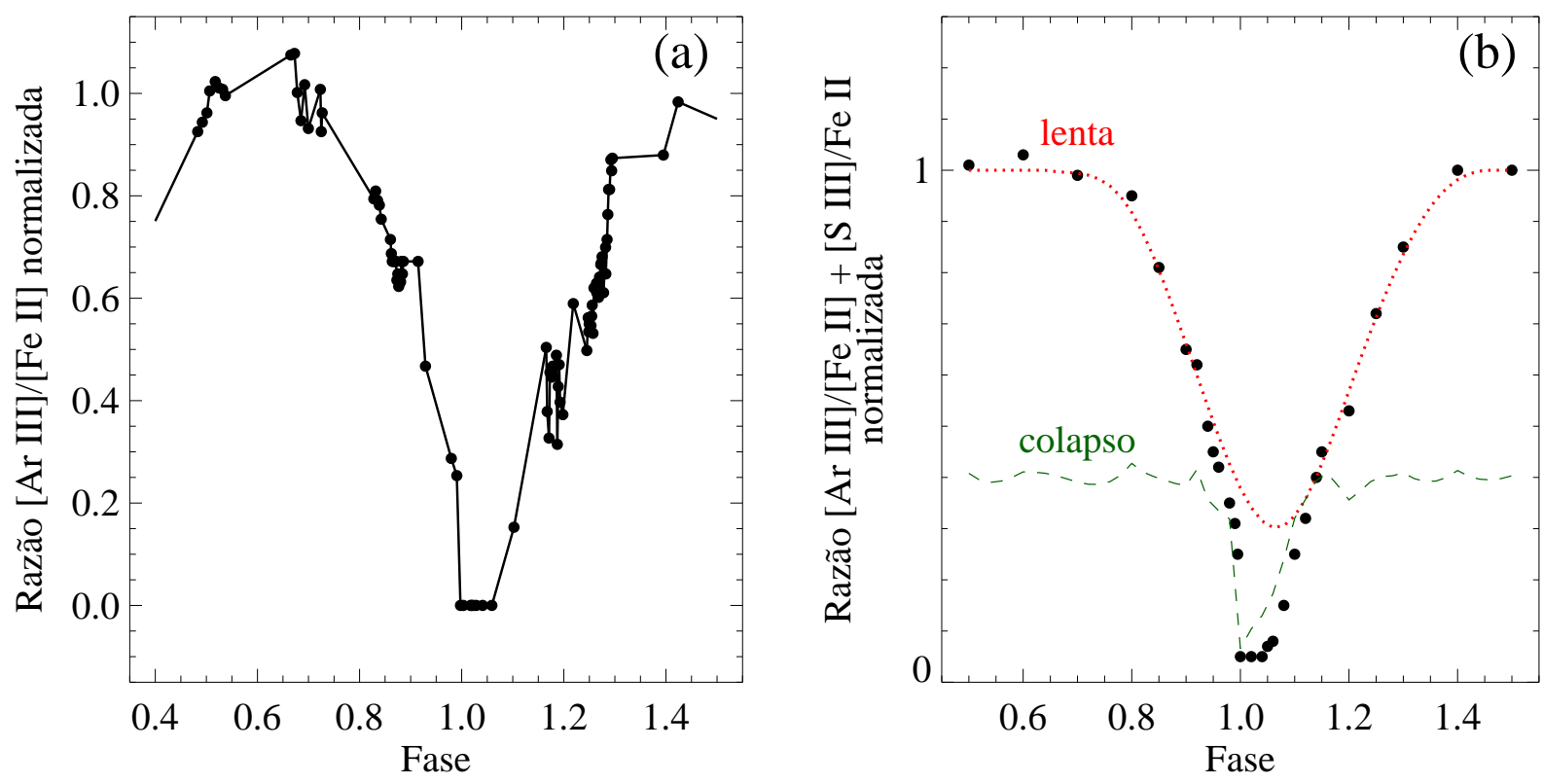

Figura 5.1: A dupla composição dos eventos: componente de variação lenta e a de colapso. (a) Razão normalizada entre as larguras equivalentes da linha do [Ar III] $\lambda 7135 e$ [Fe II] $\lambda 7155$. (b) A intensidade observada da razão entre as linhas (círculos) pode ser ajustada por uma componente gaussiana (linha pontilhada vermelha) que, ao ser subtraída, revela a componente de colapso (linha tracejada verde).

por variações no nível do contínuo), enquanto a do ferro varia muito pouco.

Outras linhas duplamente ionizadas também apresentam um comportamento similar ao do [Ar III], como por exemplo, [NeIII] $\lambda 3868$, [FeIII] $\lambda 4701$ e a linha do [S III] $\lambda 6312$. Felizmente, a linha do [S III] $\lambda 6312$ foi observada com uma densa amostragem temporal em épocas próximas ao evento de 2003.5 e por isso foi combinada com as observações do [Ar III] para melhorar a relação sinal-ruído das observações. Para compensar as variações no nível do contínuo local da linha do [S III], foi escolhida a linha do Fe II $\lambda 6318$. O resultado da média entre os dados do [Ar III] e [S III] estão na Fig. 5.1(b), onde a normalização da razão, desta vez, foi feita para os dados da fase 0.4 .

O comportamento observado na Fig. [5.1(b) foi modelado utilizando um perfil gaussiano, e o resultado desta modelagem, indicado naquela figura pela linha pontilhada vermelha, foi denominado componente de variação lenta e tem largura à meia altura de 649 dias, centrado na fase 0.069, cerca de 140 dias após a fase zero. A variação da intensidade em função da fase orbital da componente de variação lenta apresenta muitas similaridades com a curva de luz rádio em 3 cm observada por Duncan \& White (2003), como por 
exemplo, o centro do mínimo em rádio ocorre cerca de 130 dias após a fase zero. Portanto, sua natureza pode estar associada às variações que ocorrem nessa faixa rádio.

O estudo feito por Teodoro et al. (2008) mostrou que a emissão em rádio, na faixa de $3 \mathrm{~cm}$, durante a fase 0.5 é compatível com o tamanho e distribuição do Pequeno Homúnculo. Por outro lado, durante um evento, a emissão diminui drasticamente em fluxo e dimensão, passando a concentrar-se em uma região com cerca de 1 arcsec de diâmetro (Duncan \& White, 2003).

Se os eventos fossem considerados como um simples eclipse da fonte ionizante (passando por trás da primária ou de seu vento denso) ou a saída da abertura do cone de choque dos ventos da linha de visada do observador, então a radiação ionizante ainda estaria atingindo outras regiões em direções diferentes, exceto na linha de visada. O resultado líquido seria uma mudança na estrutura em pequena escala dos mapas em rádio, mas não deveriam ocorrer mudanças nas dimensões e no fluxo observado, em oposição ao que é observado.

Conforme mencionado anteriormente, tanto o fluxo quanto a dimensão da emissão rádio diminuem durante um evento, o que indica uma mudança no volume da região ionizada, que pode ser explicada considerando que o fluxo de fótons ionizantes atingindo regiões muito distantes da fonte central diminui por causa do aumento da opacidade do material circunstelar (causada, talvez, pelo acúmulo de material ao longo da estrutura espiral formada pelo cone de choque durante a passagem pelo periastro). Desta maneira, o fluxo ionizante que atinge os glóbulos de Weigelt também deve diminuir e, consequentemente, a intensidade das linhas ali formadas.

Para ilustrar a hipótese de que a opacidade controla o fluxo da radiação ionizante nos glóbulos de Weigelt, foi feita uma parametrização utilizando os dados da Fig. 5.1] onde a profundidade óptica varia com a intensidade da razão das linhas, sendo zero quando a intensidade é máxima e aumentando à medida em que a intensidade diminui. O gráfico pode ser visto na Fig. 5.2. Durante a maior parte do período, a profundidade óptica $(\tau)$ da região entre a fonte central e os glóbulos de Weigelt é pequena $(\tau<1)$, o que permite que os fótons ionizantes da fonte central possam ionizar uma parte dos glóbulos (Johansson \& 


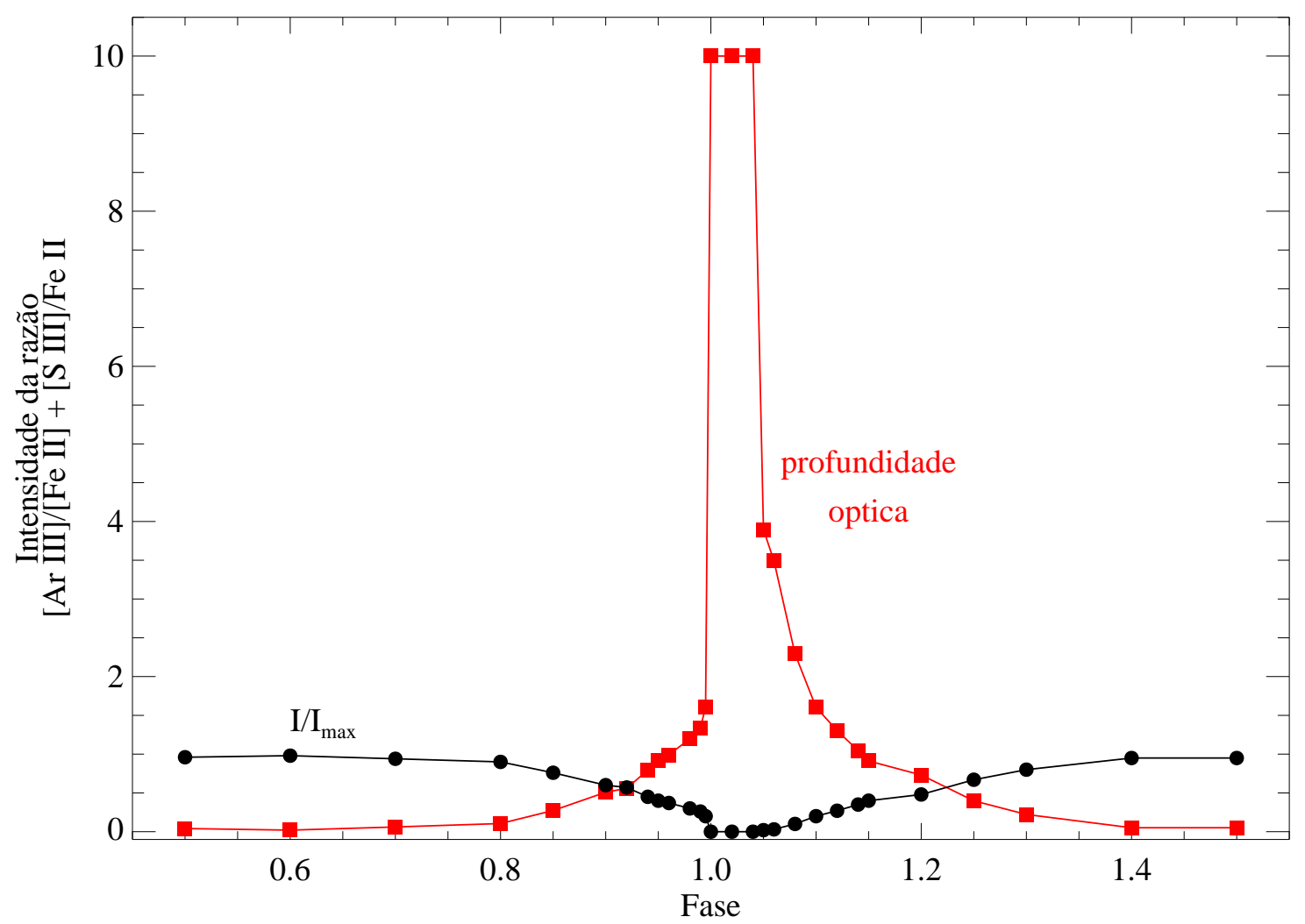

Figura 5.2: Profundidade óptica e razão entre a largura equivalente das linhas do [Ar III]/[Fe II] e do [S III]/Fe II, normalizada para fase 0.4. I/I $\max$ indica a média da razão das larguras equivalentes.

Letokhov, 2005). Porém, a profundidade óptica vista pelos glóbulos aumenta gradativamente e passa para o regime opticamente espesso $(\tau>1)$ aproximadamente 90 dias antes da fase zero. Ela tem um súbito aumento logo antes da fase zero, permanecendo muito alta $(\tau>10)$ por 100 dias e voltando abaixo de $\tau=1$ quase 9 meses depois da fase zero.

\section{A componente de declínio rápido}

Subtraindo o modelo gaussiano das observações, a diferença obtida é a curva tracejada verde ilustrada na Fig. 5.1(b), denominada componente de colapso, cujo centro ocorre na fase 0.0299 (60 dias após a fase zero) e tem largura à meia altura de aproximadamente 190 dias.

Durante a fase de colapso, o fluxo de fótons ionizante nos glóbulos de Weigelt desaparece repentinamente, fato que não pode ser causado por um simples eclipse da fonte ionizante, dado que a estrela primária possui um vento com perfil de densidade radial 
que varia gradualmente e que é opticamente espesso até distâncias de aproximadamente $800 \mathrm{R}_{\odot}$ (cerca de 3.7 U.A.; Hillier et al. 2001).

A componente de colapso também não pode ser resultado de mudanças na direção do apontamento da abertura do cone de colisão dos ventos. tendo em vista que Stahl et al. (2005) mostraram que, em latitudes próximas à região polar, a linha do He II $\lambda 4686$, refletida no lóbulo SE, desaparece quase simultaneamente com a emissão observada na direção da linha de visada da fonte central. Além disso, tanto o fluxo em raios-X quanto as componentes estreitas das linhas duplamente ionizadas (que são formadas nos glóbulos de Weigelt) desaparecem simultaneamente (1 semana mais tarde) durante a fase de colapso, confirmando que a queda no fluxo ionizante não depende da linha de visada. Uma hipótese para a origem da fase de colapso seria a de que a estrutura de colisão de ventos sofra um colapso temporário quando a secundária se aproxima do periastro. Variantes desta hipótese já foram propostas por outros autores (e.g. Soker 2005).

Martin et al. (2006) sugerem, com base no suprimento energético existente nas possíveis regiões de emissão do He II $\lambda 4686$, que uma certa quantidade extra de massa, durante um curto período, seja necessária para explicar a largura equivalente observada naquela linha e sugerem que forças de maré atuando na primária (produzidas pela proximidade da secundária) sejam responsáveis por criar instabilidades no vento da primária, culminando com uma pequena ejeção de matéria. Por um lado, o efeito das forças de maré deve ser muito pequeno para produzir uma ejeção de matéria (dada a pequena massa da estrela secundária), por outro, não se observam acúmulos de matéria na fase pós-periastro.

A Fig. 5.3 mostra o comportamento da largura equivalente da componente estreita do [S III $] \lambda 6312,[\mathrm{Ne}$ III $] \lambda 3868,[\mathrm{Ar}$ III $] \lambda 7135$ e [Fe III $] \lambda 4701$ durante a fase de colapso. Nota-se que, dentre elas, a de maior potencial de excitação ([Ne III]) é a primeira a desaparecer e a última a recuperar-se. Por outro lado, a de menor energia de transição ([Fe III] $]$ desaparece por último, mas é a primeira a ressurgir. Tal comportamento poderia ser explicado se as linhas que desaparecem primeiro fossem intrinsecamente muito menos intensas (fora da fase de colapso) do que as que desaparecem por último. Entretanto, isto não é observado, pois a largura equivalente da linha do [NeIII] (primeira a desaparecer) atingiu cerca de 


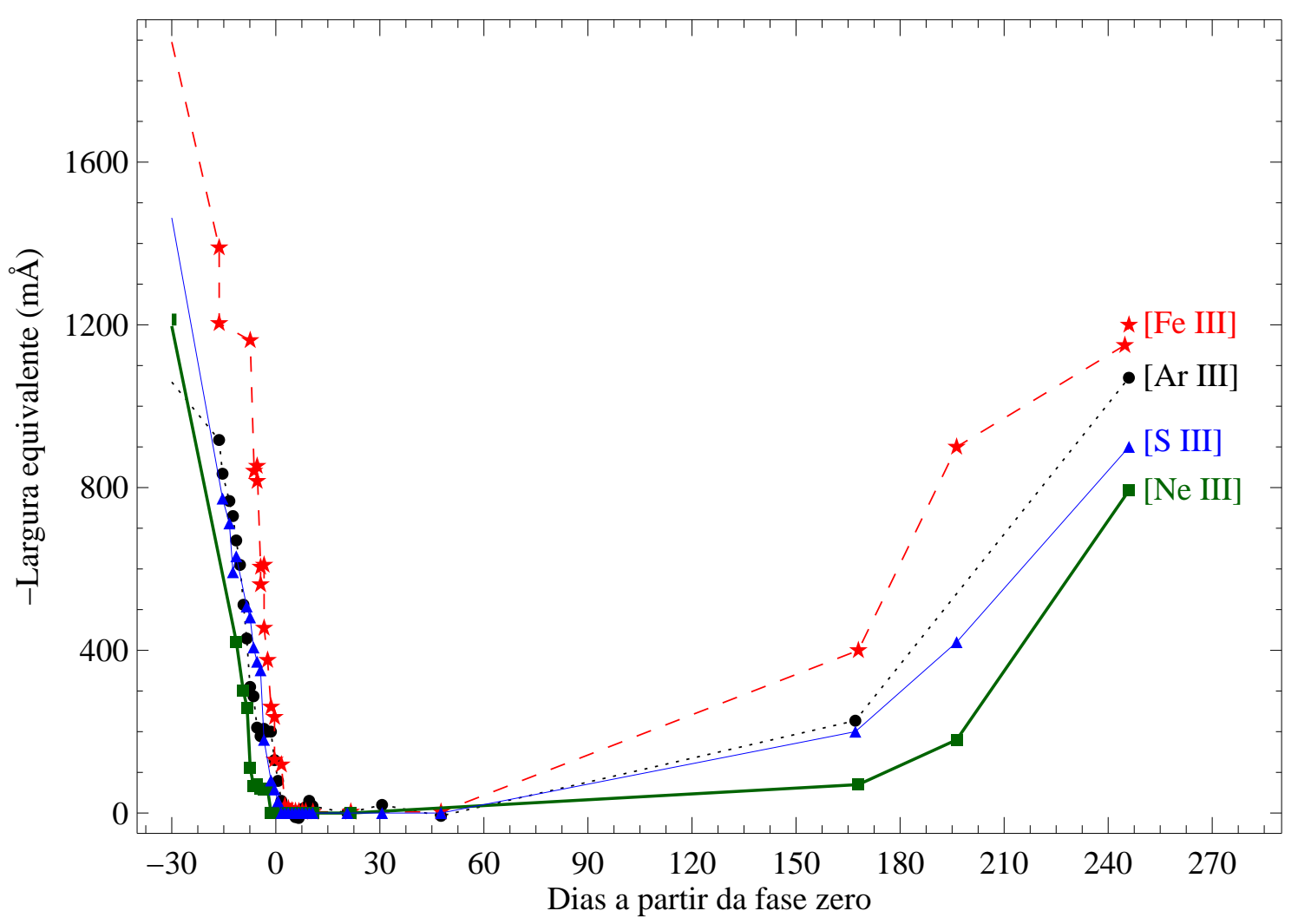

Figura 5.3: Comportamento da componente estreita das linhas de alto potencial de excitação durante a parte central do minimo. Das linhas espectrais indicadas nesta figura, a do [NeIII] é a que tem a maior energia de transição e a do [FeIII], a de menor energia.

$5500 \mathrm{~m} \AA$ no começo de 2001 (fase orbital $\approx 0.5$ ), enquanto, na mesma época, a linha do [Fe III] (última a desaparecer) teve seu máximo por volta de $2800 \mathrm{~m} \AA$. Portanto, o comportamento das linhas duplamente ionizadas é fortemente modulada pelo potencial de ionização.

É interessante notar, porém, que a linha do [S III] e do [Ar III], apesar de obedecerem à sequência observada de que a linha que desaparece primeiro recupera-se por último, parecem não seguir o padrão de que as linhas com maior potencial de excitação desaparecem primeiro, conforme mostra a Tabela 5.1. Entretanto, com os dados atuais, não é possível afirmar, com certeza, que tal comportamento seja real, tendo em vista que a incerteza na determinação da época em que as linhas desaparecem é de aproximadamente 1 dia. Além disso, deve-se ressaltar que a diferença da largura equivalente destas linhas também é similar aos erros envolvidos nas medidas. 
Tabela 5.1: Intervalo de tempo, a partir da fase zero, para desaparecimento da componente estreita da linha indicada. $n_{\mathrm{c}}$ é a densidade crítica para formação da respectiva linha.

\begin{tabular}{cccc}
\hline \hline & $\begin{array}{c}\text { Intervalo de tempo } \\
\text { Linha espectral }\end{array}$ & $\begin{array}{c}\text { Potencial de ionização } \\
(\text { dias })\end{array}$ & $\begin{array}{c}n_{\mathrm{c}} \\
\left(\mathrm{cm}^{-3}\right)\end{array}$ \\
\hline$[$ Ne III $] \lambda 3868$ & -5 & $41.0^{a}$ & $7.6 \times 10^{6}$ \\
{$[$ Ar III $] \lambda 7135$} & +2 & $27.6^{a}$ & $5 \times 10^{6}$ \\
He I $\lambda 6678$ & 0 & $24.6^{b}$ & - \\
{$[$ S III $] \lambda 6312$} & +1.5 & $23.3^{a}$ & $15 \times 10^{6}$ \\
{$[$ Fe III $] \lambda 4701$} & +3 & $16.2^{a}$ & - \\
{$[$ N II $] \lambda 5754$} & +3.5 & $14.5^{a}$ & $8.6 \times 10^{6}$ \\
\hline${ }^{a}$ Potencial correspondente ao estágio de ionização anterior $\left(\right.$ e.g. Ne ${ }^{+}$para o Ne III $)$. \\
${ }^{b}$ Potencial de ionização do He ${ }^{0}$.
\end{tabular}

Na terceira coluna da Tabela 5.1. estão listados os potenciais de ionização das linhas formadas nos glóbulos de Weigelt. Como as linhas proibidas são formadas por excitação colisional, naquela tabela está indicado o potencial de ionização do íon anterior aquele que dá origem à transição. Por exemplo, para observar a linha do [NeIII] $\lambda 3868$, foi necessário que o íon $\mathrm{Ne}^{+}$perdesse 1 elétron (ionização), transformando-se no íon $\mathrm{Ne}^{++}$, que é o responsável pela transição que dá origem à linha espectral mencionada e, portanto, é listado o potencial de ionização do $\mathrm{Ne}^{+}$e não o do $\mathrm{Ne}^{++}$. Para o hélio, entretanto, as linhas observadas são formadas, geralmente, por recombinação e, portanto, na tabela é fornecido o potencial de ionização do $\mathrm{He}^{0}$.

Analisando os dados da Tabela 5.1, pode-se observar que o intervalo de tempo para que uma dada linha espectral desapareça apresenta uma correlação com o potencial de ionização, de tal maneira que, conforme mencionado anteriormente, as linhas com alto potencial desaparecem primeiro. Parece não haver relação entre a densidade crítical] e o intervalo de tempo de seu desaparecimento, o que exclui a densidade como o fator

\footnotetext{
${ }^{1}$ Densidade na qual a taxa de desexcitação radiativa $\left(A_{21}\right)$ é igual à colisional $\left(R_{21}\right)$, dada por $n_{\mathrm{c}}=\left(\begin{array}{lll}A_{21} & g_{2} & \sqrt{T}\end{array}\right) /\left(\beta \Omega_{12}\right)$, onde $A_{21}$ é o coeficiente de emissão espontânea do nível superior 2 para o nível inferior $1, g_{2}$ é o fator de Gaunt para o nível 2, $T$ é a temperatura do gás, $\beta$ é uma constante $\left(=\sqrt{\left(2 \pi \hbar^{4}\right) /\left(k m_{e}^{3}\right)}\right)$ e $\Omega_{12}$ é a força de colisão entre os níveis.
} 
importante.

Se a radiação ionizante que chega aos glóbulos de Weigelt fosse repentinamente extinta, as linhas de alta excitação ali formadas diminuiriam de intensidade a uma taxa regulada pelo tempo de recombinação de cada uma, que para a componente estreita do He i $\lambda 6678$, por exemplo, seria de aproximadamente

$$
t_{\mathrm{rec}}=42.4 \frac{10^{6}}{N_{\mathrm{e}}}(\text { dias })
$$

onde $N_{\mathrm{e}}$ é a densidade eletrônica, em $\mathrm{cm}^{-3}$, da região onde a linha é formada, neste caso, nos glóbulos de Weigelt. Observa-se que esta linha decai em um intervalo de tempo de 5 a 10 dias e, portanto, a densidade nos glóbulos de Weigelt deve ser $>5 \times 10^{6} \mathrm{~cm}^{-3}$, que é um valor consistente com o obtido por Verner et al. (2005), que determinaram um valor $\sim 10^{7} \mathrm{~cm}^{-3}$ para a região de alta ionização com base na razão entre linhas formadas nos glóbulos de Weigelt. É consistente, também, com o valor reportado por Hartman et al. $(2005)$.

Para uma nebulosa esférica opticamente fina, a escala de tempo de ionização é similar a de recombinação. No entanto, no caso das linhas formadas nos glóbulos de Weigelt, o intervalo de tempo de recombinação é muito menor do que o de re-ionização, e portanto, o obscurecimento da fonte ionizante pelo gás presente no meio circunstelar deve ser o fator determinante do intervalo de tempo observado para a recuperação das linhas.

A fase de colapso, quando analisada utilizando a componente estreita da linha do He I $\lambda 6678$, apresenta duas características marcantes: ela é assimétrica e a fase de recuperação está tornando-se cada vez mais demorada ao longo dos anos. Ambos os efeitos descritos podem ser causados por variações intrínsecas na região onde esta linha é formada ou podem ser simplesmente um artefato resultante de um aumento do nível do contínuo estelar. Para testar esta última hipótese, é necessário verificar se o comportamento desta linha, durante a fase de colapso, sofre alguma mudança ao ser calibrada pelo fluxo do contínuo estelar, determinado através das observações fotométricas.

A Fig. [5.4(a) mostra o comportamento observado para a largura equivalente da componente estreita da linha do He I $\lambda 6678$ durante a fase de colapso para os eventos de 1992.5 

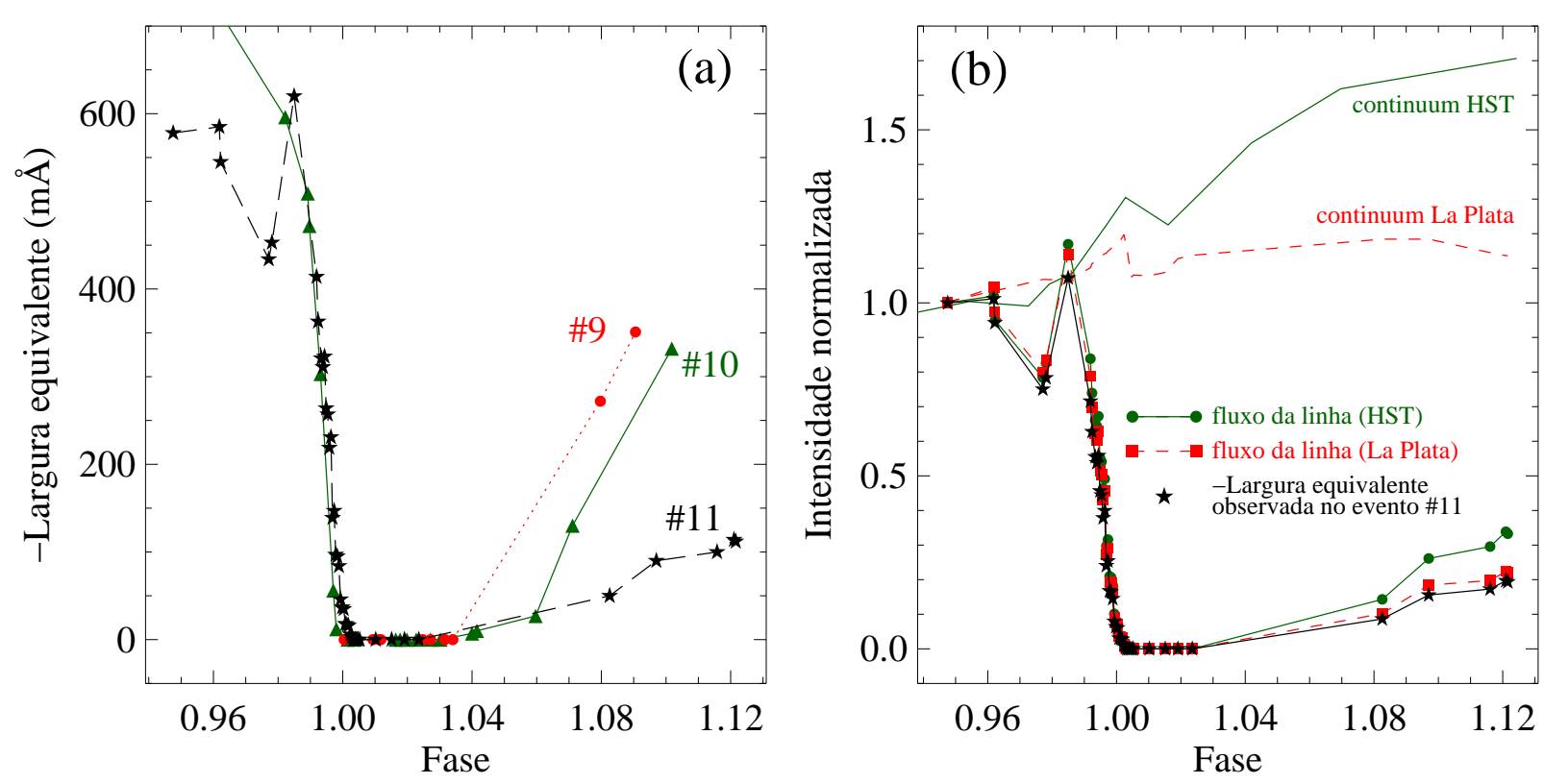

Figura 5.4: (a) Largura equivalente da componente estreita do He I $\lambda 6678$ ao longo dos últimos 3 eventos (1992.5, 1997.9 e 2003.5). (b) Quantidades normalizadas em relação ao evento \#11: contínuo da fonte central obtido pelo STIS/HST com o filtro F550M (curva contínua verde); contínuo na banda $V$ obtido por fotometria de abertura incluindo o Homúnculo e a fonte central (curva tracejada vermelha); fluxo da componente estreita da linha obtido pelo STIS/HST corrigido pelo contínuo estelar (círculos verdes); fluxo da componente estreita da linha corrigido pelo contínuo do Homúnculo (quadrados vermelhos) e a largura equivalente observada (estrelas).

(\#9), 1998.0 (\#10) e 2003.5 (\#11). Para corrigir as medidas pela variação no nível do contínuo estelar é necessário obter a fotometria durante um evento, o que foi possível para o evento de 2003.5 (\#11), durante o qual foram feitas observações fotométricas com telescópio em terra (pelo grupo de La Plata) e também com o telescópio espacial Hubble (Martin et al., 2006).

Entretanto, a amplitude das variações fotométricas dependem do tamanho da abertura utilizada para a fotometria. A fotometria do grupo de La Plata foi feita utilizando uma abertura de $22 \operatorname{arcsec}$ (o que poderia dissolver as variações da fonte central) enquanto a fotometria sintética reportada por Martin et al. (2006) foi feita com uma abertura de $0.3 \operatorname{arcsec}$ (resultando em dados livres de emissão nebular).

Por outro lado, os espectros nos quais foram feitas as medidas do evento de 2003.5 foram obtidos utilizando uma fenda com abertura entre 1.5 e 4 arcsec. Portanto, comparado com a largura da fenda, o fluxo da linha obtido com a utilização da fotometria do grupo de La Plata fornece um limite inferior para as variações do contínuo estelar, 


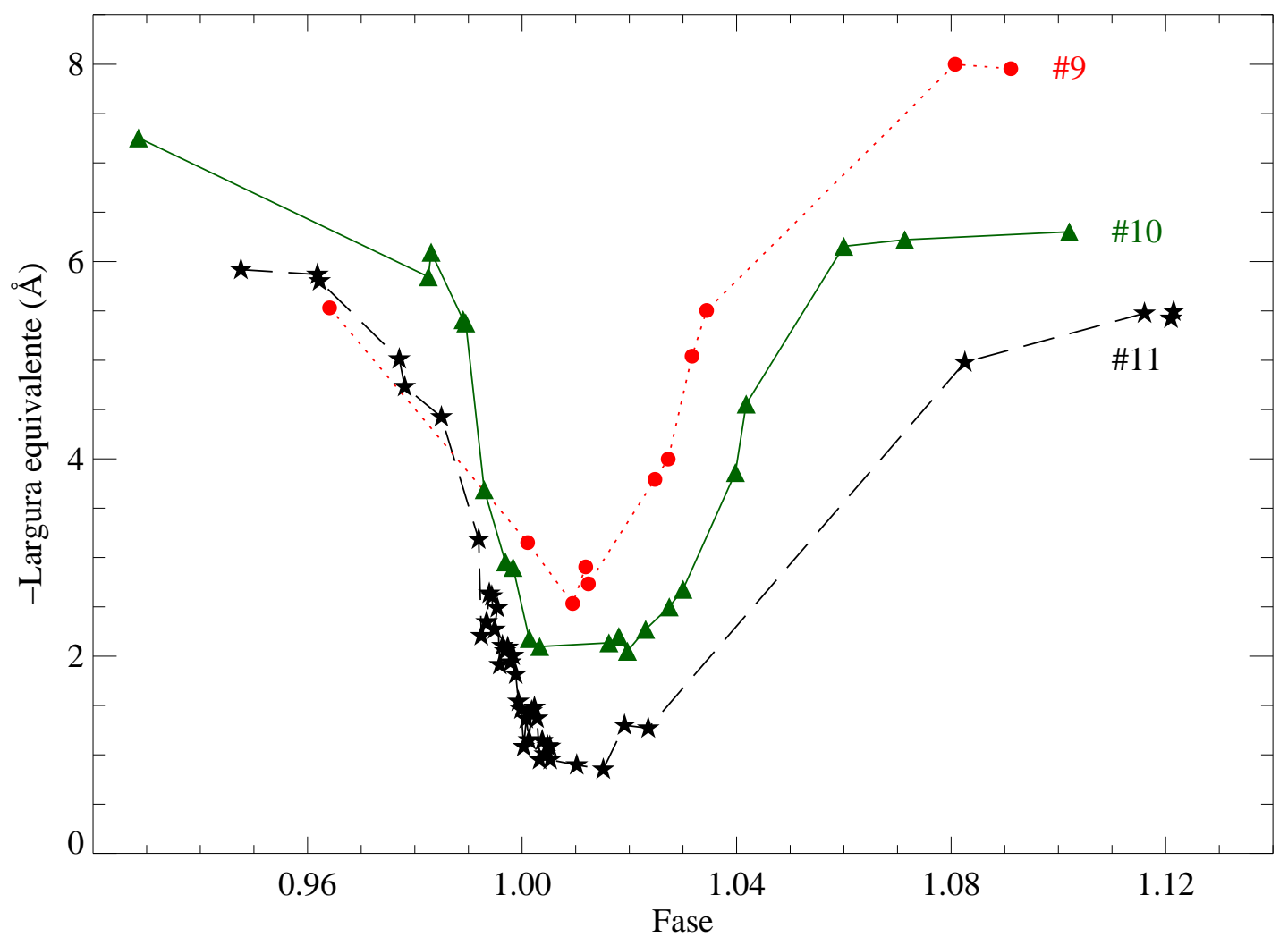

Figura 5.5: Comportamento da largura equivalente da componente larga da linha do He I $\lambda 6678$ ao longo da parte central dos últimos 3 eventos (1992.5, 1998.0 e 2003.5).

enquanto o fluxo da linha obtido com a fotometria do HST fornece um limite superior. O resultado pode ser visto na Fig. 5.4(b), onde estão mostrados as variações no nível do contínuo estelar e as correções aplicadas ao evento \#11. Note que todos os valores estão normalizados para a fase 0.96 , uma vez que são relevantes as variações temporais relativas e não os valores absolutos.

A variação real do fluxo da componente estreita da linha do He I $\lambda 6678$ está entre os dois limites mostrados na Fig. 5.4(b). Considerando os erros nas medidas, a assimetria observada antes e depois da fase zero é um comportamento real. Além disso, a fase de recuperação desta linha parece estar realmente aumentando de ciclo para ciclo, pois tal comportamento ainda é observado mesmo após corrigir o fluxo da linha pelas variações no nível do contínuo estelar.

A Fig. 5.5 mostra o comportamento da largura equivalente da componente larga da linha do He I $\lambda 6678$ durante a fase de colapso. Nota-se que esta componente apresenta 
um perfil um pouco assimétrico, no sentido de que a fase de queda é um pouco mais rápida do que a de recuperação, mas é muito menos discrepante do que o observado para a componente estreita, descrito anteriormente.

Como as linhas do He I são formadas em regiões de alta densidade e requerem um alto fluxo de fótons energéticos, acredita-se que a componente larga do He I $\lambda 6678$ seja formada nas regiões mais internas do sistema. Entretanto, sua localização exata ainda é desconhecida, mas dentre os possíveis candidatos estão as partes internas do vento da primária (expostas pela migração do cone de choque dos ventos) e a parede do cone de choque (mais adiante, nesta seção, serão apresentados argumentos a favor desta última hipótese). É importante ressaltar que as variações observadas na componentes estreita e larga desta linha não têm, necessariamente, que estar relacionadas, pois a fonte central é observada através de uma elevada extinção $\left(A_{V} \approx 7\right)$, enquanto os glóbulos de Weigelt são afetados essencialmente pela extinção interestelar $(A \approx 0.5)$.

É interessante notar que a componente larga do He I $\lambda 6678$ nunca desaparece completamente, o que sugere que deve haver sempre um fluxo ionizante da secundária iluminando a região onde ela é formada (no caso de ser formada na parede do cone de choque) ou que esta componente deve ser simplesmente a emissão intrínseca do vento da primária.

As observações feitas por Stahl et al. (2005) mostraram que a componente larga do He I $\lambda 6678$, refletida no lóbulo SE do Homúnculo (alta latitude estelar), diminui quase simultaneamente (aproximadamente 1 semana) à observada na linha de visada da fonte central (latitude intermediária). Tal comportamento exclui um mecanismo de eclipse da fonte ionizante, favorecendo um cenário no qual ocorra o colapso da estrutura do cone de choque e sua posterior restauração.

Os parâmetros do cone de choque dos ventos podem ser modificados se uma das componentes do sistema apresentar uma mudança em seus parâmetros físicos, como por exemplo, a taxa de perda de massa. Como a curva de luz em raios-X é extremamente cíclica e tal emissão é dominada pelo vento da secundária, então esta deve ser uma estrela relativamente estável. Sendo assim, qualquer mudança deve ocorrer nos parâmetros físicos da primária. Por exemplo, se a sua taxa de perda de massa diminui momentaneamente, o 

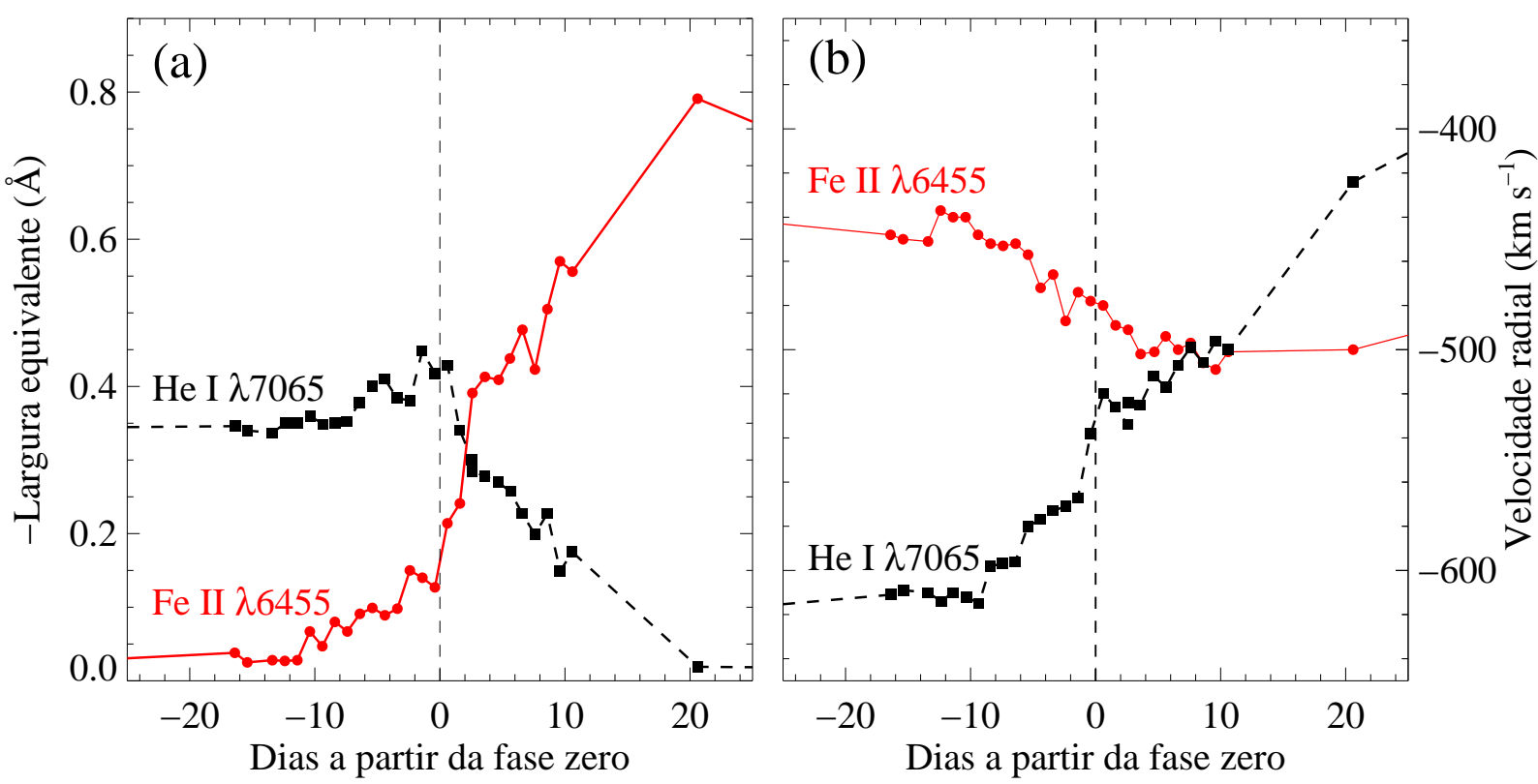

Figura 5.6: Variação da (a) largura equivalente e da (b) velocidade radial do baricentro da componente em absorção do perfil P Cygni das linhas do He I $\lambda 7065$ e do Fe II $\lambda 6455$.

cone de choque desloca-se para próximo da primária e sua abertura aumenta, o que pode reduzir o fluxo ionizante e, consequentemente, diminuir a emissão da componente larga do He I $\lambda 6678$. Portanto, a recuperação relativamente rápida da curva de luz em raios-X e da componente larga do He I $\lambda 6678$ em aproximadamente 3 meses após a fase zero, indica que neste intervalo de tempo a estrutura do cone de choque já deve ter sido restaurada, de maneira que a sua abertura esteja interceptando a linha de visada do observador.

Analisando a componente em absorção do perfil P Cygni das linhas do He I $\lambda 7065$ e do FeII $\lambda 6455$, é possível notar que elas apresentam uma anti-correlação, tanto em intensidade quanto em velocidade radial, que pode ser visto na Fig. 5.6. Esta componente em absorção deve ser formada pelo material entre o observador e a fonte central, porém, ainda existem debates sobre a região onde é formada, ou seja, se ela está diretamente relacionada à parede do cone de choque ou se é produzida no vento da primária (Nielsen et al., 2007).

A Fig. [5.6(a) mostra que durante a fase de colapso, a largura equivalente da componente em absorção do P Cygni da linha do Fe II aumenta enquanto a do He I diminui (tal comportamento também foi reportado por Nielsen et al. 2007 em espectros da fonte central tomados com o Hubble). A mesma anti-correlação também é observada no compor- 
tamento da velocidade radial de cada componente, conforme pode ser visto na Fig. [5.6(b). Como a diferença no potencial de ionização do Fe II é menor do que o do He I, estas duas linhas fornecem a oportunidade de estudar o comportamento de diferentes regiões, dado o fato de que a primeira é formada em locais mais distantes da fonte ionizante, ao contrário da segunda, que deve ser formada em regiões muito mais próximas desta.

O aumento da largura equivalente da componente em absorção do Fe II e sua cinemática indicam que o Fe II está recombinando no vento da primária, do lado mais próximo do observador (o que significa que a fonte ionizante está do lado oposto), e atinge um máximo logo após o colapso do cone de choque. Esta hipótese é corroborada pela diminuição da absorção do He I em anti-fase.

A reionização do Fe II (diminuição da largura equivalente) começa cerca de 20 dias após a fase zero, enquanto a do He I demora muito mais para começar, o que pode ser facilmente explicado considerando que a abertura do cone de choque leva um certo tempo para interceptar novamente a linha de visada do observador. Por outro lado, neste cenário, a reionização do Fe II começa antes porque a radiação ionizante da secundária penetra no vento da primária logo após a oposição.

Em relação ao comportamento cinemático, a amplitude da variação da velocidade radial da componente em absorção da linha do Fe II é menor porque ela é formada nas partes mais externas do vento da primária, onde ele já deve estar atingindo sua velocidade terminal. A linha do HeI, entretanto, é formada em uma região suscetível a uma grande aceleração. Como a linha do Fe II é produzida na região do vento da primária onde a ele está atingindo sua velocidade terminal, a linha do He I não pode ser formada no vento estelar, uma vez que esta linha requer tanto um fluxo ionizante quanto uma densidade relativamente altos, que só podem existir nas camadas muito próximas da estrela. Portanto, a formação da componente larga do He I ocorre na parede do cone de choque do vento da secundária, ou na própria fotosfera da primária, exposta pelo cone de choque dos ventos. 

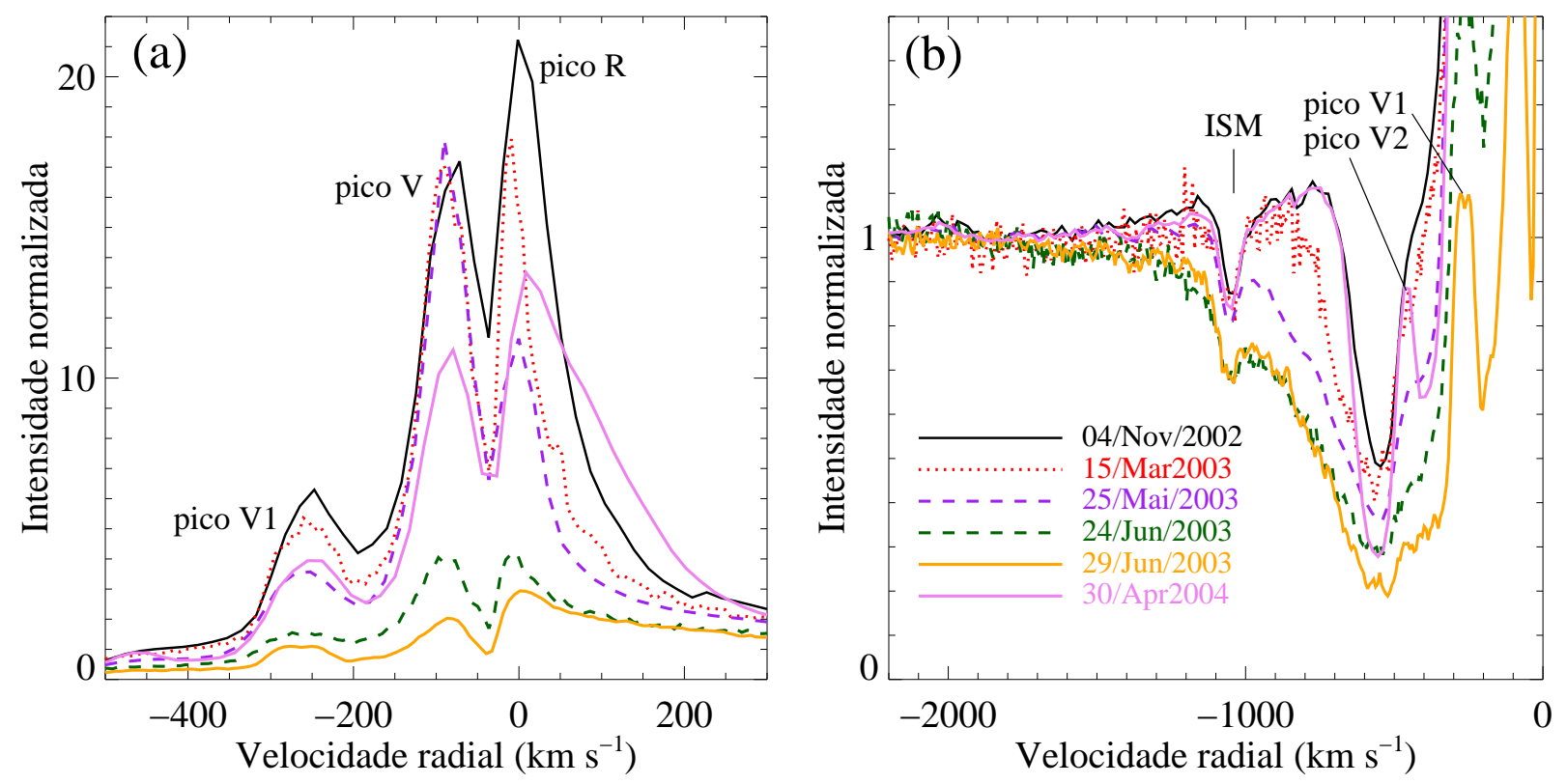

Figura 5.7: Perfil do He i $\lambda 10830$. Variações nas componentes em (a) emissão e (b) absorção. A legenda no painel (b) é válida para ambos os gráficos.

\subsection{A linha do He I $\lambda 10830$}

\subsubsection{Componentes em emissão}

Esta é uma linha de especial interesse por causa de sua complexidade: é uma linha muito intensa; apresenta muitas componentes cinemáticas e passa por variações impressionantes ao longo de um ciclo. A Fig. 5.7(a) mostra a variabilidade das componentes em emissão. Nos espectros de alta resolução, dois picos são claramente distinguíveis: um em $+12 \mathrm{~km} \mathrm{~s}^{-1}$ (pico R) e outra em $-85 \mathrm{~km} \mathrm{~s}^{-1}$ (pico V).

Ao longo da fase de alta excitação, o pico R é maior do que o pico V (ou seja, R/V>1), permanecendo assim até 105 dias antes da fase zero, quando o pico R passa a ser menor do que o $\mathrm{V}(\mathrm{R} / \mathrm{V}<1)$. Porém, cerca de 4 dias antes da fase zero o pico $\mathrm{R}$ volta a ser maior do que o $\mathrm{V}(\mathrm{R} / \mathrm{V}>1)$. Ainda é uma questão em aberto se os picos $\mathrm{R}$ e $\mathrm{V}$ são duas emissões independentes ou se ambos formam uma componente larga dividida por uma absorção em $-35 \mathrm{~km} \mathrm{~s}^{-1}$ (Damineli et al., 1998). Tal absorção, de fato, cai abaixo do contínuo, mas somente durante o mínimo. Entretanto, o contínuo onde esta absorção localiza-se não é um contínuo verdadeiro, pois ele situa-se na região da componente em absorção do perfil P Cygni da linha do He I $\lambda 10830$ e, consequentemente, acompanha suas variações. 


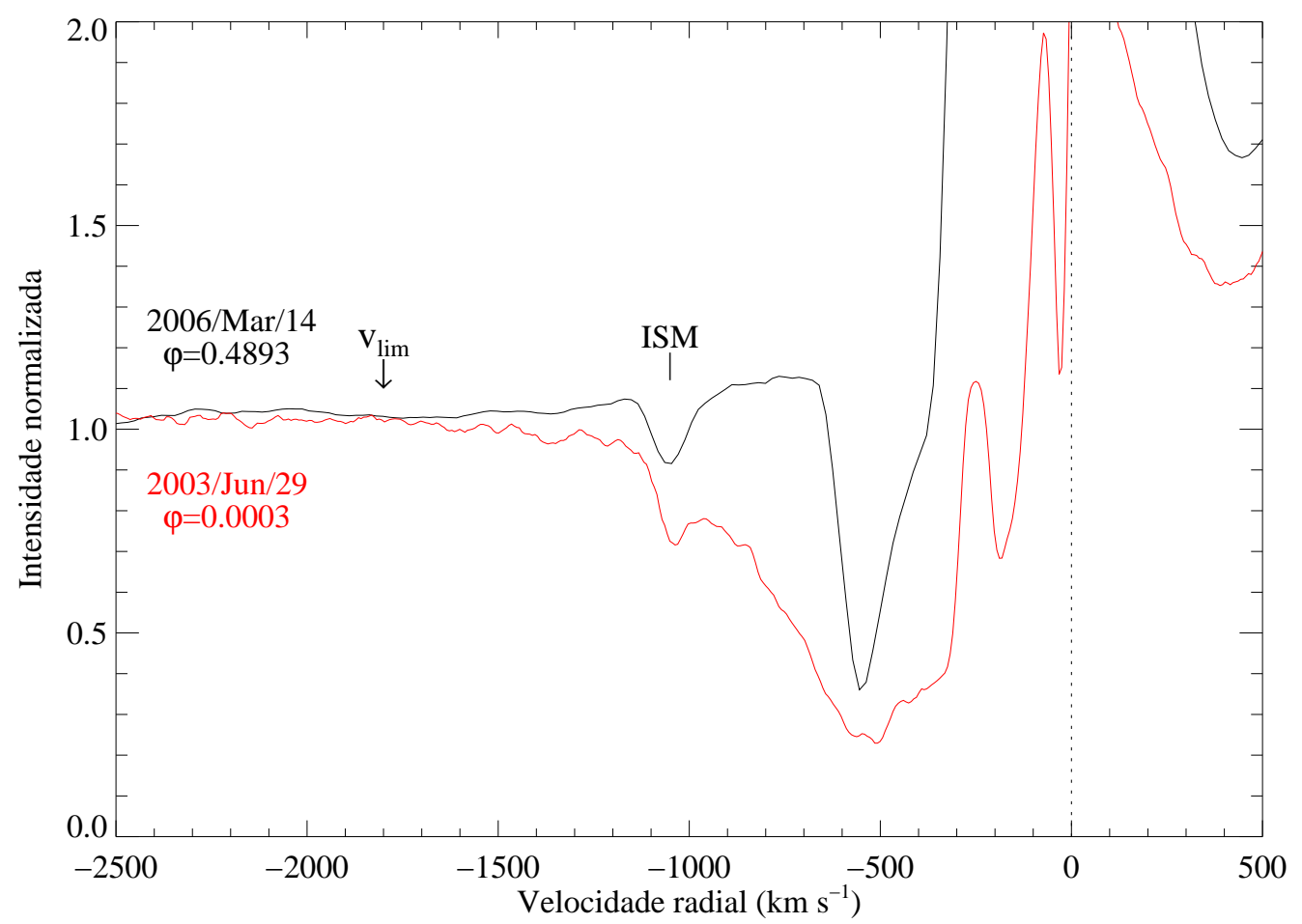

Figura 5.8: Perfil da componente em absorção da linha do He I $\lambda 10830$ em duas fases distintas: durante a fase de alta excitação (linha preta; fase $\sim 0.5$ ) e baixa excitação (linha vermelha; fase $\sim 0$ ). Note o aumento da velocidade máxima de absorção, $\mathrm{v}_{\mathrm{lim}}$, durante a fase de baixa excitação, cujo valor atinge $\sim-1800 \mathrm{~km} \mathrm{~s}^{-1}$. Espectros obtidos no $O P D$.

Na Fig. 5.7(a) e (b) é possível notar outros dois picos: um em velocidade de aproximadamente $-255 \mathrm{~km} \mathrm{~s}^{-1}$ (pico V1) e outro em $-460 \mathrm{~km} \mathrm{~s}^{-1}$. Estes picos são variáveis ao longo de todo o ciclo e também de ciclo para ciclo. Naquela figura, nota-se, ainda, a presença de uma absorção em -1060 $\mathrm{km} \mathrm{s}^{-1}$ (identificada por ISM naquela figura) que se acreditava ser uma componente de alta velocidade desta linha. Porém, Groh et al. (2007) demonstraram que se trata, na verdade, de uma componente interestelar.

\subsubsection{Componente em absorção}

Durante a fase de alta excitação, a componente em absorção do perfil P Cygni é fraca e apresenta um centróide em $-570 \mathrm{~km} \mathrm{~s}^{-1}$, em concordância com a velocidade das linhas formadas no vento estelar da primária. Durante a aproximação do periastro, esta componente começa a ficar mais larga e seu centróide desloca-se para $-650 \mathrm{~km} \mathrm{~s}^{-1}$. Este 


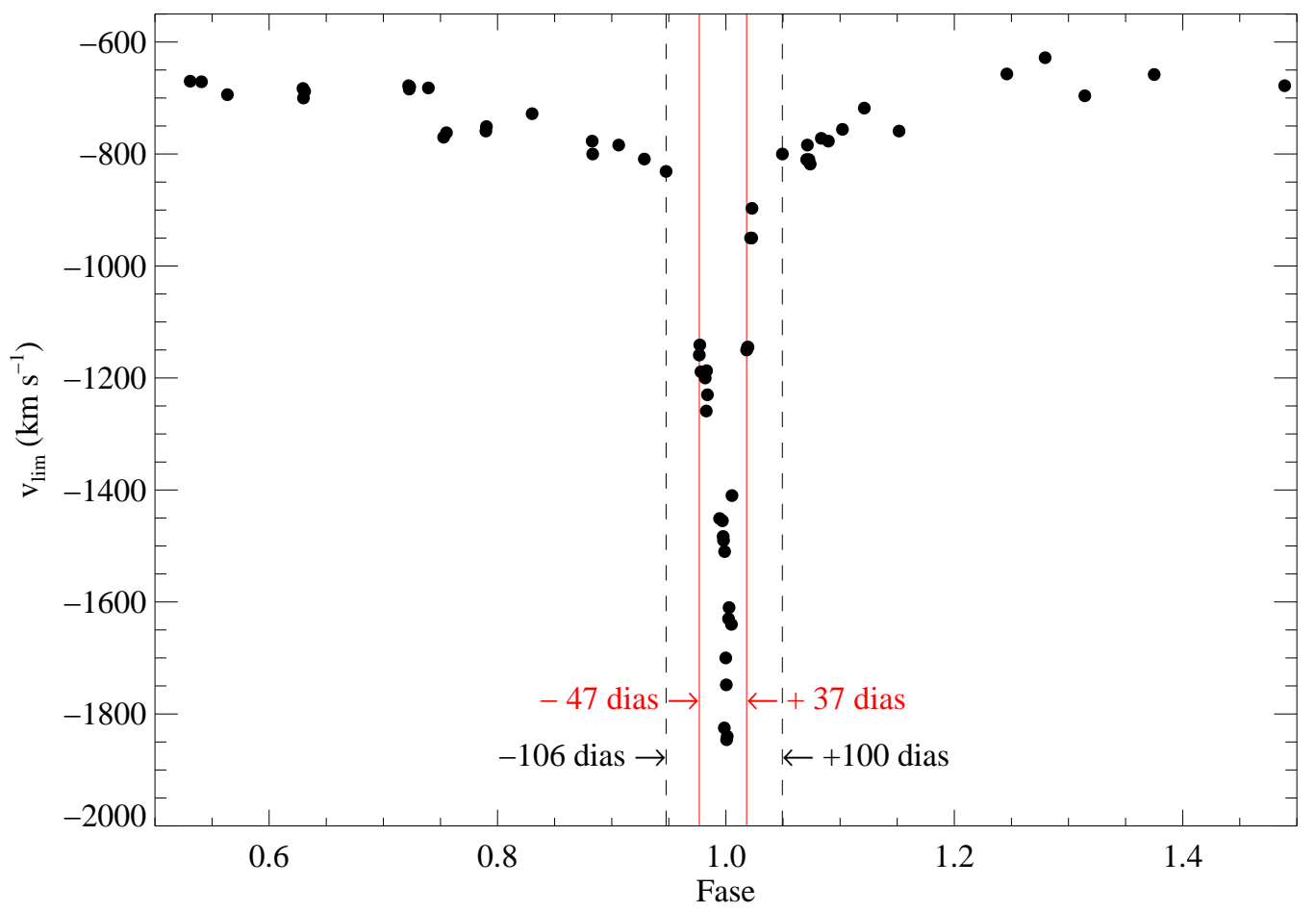

Figura 5.9: Comportamento da velocidade máxima de absorção, $\mathrm{v}_{\mathrm{lim}}$, da linha do He I $\lambda 10830$ ao longo de todo o ciclo de 5.54 anos. As linhas verticais indicam os limites inferior (linha continua) e superior (linha tracejada) na fase de transição entre o regime de variação lenta e o de colapso. O intervalo de duração do regime de colapso é $145 \pm 61$ dias.

deslocamento do centróide deve-se ao aumento da absorção em velocidades mais negativas, atingindo até $-1800 \mathrm{~km} \mathrm{~s}^{-1}$. Este comportamento é ilustrado na Fig. [5.8, onde é mostrado o espectro da linha do He I $\lambda 10830$, obtido no OPD, durante as fases $\phi \sim 0.5$ e $\phi \sim 0$. Simultaneamente à diminuição da intensidade das componentes em emissão, ocorre um aumento na largura equivalente da componente em absorção (devido a combinação do aumento na intensidade da absorção e no aumento da velocidade máxima para valores mais negativos).

A Fig. 5.9 mostra o perfil da velocidade máxima de absorção. Naquela figura, nota-se que existem, essencialmente, dois regimes: um de variação lenta e outro de colapso. Assim como nas outras linhas espectrais, a componente de variação lenta domina a maior parte do ciclo de 5.54 anos, apresentando velocidades entre -600 e $-800 \mathrm{~km} \mathrm{~s}^{-1}$. Cerca de 3 meses antes do evento, a velocidade máxima da componente em absorção começa a aumentar a uma taxa maior. A partir deste ponto, a componente de colapso passa a dominar as 
variações na velocidade máxima. Velocidades muito mais elevadas $\left(\left|\mathrm{v}_{\lim }\right|>1100 \mathrm{~km} \mathrm{~s}^{-1}\right)$, em relação ao observado na fase de alta excitação, são observadas durante um período de 84 dias, que começa cerca de 47 dias antes do evento e vai até 37 dias depois, quando

$\left|\mathrm{v}_{\text {lim }}\right|$ volta a ser $<1000 \mathrm{~km} \mathrm{~s}^{-1}$. O desaparecimento da componente de colapso acontece cerca de 3 meses depois do evento, quando $\left|\mathrm{v}_{\text {lim }}\right|$ volta a ser menor do que $800 \mathrm{~km} \mathrm{~s}^{-1}$, indicando a volta do regime no qual componente de variação lenta é dominante. Portanto, o intervalo de duração do regime de colapso é de $145 \pm 61$ dias, centrado na fase zero.

De maneira geral, o comportamento observado desta linha espectral é uma combinação de vários fatores. Primeiro, próximo do evento, os glóbulos de Weigelt deixam de ser iluminados pela radiação ionizante da secundária, pois esta é 'abafada' pelo vento denso da primária, causando a queda na intensidade das componentes estreitas. Segundo, para explicar a diminuição na intensidade da componente larga em emissão do He i $\lambda 10830$, é necessário que a região emissiva desta linha diminua durante o periastro. Como o número de fótons ionizantes produzidos pela secundária não varia, então a diminuição na intensidade das linhas em emissão do He i $\lambda 10830$ deve ser causada pelo reprocessamento da radiação ionizante no vento da primária, o que requer que a secundária esteja profundamente embebida no vento da primária durante a passagem pelo periastro.

\subsection{Uma visão multi-espectral do mínimo}

A Fig. 5.10 mostra um panorama, em várias faixas espectrais, das emissões, absorções, velocidades radiais e variações no fluxo do contínuo estelar durante o mínimo (fase de colapso). Naquela figura também estão reproduzidas os resultados publicados na literatura, conforme indicado em sua legenda.

Na Fig. [5.10(a), as quatro primeiras curvas, de cima para baixo, mostram o comportamento da largura equivalente da componente em absorção do perfil P Cygni para a linha do He I $\lambda 7065$, do He I $\lambda 10830$, do H $\alpha$ e do Fe II $\lambda 6455$. A largura equivalente da componente em absorção do He I $\lambda 7065$ é, geralmente, alta durante o ciclo de 5.5 anos, atingindo um máximo 2 dias antes da fase zero, quando começa a diminuir e atinge o mínimo 20 dias depois. Em contraste, a largura equivalente da absorção P Cygni das outras 

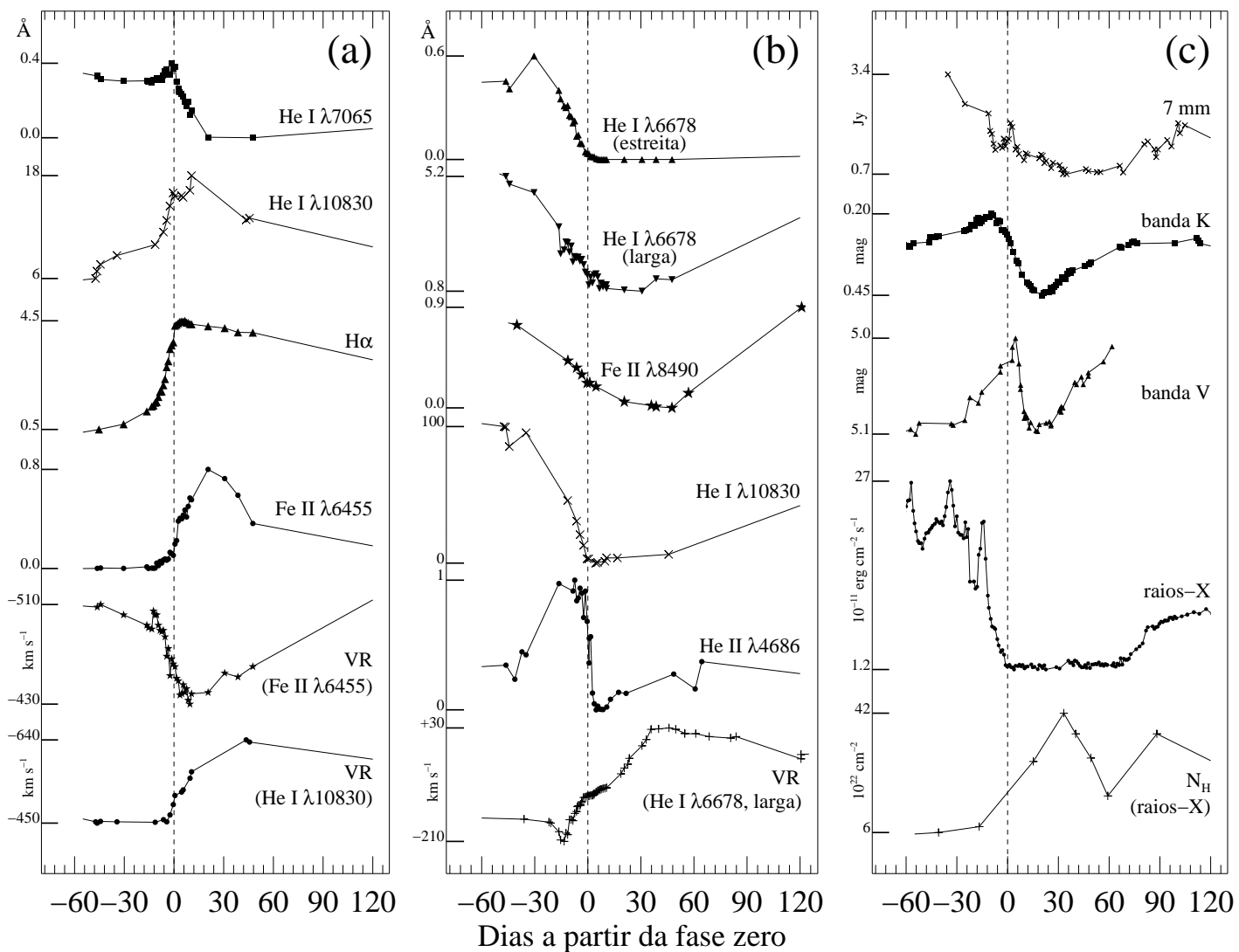

Figura 5.10: Uma visão panorâmica das variações em diversas características espectrais ao longo do espectro eletromagnético. Em (a): largura equivalente (em A) e velocidade radial (VR, em $\mathrm{km} \mathrm{s}^{-1}$ ) da componente em absorção do perfil P Cygni do He I $\lambda 7065$, He I $\lambda 10830, \mathrm{H} \alpha$ e do FeII $\lambda 6455$. Em (b): largura equivalente e velocidade radial das linhas em emissão (componente estreita e larga do He I $\lambda 6678$; Fe II $\lambda 8490$; He I $\lambda 10830$ e He II 74686 ). Em (c): curva de luz em bandas largas (7 mm: Abraham et al. 2005; banda K: Whitelock et al. 2004; banda V: Fernandez Laius et al. 2003; fluxo em raios-X: Corcoran 2005 e densidade colunar: Hamaquchi et al. 200\%).

linhas (He i $\lambda 10830, \mathrm{H} \alpha$ e Fe II $\lambda 6455)$ é baixa antes da fase zero, atinge um máximo logo após a fase zero e mantém uma largura equivalente alta durante um intervalo de tempo relativamente longo.

O comportamento da velocidade radial do centróide da componente em absorção do perfil P Cygni da linha do Fe II $\lambda 6455$ e do He I $\lambda 10830$ estão representados pelas duas curvas na parte de baixo da Fig. 5.10(a). Cerca de 2 meses antes da fase zero, a velocidade da componente em absorção do Fe II desloca-se para velocidades mais negativas, atingindo um mínimo 10 dias antes da fase zero. A amplitude da variação na velocidade desta componente é de aproximadamente $80 \mathrm{~km} \mathrm{~s}^{-1}$ durante o mínimo, o que implica que a maior parte das recombinações passam a ocorrer em regiões mais distantes da estrela. 
A velocidade radial da componente em absorção do He I $\lambda 10830$ comporta-se de maneira semelhante à do He I $\lambda 7065$. Porém, sua largura equivalente varia de maneira semelhante à do Fe II $\lambda 6455$. Isso significa que a componente em absorção do He I $\lambda 10830$ apresenta contribuições de diferentes regiões. A parte central da absorção P Cygni deve ser formada nas regiões mais internas do vento da primária e do cone de choque. Por outro lado, a absorção em altas velocidades é produzida no gás localizado a maiores distâncias. Sendo assim, a largura equivalente da componente em absorção é substancialmente afetada pela absorção nas regiões mais distantes, porém pouco modifica a velocidade radial observada.

A componente estreita em emissão do He i $\lambda 6678$, mostrada na Fig. 5.10(b), comportase de maneira semelhante às linhas proibidas duplamente ionizadas formadas nos glóbulos de Weigelt, ou seja, ela apresenta fases relativamente longas de mínimo e de recuperação. Já a componente larga desta linha, atinge o mínimo mais tarde e uma recuperação mais rápida do que a componente estreita. Uma linha estreita de fluorescência, Fe II $\lambda 8490$, atinge o mínimo muito mais tarde ainda, mas também apresenta as características de uma componente de colapso similar à do He I 26678 . A largura equivalente do complexo que forma a linha do He I $\lambda 10830$ comporta-se de maneira intermediária entre o observado para as componentes estreitas e largas das outras linhas do hélio, indicando que este linha também é composta por componentes estreitas e largas.

A linha do He II $\lambda 4686$ permanece praticamente ausente do espectro durante a maior parte do ciclo de 5.54 anos (Steiner \& Damineli, 2004). Sua largura equivalente aumenta rapidamente cerca de 1 mês antes da fase zero e, depois disso, diminui, também rapidamente, até desaparecer quase completamente. O mesmo comportamento foi reportado por Stahl et al. (2005) no espectro refletido no lóbulo SE do Homúnculo, na região conhecida como FOS4 (a cerca de 2.6 arcsec ao sul e 2.8 arcsec ao leste da fonte central). Neste ponto, o espectro refletido é produzido em altas latitudes estelares. Portanto, o desaparecimento quase simultâneo desta linha no espectro em diferentes latitudes estelares implica que esta linha não deve ser produzida pela excitação nas partes mais internas do vento da secundária, mas, em vez disso, deve estar relacionada à região de colisão dos ventos, 


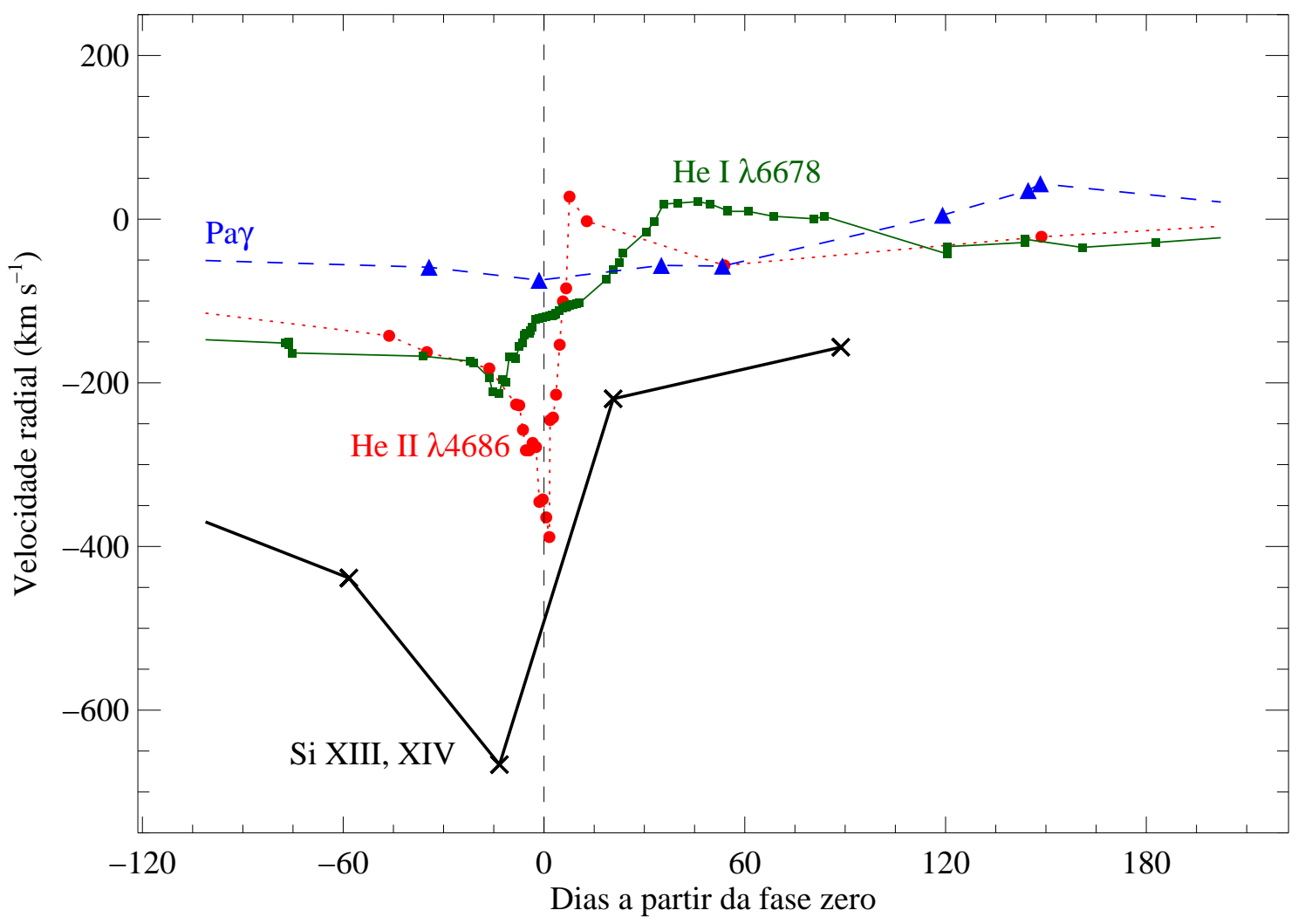

Figura 5.11: Velocidade radial das componentes largas das linhas indicadas, próximo à fase zero. O perfil indicado para a linha do Si XIII XIV é uma média dos valores reportados por Henleu et al. (2008).

que é fortemente afetada durante a passagem pelo periastro.

Na parte inferior da Fig. [5.10(b) são mostradas as medidas da velocidade radial da componente larga em emissão da linha do He i $\lambda 6678$. Nota-se que o mínimo $\left(-210 \mathrm{~km} \mathrm{~s}^{-1}\right)$ ocorre cerca de 2 semanas antes da fase zero e o máximo $\left(+30 \mathrm{~km} \mathrm{~s}^{-1}\right)$ coincide com o meio do intervalo de mínimo em raios-X (cerca de 30 dias após a fase zero). Depois disso, a velocidade desta linha apresenta um leve declínio ao longo do resto do ciclo de 5.5 anos.

A Fig. [5.10(c) mostra as curvas de luz em diferentes faixas espectrais, desde o rádio até a o fluxo em raios-X, e as variações na densidade colunar. A curva de luz em rádio, na faixa de $7 \mathrm{~mm}$, tem um formato entre aquela observada em comprimentos de onda maiores $(3 \mathrm{~cm})$, que varia lentamente ao longo de todo o ciclo, e a curva de luz em raios-X, que apresenta uma queda brusca perto da fase zero.

A curva de luz na banda $K$ foi extraída de Whitelock et al. (2004) e a da banda $V$, 
de Fernandez Lajus et al. (2003). O centro do mínimo em ambas as bandas ocorre aproximadamente 2 semanas antes do mínimo em raios-X. Além disso, a duração do mínimo nas duas bandas fotométricas é a mais curta dentre todas as características observadas.

Corcoran (2005) reportou o comportamento do fluxo de raios-X e a variação na densidade colunar, $N_{H}$, durante o mínimo e os resultados estão mostrados nas últimas duas curvas da Fig. 5.10(c). A densidade colunar varia de maneira muito similar à componente em absorção da linha do Fe II $\lambda 6455$. É importante notar que ambas atingem o valor máximo durante a metade do intervalo de tempo do mínimo em raios-X. Há um pico secundário na densidade colunar, porém não foi confirmado se trata-se de um pico real ou uma medida incorreta. Hamaguchi et al. (2007) mostraram que a temperatura da região de colisão dos ventos permanece constante durante o mínimo, em contraste ao esperado se esta região resfriasse e colapsasse. Entretanto, Corcoran (2005) e Hamaguchi et al. (2007) mostraram que ocorre uma diminuição substancial na medida de emissão durante o mínimo, o que significa que quase todo o cone de choque deve estar atrás de uma região opticamente espessa. Além disso, existem indicações, a partir do estudo do perfil das linhas na faixa dos raios-X, de que devem ocorrer significativas mudanças nas condições físicas da região de colisão dos ventos. Uma possibilidade é que sua abertura diminua durante a passagem pelo periastro, de maneira que a emissão em raios-X escape somente em determinadas direções. Portanto, a curva de luz em raios-X deve ser modulada tanto por fatores intrínsecos quanto extrínsecos (geométricos).

A Fig. 5.11 mostra o comportamento da velocidade radial nas linhas do Si XII, XIV (na

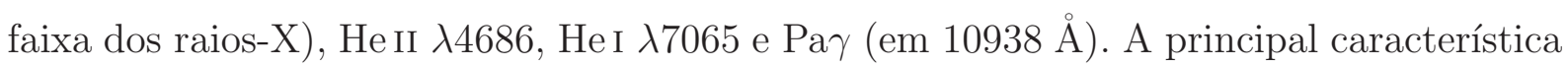
a ser notada naquela figura é que as maiores velocidades negativas são observadas nas faixas (ou transições) mais energéticas, de maneira que as linhas na faixa dos raios-X apresentam $-700 \mathrm{~km} \mathrm{~s}^{-1}$ (Henlev et al., 2008), a linha do He II $\lambda 4686$ tem $-400 \mathrm{~km} \mathrm{~s}^{-1}$, a do He I $\lambda 6678,-200 \mathrm{~km} \mathrm{~s}^{-1}$ e Pa $\gamma,-80 \mathrm{~km} \mathrm{~s}^{-1}$. Apesar das variações observadas serem devido à binaridade. no entanto. elas não acompanham o movimento orbital. Henley et al. (2008) conseguiram modelar os perfis das linhas espectrais na faixa dos raios-X, considerando que elas sejam formadas na região de colisão dos ventos. Por outro lado, 
acredita-se que a linha do He II $\lambda 4686$, por exemplo, seja formada próxima à região de emissão em raios-X (Steiner \& Damineli, 2004; Martin et al., 2006), porém em uma região mais fria, o que significa que ela deve ser formada longe do ápex do cone de choque. Como a velocidade do material escoando ao longo do cone de choque deve aumentar com a distância do ápex, as linhas de menor excitação deveriam apresentar velocidades maiores, ao contrário do que é observado. Uma possível alternativa é que, a grandes distâncias do ápex, o cone de choque transforme-se em uma estrutura dominado por células turbulentas, causadas por instabilidades Kelvin-Helmholtz. Porém, este assunto só pode ser abordado através de simulações numéricas 3D do choque entre os ventos. 


\section{Capítulo 6}

\section{A linha do He II $\lambda 4686$}

\subsection{Detecção no espectro de $\eta$ Carinae}

Esta linha, em emissão, é formada pela transição de um elétron no nível $n=4$ para $n=3$ do íon $\mathrm{He}^{+}$e requer fótons com $h \nu \geqslant 24.6 \mathrm{eV}$. Portanto, para se obter esta linha espectral em emissão, é necessária uma fonte com energia suficiente para produzir grandes quantidades de fótons com a energia requerida para a transição desta linha. No entanto, nenhuma estrela isolada é capaz de realizar tal tarefa, nem mesmo as de tipo espectral mais quentes já observadas.

A alternativa para explicar a detecção desta linha em algumas estrelas quentes é que tais objetos devem ser formados por um sistema binário massivo, onde o choque entre os dois ventos estelares criaria uma região de alta densidade e temperatura, onde é possível produzir fótons com energia na faixa dos raios-X. Tais sistemas são denominados sistema binários com colisão de ventos (Usov, 1992).

Reportada pela primeira vez por Steiner \& Damineli (2004), a detecção da linha do He II $\lambda 4686$ em emissão no espectro de $\eta$ Car é uma das principais evidências a favor do modelo de sistema binário com colisão de ventos. Esta linha foi detectada em $\eta$ Car em espectros obtidos com telescópios em terra durante os eventos de 1992.5, 1998.0 e 2003.5, porém, somente neste último evento foi observado também em dados obtidos com o HST.

Durante a fase de alta excitação, o espectro apresenta pouca ou nenhuma emissão desta linha. Ao longo do ciclo, a largura equivalente vai aumentando gradualmente até 
atingir um máximo de cerca de $2.5 \AA$ A antes do evento espectroscópico. Neste ponto, a velocidade do pico da linha é de aproximadamente $-450 \mathrm{~km} \mathrm{~s}^{-1}$, cerca de 3 vezes maior do que aquela observada no início do evento, que era de aproximadamente $-150 \mathrm{~km} \mathrm{~s}^{-1}$. Logo em seguida, a largura equivalente desta linha diminui a uma taxa correspondente a aproximadamente $10 \mathrm{~L}_{\odot}$ (após fazer as devidas correções de extinção discutidas na seção 6.4) até desaparecer completamente.

Comparando o espectro obtido na direção da fonte central (latitude $\approx 45^{\circ}$ ) com o observado na região conhecida como FOS4, localizada a aproximadamente 4 arcsec SE da fonte central, e que reflete o espectro da região polar da fonte central, Stahl et al. (2005) mostraram que a largura equivalente da linha do He II $\lambda 4686$ durante um evento depende da latitude estelar, sendo significativamente menor (por um fator 5) na direção polar do em latitudes mais próximas ao equador. Além disso, mesmo após a correção do intervalo de tempo de cerca de 20 dias entre a visão direta e a refletida no FOS4, o espectro polar apresenta uma defasagem de cerca de 10 dias em relação ao observado diretamente na fonte central, ou seja, o que é visto na direção desta sé é visto no FOS4 10 dias depois.

A determinação da largura equivalente da linha do He II $\lambda 4686$ é um procedimento extremamente delicado devido ao fato de que esta região espectral é povoada de linhas e, consequentemente, a determinação de um contínuo para normalização torna-se uma tarefa difícil. As primeiras medidas da largura equivalente desta linha foram feitas integrandose a intensidade da linha em relação ao contínuo adjacente, o que resultou em um valor menor do que o real. Isto porque, próximo ao evento, o contínuo adjacente à linha também aumenta e, quando comparado com o espectro da fase de alta excitação, a diferença chega a $1.5 \AA$ (Martin et al., 2006).

Entretanto, a comparação direta de espectros do HST da fase de alta e baixa excitação mostrou que existem duas regiões próximas da linha do He II $\lambda 4686$ que podem ser utilizadas como o contínuo local para ela Martin et al. (2006). A região do contínuo azul fica aproximadamente em $4605 \AA$, e a vermelha, em $4740 \AA$.

Outro ponto crucial na medida da largura equivalente para esta linha é a região de integração do fluxo. Isso se deve ao fato de existirem muitos blends de linhas, como 
Fe II $\lambda 4670$ ou [FeIII] $\lambda 4700$, que podem, eventualmente, contaminar as medidas. Da mesma maneira descrita anteriormente, a comparação entre os espectros na fase de alta e baixa excitação ajudaram a escolher uma região relativamente livre de contaminação. Este procedimento mostrou que a faixa espectral de 4675 a $4695 \AA$ é a mais indicada para ser integrada utilizando o contínuo discutido anteriormente.

\subsection{Comparação da largura equivalente nos últimos 4 eventos}

A melhor cobertura temporal já realizada no óptico foi obtida ao longo do evento de 2009.0. À parte alguns espectros tomados no começo do mês de Dezembro de 2008, durante a segunda quinzena daquele mês em diante, foram tomados espectros com o Goodman/SOAR quase diariamente. Todos estes espectros foram reduzidos utilizando o pacote de redução para dados do Goodman discutido anteriormente, no Capítulo 2 , Após a realização de alguns testes, ficou evidente a necessidade de que todos os dados dos eventos passados fossem medidos (quando possível) da mesma maneira que os do evento de 2009.0.

A Fig. 6.1 mostra o comportamento da largura equivalente ao longo dos 4 últimos eventos: 1992.4, 1998.0, 2003.5 e 2009.0, utilizando o período de 2022.7 dias, determinado

por Damineli et al. (2008). As medidas foram obtidas com dados de diferentes épocas, de diferentes telescópios e diferentes arranjos instrumentais, mas a concordância entre as medidas ilustra a importância da homogeneidade do método de redução e nas medições.

O monitoramento mais denso foi feito, conforme dito anteriormente, no telescópio SOAR. Os dados indicam que antes do mínimo ocorreram dois máximos locais na largura equivalente do He II $\lambda 4686$. O primeiro ocorreu a aproximadamente 30 dias antes do mínimo e o segundo, 5 dias antes. Este último pico já era esperado, uma vez que ele já foi observado no evento de 2003.5.

O máximo local na largura equivalente do He II $\lambda 4686$ que ocorre 30 dias antes do mínimo parece ser corroborado por observações do evento de 1998.0, obtidas por Peter J. 


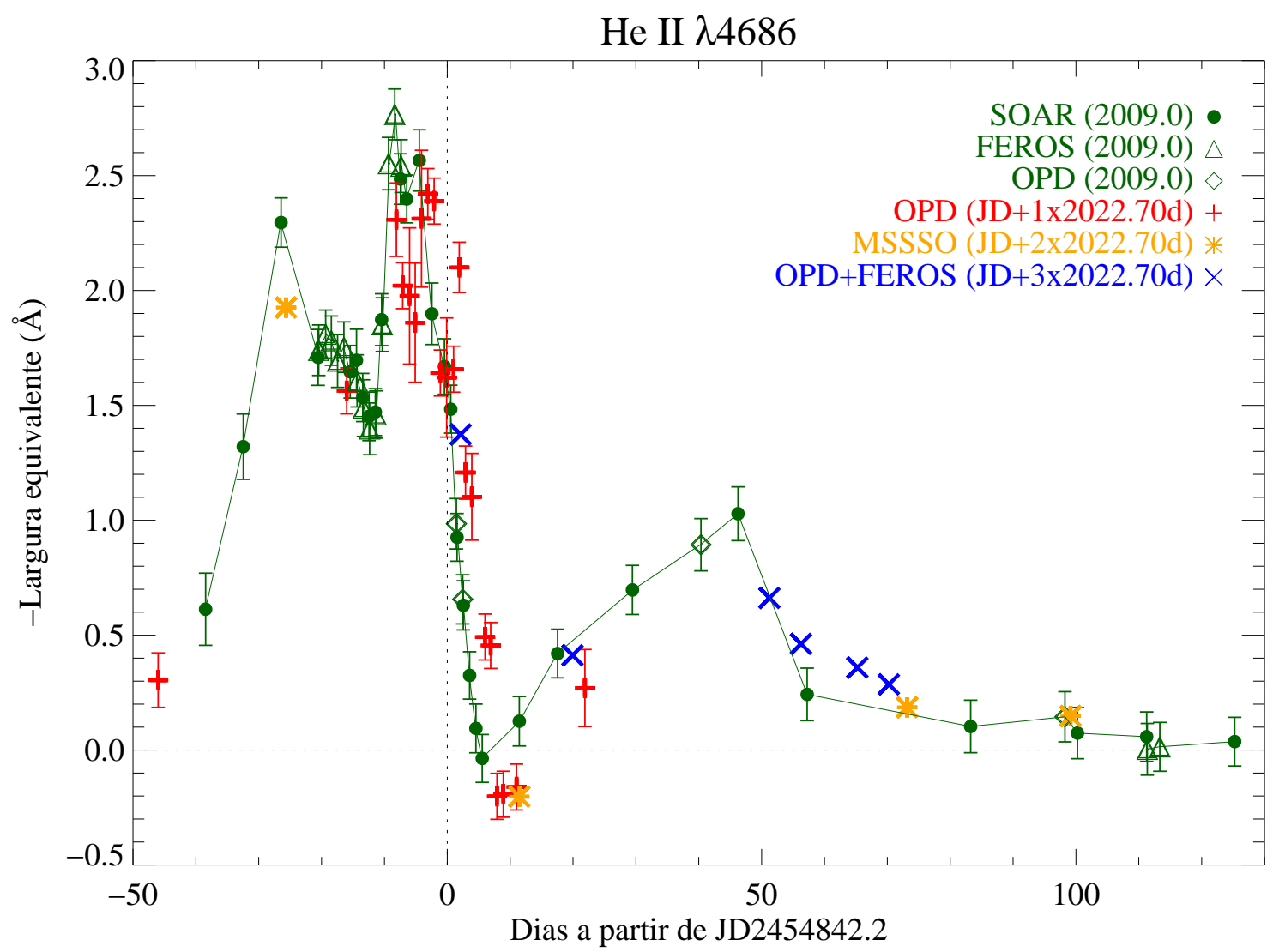

Figura 6.1: Variação da largura equivalente do He II $\lambda 4686$ durante os eventos de 1992.4 (azul), 1998.0 (amarelo), 2003.5 (vermelho) e 2009.0 (verde). A linha contínua verde conecta os pontos referentes às medidas do LNA, SOAR e FEROS e serve apenas como guia temporal. Os dados dos eventos anteriores foram deslocados de 2022.7 dias.

McGregor, utilizando espectrógrafo échelle do MSSSO (McGregor et al., 1999). Apesar destes espectros apresentarem uma baixa relação sinal/ruído $(\sim 30)$, a normalização dos espectros, seguindo a mesma metodologia para os outros espectros, resulta em uma boa concordância com os dados do SOAR e do LNA para o evento de 2009.0.

Os dados do FEROS para o monitoramento de 2009.0 também são coerentes com os dados obtidos pelo SOAR. No entanto, o monitoramento foi realizado somente entre 20 e 5 dias antes do mínimo. Mesmo com pouca cobertura temporal, estes dados foram cruciais para confirmar a parte da queda do primeiro pico (entre 20 e 10 dias antes do mínimo) e a subida para o segundo pico na largura equivalente do HeII $\lambda 4686$ (entre 10 e 5 dias antes do mínimo).

Os dados do UVES para o monitoramento do evento de 2003.5, obtidos por Theodore Gull, apresentam um contínuo extremamente irregular na região de $4686 \AA$ e, por isso, 


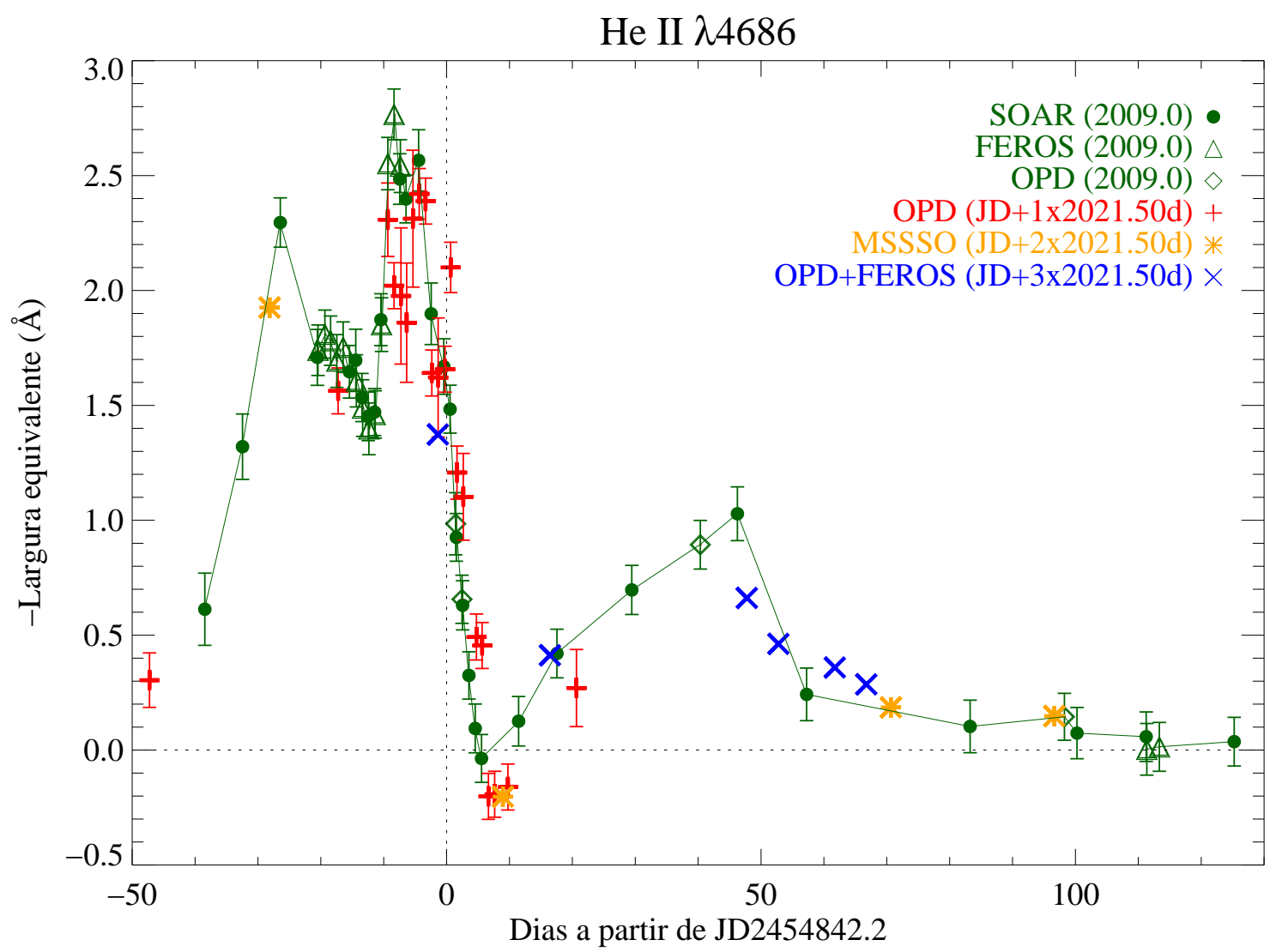

Figura 6.2: Determinação do período dos eventos de $\eta$ Car utilizando a linha do He II 4686. Os dados foram deslocados por 2021.5 dias. Note que, com este período, existe uma maior compatibilidade entre as medidas de 2003.5 e 2009.5 (monitoramentos mais densos).

não foram utilizados nesta tese. No entanto, os dados do LNA fornecem uma boa base de comparação para a parte central do evento (entre 10 antes e 20 dias depois do mínimo). Além disso, existem algumas poucas medidas tomadas alguns meses antes e depois do evento.

Analisando somente os dados de 2003.5 e de 2009.0, que são os monitoramentos mais densos temporalmente, eles são mais compatíveis entre si (considerando os erros) quando deslocados utilizando um período de 2021.5 dias e, aplicando este período a todos os dados, incluindo os dos últimos 4 eventos, é possível verificar que existe uma coerência maior do que com o período determinado por Damineli et al. (2008), conforme ilustrado na Fig. 6.2

Outro fato surpreendente que não havia sido notado nos eventos anteriores, provavelmente por falta de monitoramento adequado, é a recuperação da linha do He II $\lambda 4686$ logo 
após a fase zero. Esta linha é detectada levemente em absorção cerca de 3 a 4 dias após o mínimo e permanece assim durante os próximos 10 dias, recuperando-se rapidamente em seguida até atingir um máximo de aproximadamente $1.1 \AA$, cerca de 45 dias depois do mínimo. A partir daí, a largura equivalente desta linha volta a diminuir rapidamente, até atingir $\sim 0.1 \AA$.

Não existem muitas observações entre 15 e 50 dias após o mínimo nos eventos passados. Das observações do FEROS, de 1992, apenas um ponto parece dar suporte à existência de um pico na largura equivalente após o mínimo. Entretanto, a incerteza na medida é muito grande, da ordem de $0.4 \AA$, devido às deformações que aparecem na região de $4686 \AA$ nos espectros do FEROS desta época.

\subsection{A largura equivalente do He II $\lambda 4686$ e o fluxo em raios-X}

É interessante comparar a curva de luz da largura equivalente do He II 4686 com a de raios-X, conforme ilustrado na Fig. 6.3, Os dados em raios-X foram extraídos dos gráficos disponíveis na página de Mike Corcoran 1 , utilizando a equação para efemérides fornecida pelo mesmo: $2448776+2024 \times \phi$. Esta equação foi utilizada para recuperar o dia Juliano e compará-lo diretamente com a curva de luz do He II $\lambda 4686$.

Os gráficos superiores da Fig.6.3 apresentam a curva de luz em raios-X e de He II $\lambda 4686$ observada. Os dois picos que ocorrem antes do mínimo em raios-X parecem ter uma contrapartida na curva de luz do He II $\lambda 4686$, conforme mostrado nos gráficos inferiores da Fig. 6.3, onde as curvas de luz em raios-X para o evento de 2003.5 e 2009.0 foram adiantadas em 16.5 dias.

A recuperação da largura equivalente do He II $\lambda 4686$ parece ser bem diferente da observada para os raios-X. Os dados históricos dos eventos anteriores indicam que o He II $\lambda 4686$ apresenta um pico na largura equivalente cerca de 45 dias após a fase zero, que só foi observada em detalhes no monitoramento de 2009.0. O mesmo nunca foi observado em raios-X,

\footnotetext{
${ }^{1}$ http://asd.gsfc.nasa.gov/Michael.Corcoran/eta_car/etacar_rxte_lightcurve/index.html
} 

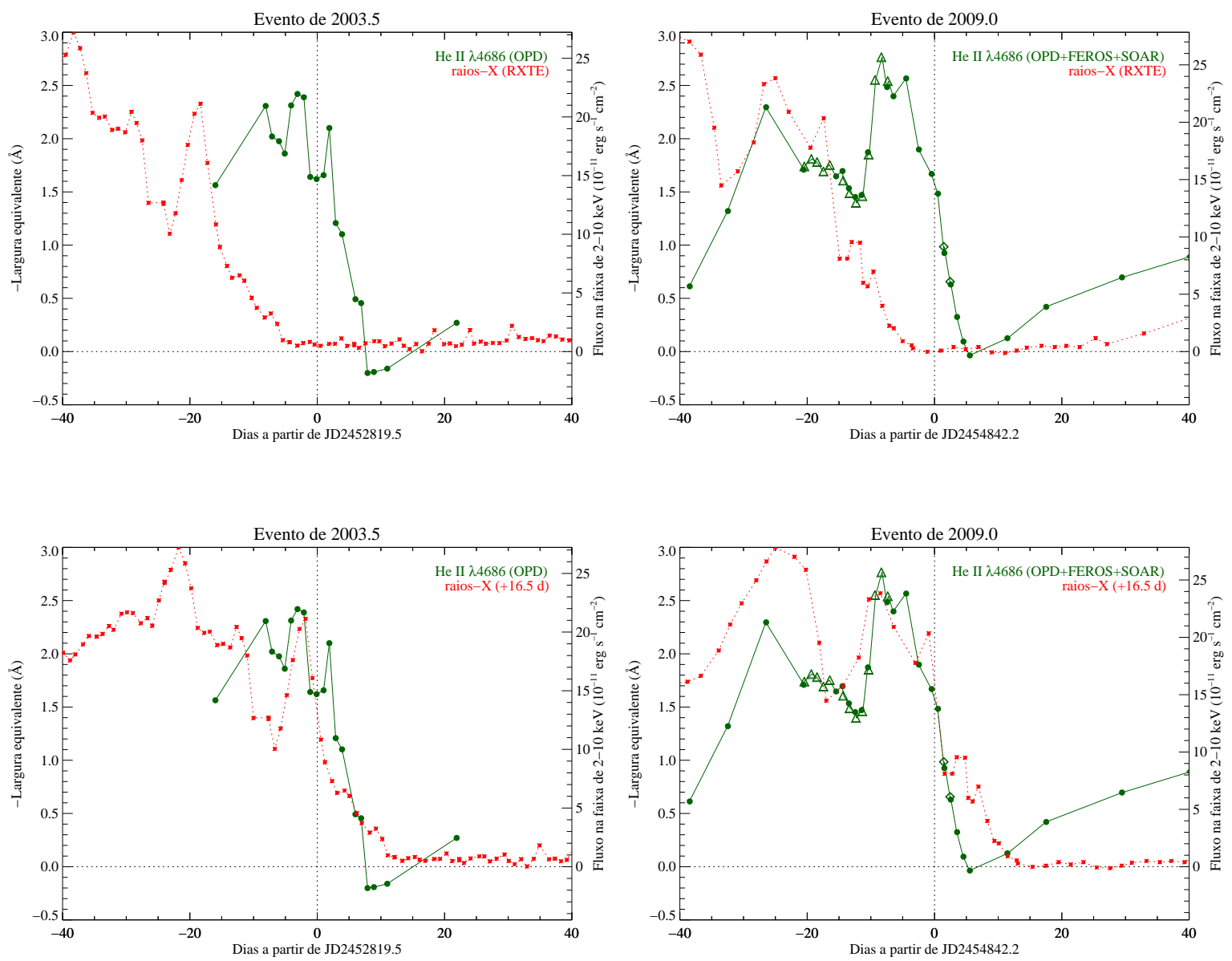

Figura 6.3: Comparação entre largura equivalente do He II $\lambda 4686$ (obtidos com o LNA, FEROS e SOAR) e o fluxo em raios-X (obtidos com o RXTE; Corcoran 2009). Os painéis à esquerda mostram a curva de luz para o evento de 2003.5 e os à direita, para o de 2009.0. Os dois painéis superiores mostram as curvas observadas, sem deslocamento algum, enquanto os inferiores, mostram as curvas de raios- $X$ deslocadas de 16.5 dias em relação ao He II $\lambda 4686$. Note como os picos se correlacionam depois de aplicar o deslocamento.

que sempre apresentou (pelo menos nos eventos de 1998.0 e 2003.5) uma fase longa $(\sim 70$ dias) de baixo fluxo.

A fase de recuperação do He II $\lambda 4686$ é bem rápida, 10 dias após o mínimo (para ambos os eventos de 2003.5 e 2009.0), enquanto o fluxo em raios-X começa a se recuperar somente depois de 70-80 dias depois do mínimo de 2003.5 e depois de 30-40 dias para o evento de 2009.0 (saída antecipada em relação aos eventos de 1998.0 e 2003.5). Quando aplicado o adiantamento de 16.5 dias na curva de luz em raios-X, de modo a correlacionar os picos pré-mínimos, a discrepância fica maior ainda, e o pico em He II definitivamente não apresenta nenhum correspondente em raios-X. 


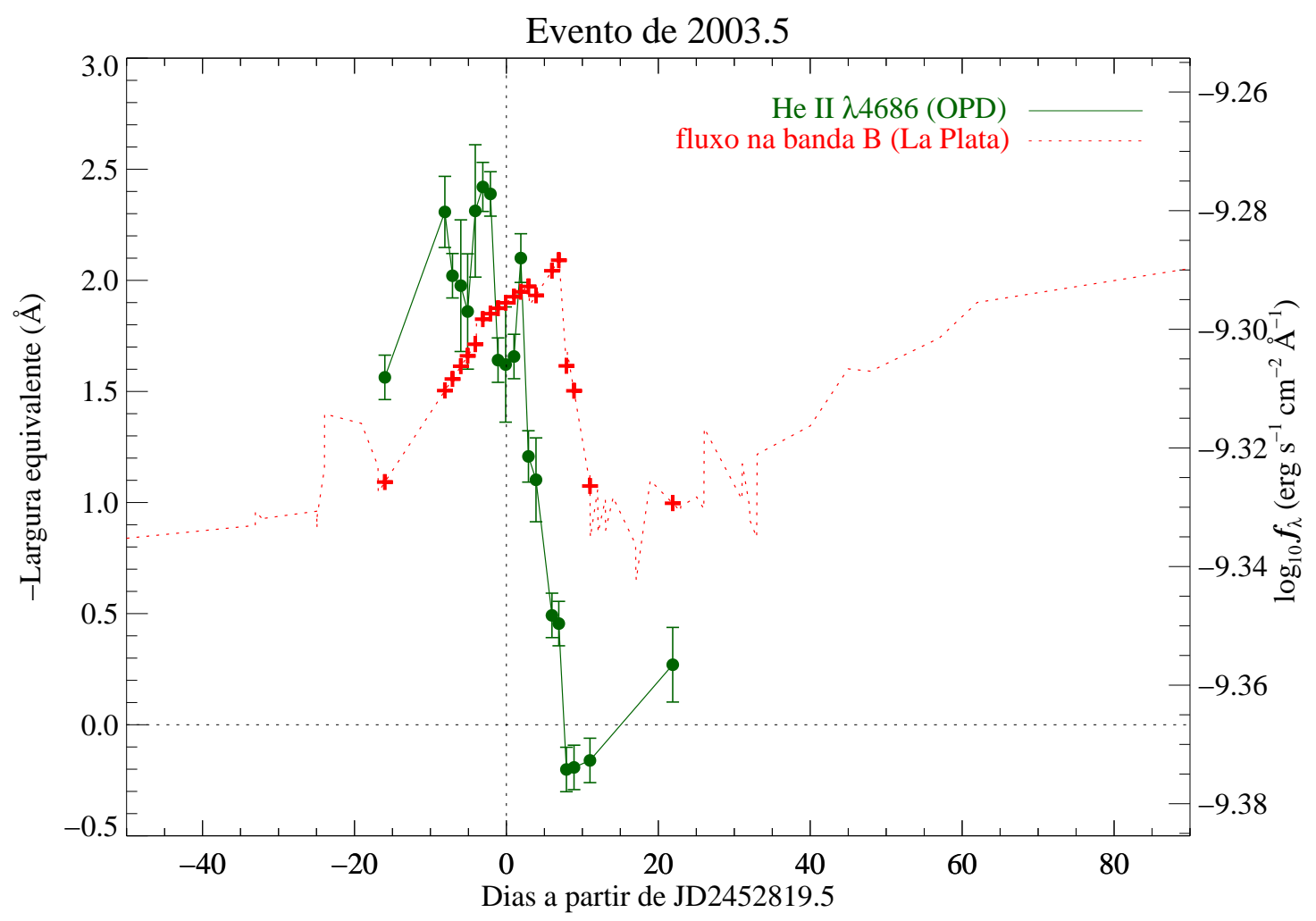

Figura 6.4: Correção da largura equivalente observada do He II $\lambda 4686$ (círculos verdes) pelo fluxo do contínuo da fonte central (linha tracejada vermelha), ambos para o evento de 2003.5 .

Este comportamento aparentemente correlacionado entre os picos pré-mínimo do He II e dos raios-X e a discrepância entre a recuperação dos mesmos pode ser explicada considerandose que eles tenham naturezas distintas e não sejam formados no mesmo processo.

\subsection{A luminosidade observada do He II $\lambda 4686$}

A Fig.6.4 e a Fig.6.5 mostram, respectivamente, a largura equivalente do He II observada para o evento de 2003.5 e 2009.0, juntamente com a fotometria para os mesmos períodos. Os dados fotométricos foram obtidos a partir das observações do grupo de La Plata utilizando uma abertura com 22 arcsec de raio que inclui toda a nebulosa do Homúnculo. Portanto, existe uma contribuição significativa de luz refletida no Homúnculo que deve ser considerada. De fato, utilizando uma abertura menor, de aproximadamente 5 arcsec, Fernando Lajús determinou que tal contribuição era de cerca de 1.16 magnitudes na banda $B$ e, portanto, este valor deve ser somado aos resultados da curva de luz do grupo de La 
Plata na banda $B$ para obter somente o fluxo da fonte central.

Com estes dados, foi possível obter o fluxo absoluto na banda $B$ e utilizá-lo para obter a luminosidade observada do He II $\lambda 4686$, conforme descrito a seguir.

A magnitude observada em um comprimento de onda qualquer, $\lambda$, é dada por

$$
m_{\lambda}=-2.5 \times \log \left(f_{\lambda}\right)+C
$$

onde $f_{\lambda}$ é o fluxo observado naquele comprimento de onda e $C$, uma constante do sistema fotométrico. Portanto, para as observações de $\eta$ Car na banda $B$, tem-se o seguinte:

$$
B^{\eta}-B^{\mathrm{pad}}=2.5 \times \log \left(\frac{f_{B}^{\mathrm{pad}}}{f_{B}^{\eta}}\right)
$$

onde o índice $\eta$ e pad referem-se, respectivamente, à $\eta$ Car e a uma estrela padrão qualquer. Como as observações são feitas no mesmo sistema fotométrico, as constantes se anulam.

Naturalmente, adota-se o fluxo de uma padrão que apresente magnitude zero em todas as bandas, de maneira que a Eq. 6.2 reduz-se ao seguinte:

$$
B^{\eta}=2.5 \times \log \left(\frac{f_{B}^{\mathrm{pad}}}{f_{B}^{\eta}}\right)
$$

onde o valor de $f_{B}^{\text {pad }}$ é muito bem conhecido, sendo 4260 Jy na banda em questão. Sendo assim, o fluxo de $\eta$ Car na banda $B$ pode ser conhecido através da seguinte relação:

$$
f_{B}^{\eta}=f_{B}^{\mathrm{pad}} \times 10^{-0.4 B^{\eta}}
$$

Para fins práticos, adota-se o valor de $f_{B}^{\text {pad }}$ em unidades de $\operatorname{erg} \mathrm{s}^{-1} \mathrm{~cm}^{-2} \AA^{-1}$, em vez de Jy. Por isso, a Eq. 6.4 passa a ter a seguinte forma:

$$
f_{B}^{\eta}=\left(\frac{4260 \mathrm{Jy}}{\lambda^{2} c}\right) \times 10^{-0.4 B^{\eta}}\left(\operatorname{erg~s}^{-1} \mathrm{~cm}^{-2} \AA^{-1}\right),
$$

onde $\lambda$ está em $\AA$ e $c$ (velocidade da luz) está em $\mathrm{km} \mathrm{s}^{-1}$. Substituindo-se os valores, 


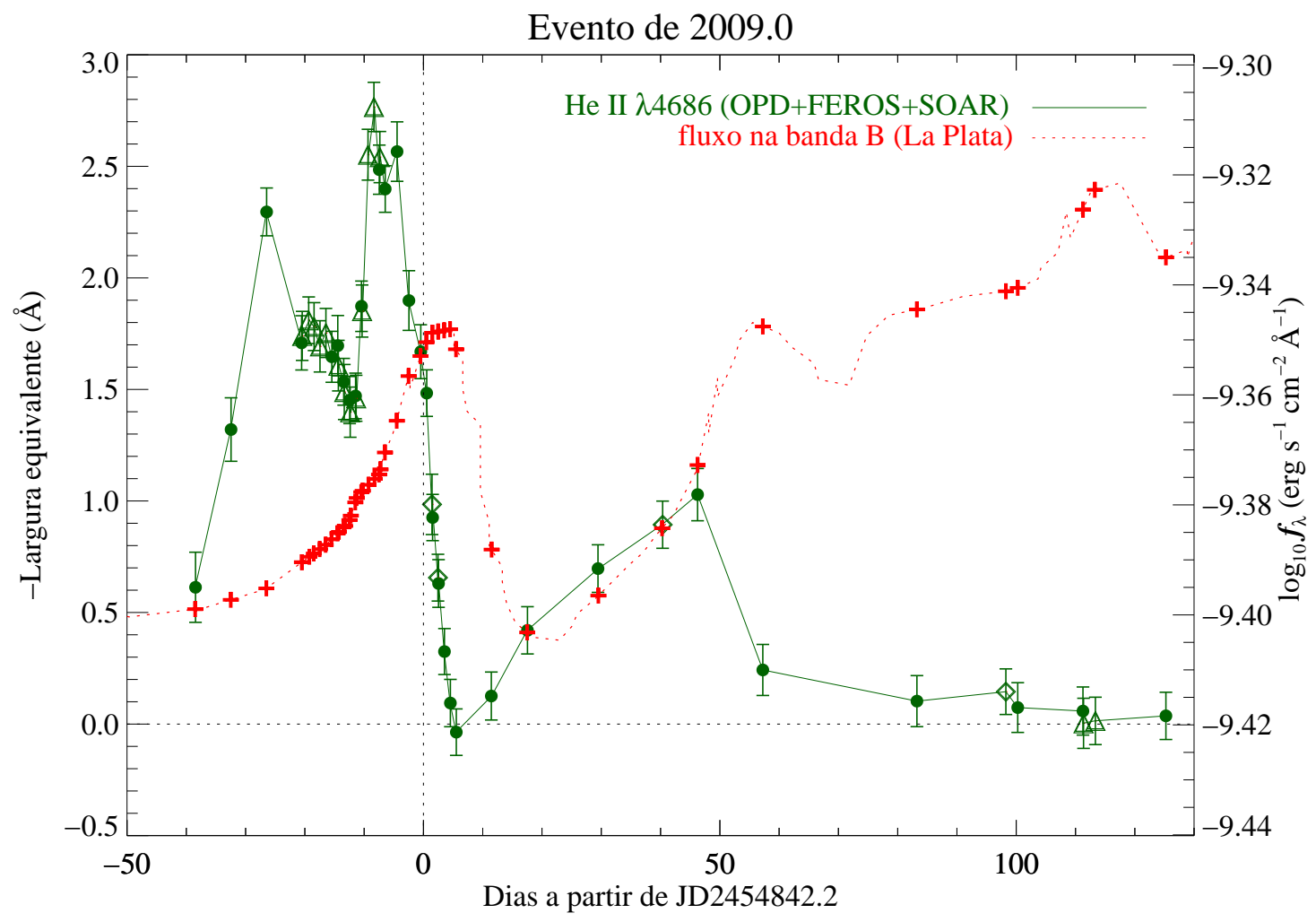

Figura 6.5: O mesmo que na Fig6.4 mas para o evento de 2009.0.

tem-se o seguinte:

$$
f_{B}^{\eta}=7.3 \times 10^{-10} \times 10^{-0.4 B^{\eta}}\left(\operatorname{erg~s}^{-1} \mathrm{~cm}^{-2} \AA^{-1}\right),
$$

É importante ressaltar que $f_{B}^{\eta}$ é o fluxo observado, ou seja, o fluxo não corrigido pela extinção total na direção da fonte central. Portanto, conhecendo o valor de $f_{B}^{\eta}$ para cada dia do monitoramento espectroscópico, é possível calcular o valor do fluxo corrigido pela extinção total, $f_{\lambda}$, através da seguinte equação:

$$
f_{\lambda}=f_{\lambda}^{\eta} \times 10^{0.4 A_{\lambda}}
$$

onde $A_{\lambda}$ é o valor da extinção total - interestelar e circunstelar - na direção da fonte central, no comprimento de onda $\lambda$. Este é um parâmetro muito difícil de ser estimado e não pode ser considerado constante para os eventos de 2003.5 e 2009.0, devido ao fato de $\eta$ Car apresentar taxas de aumento do brilho variáveis, tanto do Homúnculo quanto da fonte central. Além disso, é sabido que na direção das estrelas próximas de $\eta$ Car, a lei 


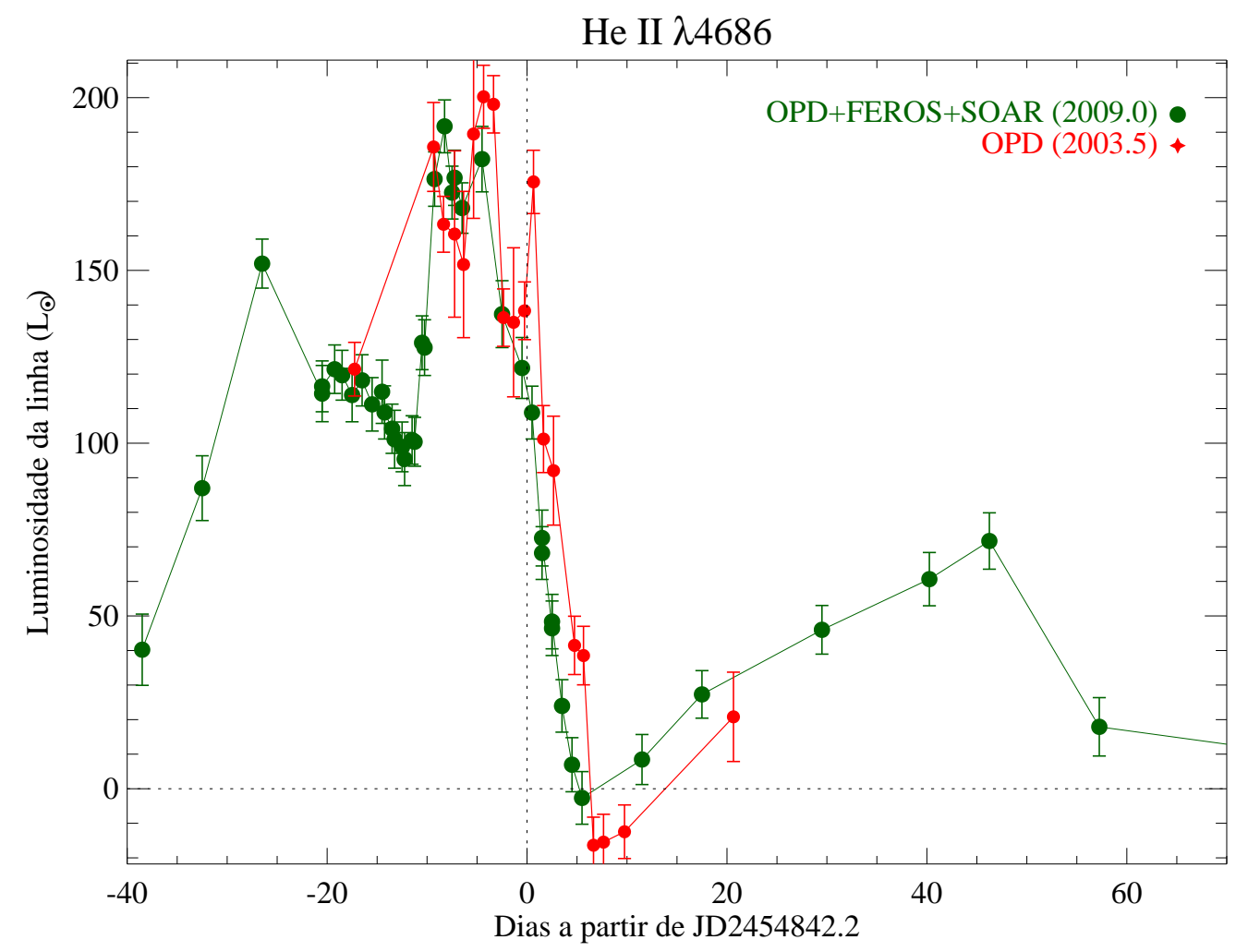

Figura 6.6: Luminosidade da linha do He II $\lambda 4686$ durante o evento de 2003.5 (círculos vermelhos) e 2009.0 (círculos verdes).

de extinção é muito diferente do valor médio observado no meio interestelar.

As estimativas de $A_{\lambda}$ feitas nesta tese foram baseadas, essencialmente, em dois trabalhos: Hillier et al. (2001), que modelou o espectro da fonte central obtido pelo HST em 1998, e no estudo detalhado feito por van Genderen et al. (2006) sobre o aumento do brilho de $\eta$ Car ao longo dos últimos 50 anos, com observações obtidas desde 1952 até 2005. Ambos os estudos chegaram à conclusão de que existe cerca de 2 magnitudes de extinção cinza, causada por grãos com dimensões maiores do que aqueles encontrados no Homúnculo e no meio interestelar. Esta componente cinza é associada ao meio circunstelar próximo à fonte central, onde podem ser formadas aglomerações (clumps) com altas densidades (e.g. glóbulos de Weigelt).

Os detalhes da dedução do valor de $A_{\lambda}$, com $\lambda=4686$, para cada evento estão no Apêndice A] Os resultados são: $A_{4686}=6.5$ e 6.1 para o evento de 2003.5 e 2009.0, respectivamente, assumindo uma lei de extinção com $R_{V}=4.9$ e $E(B-V)=1.0$. Utilizando estes valores, o resultado está apresentado na Fig.6.6. onde nota-se que, em 


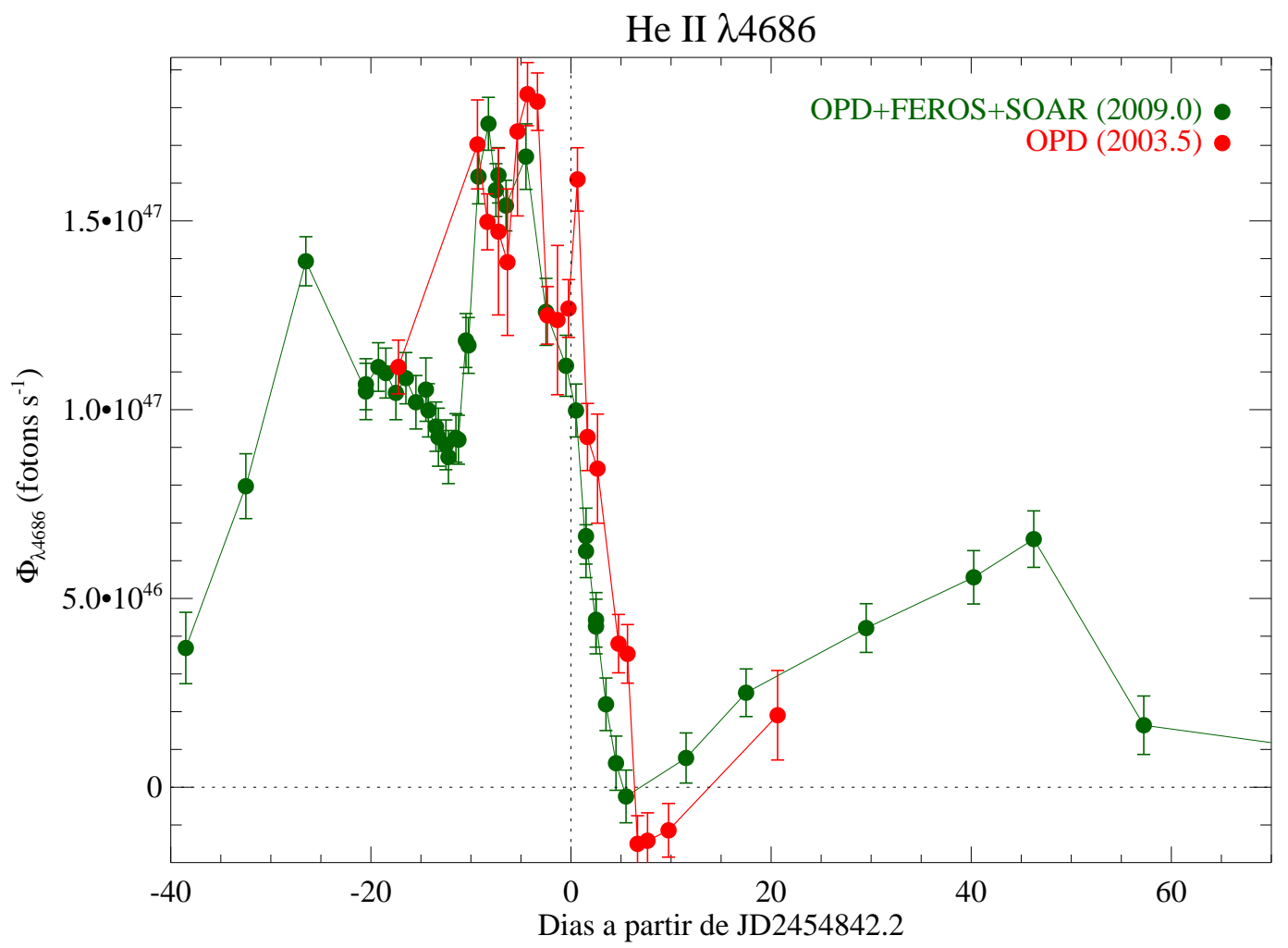

Figura 6.7: Número de fótons por segundo na linha do He II $\lambda 4686$ durante o evento de 2003.5 (círculos vermelhos) e 2009.0 (círculos verdes).

ambos os eventos, tanto o perfil quanto a luminosidade da linha do He II 4686 mantiveramse essencialmente os mesmos.

Na Fig.6.7 é mostrado o fluxo de fótons na linha do He II $\lambda 4686$ correspondente à luminosidade observada para cada evento. Este é um resultado robusto e puramente observacional, baseado essencialmente nas medidas da largura equivalente e na fotometria. As únicas considerações feitas sem determinação observacional direta dizem respeito à extinção total na linha de visada da fonte central. Porém, até mesmo este parâmetro foi razoavelmente bem determinado por outros autores (e.g. Hillier et al.|2001: van Genderen et al. 2006) utilizando diferentes técnicas observacionais e teóricas. Portanto, qualquer modelo físico teórico para o sistema $\eta$ Car tem que ser capaz de reproduzir, entre outras coisas, o resultado mostrado na Fig.6.7 

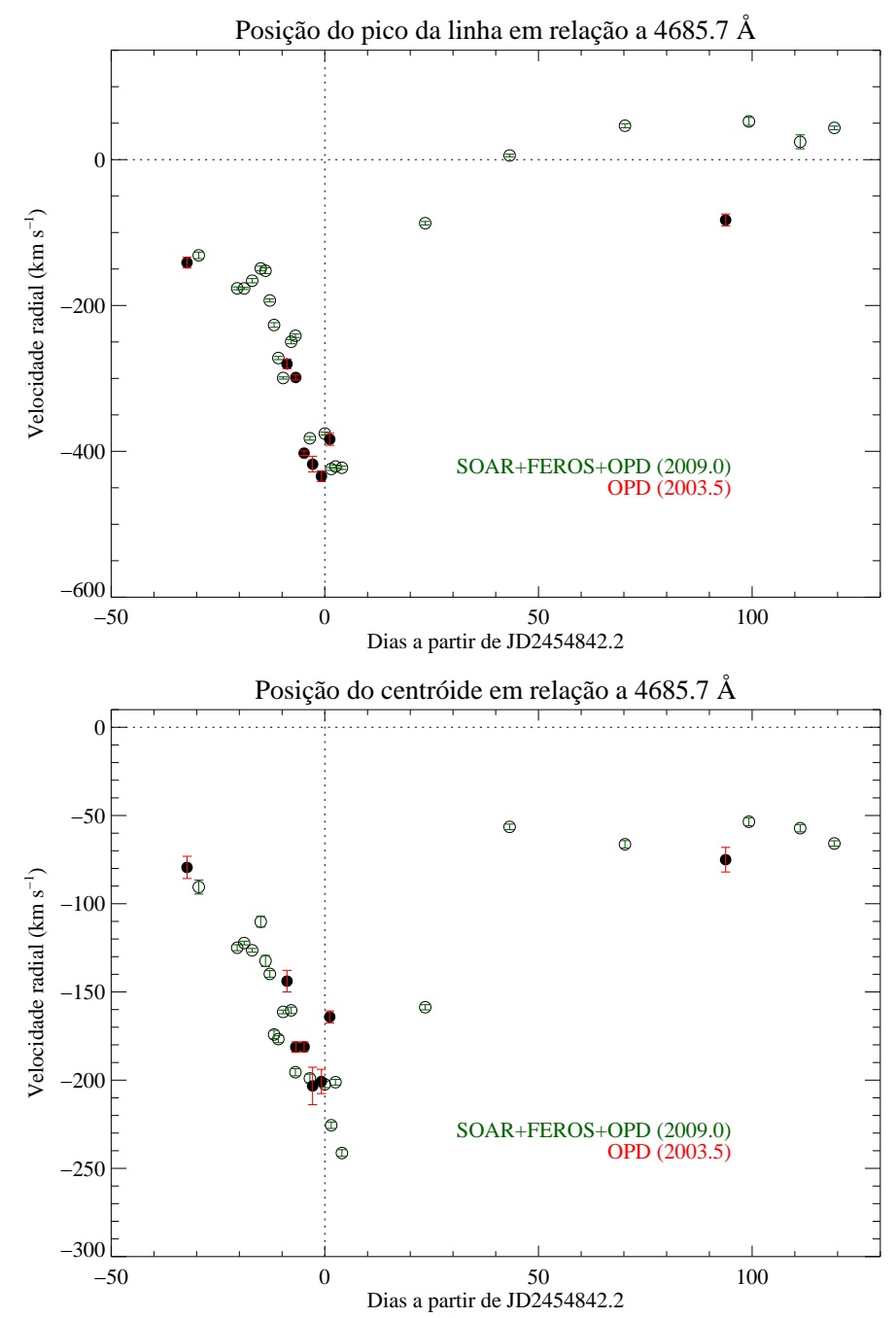

Figura 6.8: Comportamento da velocidade radial observada na linha do He II $\lambda 4686$. O painel superior mostra a velocidade do pico da linha e o painel inferior, a do baricentro.

\subsection{Cinemática}

Os perfis de velocidade do pico e do centróide da linha do He II 4686 durante o evento de 2003.5 e 2009.0 estão mostrados na Fig.6.8, onde não são mostradas as medidas durante o mínimo porque estas apresentam erros muito grandes na determinação do pico da linha.

Evidentemente, a cinemática do pico da linha apresenta um comportamento diferente do centróide. De fato, enquanto a velocidade radial do primeiro tem uma amplitude da ordem de $500 \mathrm{~km} \mathrm{~s}^{-1}$, a do centróide é de apenas $200 \mathrm{~km} \mathrm{~s}^{-1}$. Além disso, logo após a fase zero, a velocidade do pico chega a $+50 \mathrm{~km} \mathrm{~s}^{-1}$, enquanto a do centróide estabiliza-se em torno de $-60 \mathrm{~km} \mathrm{~s}^{-1}$.

O comportamento do pico e do centróide da linha, descrito acima, deve-se ao fato de 
que eles representam o comportamento de regiões diferentes: o pico da linha deve originarse em uma região relativamente mais densa, enquanto o centróide deve ser formado em uma região mais extensa (incluindo altas e baixas densidades).

Considerando que a linha do He II $\lambda 4686$ seja formada ao longo do cone de choque entre os ventos, sua cinemática pode ser explicada pela orientação orbital. Próximo ao periastro, o ângulo subentendido pelo observador e o eixo que une as duas estrelas pode ser muito próximo ao de abertura do cone. Isso faz com que a velocidade projetada seja praticamente a mesma do material escoando ao longo do cone que, segundo vários modelos (Abraham \& Falceta-Gonçalves, 2007; Kashi \& Soker, 2008a; Gull et al., 2009), deve ser algo em torno de -400 a $-500 \mathrm{~km} \mathrm{~s}^{-1}$. Além do mais, por causa dessa orientação, a densidade colunar ao longo da linha de visada fica muito maior do que em qualquer outra direção durante a passagem pelo periastro, aumentando o número de absorvedores na linha de visada e, consequentemente, o número de recombinações também. Por isso, a parede do cone de choque alinhada com a linha de visada do observador deve ser a região responsável pelo pico do He II $\lambda 4686$.

A velocidade do centróide, por outro lado, corresponde à velocidade média (projetada) de toda a região emissiva ao longo das paredes do cone de choque, em todas as direções. Isso significa que, se o plano orbital estiver próximo ao plano equatorial da primária e o periastro ocorrer do lado mais distante $\left(\omega \approx 270^{\circ}\right)$, ao longo de todo o período orbital o observador sempre estará na direção de uma componente projetada negativa. Por exemplo, durante o apastro, as componentes projetadas na linha de visada ao longo das paredes do cone de choque varrem o intervalo de +300 até $-500 \mathrm{~km} \mathrm{~s}^{-1}$, segundo o modelo de (Gull et al. , 2009). Uma média ponderada pela área projetada ao longo do cone em todas as direções resulta em uma velocidade média de $-75 \mathrm{~km} \mathrm{~s}^{-1}$, que é compatível com o valor observado para a velocidade do centróide do He II $\lambda 4686$ após o periastro (ver Fig.6.8).

Próximo ao periastro, o centróide também apresenta um aumento no valor absoluto da velocidade projetada ( $\mathrm{de}-200 \mathrm{a}-250 \mathrm{~km} \mathrm{~s}^{-1}$ ). Isto pode ser interpretado como sendo devido à mudança na componente predominante, que passa a ser a região de formação do 
pico da linha, e não mais uma média de todo o cone de choque. 


\section{Capítulo 7}

\section{Discussão}

Existe um consenso entre os pesquisadores de que $\eta$ Car é composta por um sistema binário com alta excentricidade e colisão de ventos. Portanto, toda a discussão apresentada nesta seção é baseada nesta hipótese.

\subsection{Sobre o período orbital e sua estabilidade}

A utilização da razão entre o pico de intensidade da linha do [N II] $\lambda 5754$ e do [Fe II] $\lambda 5746$ mostrou-se um método extremamente robusto para a determinação do período orbital. Outros métodos, como a medida da largura equivalente de componentes estreitas durante um evento, dependem de diferentes fatores que nem sempre podem ser corrigidos, como por exemplo, variações no nível do contínuo estelar ou efeitos de transferência radiativa em uma determinada linha espectral.

A componente estreita da linha do [N II] $\lambda 5754$ é relativamente intensa, livre de blends e localiza-se muito próxima à linha do [Fe II], que varia muito pouco ao longo de todo o ciclo e, por isso, foi utilizada para normalização das mudanças no contínuo local. Nos últimos 4 eventos (desde 1992 até 2009), a razão entre [N II] $\lambda 5754$ e [Fe II] $\lambda 5746$ tem mostrado um comportamento extremamente cíclico, com o aparecimento de uma componente de colapso cerca de 10 a 15 dias antes da fase zero.

É interessante notar que, assim como a componente larga das linhas do hélio, a componente estreita da linha do [N II] $\lambda 5754$ também não desaparece completamente após a 
fase zero, mas, sim, atinge um valor mínimo correspondente a aproximadamente $85 \%$ do pico do [Fe II $] \lambda 5746$.

A linha do [N II] $\lambda 5754$ tem um potencial de ionização intermediária, cerca de $14.5 \mathrm{eV}$, e é sensível à mudancas na temperatura eletrônica do gás em que é formado (Reynolds et al., 2001). O desaparecimento da linha indica que íons $\mathrm{N}^{+}$se recombinam devido ao desaparecimento do fluxo ionizante durante o evento espectroscópico.

Durante as fases anteriores à entrada no mínimo, o cone de choque ainda aponta para os glóbulos de Weigelt. Entretanto, à medida que a secundária se aproxima da primária, a orientação da abertura do cone vai mudando gradualmente, até que, por volta de 10 a 15 dias antes da fase zero, ela muda bruscamente devido ao movimento orbital, que por ser muito excêntrico, gera mudanças muito rápidas na configuração do cone de choque em épocas próximas à passagem pelo periastro. Neste cenário, o início da fase de colapso na intensidade desta linha em $\eta$ Car pode indicar o momento no qual a abertura do cone de choque sai da linha de visada dos glóbulos de Weigelt e/ou a estrutura do cone de choque entra em colapso. Por outro lado, a recuperação da linha do [N II] $\lambda 5754$, após a fase zero, é muito lenta: durante a fase de colapso a intensidade do pico da linha do [N II] caiu em $50 \%$ (a razão foi de 1.5 para 1.0) em apenas 5 dias, mas foram necessários cerca de 80 dias, após a intensidade da linha do [N II] igualar a do [Fe II] (razão 1.0), para que a primeira voltasse a ser $50 \%$ mais intensa do que a última (razão 1.5).

A partir do momento que a radiação da secundária deixa de atingir os glóbulos de Weigelt, as linhas ali formadas se recombinam em uma escala de tempo que depende da densidade eletrônica da região. No entanto, nem todos os íons $\mathrm{N}^{+}$se recombinam, pois a linha do [N II] $\lambda 5754$, conforme mencionado anteriormente, não desaparece completamente. Isso pode ser explicado como sendo resultado do fato de que a estrela primária possui uma temperatura alta o suficiente $(\approx 15000 \mathrm{~K})$ para produzir fótons com energia acima de $14.5 \mathrm{eV}$. Isso também explica o por que a linha do [Fe II] $\lambda 5746$ não varia durante o evento: a secção de choque do íon $\mathrm{Fe}^{+}$é praticamente zero para fótons com energia muito maior do que $7.9 \mathrm{eV}$ (porém, abaixo do seu limite de ionização, que é de $\approx 16.2 \mathrm{eV}$ ) e, portanto, os fótons produzidos pela estrela primária, com energia entre 14.5 e $16.2 \mathrm{eV}$, 
podem ionizar o íon $\mathrm{N}^{0}$ sem, no entanto, excitar/ionizar os íons de $\mathrm{Fe}^{+}$.

O período obtido através da minimização da dispersão dos dados da razão [N II]/[Fe II] dos 4 últimos eventos (1992.5, 1998.0, 2003.5 e 2009.0), foi de 2021.5 dias, com um erro estimado em 1 dia. As observações feitas por Gaviola (1953) mostram que em 19 de Abril de 1948, a linha do [N II] $\lambda 5754$ estava menor do que a do [Fe II] $\lambda 5746$. Isso implica que a fase zero do primeiro evento havia ocorrido, no máximo, 75 dias antes da observação. Com isto, foi possível determinar um limite superior para o período médio dos ciclos, utilizando uma linha de base de 60 anos, cujo valor foi de 2023.6 dias. Comparando o período atual com o período médio, notou-se que, em 11 ciclos, o período diminuiu, no máximo, 0.38 dias por ciclo. Em um sistema binário, no qual as componentes perdem massa através de ventos estelares, ocorrem variações no período orbital devido à variações no momento angular específico do sistema. No caso de $\eta$ Car, no entanto, as variações no período observadas, devem ser atribuídas às incertezas nas medidas e não a um reflexo da perda de massa da primária, pois o valor de 0.38 dias por ciclo é quase 4 vezes superior ao esperado para variações em um sistema binário com as características de $\eta$ Car.

\subsection{Sobre as características do evento espectroscó- pico}

Utilizando a componente estreita das linhas proibidas é possível distinguir dois regimes durante um evento espectroscópico: uma fase de variações lentas e outra de colapso. A primeira ocupa quase todo o período de 5.54 anos, está centrada em uma fase mais tardia do que a componente de colapso e sua fase de queda e recuperação é praticamente simétrica. Como as linhas de transição proibida são formadas nos glóbulos de Weigelt, as variações que elas apresentam refletem a maneira com que os glóbulos 'veêm' a radiação da fonte central, que é essencialmente a radiação da secundária escapando através do cone de choque.

A queda suave e posterior recuperação da componente de variação lenta indicam que a região interior do cone de choque não é completamente transparente. Portanto, a com- 
ponente de variação lenta é resultado de variações tanto no formato do cone quanto na coluna de gás que ele contém, que variam ao longo do período conforme a secundária viaja ao longo de sua órbita ao redor da primária, adentrando regiões mais densas do seu vento.

Quanto à componente de colapso, ela é detectada em várias regiões espectrais: raios-X, linhas de alto potencial de excitação, nas linhas em emissão do He I e na componente em absorção do perfil P Cygni das linhas do He I.

Devido às incertezas nos parâmetros estelares e orbitais, não é certo o quão próximas de si as estrelas se aproximam durante o periastro. Entretanto, por causa das densidades muito maiores na base dos ventos estelares, além das mudanças rápidas na posição da secundária na órbita, é muito provável que ocorram instabilidades no cone de choque, criando perturbações que podem alterar sua geometria e eventualmente até causar sua desestruturação. Isso explicaria a fase de colapso. Além disso, como a abertura do cone de choque não deve estar alinhada simetricamente em fases próximas do periastro, sua estrutura antes e depois da passagem pelo periastro não devem ser idênticas. Embora não seja possível identificar de maneira definitiva, com os dados mostrados nesta tese, a presença da fase de recuperação da estrutura do cone de choque, ela deve ocorrer pelo menos 3 meses após a fase zero.

As linhas duplamente ionizadas apresentam um comportamento interessante durante a fase de colapso: aquelas com maior potencial de ionização desaparecem mais rapidamente do que aquelas com menor potencial. Por outro lado, a recuperação das linhas de maior potencial de ionização é mais lenta do que as de menor potencial. Isso significa que a radiação que atinge os glóbulos de Weigelt apresenta um espectro que torna-se gradativamente 'menos duro' antes de um evento e, depois, durante a fase de recuperação, torna-se progressivamente 'mais duro'. Tal comportamento deve ser causado por efeitos de variação na opacidade no gás entre a fonte ionizante e os glóbulos.

As características mais energéticas (e.g. He II $\lambda 4686$ e raios-X) apresentam somente a componente de colapso enquanto na faixa de emissão em rádio de $3 \mathrm{~cm}$, a componente de variação lenta domina a curva de luz. O mínimo na curva de luz na faixa de $7 \mathrm{~mm}$ em rádio tem seu centro cerca de 42 dias depois da fase zero. Apesar de o cone de choque 
contribuir para a emissão nesta faixa espectral, provavelmente a maior contribuição à curva de luz em $7 \mathrm{~mm}$ deve ser vir do material ao redor do sistema binário. A escala de tempo de recombinação deste gás pode ser a causa da defasagem entre a fase zero e o mínimo de emissão na faixa de $7 \mathrm{~mm}$.

A componente em absorção do perfil P Cygni das linhas do He I e sua componente larga não podem ser formadas no vento da primária, uma vez que as velocidades observadas nestas linhas são maiores do que a velocidade observada na linha do Fe II $\lambda 6455$, que é formada nas regiões mais externas do vento da primária (que já atingiram a velocidade terminal). Como a componente em absorção do Fe II $\lambda 6455$ atinge o máximo de intensidade (e máxima velocidade negativa) cerca de 3 semanas depois da fase zero, o vento da primária tem que estar recombinado em sua máxima extensão nesta época, o que deve ocorrer quando a secundária está em oposição. Esta interpretação é corroborada pelo fato de que, próximo à fase zero, a velocidade da componente em absorção do perfil P Cygni do Fe II $\lambda 6455$ muda para o lado negativo enquanto a absorção na linha do He II $\lambda 7065$ muda para o lado positivo. Este comportamento também é observado em outras linhas associadas ao cone de choque, como a componente larga do He II 6678. Além disso, a linha de fluorescência do Fe II $\lambda 8490$ também atinge um mínimo por volta da fase 0.015. Todas estas observações sugerem que a oposição da secundária ocorra entre 20 e 30 dias depois da fase zero. Porém, é importante ressaltar que esta interpretação não implica em um eclipse no sentido clássico pois isso depende do ângulo de inclinação do plano orbital, que ainda é incerto.

A linha do He I $\lambda 10830$ indica que existe material em latitudes intermediárias (linha de visada) que atingem velocidades negativas $(\approx-1900 \mathrm{~km} / \mathrm{s})$ maiores do que as tipicamente vistas durante a fase de alta excitação $(\approx-550 \mathrm{~km} / \mathrm{s})$. A localização exata deste material ainda é incerta, mas as variações na razão entre os picos em emissão (V/R) sugerem que existem outras regiões contribuindo para formação desta linha além dos glóbulos de Weigelt e do vento da secundária. Entretanto, é importante ressaltar que a alta velocidade observada na componente em absorção do He II $\lambda 10830$ não pode ser produzida no vento da secundária, pois a densidade é muito baixa (considerando que a secundária seja uma 
estrela tipo O) para absorver uma quantidade relativamente grande do fluxo do contínuo (e saturar a linha) como é observado.

\subsection{Sobre o mapeamento espacial do Homúnculo uti- lizando os mapas de velocidade da linha do [Fe II] $\lambda 12567$ e do He I $\lambda 10830$}

Através do mapeamento da linha do [Fe II] $\lambda 12567$, foram mapeadas estruturas que não haviam sido relatadas na literatura. O lóbulo SE do Pequeno Homúnculo foi detectado, indubitavelmente, porém o lóbulo NW não pode ser separado da forte emissão proveniente das regiões equatoriais que estão na mesma linha de visada. Isso deve-se ao fato de que a emissão do lóbulo SE do Pequeno Homúnculo é intensa o suficiente para ser observada através do lóbulo SE do Homúnculo.

Os mapas de velocidade da linha do [Fe II] $\lambda 12567$ revelaram que as colisões do vento da fonte central contra a parede interna dos lóbulos do Homúnculo são mais intensas nas regiões polares, onde a densidade é maior. Este resultado concorda com o apresentado

por Davidson et al. (2001) mas o estudo apresentado nesta tese revelou detalhes espaciais antes desconhecidos.

Foi confirmado que a região conhecida como SE hole, localizada no lóbulo SE do Homúnculo, é, de fato, uma região onde a densidade é muito menor do que a média do lóbulo. Nessa região, a emissão na linha do [Fe II] $\lambda 12567$ diminui consideravelmente, enquanto a linha do $\mathrm{H}_{2} 1-0 \mathrm{~S}(1)$ não apresenta emissão alguma. Além disso, as linhas da série do H e do He I $\lambda 10830$ também apresentam uma queda na emissão na região onde localiza-se o SE hole. Outro fato que corrobora a ideia de que esta região seja mesmo um 'buraco' no lóbulo, é que é possível detectar a emissão do $\mathrm{H}_{2}$ proveniente da parte posterior do lóbulo SE, o que não deveria ocorrer se o SE hole fosse a sombra projetada no lóbulo de uma condensação entre o observador e a fonte central.

A comparação entre imagens na região do infra-vermelho médio sugerem que existe uma contra-partida do SE hole no lóbulo NW, o que é confirmado nos mapas de velocidade 
da linha do [FeII] $\lambda 12567$. É interessante ressaltar que as coordenadas do 'buraco' no lóbulo NW são 'espelhadas' em relação às do SE hole, isto é, as coordenadas do buraco no lóbulo NW podem ser obtidas através da rotação de $180^{\circ}$ em torno da fonte central. Como a emissão da linha do [Fe II] $\lambda 12567$ é proveniente do interior dos lóbulos e a emissão do $\mathrm{H}_{2}$ tem origem na parte externa dos mesmos, ambas foram combinadas de maneira a obter-se a espessura dos lóbulos na região polar, cujo valor obtido foi de $\approx 7 \times 10^{16} \mathrm{~cm}$. A presença de dois 'buracos' em latitudes superiores a $85^{\circ}$ sugere que, durante a Grande Erupção, a taxa de perda de massa nos polos deva ter sido inibida por algum mecanismo de natureza desconhecida.

Utilizando o mapa de emissão rádio em $3 \mathrm{~cm}$ (Duncan \& White, 2003), foi possível confirmar que o fluxo ionizante é espacialmente coincidente com a extensão do Pequeno Homúnculo e, portanto, pode ser considerado como uma pequena região H II. Desta maneira, o fluxo em rádio durante a fase de alta excitação foi utilizado para determinar a natureza da fonte ionizante (a estrela secundária). O resultado sugere que a secundária seja uma estrela de tipo espectral e classe de luminosidade entre O5.5 III e O7 I. Entretanto, não é possível descartar tipos espectrais mais quentes porque o valor obtido para o fluxo de fótons no contínuo de Lyman é apenas um limite inferior.

Os mapas de velocidade da linha do He I $\lambda 10830$ confirmaram a existência de uma emissão intrínseca confinada a uma estreita região (feixe) que foi interpretado como sendo o fluxo ionizante da secundária escapando pela região equatorial. O ângulo de posição desta estrutura é de aproximadamente P.A. $=-48 \llbracket$ e pode ser detectada a distâncias maiores que 10 arcsec da fonte central. Com base nas medidas de velocidade e posição, esta estrutura localiza-se em latitudes próximas do plano equatorial do Homúnculo, com ângulo de inclinação de $i \approx 44^{\circ}$. Provavelmente, esta estrutura está relacionada com a região conhecida como radio spot, que é onde localiza-se o pico na emissão em rádio na faixa de $3 \mathrm{~cm}$. Apesar desta região estar na mesma linha de visada que o filamento de Sr (região povoada de íons com baixo potencial de ionizacão como o Ti II. [V II] e [Fe II]: Zethson et al. 1999; Hartman et al. 2001, 2004), elas estão desconectadas espacialmente. Enquanto

\footnotetext{
${ }^{1} \mathrm{O}$ sinal negativo indica que o ângulo é contado a partir do Norte para o Oeste.
} 
a primeira região é uma região ionizada cujo pico de emissão ocorre com velocidade de $-250 \mathrm{~km} / \mathrm{s}$, a segunda região é caracterizada por linhas de íons com baixo potencial de ionização, com velocidades típicas de aproximadamente $-110 \mathrm{~km} / \mathrm{s}$ e provavelmente protegidas da radiação ionizante por uma 'cortina' de íons do $\mathrm{H}^{0}$ e $\mathrm{Fe}^{+}$(Bautista et al., 2002, 2006).

\subsection{Sobre as possíveis regiões e mecanismos respon- sáveis pela emissão do He II $\lambda 4686$}

O comportamento observado da luminosidade do He II $\lambda 4686$ pode ser dividido em duas partes: uma pré-mínimo e outra pós-mínimo. Próximo à fase zero, existem dois picos na emissão desta linha. Tais picos, quando deslocados de -16.5 dias, coincidem com os dois picos observados na faixa dos raios-X. Estaria o fluxo em raios-X correlacionado à emissão do He II $\lambda 4686 ?$

Em um sistema binário com colisão de ventos, no qual a excentricidade é tão alta quanto em $\eta$ Car, a distância entre as estrelas diminui consideravelmente à medida em que a secundária se aproxima do periastro. Desta maneira, o comportamento do fluxo em raios-X pode ser estimado por uma lei que varia com $D^{-1}$, onde $D$ é a distância entre as estrelas. A curva de luz em 2-10 keV apresenta picos de emissão que estão sobrepostos à variação causada pelo aumento da proximidade entre as duas estrelas.

Para testar a hipótese de que o fluxo em raios-X está correlacionado à emissão do He II $\lambda 4686$, considere que os fótons na faixa do UV extremo/raios-X moles (doravante $\mathrm{eUV} / \mathrm{sXR}$, extreme $U V /$ soft $X$-rays), produzidos na região de colisão dos ventos, estejam sendo utilizados na produção de íons $\mathrm{He}^{++}$próximos ao ápex do cone de choque, onde o material pode atingir $T>10^{6} \mathrm{~K}$. Assumindo que o material contido na região de colisão de ventos escoe a cerca de $450 \mathrm{~km} \mathrm{~s}^{-1}$, então depois de 16.5 dias os íons de $\mathrm{He}^{++}$estarão a aproximadamente 4 unidades astronômicas do ápex, onde a temperatura já diminuiu o suficiente $\left(\sim 10^{4}-10^{5} \mathrm{~K}\right)$ para que o $\mathrm{He}^{++}$possa recombinar-se em $\mathrm{He}^{+}$(responsável pela linha do He II $\lambda 4686)$ e, posteriormente, em $\mathrm{He}^{0}$ (responsável pelas linhas do He I). 


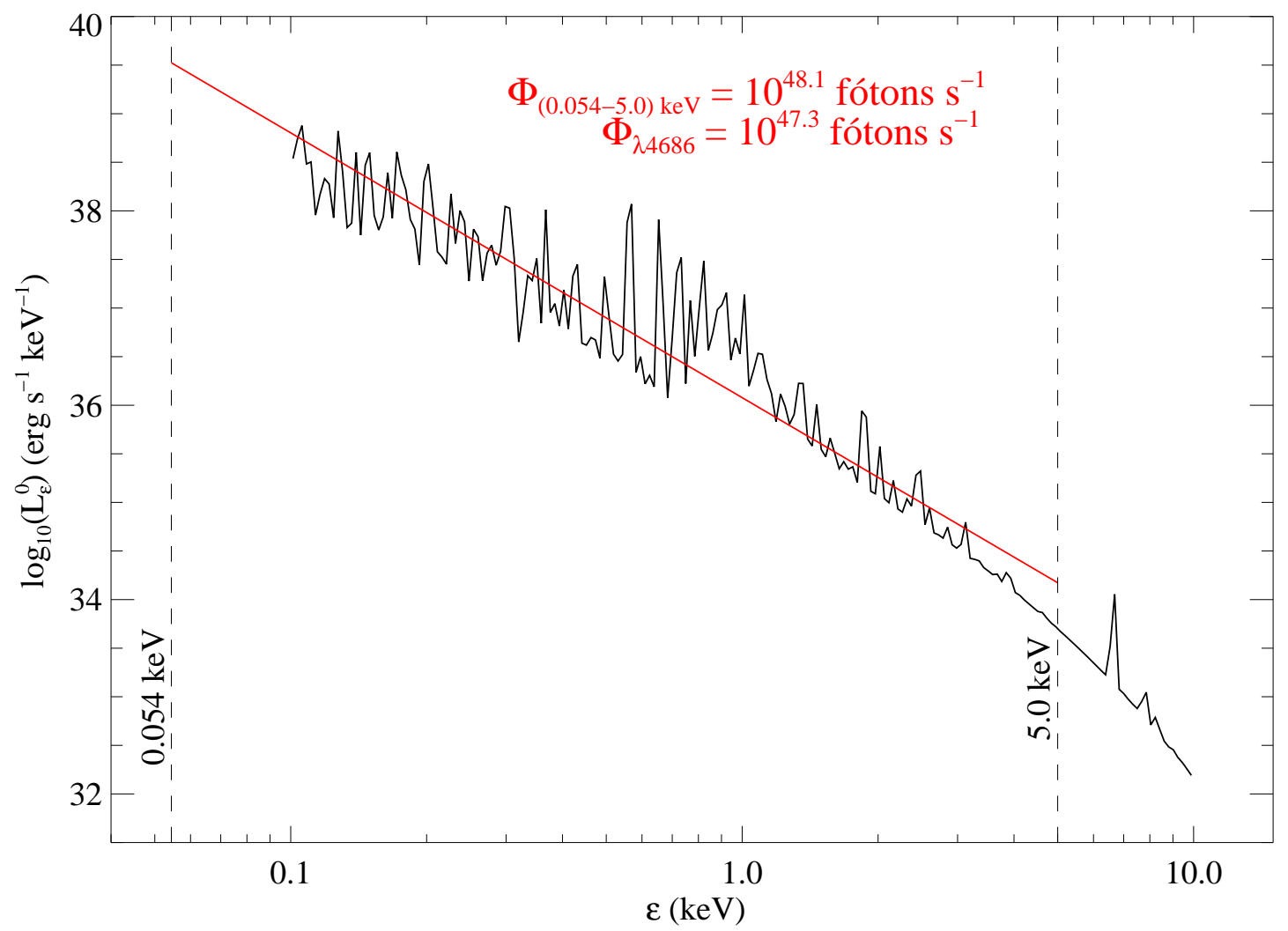

Figura 7.1: Espectro intrínseco na faixa do UV extremo/raios-X obtido pelo modelo 3D de Parkin et al. (2009). A linha contínua vermelha é a regressão linear realizada para obter o valor do número de fótons na faixa de 0.054 a $5.0 \mathrm{keV}$ (indicada pelas linhas verticais), produzido no choque dos ventos. Deste total, $15 \%$ é convertido em fótons com $\lambda=4686$ A.

Isso explicaria a defasagem observada entre a curva de luz do He II $\lambda 4686$ e o fluxo em raios-X: como a maior parte do fluxo em raios-X é formado próximo ao ápex, ele responde às variações antes do He II $\lambda$ 4686. É possível que a componente em absorção da linha do He I $\lambda 7065$ e uma parte da do He I $\lambda 10830$ sejam formadas nesta região (cerca de 4 UA do ápex).

Entretanto, para avaliar a hipótese de que o He II $\lambda 4686$ seja produto da recombinação de íons $\mathrm{He}^{+}$formados pelo fluxo eUV/sRX, é necessário saber se a região de colisão dos ventos produz um espectro de emissão capaz de explicar a luminosidade do He II $\lambda 4686$ observada $\left(\approx 10^{47.3} \mathrm{~s}^{-1}\right)$. Para isso, a Fig. 7.1 mostra a previsão da luminosidade monocromática intrínseca do modelo hidrodinâmico de Parkin et al. (2009), no intervalo de 0.1 a $10 \mathrm{keV}$, para a emissão do choque do lado da secundária. No entanto, é necessário analisar a distribuição do fluxo eUV/sXR para energias acima do potencial de ionização 
do $\mathrm{He}^{++}$, cujo valor é de $54.4 \mathrm{eV}$. Portanto, foi ajustada uma curva (linha vermelha na Fig. (7.1) ao espectro previsto pelo modelo de Parkin et al. (2009) e tal ajuste foi utilizado para determinar o contínuo do espectro no intervalo de 0.054 a $5.0 \mathrm{keV} 2$, região delimitada pelas linhas tracejadas verticais na Fig. 17.1. Neste intervalo de energia, o espectro segue uma lei de potência dada por $\log \left(L_{\epsilon}\right) \propto \epsilon^{-2.73}$ (em $\operatorname{erg~s}^{-1} \mathrm{keV}^{-1}$ ), e o fluxo de fótons previsto pelo modelo é de aproximadamente $10^{48.1}$ fótons $\mathrm{s}^{-1}$.

Utilizando o código CLOUDY para simular uma nebulosa com $N(\mathrm{He}) / N(\mathrm{H}) \approx 0.1$ sendo iluminada por um contínuo dado pela lei de potência mencionadd3, o resultado é que o número de fótons com $\lambda=4686 \AA$ é de aproximadamente $15 \%$ do fluxo eUV/sXR no intervalo de 0.054 a $5.0 \mathrm{keV}$, ou seja, cada 100 fótons na faixa do eUV/sXR produzem 15 fótons capazes de excitar a transição do He II 4686 (este valor, é claro, depende da densidade numérica do meio e é praticamente constante até $\left.n_{e} \sim 10^{11} \mathrm{~cm}^{-3}\right)$. Aplicando este valor ao número de fótons previsto pelo modelo de Parkin et al. (2009), nota-se que o resultado é $10^{47.3}$ fótons $\mathrm{s}^{-1}$. Portanto, o número de fótons com comprimento de onda de $4686 \AA$, produzido pelo espectro eUV/sXR do choque de ventos, é exatamente igual à luminosidade observada do He II $\lambda 4686$.

No entanto, deve-se tomar muito cuidado com esta interpretação, pois o mecanismo descrito implica em uma eficiência extremamente elevada, ou seja, que praticamente toda a radiação na faixa de 0.054 a $5 \mathrm{keV}$ seja utilizada para ionizar o $\mathrm{He}^{0}$ ou $\mathrm{He}^{+}$. Porém, é possível que os fótons com energia acima de 550 eV escapem sem serem absorvidos ou que o sejam por outros íons (como o $\mathrm{N}^{5+}$ ), convertendo-se em fótons menos energéticos. Desta maneira, a fração do fluxo intrínseco de fótons na faixa de raios-X que é efetivamente convertida em fótons com $\lambda=4686 \AA$ A deve ser menor do que o previsto utilizando o modelo de Parkin et al. (2009). Portanto, o fluxo intrínseco na faixa do eUV/sXR, produzido pelo choque do vento da secundária, pode não ser suficiente para explicar o fluxo observado de fótons na linha do He II $\lambda 4686$ se for considerado como sendo a única fonte ionizante do $\mathrm{He}^{0}$ ou $\mathrm{He}^{+}$.

\footnotetext{
${ }^{2}$ Acima de $5 \mathrm{keV}$, a seção de choque do $\mathrm{He}^{+}$é muito pequena, cerca de $10^{6}$ vezes menor do que em $54.4 \mathrm{eV}$, e, portanto, este valor foi definido como limite superior da região de integração.

${ }^{3}$ Esta simulação foi feita por Roberto B. Menezes e pelo Prof. João E. Steiner.
} 
Outro mecanismo para explicar a emissão do He II $\lambda 4686$ seria a formação de um íon $\mathrm{He}^{++}$pela radiação na faixa dos raios-X e sua posterior recombinação em $\mathrm{He}^{+}$em alguma região ao longo do cone de choque, explicando a defasagem entre a emissão em raios-X e o fluxo de He II $\lambda 4686$. Entretanto, já foi discutido anteriormente que o fluxo em raios-X do choque do vento da secundária não consegue criar fótons suficientes para explicar a luminosidade observada do He II $\lambda$ 4686. Mesmo que algum mecanismo ionizante diferente consiga produzir os íons $\mathrm{He}^{++}$, ainda assim a hipótese de recombinação ao longo do cone de choque não é capaz de explicar a luminosidade observada do He II $\lambda 4686$. Isso pode ser verificado considerando que na região do choque, a conservação da massa estabelece o seguinte

$$
\rho_{1} v_{1}=\rho_{2} v_{2}
$$

onde $\rho$ é a densidade numérica, $v$ é a velocidade do meio, o índice 1 refere-se ao vento da primária e o 2, ao da secundária. Segundo os modelos hidrodinâmicos, a velocidade terminal do vento da primária é aproximadamente 6 vezes menor do que o da secundária e, utilizando a equação 7.1, obtem-se que o vento da secundária deve ser 6 vezes menos denso do que o da primária. Portanto, considerando que metade do valor da taxa de perda de massa da secundária $\left(10^{-5} \mathrm{M}_{\odot}\right.$ ano $\left.{ }^{-1}\right)$ entra na onda de choque, então $\approx 4 \times 10^{44}$ átomos de $\mathrm{H}$ estão entrando e saindo da região de choque por segundo e, assumindo $N(\mathrm{He}) / N(\mathrm{H})=0.20$ como um valor médio, então $\approx 8 \times 10^{43}$ átomos de He entram e saem da região de choque por segundo. Se cada átomo de He for convertido em $\mathrm{He}^{++}$ por fótons na faixa do $\mathrm{eUV} / \mathrm{sXR}$ e, posteriormente, recombinado uma única vez, em uma região mais fria ao longo do cone de choque, o resultado é que, nestas condições, serão produzidos $0.15 \times 8 \times 10^{43}=1.2 \times 10^{43}$ fótons de He II $\lambda 4686$ por segundo. Tal valor é cerca de 17000 vezes menor do que o observado! Portanto, para produzir a luminosidade observada na linha do He II $\lambda 4686$ através deste mecanismo, é necessário a existência de uma fonte de energia ionizante auxiliar e/ou que as taxas de perda de massa envolvidas aumentem, pelo menos temporariamente.

É possível que um aumento (ainda que temporário) na densidade de elétrons e íons em uma dada região (no choque ou no vento das estrelas) possa aumentar significativamente a 
emissão de fótons do He II $\lambda 4686$ porque fótons com $\lambda=1215.2 \AA$ provenientes de ambas as estrelas podem excitar o $\mathrm{He}^{+}$do nível 2 para o 4, convertendo-os em fótons com $\lambda=1640$ e $4686 \AA$ (correspondente às transições 3-2 e 4-3, respectivamente) e se a densidade for suficientemente alta, a produção de fótons com $\lambda 1215 \AA$ aumenta proporcionalmente.

Segundo Martin et al. (2006), no caso de $\eta$ Car, tal mecanismo só é eficiente onde a densidade de elétrons e íons for superior a $10^{10.2} \mathrm{~cm}^{-3}$ porque os fótons com energia acima de $13.6 \mathrm{eV}(\lambda \leq 912 \AA)$, provenientes de ambas as estrelas, podem ionizar o $\mathrm{He}^{+}$a partir do seu nível $n=2$ (cuja população pode ser significativamente aumentada por causa do fluxo de fótons com $\lambda=304 \AA$ produzidos dentro da região $\mathrm{He}^{++}$), aumentando a extensão da região $\mathrm{He}^{++}$(incluindo mais íons) e, consequentemente, o número de recombinações que contribuem para emissão dos fótons de $\lambda \approx 4686 \AA$. De fato, aqueles autores mostraram que, ao considerar este mecanismo, a produção de fótons com $\lambda=4686 \AA$ pode chegar a $10 \%$ (ou mais!) do valor do fluxo de fótons na faixa de $54-550 \mathrm{eV}$, em regiões onde a densidade é superior a $10^{10.2} \mathrm{~cm}^{-3}$. Neste caso, o fluxo de de fótons na faixa do eUV/sXR é essencial para iniciar o processo mas não é o responsável pelo suprimento energético que produz os fótons do He II $\lambda$ 4686. De fato, o responsável pelo suprimento energético são os fótons com $\lambda=1215 \AA$ produzidos na região $\mathrm{He}^{++}$(região de colisão dos ventos). Portanto, este mecanismo pode explicar a luminosidade observada da linha do He II $\lambda 4686$.

É importante ressaltar que o mecanismo que acabou de ser descrito é extremamente sensível às variações na densidade numérica $\left(\propto n_{e}^{3}\right)$ e, portanto, quanto maior a densidade na região pré-choque, maior é o fluxo eUV/sXR produzido pela colisão e, consequentemente, maior é a emissão do He II $\lambda 4686$. Esta sensibilidade à densidade é a responsável pelo rápido aumento na emissão do He II $\lambda 4686$ antes da fase zero, quando a secundária adentra as regiões mais internas (mais densas) do vento da primária. Além disso, um aumento (temporário) na densidade do vento da primária (nas regiões equatoriais) parece ser observado ao longo do evento espectroscópico, durante o qual as linhas do H e do He apresentam um aumento na largura equivalente da componente em absorção, que é maior nas regiões de baixa latitude (linha de visada) do que na região polar (FOS4: Stahl et al. 2005). Isso ajudaria a aumentar temporariamente a produção de fótons He II $\lambda 4686$ 
através do mecanismo descrito.

A produção de fótons de He II $\lambda 4686$ através de fótons com $\lambda \approx 1215 \AA$, provenientes exclusivamente do campo de radiação estelar também é um possível mecanismo. Entrentanto, no vento da primária, os fótons com $\lambda \approx 1215 \AA$ são produzidos somente nas partes mais internas, onde a profundidade óptica é extremamente elevada e, portanto, só podem escapar durante o período em que a secundária adentra tais regiões, ou seja, em épocas próximas ao periastro, durante o qual ela abre caminho para que os fótons com $\lambda \approx 1215 \AA$ iluminem a região pré-choque do lado da primária. Como a secundária apresenta uma luminosidade que não passa de $10 \%$ do valor da primária (além de ser muito menos denso), então o fluxo de fótons com $\lambda \approx 1215 \AA$ é muito maior na região pré-choque do lado da primária do que do lado da secundária. No entanto, é relativamente fácil verificar que tal mecanismo atuando isoladamente também não é capaz de produzir o pico observado na largura equivalente.

A energia emitida (em erg $\mathrm{s}^{-1} \mathrm{~cm}^{-2}$ ster $^{-1}$ ) pelo campo de radiação da primária no intervalo de comprimento de onda $\Delta \lambda$, centrado em $\lambda_{c}$, é dado por $\int I_{\lambda} d \lambda$, onde $I_{\lambda}$ é a intensidade específica no comprimento de onda $\lambda$. Considerando que cada fóton emitido dentro de um ângulo sólido $\Omega$ e com comprimento de onda no intervalo $\Delta \lambda(=\Delta v / c$, onde $\Delta v$ é a velocidade dos íons na região emissora e $c$, a velocidade da luz) seja absorvido por um íon $\mathrm{He}^{+}$, então o fluxo de fótons (representado por $\Phi$, em fótons $\mathrm{s}^{-1} \mathrm{~cm}^{-2}$ ) com $\lambda=1215 \AA$ deve ser igual ao fluxo de fótons com $\lambda=4686 \AA$. Como o fluxo de fótons, no intervalo $\Delta \lambda$ é dado por

$$
\Phi=\frac{1}{h\left(c / \lambda_{c}\right)} \int_{\Omega} \int_{\lambda} I_{\lambda} d \lambda d \Omega=\frac{\Omega \lambda_{c}}{h c} \int_{\lambda} I_{\lambda} d \lambda,
$$

então, tem-se o seguinte:

$$
\frac{\Omega_{1} \lambda_{c 1}}{h c} \int_{\lambda_{1}}^{\lambda_{2}} I_{\lambda 1215} d \lambda=\frac{\Omega_{2} \lambda_{c 2}}{h c} \int_{\lambda_{1}^{\prime}}^{\lambda_{2}^{\prime}} I_{\lambda 4686} d \lambda,
$$

onde $\lambda_{c 1}=1215 \AA, \lambda_{c 2}=4686 \AA, \Omega_{1}$ e $\Omega_{2}$ são os ângulos sólidos sob os quais os fótons com $\lambda=1215 \AA$ e $\lambda=4686 \AA$ estão sendo emitidos, respectivamente, $h$ é a constante de Planck 
e $c$, a velocidade da luz no vácuo. O intervalo de integração para cada região espectral (de $\lambda_{1}$ a $\lambda_{2}$ para fótons em $1215 \AA$ e de $\lambda_{1}^{\prime}$ a $\lambda_{2}^{\prime}$ para fótons em $4686 \AA$ ) é definido pela velocidade dos íons no meio onde os fótons são absorvidos, ou seja, $\lambda_{2}-\lambda_{1}=\Delta \lambda=\Delta v / c$. Em relação ao contínuo estelar, este intervalo espectral pode ser interpretado como sendo a largura equivalente da linha.

Assumindo que o contínuo estelar seja uma curva suave, a equação 7.3 pode ser reescrita da seguinte maneira:

$$
\begin{aligned}
\frac{\Omega_{1} \lambda_{c 1}}{h c} I_{\lambda 1215} \int_{\lambda_{1}}^{\lambda_{2}} d \lambda & =\frac{\Omega_{2} \lambda_{c 2}}{h c} I_{\lambda 4686} \int_{\lambda_{1}^{\prime}}^{\lambda_{2}^{\prime}} d \lambda \\
\Omega_{1} \lambda_{c 1} I_{\lambda 1215} \Delta \lambda & =\Omega_{2} \lambda_{c 2} I_{\lambda 4686} \Delta \lambda^{\prime}
\end{aligned}
$$

Portanto, em relação ao contínuo estelar, a largura equivalente $\left(\Delta \lambda^{\prime}\right)$ da linha do He I $\lambda 4686$ pode ser obtida pela seguinte equação:

$$
\Delta \lambda^{\prime}=\frac{\Omega_{1}}{4 \pi} \frac{\lambda_{c 1} I_{\lambda 1215}}{\lambda_{c 2} I_{\lambda 4686}} \frac{\Delta v}{c} .
$$

onde foram feitas as substituições $\Delta \lambda=\Delta v / c$ e $\Omega_{2}=4 \pi$. Esta última substituição foi feita considerando que os fótons de He II $\lambda 4686$ sejam emitidos isotropicamente. Utilizando a função de Planck para estimar $I_{\lambda}$, é possível ver que para $T=10000,15000$ e $20000 \mathrm{~K}$, a razão $\lambda_{c 1} I_{\lambda 1215} / \lambda_{c 2} I_{\lambda 4686}$ é igual a $0.033,0.56$ e 2.17 , respectivamente. Como os fótons com $\lambda \approx 1215 \AA$ são produzidos nas regiões mais internas do vento da primária, onde a profundidade óptica é alta, dificilmente esta razão atinge valores superiores a 1 (que, aliás, ocorre em regiões onde a temperatura é da ordem de 17000 K). Além disso, os fótons com comprimento de onda próximos de $1215 \AA$ são produzidos na região de aceleração do vento da primária, onde provavelmente $\Delta v \approx$ não deve ser maior do que $200 \mathrm{~km} / \mathrm{s}$. O fator geométrico, $\Omega_{1} / 4 \pi$, também deve ser pequeno do ponto de vista dos fótons produzidos nas regiões mais internas do vento da primária (com certeza $\ll 0.5$ ). Aplicando estas estimativas $\left(\Omega_{1} / 4 \pi \sim 0.1 ; \lambda_{c 1} I_{\lambda 1215} / \lambda_{c 2} I_{\lambda 4686} \sim 1\right.$ e $\left.\Delta v \approx 200 \mathrm{~km} / \mathrm{s}\right)$ à equação [7.5, o resultado mostra que os fótons com $\lambda \approx 1215 \AA$ produzidos nas regiões mais internas do vento da primária (e que são liberados pela inserção da secundária no vento da primária 
durante a aproximação do periastro) são capazes de produzir, no máximo, uma largura equivalente da ordem de $0.1 \AA$ na linha do He II $\lambda 4686$, muito menor que o observado.

\subsection{Sobre as altas velocidades observadas na compo- nente em absorção da linha do He I $\lambda 10830$}

A linha do He i $\lambda 10830$ apresenta várias componentes, tanto em emissão quanto em absorção. Durante o evento, as componentes em emissão diminuem de intensidade enquanto a 'força' da absorção aumenta (no evento de 2009.0 esta componente praticamente saturou), assim como o valor da velocidade terminal, que tende a velocidades mais negativas. Entretanto, foi observado que existem dois regimes de velocidade na componente em absorção desta linha: o de variação lenta e o de colapso. A primeira é detectada ao longo da maior parte do ciclo de 5.54 anos enquanto a segunda, é restrita a uma faixa temporal de $145 \pm 61$ dias centrada na fase zero.

Como a componente em absorção deve ser estar localizada entre a fonte central e o observador, existem essencialmente 3 possibilidades para a origem do material responsável pela absorção em altas velocidades durante o regime de colapso:

1. o material ejetado do vento da primária;

2. o vento da estrela secundária;

3. a região de colisão dos ventos.

A hipótese 1 implica que durante a fase de colapso, a estrela primária passa por um breve período de ejeção de matéria com $\left|\mathrm{v}_{\lim }\right| \sim 2000 \mathrm{~km} \mathrm{~s}^{-1}$, ou seja, muito acima do observado durante o período de alta excitação, que é $\left|\mathrm{v}_{\lim }\right| \sim 600-800 \mathrm{~km} \mathrm{~s}^{-1}$. A colisão entre o vento da secundária, movendo-se a $2000 \mathrm{~km} \mathrm{~s}^{-1}$, e o material ejetado pela primária, com aproximadamente a mesma velocidade, produziria uma mudança no espectro de raios-X, sendo que a produção de um espectro mais 'duro' seria favorecida, aumentando, assim, o parâmetro conhecido como hardness ratio, porém este aumento não é observado (Corcoran, 2005; Hamaguchi et al., 2007). Portanto, a hipótese 1 é altamente 
improvável, a menos que os parâmetros físicos, como densidade e volume-filling factor, sejam tão baixos que não influenciam no parâmetro hardness ratio nem na componente em absorção de $\mathrm{H} \alpha$, que foi utilizada por Smith et al. (2003) para mapear o vento da primária.

Em relação à hipótese 2, para que o vento da secundária seja responsável pelo material de alta velocidade na linha de visada do observador, é necessário que a secundária esteja entre este e a fonte central, implicando em $i \sim 90^{\circ}$. Entretanto, com este ângulo de inclinação é difícil encontrar uma orientação orbital que seja capaz de reproduzir o comportamento observado na linha do He i $\lambda 10830$. Se $\omega \sim 90^{\circ}$, a absorção no vento da secundária acontece somente antes ou depois do evento (neste caso o evento coincide com a passagem pelo periastro). Por outro lado, se $\omega \sim 270^{\circ}$, então a absorção em altas velocidades deveria ser visível ao longo de todo o ciclo, em oposição ao que é observado. Além disso, a temperatura associada à estrela secundária, derivada por vários métodos diferentes, indica que ela seja de tipo espectral $\mathrm{O}$ e, portanto, a densidade do seu vento é muito baixa para causar uma absorção tão intensa quanto a que é observada. Uma possibilidade seria uma companheira na fase de Wolf-Rayet mas a primária, que é mais massiva do que a secundária, ainda está na fase de queima do $\mathrm{H}$ o que implica que a secundária não pode estar em um estágio evolutivo posterior ao da primária.

A hipótese 3 é a mais provável, ou seja, o surgimento de velocidades $\left|\mathrm{v}_{\text {lim }}\right|>1100 \mathrm{~km} \mathrm{~s}^{-1}$ durante o regime de colapso deve estar relacionado a absorção no material do cone de choque que cruza a linha de visada do observador em épocas próximas à fase zero. A comparação entre o perfil observado da linha do He I $\lambda 10830$ (especialmente a componente em absorção) ao longo da fase de colapso e os modelos hidrodinâmicos 3D pode colocar fortes restrições na orientação orbital. Por exemplo, as simulações de Okazaki et al. (2008) mostram que a absorção em altas velocidades antes da fase zero (assumindo $i=90^{\circ}$, ou seja, no plano orbital) não acontece para longitude do periastro $45^{\circ}<\omega<180^{\circ}$. Neste intervalo, somente o vento da primária (com velocidades da ordem de $600-800 \mathrm{~km} \mathrm{~s}^{-1}$ ) é visto antes da fase zero. A absorção em altas velocidades só aparece cerca de 50 dias depois da fase zero, em oposição ao observado. Este resultado é válido para qualquer que 
seja o valor de $i$.

Por outro lado, assumindo $i \sim 41^{\circ}$ e $\omega \sim 270^{\circ}$, o surgimento da absorção em altas velocidades coincide com o aumento da densidade na região de colisão dos ventos que intercepta a linha de visada, segundo as simulações de Okazaki et al. (2008). Como o perfil de densidade segue uma lei de $r^{-2}$, isso explicaria o perfil suave da componente em absorção em altas velocidades. Além disso, esta configuração é compatível com o comportamento observado para as variações na direçã da iluminação da radiação UV em épocas próximas à fase zero (Smith et al., 2004). 


\section{Capítulo 8}

\section{Conclusões e perspectivas}

As principais conclusões obtidas são as seguintes:

- a região conhecida como SE hole é, de fato, um buraco no lóbulo do Homúnculo, cujo diâmetro é de $\approx 6 \times 10^{16} \mathrm{~cm}$. Além disso, foi confirmado a presença de um buraco similar no lóbulo NW, com as mesmas coordenadas do SE hole mas com uma rotação de $180^{\circ}$ em relação a fonte central;

- durante um evento espectroscópico, a emissão rádio na faixa dos $3 \mathrm{~cm}$ reduz de intensidade e extensão, concentrando-se em uma região circular ao redor da fonte central. Por outro lado, durante a fase de alta excitação, a emissão em rádio tem a mesma distribuição espacial que o Pequeno Homúnculo, sugerindo que este atua como uma pequena região H II para a radiação ionizante. Além disso, a cinemática do Pequeno Homúnculo também é compatível com a cinemática observada para a componente larga da emissão rádio em $3 \mathrm{~cm}$;

- com base no número de fótons emitidos no contínuo de Lyman (relacionados ao fluxo rádio), a classificação da estrela secundária está entre O5.5 III e O7 I;

- foi detectada uma componente em emissão da linha do He I $\lambda 10830$ confinada a uma região estreita (um feixe com P.A. $=-48^{\circ}$ ) na direção do lóbulo NW e que estendese desde a fonte central até distâncias maiores que 10 arcsec. Além disso, esta componente apresenta um perfil de velocidade que é mais negativa quanto maior for 
a distância projetada até a fonte central. Esta componente está relacionada à região conhecida como radio spot, que é onde se localiza o pico da componente estreita da emissão em rádio, e é causada pela excitação do $\mathrm{He}^{0}$ por fótons energéticos provenientes da fonte central;

- os ciclos de 5.54 anos são verdadeiramente periódicos e só podem ser interpretados em um cenário de binaridade;

- o melhor período determinado com base nos dados dos últimos 4 eventos é de $2021.5 \pm 1 \mathrm{~d}$

- os ciclos de 5.54 anos têm dois regimes: o de colapso, centrado em 140 dias após a fase zero e com FWHM=649 dias, e o de variação lenta, que é observado ao longo de todas as fases;

- as características (linhas espectrais, fluxo, etc.) provenientes de altas energias são moduladas pela componente de colapso e as de baixa energia, pela de variação lenta;

- a linha do He II $\lambda 4686$ deve ser formada na parede do cone de choque formado pela colisão dos ventos, e a maior contibuição deve originar-se na região ionizada pelo choque no lado da estrela primária;

- o mecanismo mais favorável para explicar o pico de emissão do He II $\lambda 4686$ é a produção de fótons com $\lambda \approx 1215 \AA$ (transição entre os níveis 4 e 2 do $\mathrm{He}^{+}$) a partir da radiação eUV/sXR proveniente do choque entre ventos;

- a componente em absorção das linhas do He i $\lambda 10830$, Si IV $\lambda \lambda 1394-1403$ e C IV $\lambda 1548$ atingem velocidades $\left|\mathrm{v}_{\text {lim }}\right|>1100 \mathrm{~km} \mathrm{~s}^{-1}$ durante um curto período de 84 dias e são formadas no gás que escoa da colisão dos ventos;

- as observações espectroscópicas favorecem um cenário no qual a passagem da secundária pelo periastro ocorra em oposição e a órbita esteja próxima ao plano equatorial. 


\section{Perspectivas}

A curva de luz histórica de $\eta$ Car mostra vários períodos de aumento e diminuição do brilho da fonte central. Em algumas épocas estas variações de longo termo são causadas pela extinção circunstelar, como nas épocas consecutivas à formação do Homúnculo e do Pequeno Homúnculo. Entretanto, desde a década de 40, o brilho da fonte central vem continuamente aumentando e, atualmente, a magnitude da fonte central é aproximadamente a mesma que aquela observada antes da Grande Erupção. Por isso, é extremamente importante a realização de um estudo das variações que ocorreram no espectro da fonte central ao longo dos últimos 50-60 anos. Isto pode trazer importantes indicações sobre as variações nos parâmetros físicos do meio circunstelar e até mesmo sobre a natureza do mecanismo responsável pelo aumento secular do brilho. Além disso, pode ser uma oportunidade de ouro para estudar em detalhes a fase que precede uma explosão de SN.

Com os resultados apresentados nesta tese, é possível planejar as épocas de interesse para o monitoramento do próximo evento, que ocorrerá em 24 de Julho de 2014 ( \pm 1 dia). Por exemplo, na região do infra-vermelho, em $\lambda=10830 \AA$, o monitoramento deve ser mais denso a partir de Abril de 2014, quando acontece a transição do regime de variação lenta para o de colapso. Como a época em que aparecem as altas velocidades da componente em absorção pode colocar fortes restrições nos parâmetros orbitais, é de extrema importância monitorar a fase de transição de regimes para determinar quando o material com altas velocidades começa a cruzar a linha de visada. No entanto, no evento de 2014, o acompanhamento das épocas logo após a fase zero será impossibilitado porque $\eta$ Car deixará de ser visível no céu noturno. Por isso, o ideal seria a realização de um monitoramento no Polo Sul, utilizando um telescópio de pequeno porte, o que daria uma amostragem temporal de horas. Entretanto, os custos para tal empreitada são elevados, podendo inviabilizar a execução deste projeto.

Os dados do monitoramento de 2009.0 (obtidos com o Goodman/SOAR), juntamente com os dados de 2003.5 (obtidos no OPD), permitirão uma maior precisão na determinação da fase zero e, possivelmente, até mesmo a detecção do momento em que a estrela secundária passa pelo periastro. 


\section{Referências Bibliográficas}

Abraham, Z. \& Falceta-Gonçalves, D.: 2007, Wind-wind collision in the $\eta$ Carinae binary system - III. The HeII $\lambda 4686$ line profile, MNRAS 378, 309

Abraham, Z., Falceta-Gonçalves, D., Dominici, T., Caproni, A., \& Jatenco-Pereira, V.: 2005, Wind-wind collision in the $\eta$ Carinae binary system - II. Constraints to the binary orbital parameters from radio emission near periastron passage, MNRAS 364, 922

Agnoletto, I., Benetti, S., Cappellaro, E., Zampieri, L., Turatto, M., Mazzali, P., Pastorello, A., Valle, M. D., Bufano, F., Harutyunyan, A., Navasardyan, H., Elias-Rosa, N., Taubenberger, S., Spiro, S., \& Valenti, S.: 2009, SN 2006gy: Was it Really Extraordinary?, ApJ 691, 1348

Akashi, M., Soker, N., \& Behar, E.: 2006, Accretion onto the Companion of $\eta$ Carinae during the Spectroscopic Event. II. X-Ray Emission Cycle, ApJ 644, 451

Alexander, M. E.: 1976, Precession and nutation in close binary systems, ApESSS 45, 105

Allen, D. A. \& Hillier, D. J.: 1993, The Shape of the Homunchulus Nebula around Eta-Carinae, Proceedings of the Astronomical Society of Australia 10, 338

Andriesse, C. D., Packet, W., \& de Loore, C.: 1981, The fluctuation theory of mass loss - Application to the evolution of massive stars, A\& $A$ 95, 202

Bath, G. T.: 1979, Accretion powers the brightest stars, Nature 282, 274

Bautista, M. A., Gull, T. R., Ishibashi, K., Hartman, H., \& Davidson, K.: 2002, Excitation of Srii lines in Eta Carinae, MNRAS 331, 875 
Bautista, M. A., Hartman, H., Gull, T. R., Smith, N., \& Lodders, K.: 2006, [TiII] and [NiII] emission from the strontium filament of $\eta$ Carinae, MNRAS 370, 1991

Bohigas, J., Tapia, M., Ruiz, M. T., \& Roth, M.: 2000, Possible detection of an old bipolar shell associated with $\eta$ Carinae, MNRAS 312, 295

Borgwald, J. M. \& Friedlander, M. W.: 1993, Eta Carinae - A new model, ApJ 408, 230

Burbidge, G. R.: 1962, A Speculation Concerning the Evolutionary State of Eta Carinae., ApJ 136, 304

Burbidge, G. R. \& Stein, W. A.: 1970, Cosmic Sources of Infrared Radiation, ApJ 160, 573

Cardelli, J. A., Clayton, G. C., \& Mathis, J. S.: 1988, The determination of ultraviolet extinction from the optical and near-infrared, ApJL 329, L33

Carpenter, J. M., Snell, R. L., \& Schloerb, F. P.: 1990, Molecular clouds associated with luminous far-infrared sources in the outer Galaxy, ApJ 362, 147

Castor, J. I., Abbott, D. C., \& Klein, R. I.: 1975, Radiation-driven winds in Of stars, ApJ 195, 157

Corcoran, M. F.: 2005, X-Ray Monitoring of $\eta$ Carinae: Variations on a Theme, AJ 129, 2018

Cox, P., Mezger, P. G., Sievers, A., Najarro, F., Bronfman, L., Kreysa, E., \& Haslam, G.: 1995, Millimeter emission of eta Carinae and its surroundings, $A \& A$ 297, 168

Crowther, P. A.: 2007, Physical Properties of Wolf-Rayet Stars, ARA\& A 45, 177

Currie, D. G., Dowling, D. M., Shaya, E. J., Hester, J., Scowen, P., Groth, E. J., Lynds, R., O'neil, Jr., E. J., \& Wide Field/Planetary Camera Instrument Definition Team: 1996, Astrometric Analysis of the Homunculus of eta Carinae With the Hubble Space Telescope, AJ 112, 1115

Damineli, A.: 1996, The 5.52 Year Cycle of Eta Carinae, ApJ 460, L49 
Damineli, A., Conti, P. S., \& Lopes, D. F.: 1997, Eta Carinae: a long period binary?, New Astronomy 2, 107

Damineli, A., Hillier, D. J., Corcoran, M. F., Stahl, O., Groh, J. H., Arias, J., Teodoro, M., Morrell, N., Gamen, R., Gonzalez, F., Leister, N. V., Levato, H., Levenhagen, R. S., Grosso, M., Colombo, J. F. A., \& Wallerstein, G.: 2008, A multispectral view of the periodic events in $\eta$ Carinae, MNRAS 386, 2330

Damineli, A., Hillier, D. J., Corcoran, M. F., Stahl, O., Levenhagen, R. S., Leister, N. V., Groh, J. H., Teodoro, M., Albacete Colombo, J. F., Gonzalez, F., Arias, J., Levato, H., Grosso, M., Morrell, N., Gamen, R., Wallerstein, G., \& Niemela, V.: 2008, The periodicity of the $\eta$ carinae events, MNRAS 384, 1649

Damineli, A., Kaufer, A., Wolf, B., Stahl, O., Lopes, D. F., \& de Araújo, F. X.: 2000, $\eta$ Carinae: Binarity Confirmed, ApJ 528, L101

Damineli, A., Stahl, O., Kaufer, A., Wolf, B., Quast, G., \& Lopes, D. F.: 1998, Long-term spectroscopy of eta Carinae. I. The high and low excitation phases, A\&AS 133, 299

Damineli, A., Stahl, O., Wolf, B., Kaufer, A., \& Jablonski, F. J.: 1999, The Historical Evidence for the 5. 52-Year Cycle, em J. A. Morse, R. M. Humphreys, \& A. Damineli (eds.), Eta Carinae at The Millennium, Vol. 179 of Astronomical Society of the Pacific Conference Series, pp 221-+

Davidson, K.: 1971, On the nature of Eta Carinae., MNRAS 154, 415

Davidson, K.: 1987, The relation between apparent temperature and mass-loss rate in hypergiant eruptions, ApJ 317, 760

Davidson, K.: 1999, Why the Binary Hypothesis Isn't a Panacea, em J. A. Morse, R. M. Humphreys, \& A. Damineli (eds.), Eta Carinae at The Millennium, Vol. 179 of Astronomical Society of the Pacific Conference Series, pp 304-+

Davidson, K., Dufour, R. J., Walborn, N. R., \& Gull, T. R.: 1986, Ultraviolet and visual wavelength spectroscopy of gas around ETA Carinae, ApJ 305, 867 
Davidson, K., Ebbets, D., Johansson, S., Morse, J. A., \& Hamann, F. W.: 1997, HST/GHRS Observations of the Compact Slow Ejecta of ETA Carinae, AJ 113, 335

Davidson, K., Ebbets, D., Weigelt, G., Humphreys, R. M., Hajian, A. R., Walborn, N. R., \& Rosa, M.: 1995, HST/FOS spectroscopy of ETA Carinae: the star itself, and ejecta within 0.3 arcsec, $A J \mathbf{1 0 9}, 1784$

Davidson, K., Gull, T. R., \& Ishibashi, K.: 2001, Recent Results from HST/STIS Spectroscopy of eta Carinae, em M. de Groot \& C. Sterken (eds.), P Cygni 2000: 400 Years of Progress, Vol. 233 of Astronomical Society of the Pacific Conference Series, pp $173-+$

Davidson, K., Smith, N., Gull, T. R., Ishibashi, K., \& Hillier, D. J.: 2001, The Shape and Orientation of the Homunculus Nebula Based on Spectroscopic Velocities, AJ 121, 1569

Davidson, K., Walborn, N. R., \& Gull, T. R.: 1982, The remarkable spectrum of some material ejected by Eta Carinae, ApJL 254, L47

de Jager, C.: 1984, The stability limit of hypergiant photospheres, A\& A 138, 246

Doom, C., de Greve, J. P., \& de Loore, C.: 1986, Stellar evolution in the upper Hertzsprung-Russell diagram, ApJ 303, 136

Dufour, R. J.: 1989, Shell nebulae around luminous evolved stars, Revista Mexicana de Astronomia y Astrofisica, vol. 18 18, 87

Dufour, R. J., Glover, T. W., Hester, J. J., Currie, D. G., van Orsow, D., \& Walter, D. K.: 1999, HST-FOS UV-Optical Spectra of Ejecta from Eta Carinae: an Atlas and Discussion, em J. A. Morse, R. M. Humphreys, \& A. Damineli (eds.), Eta Carinae at The Millennium, Vol. 179 of Astronomical Society of the Pacific Conference Series, pp $134-+$

Duncan, R. A. \& White, S. M.: 2003, Radio evidence of recent mass ejection from $\eta$ Carinae, MNRAS 338, 425 
Duncan, R. A., White, S. M., \& Lim, J.: 1997, Evolution of the radio outburst from the supermassive star eta Carinae from 1992 to 1996, MNRAS 290, 680

Falceta-Gonçalves, D. \& Abraham, Z.: 2009, Constraining the orbital orientation of $\eta$ Carinae from H Paschen lines, MNRAS pp 1245-+

Falceta-Gonçalves, D., Jatenco-Pereira, V., \& Abraham, Z.: 2005, Wind-wind collision in the $\eta$ Carinae binary system: a shell-like event near periastron, $M N R A S \mathbf{3 5 7}, 895$

Feast, M., Whitelock, P., \& Marang, F.: 2001, Variability of $\eta$ Carinae - III, MNRAS 322,741

Feinstein, A. \& Marraco, H. G.: 1974, On a possible three-year cycle of eta Carinae., $A \mathscr{G} A$ 30, 271

Fernandez Lajus, E., Gamen, R., Schwartz, M., Salerno, N., Llinares, C., Farina, C., Amorín, R., \& Niemela, V.: 2003, Optical CCD Observations of Eta Carinae at La Plata Observatory, Information Bulletin on Variable Stars 5477, 1

Filipovic, M. D., Jones, P. A., \& White, G. L.: 2003, The relation between radio flux density and ionising ultra-violet flux for HII regions and supernova remnants in the Large Magellanic Cloud, Serbian Astronomical Journal 166, 31

Fraley, G. S.: 1968, Supernovae Explosions Induced by Pair-Production Instability, ApESSS 2, 96

Gallagher, J. S.: 1989, Close binary models for luminous blue variables stars, em K. Davidson, A. F. J. Moffat, \& H. J. G. L. M. Lamers (eds.), IAU Colloq. 113: Physics of Luminous Blue Variables, Vol. 157 of Astrophysics and Space Science Library, pp $185-192$

Garmany, C. D. \& Fitzpatrick, E. L.: 1988, The H-R Diagrams of the Magellanic Clouds, em Bulletin of the American Astronomical Society, Vol. 20 of Bulletin of the American Astronomical Society, pp 967-+

Gaviola, E.: 1950, Eta Carinae. I. The Nebulosity., ApJ 111, 408 
Gaviola, E.: 1953, Eta Carinae. II. The Spectrum., ApJ 118, 234

Graham, J. R., Wright, G. S., \& Longmore, A. J.: 1987, Infrared spectroscopy of the supernova remnant IC 443, ApJ 313, 847

Gratton, L.: 1963, The problem of Eta Carinae, em L. Gratton (ed.), Star Evolution, pp $297-+$

Groh, J. H., Damineli, A., \& Jablonski, F.: 2007, Spectral atlas of massive stars around He I $10830 \AA, A \& A$ 465, 993

Gull, T. R., Ishibashi, K., \& Davidson, K.: 2001, Nebular observations of the ejecta surrounding eta Carinae using the STIS and HST, em M. de Groot \& C. Sterken (eds.), P Cygni 2000: 400 Years of Progress, Vol. 233 of Astronomical Society of the Pacific Conference Series, pp 185-+

Gull, T. R., Nielsen, K. E., Corcoran, M. F., Madura, T. I., Owocki, S. P., Russell, C. M. P., Hillier, D. J., Hamaguchi, K., Kober, G. V., Weis, K., Stahl, O., \& Okazaki, A. T.: 2009, The extended interacting wind structure of Eta Carinae, MNRAS 396, 1308

Hamaguchi, K., Corcoran, M. F., Gull, T., Ishibashi, K., Pittard, J. M., Hillier, D. J., Damineli, A., Davidson, K., Nielsen, K. E., \& Kober, G. V.: 2007, X-Ray Spectral Variation of $\eta$ Carinae through the 2003 X-Ray Minimum, ApJ 663, 522

Hartman, H., Damineli, A., Johansson, S., \& Letokhov, V. S.: 2005, Time variations of the narrow Fe II and H I spectral emission lines from the close vicinity of $\eta$ Carinae during the spectral event of 2003, $A \mathscr{E} A$ 436, 945

Hartman, H., Gull, T., Johansson, S., Smith, N., \& HST Eta Carinae Treasury Project Team: 2004, Identification of emission lines in the low-ionization strontium filament near Eta Carinae, A\&A 419, 215

Hartman, H., Zethson, T., Johansson, S., Gull, T., Ishibashi, K., Davidson, K., \& Smith, N.: 2001, Identification of Lines in the Strontium Region of Eta Carinae, em T. R. 
Gull, S. Johannson, \& K. Davidson (eds.), Eta Carinae and Other Mysterious Stars: The Hidden Opportunities of Emission Spectroscopy, Vol. 242 of Astronomical Society of the Pacific Conference Series, pp 107-+

Henley, D. B., Corcoran, M. F., Pittard, J. M., Stevens, I. R., Hamaguchi, K., \& Gull, T. R.: 2008, Chandra X-Ray Grating Spectrometry of $\eta$ Carinae near X-Ray Minimum. I. Variability of the Sulfur and Silicon Emission Lines, ApJ 680, 705

Hillier, D. J., Davidson, K., Ishibashi, K., \& Gull, T.: 2001, On the Nature of the Central Source in $\eta$ Carinae, ApJ 553, 837

Hillier, D. J., Gull, T., Nielsen, K., Sonneborn, G., Iping, R., Smith, N., Corcoran, M., Damineli, A., Hamann, F. W., Martin, J. C., \& Weis, K.: 2006, The UV Scattering Halo of the Central Source Associated with $\eta$ Carinae, ApJ 642, 1098

Howarth, I. D. \& Prinja, R. K.: 1989, The stellar winds of 203 Galactic O stars - A quantitative ultraviolet survey, ApJS 69, 527

Hoyle, F., Solomon, P. M., \& Woolf, N. J.: 1973, Massive Stars and Infrared Sources, ApJL 185, L89+

Humphreys, R. M. \& Davidson, K.: 1979, Studies of luminous stars in nearby galaxies. III - Comments on the evolution of the most massive stars in the Milky Way and the Large Magellanic Cloud, ApJ 232, 409

Humphreys, R. M., Davidson, K., \& Koppelman, M.: 2008, The Early Spectra of Eta Carinae 1892 to 1941 and the Onset of its High Excitation Emission Spectrum, AJ 135,1249

Hutchings, J. B.: 1976, Stellar winds from hot supergiants, ApJ 203, 438

Iping, R. C., Sonneborn, G., Gull, T. R., Massa, D. L., \& Hillier, D. J.: 2005, Detection of a Hot Binary Companion of $\eta$ Carinae, ApJL 633, L37

Ishibashi, K., Gull, T. R., Davidson, K., Smith, N., Lanz, T., Lindler, D., Feggans, K., Verner, E., Woodgate, B. E., Kimble, R. A., Bowers, C. W., \& Kraemer, S. et al..: 
2003, Discovery of a Little Homunculus within the Homunculus Nebula of $\eta$ Carinae, AJ 125, 3222

Johansson, S. \& Letokhov, V. S.: 2005, Astrophysical laser operating in the OI 8446-Åline in the Weigelt blobs of $\eta$ Carinae, MNRAS 364, 731

Kasen, D., Heger, A., \& Woosley, S.: 2008, The First Stellar Explosions: Theoretical Light Curves and Spectra of Pair-Instability Supernovae, em B. W. O'Shea \& A. Heger (eds.), First Stars III, Vol. 990 of American Institute of Physics Conference Series, pp $263-267$

Kashi, A. \& Soker, N.: 2008a, Accretion onto the companion of Eta Carinae during the spectroscopic event. V: The infrared decline, New Astronomy 13, 569

Kashi, A. \& Soker, N.: 2008b, The orientation of the $\eta$ Carinae binary system, MNRAS 390,1751

Kashi, A. \& Soker, N.: 2009, Explaining the Early Exit of Eta Carinae from its 2009 X-Ray Minimum with the Accretion Model, ApJL 701, L59

Khaliullin, K. F.: 1974, Mass loss by Wolf-Rayet stars, Soviet Astronomy 18, 229

Lamers, H. J. G. L. M. \& Leitherer, C.: 1993, What are the mass-loss rates of O stars?, ApJ 412, 771

Le Sueur, A.: 1870, Observations with the Great Melbourne Telescope, in a Letter to Prof. Stokes, Royal Society of London Proceedings Series I 19, 18

Leitherer, C.: 2009, Empirical Mass-Loss Rates across the Upper Hertzsprung-RussellDiagram, ArXiv e-prints

Lynn, W. T.: 1907, Willaim John Burchell and eta Argus, The Observatory 30, 138

Maeder, A.: 1983, Evolution of chemical abundances in massive stars. I - OB stars, Hubble-Sandage variables and Wolf-Rayet stars - Changes at stellar surfaces and galactic enrichment by stellar winds. II - Abundance anomalies in Wolf-Rayet stars in relation with cosmic rays and 22/Ne in meteorites, $A \& A$ 120, 113 
Maeder, A.: 1992, The $\rho$-inversion and the geyser model for supergiant envelopes, em C. de Jager \& H. Nieuwenhuijzen (eds.), Instabilities in Evolved Super- and Hypergiants, pp $138-+$

Maeder, A. \& Desjacques, V.: 2001, The shape of eta Carinae and LBV nebulae, $A \mathscr{E} A$ 372, L9

Maeder, A. \& Meynet, G.: 1989, Grids of evolutionary models from 0.85 to 120 solar masses - Observational tests and the mass limits, A\&A 210, 155

Martin, J. C., Davidson, K., Humphreys, R. M., Hillier, D. J., \& Ishibashi, K.: 2006, On the He II Emission in $\eta$ Carinae and the Origin of Its Spectroscopic Events, ApJ 640, 474

Martin, J. C., Davidson, K., \& Koppelman, M. D.: 2006, The Chrysalis Opens? Photometry from the $\eta$ Carinae Hubble Space Telescope Treasury Project, 2002-2006, AJ 132,2717

Martins, F., Schaerer, D., \& Hillier, D. J.: 2005, A new calibration of stellar parameters of Galactic O stars, $A \mathscr{E} A$ 436, 1049

McGregor, P. J., Rathborne, J. M., \& Humphreys, R. M.: 1999, Optical Spectroscopy of the Eta Carinae Low-Excitation Event from Mt. Stromlo Observatory, em J. A. Morse, R. M. Humphreys, \& A. Damineli (eds.), Eta Carinae at The Millennium, Vol. 179 of Astronomical Society of the Pacific Conference Series, pp 236-+

McKee, C. F., Chernoff, D. F., \& Hollenbach, D. J.: 1984, Infrared spectroscopy of interstellar shocks, em M. F. Kessler \& J. P. Phillips (eds.), Galactic and Extragalactic Infrared Spectroscopy, Vol. 108 of Astrophysics and Space Science Library, pp 103-131

Meaburn, J.: 1999, The Extensive $\eta$ Carinae Scattering and Emission-Line Nebulosities, em J. A. Morse, R. M. Humphreys, \& A. Damineli (eds.), ASP Conf. Ser. 179: Eta Carinae at The Millennium, p. 159 
Mezger, P. G. \& Henderson, A. P.: 1967, Galactic H II Regions. I. Observations of Their Continuum Radiation at the Frequency 5 GHz, ApJ 147, 471

Mezger, P. G., Smith, L. F., \& Churchwell, E.: 1974, IR-excess Radiation and the Absorption Characteristics of Dust in Galactic H II Regions, A $\mathscr{E} A$ 32, 269

Mokiem, M. R., de Koter, A., Evans, C. J., Puls, J., Smartt, S. J., Crowther, P. A., Herrero, A., Langer, N., Lennon, D. J., Najarro, F., Villamariz, M. R., \& Yoon, S.-C.: 2006, The VLT-FLAMES survey of massive stars: mass loss and rotation of early-type stars in the SMC, $A \& A 456,1131$

Morgan, L. K., Thompson, M. A., Urquhart, J. S., White, G. J., \& Miao, J.: 2004, A radio and mid-infrared survey of northern bright-rimmed clouds, $A \mathscr{E} A$ 426, 535

Morse, J. A., Davidson, K., Bally, J., Ebbets, D., Balick, B., \& Frank, A.: 1998, Hubble Space Telescope Wide Field Planetary Camera 2 Observations of eta Carinae, AJ 116, 2443

Morse, J. A., Kellogg, J. R., Bally, J., Davidson, K., Balick, B., \& Ebbets, D.: 2001, Hubble Space Telescope Proper-Motion Measurements of the $\eta$ Carinae Nebula, ApJ 548, L207

Nielsen, K. E., Ivarsson, S., \& Gull, T. R.: 2007, Eta Carinae across the 2003.5 Minimum: Deciphering the Spectrum toward Weigelt D, ApJS 168, 289

Nielsen, K. E., Kober, G. V., Weis, K., Gull, T. R., Stahl, O., \& Bomans, D. J.: 2009, Eta Carinae Across the 2003.5 Minimum: Analysis in the Visible and Near-Infrared Spectral Region, ApJS 181, 473

Ofek, E. O., Cameron, P. B., Kasliwal, M. M., Gal-Yam, A., Rau, A., Kulkarni, S. R., Frail, D. A., Chandra, P., Cenko, S. B., Soderberg, A. M., \& Immler, S.: 2007, SN 2006gy: An Extremely Luminous Supernova in the Galaxy NGC 1260, ApJL 659, L13 
Okazaki, A. T., Owocki, S. P., Russell, C. M. P., \& Corcoran, M. F.: 2008, Modelling the RXTE light curve of $\eta$ Carinae from a 3D SPH simulation of its binary wind collision, MNRAS 388, L39

Ostriker, J. P. \& Gunn, J. E.: 1971, Do Pulsars Make Supernovae?, ApJL 164, L95+

Owocki, S. P., Cranmer, S. R., \& Gayley, K. G.: 1996, Inhibition FO Wind Compressed Disk Formation by Nonradial Line-Forces in Rotating Hot-Star Winds, ApJL 472, $\mathrm{L} 115+$

Owocki, S. P., Cranmer, S. R., \& Gayley, K. G.: 1998, Latitudinal Dependence of Radiatively Driven Mass Loss from Rapidly Rotating Hot-Stars, em A. M. Hubert \& C. Jaschek (eds.), B[e] stars, Vol. 233 of Astrophysics and Space Science Library, pp $205-+$

Parkin, E. R., Pittard, J. M., Corcoran, M. F., Hamaguchi, K., \& Stevens, I. R.: 2009, 3D modelling of the colliding winds in $\eta$ Carinae - evidence for radiative inhibition, MNRAS 394, 1758

Penny, L. R. \& Gies, D. R.: 2009, A FUSE Survey of the Rotation Rates of Very Massive Stars in the Small and Large Magellanic Clouds, ApJ 700, 844

Pittard, J. M. \& Corcoran, M. F.: 2002, In hot pursuit of the hidden companion of eta Carinae: An X-ray determination of the wind parameters, $A \& A$ 383, 636

Pittard, J. M. \& Corcoran, M. F.: 2003, The Wind Properties of Eta Carinae, em J. Arthur \& W. J. Henney (eds.), Revista Mexicana de Astronomia y Astrofisica Conference Series, pp 81-81

Prinja, R. K., Barlow, M. J., \& Howarth, I. D.: 1990, Terminal velocities for a large sample of O stars, B supergiants, and Wolf-Rayet stars, ApJ 361, 607

Quimby, R. M., Aldering, G., Wheeler, J. C., Höflich, P., Akerlof, C. W., \& Rykoff, E. S.: 2007, SN 2005ap: A Most Brilliant Explosion, ApJL 668, L99 
Reynolds, R. J., Sterling, N. C., Haffner, L. M., \& Tufte, S. L.: 2001, Detection of [N II] $\lambda 5755$ Emission from Low-Density Ionized Interstellar Gas, ApJL 548, L221

Ringuelet, A. E.: 1958, Note on the nebulosity around Eta Carinae. Mit 1 Textabbildung, Zeitschrift fur Astrophysik 46, 276

Rodgers, A. W. \& Searle, L.: 1967, Spectrophotometry of the object $\eta$ Carinae, MNRAS 135, 99

Seab, C. G., Shull, J. M., \& McKee, C. F.: 1984, Emission from Interstellar Shocks with Grain Destruction, em Bulletin of the American Astronomical Society, Vol. 16 of Bulletin of the American Astronomical Society, pp 927-+

Shull, J. M. \& Draine, B. T.: 1987, The physics of interstellar shock waves, em D. J. Hollenbach \& H. A. Thronson, Jr. (eds.), Interstellar Processes, Vol. 134 of Astrophysics and Space Science Library, pp 283-319

Smith, N.: 2002, Dissecting the Homunculus nebula around Eta Carinae with spatially resolved near-infrared spectroscopy, MNRAS 337, 1252

Smith, N.: 2006, The Structure of the Homunculus. I. Shape and Latitude Dependence from $\mathrm{H}_{2}$ and [Fe II] Velocity Maps of $\eta$ Carinae, ApJ 644, 1151

Smith, N.: 2008, A blast wave from the 1843 eruption of $\epsilon$ Carinae, Nature 455, 201

Smith, N., Davidson, K., Gull, T. R., Ishibashi, K., \& Hillier, D. J.: 2003, Latitudedependent Effects in the Stellar Wind of $\eta$ Carinae, ApJ 586, 432

Smith, N., Foley, R. J., Bloom, J. S., Li, W., Filippenko, A. V., Gavazzi, R., Ghez, A., Konopacky, Q., Malkan, M. A., Marshall, P. J., Pooley, D., Treu, T., \& Woo, J.-H.: 2008, Late-Time Observations of SN 2006gy: Still Going Strong, ApJ 686, 485

Smith, N., Gehrz, R. D., \& Krautter, J.: 1998, The Infrared Morphology of eta Carinae, AJ 116, 1332 
Smith, N., Li, W., Foley, R. J., Wheeler, J. C., Pooley, D., Chornock, R., Filippenko, A. V., Silverman, J. M., Quimby, R., Bloom, J. S., \& Hansen, C.: 2007, SN 2006gy: Discovery of the Most Luminous Supernova Ever Recorded, Powered by the Death of an Extremely Massive Star like $\eta$ Carinae, ApJ 666, 1116

Smith, N. \& Morse, J. A.: 2004, Nitrogen and Oxygen Abundance Variations in the Outer Ejecta of $\eta$ Carinae: Evidence for Recent Chemical Enrichment, ApJ 605, 854

Smith, N., Morse, J. A., Collins, N. R., \& Gull, T. R.: 2004, The Purple Haze of $\eta$ Carinae: Binary-induced Variability?, ApJL 610, L105

Smith, N., Morse, J. A., Gull, T. R., Hillier, D. J., Gehrz, R. D., Walborn, N. R., Bautista, M., Collins, N. R., Corcoran, M. F., Damineli, A., Hamann, F., Hartman, H., Johansson, S., Stahl, O., \& Weis, K.: 2004, Kinematics and Ultraviolet to Infrared Morphology of the Inner Homunculus of $\eta$ Carinae, ApJ 605, 405

Smith, N., Vink, J. S., \& de Koter, A.: 2004, The Missing Luminous Blue Variables and the Bistability Jump, ApJ 615, 475

Soker, N.: 2003, Accretion-Induced Collimated Fast Wind Model for $\eta$ Carinae, ApJ 597, 513

Soker, N.: 2005, Accretion by the Secondary in $\eta$ Carinae During the Spectroscopic Event. I. Flow Parameters, ApJ 635, 540

Soker, N.: 2007, Accretion onto the Companion of $\eta$ Carinae during the Spectroscopic Event. IV. The Disappearance of Highly Ionized Lines, ApJ 661, 482

Soker, N. \& Behar, E.: 2006, Accretion onto the Companion of $\eta$ Carinae during the Spectroscopic Event. III. The He II $\lambda 4686$ Line, ApJ 652, 1563

Stahl, O., Weis, K., Bomans, D. J., Davidson, K., Gull, T. R., \& Humphreys, R. M.: 2005, A spectroscopic event of $\eta$ Car viewed from different directions: The data and first results, $A \mathscr{E} A$ 435, 303 
Steiner, J. E. \& Damineli, A.: 2004, Detection of He II $\lambda 4686$ in $\eta$ Carinae, ApJL 612, L133

Stothers, R. \& Chin, C.-W.: 1983, Possible mechanisms for the Hubble-Sandage /S Doradus/ variables, ApJ 264, 583

Stothers, R. B. \& Chin, C.-W.: 1993, Dynamical instability as the cause of the massive outbursts in Eta Carinae and other luminous blue variables, ApJL 408, L85

Talbot, Jr., R. J.: 1971, Nonlinear Pulsations of Unstable Massive Main-Sequence Stars. II. Finite-Amplitude Stability, ApJ 165, 121

Tammann, G. A. \& Sandage, A.: 1968, The Stellar Content and Distance of the Galaxy NGC 2403 IN the M81 Group, ApJ 151, 825

Tapia, M., Roth, M., Vázquez, R. A., \& Feinstein, A.: 2003, Imaging study of NGC 3372, the Carina nebula - I. UBVRIJHK photometry of $\operatorname{Tr} 14$, Tr 15, Tr 16 and Car I, MNRAS 339, 44

Teodoro, M., Damineli, A., Sharp, R. G., Groh, J. H., \& Barbosa, C. L.: 2008, Nearinfrared integral field spectroscopy of the Homunculus nebula around $\eta$ Carinae using Gemini/CIRPASS, MNRAS 387, 564

Thackeray, A. D.: 1949, Nebulosity surrounding eta Carinae, The Observatory 69, 31

Thackeray, A. D.: 1956, The distance and absolute magnitude of eta Carinae, The Observatory 76, 103

Thackeray, A. D.: 1967, Coudé spectra of Eta Carinae and the strongest lines of [Fe II] and [Ni II], MNRAS 135, 51

Tuthill, P., Monnier, J., Tanner, A., Figer, D., Ghez, A., \& Danchi, W.: 2006, Pinwheels in the Quintuplet Cluster, Science 313, 935

Tutukov, A. V. \& Yungelson, L. R.: 1980, The Evolutionary Status of Stars with M> 50-SOLAR-MASSES, Soviet Astronomy Letters 6, 271 
Usov, V. V.: 1992, Stellar wind collision and X-ray generation in massive binaries, ApJ $\mathbf{3 8 9}, 635$

van Boekel, R., Kervella, P., Schöller, M., Herbst, T., Brandner, W., de Koter, A., Waters,

L. B. F. M., Hillier, D. J., Paresce, F., Lenzen, R., \& Lagrange, A.-M.: 2003, Direct measurement of the size and shape of the present-day stellar wind of eta Carinae, $A \mathscr{E} A$ 410, L37

van Genderen, A. M., de Groot, M. J. H., \& The, P. S.: 1994, The optical and near infrared variability of eta Carinae: A binary luminous blue variable?, $A \& A$ 283, 89

van Genderen, A. M., Sterken, C., Allen, W. H., \& Walker, W. S. G.: 2006, An overview of the photometric events, trends and brightenings of eta Carinae, Journal of Astronomical Data 12, 3

Verner, E., Bruhweiler, F., \& Gull, T.: 2005, The Binarity of $\eta$ Carinae Revealed from Photoionization Modeling of the Spectral Variability of the Weigelt Blobs B and D, ApJ 624, 973

Viotti, R., Rossi, L., Cassatella, A., Altamore, A., \& Baratta, G. B.: 1989, The ultraviolet spectrum of Eta Carinae, ApJS 71, 983

von Zeipel, H.: 1924, The radiative equilibrium of a slightly oblate rotating star, $M N R A S$ 84,684

Walborn, N. R., Blanco, B. M., \& Thackeray, A. D.: 1978, Proper motions in the outer shell of Eta Carinae, ApJ 219, 498

Warren-Smith, R. F., Scarrott, S. M., Murdin, P., \& Bingham, R. G.: 1979, Optical polarization map of Eta Carinae and the nature of its outburst, MNRAS 187, 761

Weigelt, G. \& Ebersberger, J.: 1986, Eta Carinae resolved by speckle interferometry, $A \& A$ 163, L5

Weigelt, G., Kraus, S., Driebe, T., Petrov, R. G., Hofmann, K.-H., Millour, F., Chesneau, O., Schertl, D., Malbet, F., Hillier, J. D., Gull, T., Davidson, K., Domiciano de Souza, 
A., Antonelli, P., Beckmann, U., \& Bresson, Y.: 2007, Near-infrared interferometry of $\eta$ Carinae with spectral resolutions of 1500 and 12000 using AMBER/VLTI, $A \& A$ 464,87

Westphal, J. A. \& Neubebauer, G.: 1969, Infrared Observations of Eta Carinae to 20 Microns, ApJL 156, L45+

White, S. M., Duncan, R. A., Lim, J., Nelson, G. J., Drake, S. A., \& Kundu, M. R.: 1994, The radio source around Eta Carinae, ApJ 429, 380

Whitelock, P. A., Feast, M. W., Marang, F., \& Breedt, E.: 2004, The 2003 shell event in $\eta$ Carinae, MNRAS 352, 447

Woosley, S. E., Blinnikov, S., \& Heger, A.: 2007, Pulsational pair instability as an explanation for the most luminous supernovae, Nature 450, 390

Zanella, R., Wolf, B., \& Stahl, O.: 1984, Spectroscopy of the shell episode of Eta CAR (1981-1983), A\&A 137, 79

Zethson, T., Johansson, S., Davidson, K., Humphreys, R. M., Ishibashi, K., \& Ebbets, D.: 1999, Strange velocities in the equatorial ejecta of eta Carinae, $A \& A 344,211$ 


\section{Apêndice A}

\section{$A_{V}$ na direção da fonte central}

Todos os cálculos feitos nesta seção para determinação da extinção total na direção da fonte central baseiam-se nos resultados obtidos por Hillier et al. (2001), van Genderen et al. (2006). Também foram utilizados as observações fotométricas realizadas pelo grupo de La Plata, que possuem uma excelente amostragem temporal. Porém, como as observações do grupo de La Plata começaram em 2003.5, não foi possível determinar as taxas de variações do brilho de $\eta$ Car antes desta época. Por outro lado, van Genderen et al. (2006) mostraram que, baseado no resultado de Hillier et al. (2001), a extinção total na direção da fonte central em 2006.0, era $A_{V}(2006.0)=5.7$. Portanto, esta época foi utilizada como referência para a determinação do valor de $A_{V}$ para o evento de 2003.5 e 2009.0.

A Fig. A.1 mostra as taxas de variação no brilho da fonte central desde 1910. Nota-se que, desde a década de 40, o brilho tem aumentado de maneira contínua, a uma taxa de $-0.02 \mathrm{mag}_{\mathrm{ano}}{ }^{-1}$. Por volta de 1998, esta taxa aumentou para $-0.06 \mathrm{mag} \mathrm{ano}^{-1}$, mantendo-se assim até o presente. A natureza exata do aumento secular do brilho da fonte central ainda é incerto. No entanto, foi comprovado que tal aumento não se deve única e exclusivamente à diminuição da extinção na linha de visada. Além disso, existem, pelo menos, 3 componentes de extinção: a circunstelar, o Homúnculo e a interestelar, o que torna a questão de determinar o $A_{V}$ na direção da fonte central ainda mais complexa. Como o estudo e a decomposição de cada componente da extinção total na direção da fonte central não é o objetivo desta tese - mas sim, obter uma estimativa do valor de $A_{V}$ em duas 


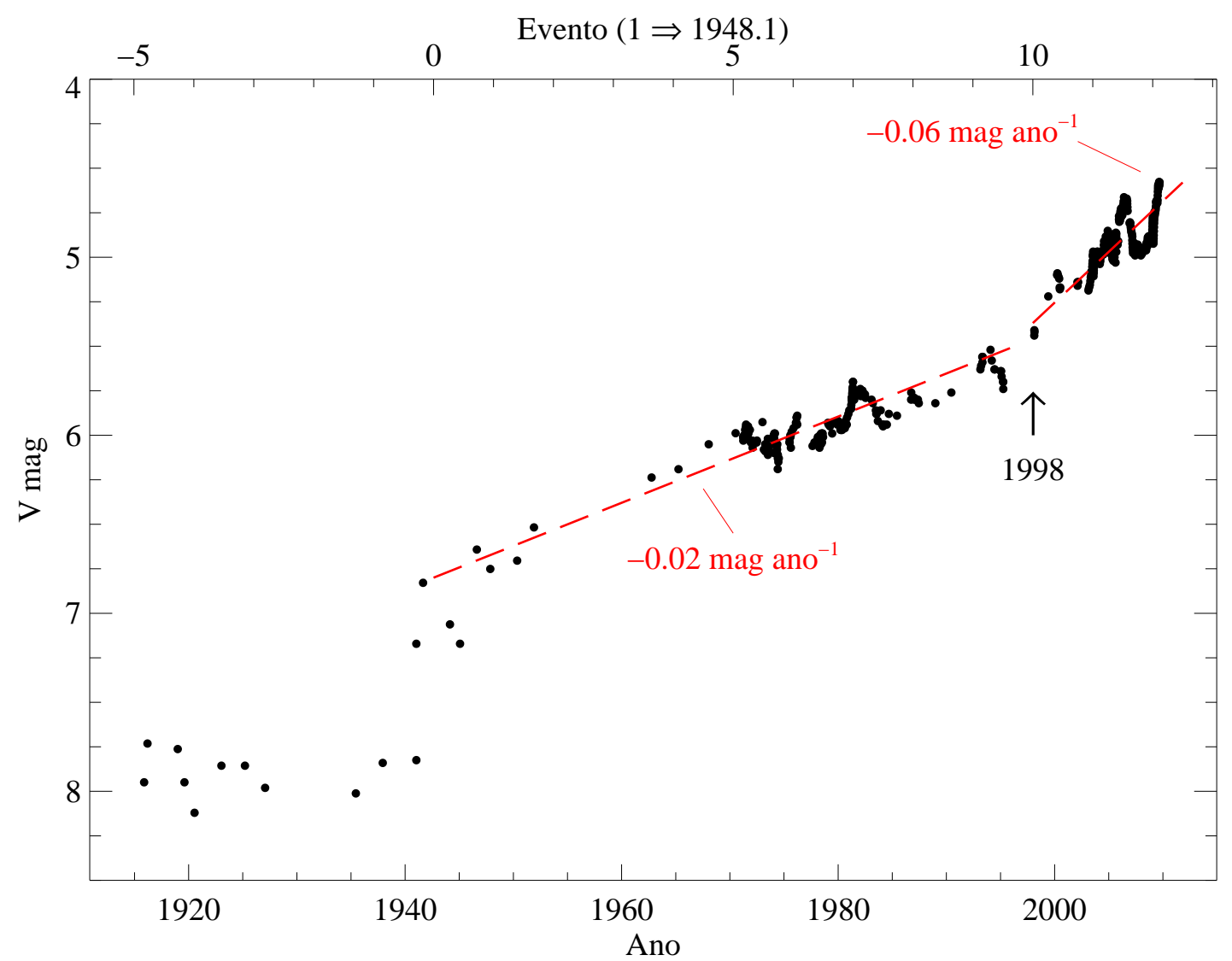

Figura A.1: Curva de luz de $\eta$ Car na banda $V$ desde 1910. Após o evento 0, em meados de 1942, houve um aumento de $\approx 1$ magnitude no brilho da fonte central em menos de 5 anos (-0.2 mag/ano). Depois disso, a taxa de aumento permaneceu constante em -0.02 mag/ano até o evento de 1997.9, quando passou para -0.06 mag/ano.

épocas (2003.5 e 2009.0) muito próximas à época de referência (2006.0) -, foi utilizada a aproximação de que a maior parte do aumento secular do brilho é devido a variações na componente circunstelar. Considerando que o Homúnculo apresenta uma taxa de expansão muito baixa e que a componente interestelar não se modifica, as considerações feitas nesta tese para a determinação de $A_{V}$ são razoáveis.

Conforme mencionado anteriormente, tomando como referência o valor para a extinção na direcão da fonte central de $A_{V}(2006.0)=5.7$ (determinado por van Genderen et al. (2006)) e corrigindo-o pela taxa observada de aumento do brilho desde 1998 $\left(\approx-0.06 \mathrm{mag} \mathrm{ano}^{-1}\right)$, obtem-se que $A_{V}(2003.5) \approx 5.6$ e $A_{V}(2009.0) \approx 5.9$.

Apesar de ser considerado, nesta tese, que as variações na curva de luz estejam associadas às variações somente na componente circunstelar, evidentemente, os valores obtidos neste apêndice para $A_{V}(2003.5)$ e $A_{V}(2009.0)$ incluem todas as componentes de extinção. 
Entretanto. conforme a discussão em Hillier et al. (2001) e o trabalho de van Genderen et al. (2006), existem cerca de 2 magnitudes de extinção cinza associada à componente circunstelar (o coronógrafo natural existente na linha de visada), onde os grãos podem ter dimensões maiores do que a observada no meio interestelar. Portanto, a lei de extinção para converter $A_{V}$ em $A_{\lambda=4686}$, deve ser aplicada somente à componente interestelar.

O estudo de van Genderen et al. (2006) mostrou que na direção da fonte central, a lei de extinção segue um comportamento regido por $R_{V}=4.9\left(=A_{V} / E(B-V)\right)$ e, utilizando o formalismo de Cardelli et al. (1988), finalmente obtem-se que o valor total da extinção é $A_{4686}(2003.5)=6.5$ e $A_{4686}(2009.0)=6.1$, onde a componente circunstelar (componente cinza) é responsável por 2 magnitudes de extinção. 


\section{Apêndice B}

\section{Artigos}

Neste Apêndice estão os artigos dos quais participei como autor ou co-autor e que geraram os resultados discutidos nesta tese.

1. Damineli, A.; Hillier, D. J.; Corcoran, M. F.; Stahl, O.; Levenhagen, R. S.; Leister, N. V.; Groh, J. H.; Teodoro, M.; Albacete Colombo, J. F.; Gonzalez, F.; Arias, J.; Levato, H.; Grosso, M.; Morrell, N.; Gamen, R.; Wallerstein, G. \& Niemela, V. The periodicity of the $\eta$ Carinae events, MNRAS, 2008, 384, 1649-1656;

2. Damineli, A.; Hillier, D. J.; Corcoran, M. F.; Stahl, O.; Groh, J. H.; Arias, J.; Teodoro, M.; Morrell, N.; Gamen, R.; Gonzalez, F.; Leister, N. V.; Levato, H.; Levenhagen, R. S.; Grosso, M.; Colombo, J. F. A. \& Wallerstein, G. A multispectral view of the periodic events in $\eta$ Carinae, MNRAS, 2008, 386, 2330-2344;

3. Teodoro, M.; Damineli, A.; Sharp, R. G.; Groh, J. H. \& Barbosa, C. L. Nearinfrared integral field spectroscopy of the Homunculus nebula around $\eta$ Carinae using Gemini/CIRPASS, MNRAS, 2008, 387, 564-576;

4. Teodoro et al. 2009, The Goodman/SOAR optical monitoring of the 2009.0 spectroscopic event of $\eta$ Carinae: (I) The He II $\lambda 4686$ light curve, em preparação. 


\title{
The periodicity of the $\eta$ Carinae events ${ }^{\star} \dagger+\oint \Phi$
}

\author{
A. Damineli, ${ }^{1} \|$ D. J. Hillier, ${ }^{2}$ M. F. Corcoran, ${ }^{3,4}$ O. Stahl, ${ }^{5}$ R. S. Levenhagen, ${ }^{1}$ \\ N. V. Leister, ${ }^{1}$ J. H. Groh, ${ }^{1}$ M. Teodoro, ${ }^{1}$ J. F. Albacete Colombo, ${ }^{6}$ F. Gonzalez, ${ }^{7}$ \\ J. Arias, ${ }^{8}$ H. Levato, ${ }^{7}$ M. Grosso, ${ }^{7}$ N. Morrell, ${ }^{9}$ R. Gamen, ${ }^{7}$ G. Wallerstein ${ }^{10}$ \\ and V. Niemela ${ }^{\star}$ \\ ${ }^{1}$ Instituto de Astronomia, Geofísica e Ciências Atmosféricas, Universidade de São Paulo, Rua do Matão 1226, Cidade Universitária, \\ São Paulo 05508-900, Brazil \\ ${ }^{2}$ Department of Physics and Astronomy, University of Pittsburgh, 3941 O'Hara Street, Pittsburgh, PA 15260, USA \\ ${ }^{3}$ CRESST and X-ray Astrophysics Laboratory, NASA/GSFC, Greenbelt, MD 20771, USA \\ ${ }^{4}$ Universities Space Research Association, 10211 Wincopin Circle, Suite 500 Columbia, MD 21044, USA \\ ${ }^{5}$ ZAH, Landessternwarte, Königstuhl 12, D-69117 Heidelberg, Germany \\ ${ }^{6}$ UNLP - Facultad de Ciencias Astronomicas y Geofisicas de La Plata (FCAGLP), Buenos Aires, Argentina \\ ${ }^{7}$ Complejo Astronomico El Leoncito, Casilla de Correo 467, San Juan, Argentina \\ ${ }^{8}$ Departamento de Física, Universidad de La Serena, Chile \\ ${ }^{9}$ Las Campanas Observatory, Carnegie Observatories, Casilla 601, La Serena, Chile \\ ${ }^{10}$ Department of Astronomy, University of Washington, Seattle, WA 98195, USA
}

Accepted 2007 December 5. Received 2007 November 1; in original form 2007 August 7

\begin{abstract}
Extensive spectral observations of $\eta$ Carinae over the last cycle, and particularly around the 2003.5 low-excitation event, have been obtained. The variability of both narrow and broad lines, when combined with data taken from two earlier cycles, reveal a common and welldefined period. We have combined the cycle lengths derived from the many lines in the optical spectrum with those from broad-band X-rays, optical and near-infrared observations, and obtained a period length of $P_{\text {pres }}=2022.7 \pm 1.3 \mathrm{~d}$.

Spectroscopic data collected during the last $60 \mathrm{yr}$ yield an average period of $P_{\text {avg }}=$ $2020 \pm 4 \mathrm{~d}$, consistent with the present-day period. The period cannot have changed by more than $\Delta P / P=0.0007$ since 1948. This confirms the previous claims of a true, stable periodicity, and gives strong support to the binary scenario. We have used the disappearance of the narrow component of He 16678 to define the epoch of the Cycle 11 minimum, $T_{0}=$ JD 245 2819.8. The next event is predicted to occur on 2009 January $11( \pm 2 \mathrm{~d})$. The dates for the start of the minimum in other spectral features and broad-bands are very close to this date, and have well-determined time-delays from the He I epoch.
\end{abstract}

Key words: stars: general - stars: individual: eta Carinae - stars: binary.

\section{INTRODUCTION}

$\eta$ Carinae is one of the most-luminous stars in the Milky Way and contains many mysteries. It has been attracting attention since the 1820 s, when it suffered large brightness fluctuations, culminating

\footnotetext{
^Based partially on data collected at the OPD-LNA/MCT.

$\dagger$ Based partially on data collected at ESO telescopes.

$\ddagger$ Based partially on data collected at the Casleo Observatory.

$\S$ Based partially on data collected at Magellan Telescopes.

\Based partially on data collected at CTIO.

||E-mail: damineli@astro.iag.usp.br

$\star \star$ Deceased
}

with the giant eruption that ejected the Homunculus in 1843. The star faded to naked eye invisibility, and after the discovery of the supernovae in the XIXth century it was classified as a slow supernova. However, around 1940, it started to brighten again, indicating that the star was only hidden by dust, not destroyed.

The spectrum is rich in emission lines of low-excitation species: HI, Fe II, [Fe II], [Ni II], Ti II, etc. (Thackeray 1953); after 1944 (Gaviola 1953) high-excitation forbidden lines of [Ne III], [Ar III], [S III] and [Fe III] can also be readily identified (see also Damineli et al. 1998, and references therein). Today, we know that the narrow lines (forbidden and permitted) are emitted in the Weigelt blobs (Weigelt \& Ebersberger 1986), at $\sim 0.3$ arcsec from the central star (Davidson et al. 1995) and the broad emission lines are formed in the wind of the central object (Hillier \& Allen 1992; Davidson et al. 
1995). The combination of high- and low-excitation lines in the same object, however, was paradoxical.

A key to understanding this interesting object was found recently through the study of the variability of the high-excitation lines. The high-excitation forbidden lines disappeared temporarily in 1948, and again in 1965, 1981, 1987 and 1992. These 'spectroscopic events' (Gaviola 1953; Rodgers \& Searle 1967; Thackeray 1967; Zanella, Wolf \& Stahl 1984) or 'low-excitation events' (Damineli et al. 1998) were believed to be part of S Doradus cycles, commonly seen in other Luminous Blue Variable stars similar to $\eta$ Carinae. This interpretation seemed to be supported by the He I $\lambda 10830$ line which went to minimum (Damineli 1996) when the near-infrared light curve went to maximum (Whitelock et al. 1994). The maxima in the near-infrared light curves were not truly periodic and the length of the quasi-period was different for different pass-bands. However, the spectroscopic events were demonstrated to be periodic (Damineli et al. 2000), in contrast to the incoherent character of the S Doradus oscillations. Damineli, Conti \& Lopes (1997) and others proposed a binary model with a highly eccentric orbit, a hotter secondary component and a strong wind-wind collision (WWC). Binarity is interesting as it potentially allows the direct measurement of the mass of the stars, their most fundamental parameter. The binary scenario has provided a framework for understanding the star and provided guidelines for fruitful observations, although some prefer a model in which there are periodic shell ejections (Martin et al. 2006). In Fig. 1, we present examples of high- and low-excitation-state spectra of $\eta$ Carinae.

The observation of an event in 1997.95, as was predicted, brought more confidence to the true periodic nature of the variation (Damineli et al. 2000). Feast, Whitelock \& Marang (2001) used archival spectra to identify three previously unreported events, in 1953, 1959 and 1970, which also fit the 5.5-yr period. Moreover, those authors discovered that the dips on top of the broad quasiperiodic near-infrared maxima were truly periodic and correlated with the behaviour of the high-excitation lines. An extensive X-raymonitoring campaign was started in 1996 with the RXTE satellite and revealed deep minima in 1997.95 and 2003.49 which coincided with the minima seen at other wavelengths (Corcoran 2005). X-ray observations inside and outside the minimum performed with Chandra and XMM furnished details on the column density $\left(N_{\mathrm{H}}\right)$, temperature and chemical composition of the colliding wind shock (Hamaguchi et al. 2007). van Genderen et al. (2006) showed that the optical light curve displays periodic dips like those in the nearinfrared and Lajús et al. (2003) reported a very detailed light curve in the $B, V, R$ and $I$ bands for the 2003.49 event. The events were recorded also at radio-cm (Duncan \& White 2003) and radio-mm (Abraham et al. 2005), but no specific value to the period length was reported for those wavelengths.

Many other features vary periodically in intensity and radial velocity, like the broad emission and P Cygni absorption components, and can also be used to derive the period length. One of them is He II $\lambda 4686$ discovered by Steiner \& Damineli (2004), which raises and drops just before minimum faster than any other feature over the entire spectrum. Although faint [equivalent width $(\mathrm{EW})<2 \AA$ ] it was frequently monitored with high signal-to-noise ratio $(\mathrm{S} / \mathrm{N})$ along the last event. Unfortunately, it was observed only occasionally in the previous events, precluding its use to measure the period. This spectral line deserves better monitoring in future events, not only to improve the accuracy of the derived period, but also because it is the highest-excitation feature observed at optical wavelengths, and its origin remains a mystery.

To facilitate discussion, we label the events by numbers as described by Groh \& Damineli (2004): number one (\#1) is assigned to the event observed in 1948 by Gaviola, so that the event of 2003.49 is \#11. We define cycle as the time-interval between the starting of two consecutive minima, so that cycle \#9 started at the 1992.42 minimum and finished when cycle \#10 was starting in 1997.95. Because of observational reasons, that will become clear later in this paper, the starting point of a cycle is defined by the disappearance of the $\mathrm{He}$ I $\lambda 6678$ narrow-line component. With this definition, phases along the cycle are defined in a unique way for all measured quantities.

This paper is organized as follows. We present in Section 2 the observations, in Section 3 the definition of phase 0 of the minimum, in Section 4 the determination of the period length, in Section 5 the stability of the period, in Section 6 the relation between the sharp peaks during the giant eruption and periastron passages, and in Section 7 the discussion and conclusions.

\section{OBSERVATIONS AND MEASUREMENTS}

The majority of the ground-based observations presented in this paper came from a monitoring campaign started in 1989 at the Coudé focus of the 1.6-m telescope of the Pico dos Dias Observatory (OPD-LNA/Brazil). The observational set-up at OPD was kept
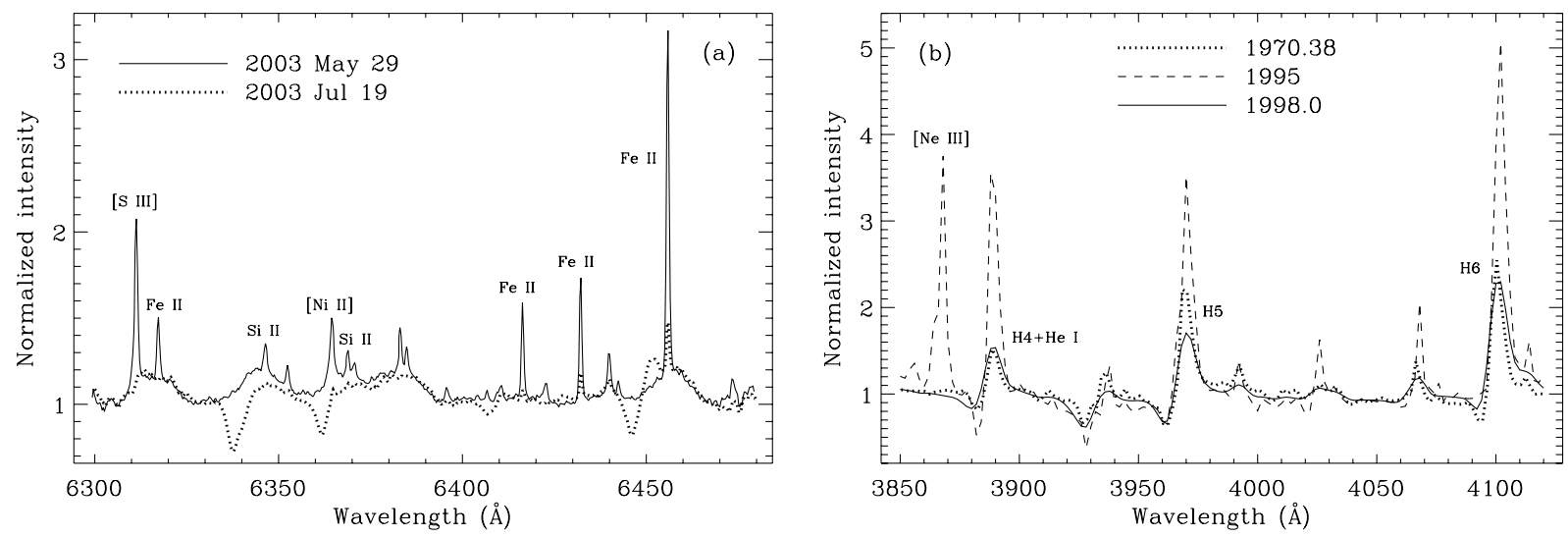

Figure 1. Sample of the $\eta$ Carinae spectra at high- and low-excitation states. (a) High-resolution red spectrum showing the disappearance of narrow emission lines and strengthening of P Cygni absorption components during the minimum. (b) Low-resolution blue spectra showing the high state in 1995 and two spectra during the minimum taken on 1997 December 31 and 1970 May 17. 
essentially unchanged through the campaign: a dispersion grating with $6001 \mathrm{~mm}^{-1}$, entrance slit-width $\sim 1.3$ arcsec, and exposure time $\sim 5 \mathrm{~s}$ in $\mathrm{H} \alpha$ increasing to $\sim 15 \mathrm{~min}$ at 3500 and $10800 \AA$. Spectra were extracted along $\sim 2$ arcsec in the spatial direction and no measurable differences in line intensities were seen when changing the extraction size by a factor of 2 . Three different CCDs have been used, with resolving powers $R=25 \mathrm{~km} \mathrm{~s}^{-1}\left(0.25 \AA\right.$ pixel $\left.^{-1}\right)$ at $\mathrm{H} \alpha$ in 2003 and $R=50 \mathrm{~km} \mathrm{~s}^{-1}\left(0.39 \AA\right.$ pixel $\left.^{-1}\right)$ in the preceding years. On some occasions, a $1024 \times 1024$ Hawaii detector was used to observe the He I $\lambda 10830$ line, delivering a spectral resolution $R=$ $40 \mathrm{~km} \mathrm{~s}^{-1}\left(0.65 \AA \mathrm{pixel}^{-1}\right)$. On other occasions, spectra of this line were taken at $R=15 \mathrm{~km} \mathrm{~s}^{-1}$ with a thinned CCD. After correcting for fringes and degrading the spectral resolution, these spectra were almost identical to those collected with the infrared array at the same date. Observations in 1992 and 1997-98 were done with a thick CCD that was almost free of fringes, but had a low sensitivity in the blue, which explains the poor coverage of important lines in that spectral range. For wavelengths longer than $6500 \AA$, telluric absorptions and fringes (in thinned CCDs) were removed by using templates constructed from spectra of bright early-type stars ( $\theta$ Carinae, $\zeta$ Ophiuci or $\zeta$ Puppis) observed immediately after or before $\eta$ Carinae.

For the 2003 event, we also used spectra taken with the spectrographs REOSC $\left(R=25 \mathrm{~km} \mathrm{~s}^{-1}\right)$ and $\operatorname{EBASIM}\left(R=7 \mathrm{~km} \mathrm{~s}^{-1}\right)$ attached to the 2.15-m CASLEO telescope (Argentina), and spectra taken at CTIO with the 4.0-m Echelle Spetrograph $\left(R=8 \mathrm{~km} \mathrm{~s}^{-1}\right)$ and at Magellan with the MIKE Spectrograph $\left(R=12 \mathrm{~km} \mathrm{~s}^{-1}\right)$. For the 1997-98 event, we used spectra collected at La Silla/ESO with CAT-CES $\left(R=12 \mathrm{~km} \mathrm{~s}^{-1}\right)$. For the 1992 event, we also used spectra collected with the FLASH/HEROS spectrograph attached to the $50-\mathrm{cm}$ telescope (ESO/Chile) with a fibre diameter $\sim 5$ arcsec and spectral resolution $R=12 \mathrm{~km} \mathrm{~s}^{-1}$. On several occasions, we used the FEROS spectrograph attached to the 1.52-m telescope at La Silla to cover the entire optical window at resolution $R=$ $12 \mathrm{~km} \mathrm{~s}^{-1}$.

Before measuring the spectral features, we degraded the spectra to a dispersion of $0.39 \AA$ pixel $^{-1}$. This step was not really necessary but it helped facilitate the adoption of the same limits between the narrow and broad components, and positioning of the stellar continuum, when measuring the spectra. Since we adopted the observations collected at the LNA Observatory as a reference, we added data from other sources only in the case where they merged smoothly to the line intensity curve. This criterion was fulfilled by almost all ground-based observations, confirming our expectation that slit-widths in the range 1-3 arcsec would give the same results independent of the position angle of the slit. This happens because the main emitting region is smaller than 1 arcsec and has a huge contrast to the surrounding Homunculus nebula and also because the seeing full width at half-maximum is larger than 1 arcsec, smearing out the emitting region. In a forthcoming paper (on the long-term behaviour of the spectral lines), we will present the complete list of observations from the entire campaign and a table with individual measurements. Fig. 1(a) displays spectra representative of the high- and low-excitation states, showing the disappearance of the high-excitation lines and enhancement of P Cygni absorption profiles during the minimum. Fig. 1(b) shows spectra in the blue for the high-excitation state of 1995 and for the low-excitation state of 1997 and 1970 (see also Damineli et al. 1998 for the full spectral range 3850-11000 A).

Spectra from the Space Telescope Imaging Spectrometer (STIS) onboard the Hubble Space Telescope are available for the 2003.49 and 1997.95 events, though for consistency we do not include them here since the slit-width is much narrower than used in the groundbased observations, sampling only a part of the inner circumstellar nebulosity. These data are of course important for disentangling stellar from circumstellar variations, and have been more fully described in Nielsen et al. (2007a), Nielsen, Ivarsson \& Gull (2007b), Gull, Kober \& Nielsen (2006) and Davidson et al. (2005). Since the wind of the primary star is resolved by the STIS slit and the slit's position angle varied in different visits, care must be taken when comparing line profiles from different epochs. This applies to the lower excitation transitions, formed far from the central source(s) that may be subject to spatial asymmetries.

All the data processing and measurements were done in the standard way using IRAF packages. Narrow lines were modelled by Gaussian fitting and deblended from the broad components. Since they are seated on top of broad line profiles, which are themselves variable, we referred their EWs to the local stellar continuum, in order that these measurements correspond to line flux normalized to the local stellar continuum, instead of classical EW. As in the case of EW, this kind of measurement is translated into line flux when multiplied by the stellar continuum flux. Because of this, we use the simple designation of EW in place of normalized line flux. Broad line emission profiles were separated from the narrow components, when they existed, and their EWs and baricentres (for radial velocities) were measured by direct integration along the line profile. Radial velocities are in the heliocentric reference system.

It is difficult to attribute errors to single measurements, as the main source is systematic, not statistical. The spectra were well exposed, in order that photon noise is very low, except in the violet region. The major source of error is linked to the stellar continuum, because of line blendings and changes in relative intensity of line/continuum, as the seeing changes and smears out the central source of emission lines. The random errors can be judged by the smoothness of the curves in line intensity and the plots show that they are small, in general comparable to the size of the symbols in the figures. We minimized the errors by overplotting the spectra and pointing the cursor always in the same position. We must warn, however, that this procedure does not eliminate the systematic errors.

\section{DEFINING PHASE O FOR THE SPECTROSCOPIC EVENT}

A simple method to measure the periodicity of the events is through the disappearance of spectroscopic features like the high-ionization lines or the narrow components of He I (Fig. 2a). In practice, this is difficult because of the following: (i) the time-sampling has been too coarse to pick up the exact time when the feature disappears; (ii) spectroscopic features reach minimum at different times; (iii) minima are usually reached asymptotically for many important spectral features, often taking up to a week to disappear completely; and (iv) when the line EWs are less than $\sim 100 \mathrm{~m} \AA$, they are difficult to measure, unless the spectra have very high $\mathrm{S} / \mathrm{N}$. In addition to producing a large uncertainty in the epoch of the minimum, faint features may not be directly connected to the emitting region, but can be light echoes that fall inside the slit aperture. Moreover, in some cases a very faint blended line remains in emission through the minimum, as in the case of [Ar III] $\lambda 7135$.

In order to minimize these problems, we restricted our analysis to the phase of steep decline, which lasts for $\sim 2$ weeks, starting $\sim 3$ weeks before complete disappearance. We performed a linear fit, and extrapolated it to zero intensity to determine the time of minimum (Fig. 2b). This procedure is much more robust than other techniques, since it does not require a dense time-sampling along the minimum. 

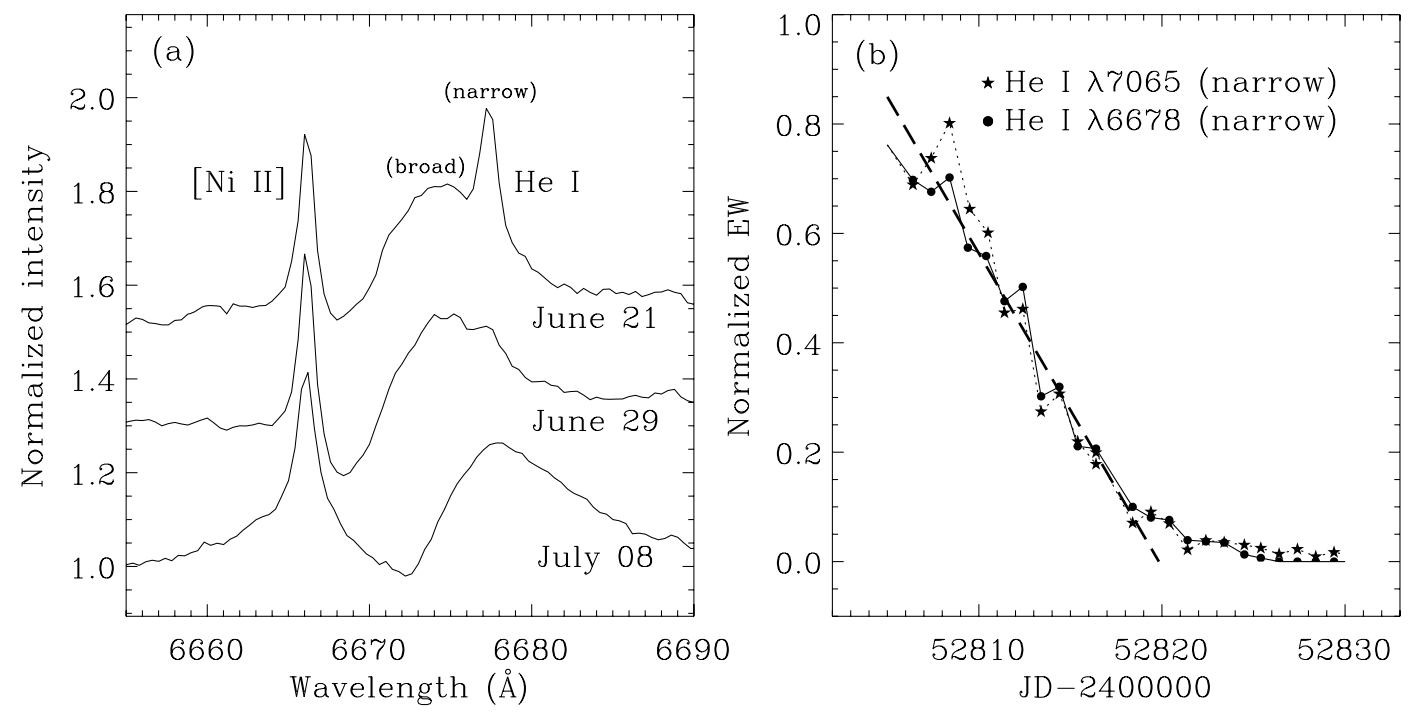

Figure 2. Definition of phase 0 - (a) He I $\lambda 6678$ line profiles observed along $17 \mathrm{~d}$ in 2003 , showing the disappearance of the narrow component. (b) The fading phase, showing our method to derive phase 0 (JD 245 2819.8) of $\mathrm{He} \mathrm{I} \lambda 6678$ and $\lambda 7065$ narrow-line components.

It is relatively insensitive to the $\mathrm{S} / \mathrm{N}$ of the spectrum, and is easily reproducible by other observers. The epoch of minimum, that is, phase 0 (the starting point of the deepest part of the minimum) for the He I $\lambda 6678$ narrow-line component derived by this method is $T_{0}=$ JD 2452819.8 (2003 June 29 or 2003.491). Since He I $\lambda 6678$ is strategic for the spectroscopic event (it has a long observational history, shows clear, easily measured variability and lies in a spectral range with good CCD efficiency), we chose it for our definition of phase 0 .

There are two situations for which it is useful to find signatures that indicate the time of phase 0: when examining non-calibrated historical spectra or when trying to track the evolution of an event during a monitoring campaign. As the high-excitation lines are much more variable than the lower excitation lines, and because the spectrum has plenty of lines, it is relatively easy to find line pairs that interchange peak intensity ratio with time. A high-excitation line, as the minimum approaches, decreases until its peak is equal in strength to that of some nearby low-excitation line (in general Fe II or [Fe II]), and we record the date when this occurs. The faster the high-excitation line varies, the more accurate is the determination of the time of change in the line ratio. This happens for dates close to phase 0 , when the variability is high, but we were able to find good line pairs up to three months before phase 0 and almost $2 \mathrm{yr}$ after.

We display in Table 1 the time in days for the inversion in peak intensity ratios, relative to phase 0 . Negative values represent dates before phase 0 and positive values dates later than phase 0 . Entries in column 2 are for the fading phase and in column 3 for the recovering phase, except for $\mathrm{He}$ I $\lambda 10830$, which displays the two ratio inversions in the fading phase. Times are shorter in column 2 than in column 3 due to the fact that the fading phase is fast and the recovering phase is slow. From an examination of data for the last three cycles, we found that times in column 2 are accurate to $\sim 15$ per cent and in column 3 to $\sim 25$ per cent.

In Table 1 , we have also listed the line He I $\lambda 10830$. It has a double peak, like in classical Be stars. The $V$ ('violet') and $R$ ('red') peaks are variable, both in intensity and in their relative strength. For almost the entire 5.5-yr cycle, $R>V$. As the minimum approaches, the $R$ peak starts decreasing faster than the other, in such a manner
Table 1. Time-delays in days, relative to phase 0 , when the intensity of line-peaks changes ratio.

\begin{tabular}{|c|c|c|}
\hline Line ratio & Change to $<1$ & Change to $>1$ \\
\hline He I $10830 R / V^{a}$ peaks & -105 & -4 \\
\hline He I 4471/[Fe II] 4475 & -46 & +550 \\
\hline [S III] 6312/Fe II 6317 & -15 & +442 \\
\hline [Fe III] 4658/[Fe II] 4640 & -17 & +358 \\
\hline Не I 7065/[Fe II] 7171 & -9 & +148 \\
\hline He I 6678/[Ni II] 6666 & -9 & +145 \\
\hline [Fe III] 4658/[Fe II] 4475 & -8 & +250 \\
\hline [Fe III] 4658/[Fe II] 4665 & -5 & +168 \\
\hline He I $5876 / \mathrm{Na}$ I 5890 & 0 & +18 \\
\hline [N II] 5754/[Fe II] 5746 & +1 & +79 \\
\hline Fe II 8490/Fe II 8499 & +7 & +40 \\
\hline
\end{tabular}

${ }^{a}$ 'Red' $(R)$ and 'violet' $(V)$ peak intensity ratio.

that $105 \mathrm{~d}$ before phase 0 they reach $V=R$, changing to $R<V$ subsequently. The $R<V$ state lasts for almost three months when the rate of fading of the $R$ peak slows down and the $V$ peak starts falling fast. Just $4 \mathrm{~d}$ before phase 0 , the peaks again reach $V=R$ and return to $R>V$.

\section{THE PERIOD LENGTH}

There are a number of ways to measure the period length; the best one for spectroscopic data is based on the He I narrow-line components. The $\mathrm{EW}$ of this feature remained relatively constant at $\sim 1500 \mathrm{~m} \AA$ for most of cycle \#10. About three weeks before phase 0 , it began to change fast, declining by $\sim 25 \mathrm{~m}^{\circ} \mathrm{d}^{-1}$. We used this segment of the line-intensity curve to measure the period, applying a scheme of epoch folding and minimization of differences similar to that used by Corcoran (2005). Since we sampled better the fading phase to the minimum, it was sufficient to shift this piece of the line-intensity curve from event \#10 until it matched that of event \#11 (Fig. 3a) to derive the period. We repeated the same procedure with event \#9, getting the best fit for $P=2026 \mathrm{~d}$ with an uncertainty of $2 \mathrm{~d}$. A careful examination of Fig. 3a, however, indicates that 

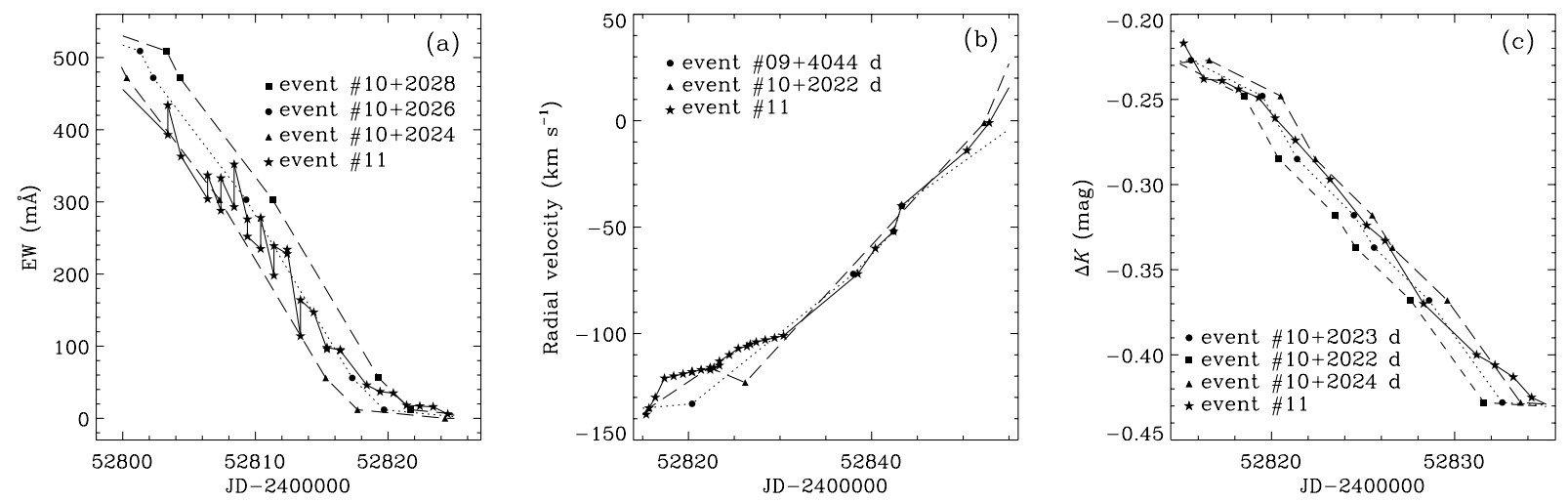

Figure 3. Period length: (a) from the EW He I $\lambda 6678$ narrow-line component along the latest two events; (b) from radial velocity of the He I $\lambda 6678$ broad component in the last three events; and (c) from the $K$ band by using the method of folding the two latest events and minimizing the residuals.

the slope of the fading phase was steeper during event \#10 than in event \#11. This is due to secular changing in the line intensity and this is the main source of errors in the period determination by this method.

The broad component of He I $\lambda 6678$ also changes quickly before the minimum. Its radial velocity decreases slowly in between the events, but three weeks before phase 0 it reverses the trend, and starts to increase. About 4 weeks after phase 0 , the radial velocity increases at a rate of $\sim 5 \mathrm{~km} \mathrm{~s}^{-1}$ per day. The steep rise in the radial velocity curve is useful to determine the period length, in the same way as we have done for intensity of the narrow component. This procedure might be more robust than using EWs, since radial velocities are much less affected by the secular variations in intensity. By combining radial velocities from the last three events (events \#9, $\# 10$ and \#11), we derive $P=2022 \pm 1 \mathrm{~d}$ (Fig. 3b).

Other spectral features were observed, whenever possible, and some of them also were useful for measuring the period length. The total EW of the He I $\lambda 10830$ line recorded in the last three events gives $P=2022 \pm 1 \mathrm{~d}$. The EW of the P Cygni absorption component of the Fe II $\lambda 6455 \AA$ line (also using the last three events) gives $P=$ $2021 \pm 2 \mathrm{~d}$ and the radial velocity curve of the same line (events $\# 9$ and \#11) results in $P=2022 \pm 2 \mathrm{~d}$. The EW of Si II $\lambda 6347 \AA \mathrm{P}$ Cygni component (events \#9 and \#11) results in $P=2022 \pm 1 \mathrm{~d}$.

These periods are in good agreement with $P=2024 \pm 2 \mathrm{~d}$ derived from X-rays (Corcoran 2005), with $P=2023 \pm 3 \mathrm{~d}$ from the $K$-band light curve (Whitelock et al. 2004), and with $P=2021.5 \pm$ $0.5 \mathrm{~d}$ from the $V$ band (van Genderen et al. 2006). We re-derived the periods obtained by those authors, using their published data and applying the technique of folding the pre-minimum branch of two events, events \#10 and \#11 in the case of Whitelock et al. (2004) and events \#7 and \#11 in the case of van Genderen et al. (2006). In the case of $V$-band photometry, we combined the light curve of van Genderen et al. (2006) with that of Lajús et al. (2003) in order to get a better definition of the descending branch of the 2003.5 minimum. The derived period was the same as published by van Genderen et al. (2006), but with an uncertainty of $2 \mathrm{~d}$ instead of $0.5 \mathrm{~d}$. In the case of near-infrared, Whitelock et al. (2004) used the lower point in the $K$-band minimum. Our procedure of minimization of residuals applied to the $J H K L$-band photometry (Fig. 3c) gave the same period, but with a tighter constraint. It is encouraging to see that the period is robustly defined, independent of the particular choices made by different authors during the measurements (Table 2).

Since there is no reason to suppose that the period length would depend on the particular technique used, we combined all these
Table 2. Period length in days from different spectral regions.

\begin{tabular}{ll}
\hline Period \pm error & Spectral feature or pass-band \\
\hline $2026 \pm 2$ & He I 6678 narrow component EW \\
$2024 \pm 2$ & X-rays \\
$2023 \pm 1$ & $J$ band \\
$2023 \pm 1$ & $H$ band \\
$2023 \pm 1$ & $K$ band \\
$2023 \pm 2$ & $L$ band \\
$2022 \pm 2$ & Fe II 6455 P Cygni absolute radial velocity \\
$2022 \pm 1$ & Si II 6347 EW \\
$2022 \pm 1$ & He I 6678 broad radial velocity \\
$2022 \pm 1$ & He I 10830 EW \\
$2021.5 \pm 2$ & $V$ band \\
$2021 \pm 2$ & Fe II 6455 P Cygni absolute EW \\
$2022.7 \pm 1.3$ & Average \pm standard deviation \\
\hline
\end{tabular}

individual periods to get a mean value to the period. We call it the present-day period $\left(P_{\text {pres }}\right)$ to differentiate from that determined from historical observations. Since the systematic errors may be more important than statistical errors, we report the uncertainty in the period as a simple standard deviation.

$P_{\text {pres }}=2022.7 \pm 1.3 \mathrm{~d} \quad$ or $\quad P_{\text {pres }}=5.538 \pm 0.004 \mathrm{yr}$.

Regarding the times of phase 0 , there is no reason to expect that different features give the same epoch, since they are produced in a variety of regions - in the stellar winds, in the WWC and in the circumstellar material. Since we are dealing mostly with spectroscopic lines, we define, for reasons discussed earlier, phase 0 of the spectroscopic events from the disappearance of the He I narrow-line intensity. This yields the following ephemeris:

$\mathrm{JD}($ phase 0$)=2452819.8 \pm 0.5+(2022.7 \pm 1.3 \mathrm{~d}) E$.

The uncertainty is only 0.07 per cent of the period length, which enables us to accurately predict the time of phase 0 of the next spectroscopic event: JD $2454842.5 \pm 2$ (2009 January 9-13).

\section{STABILITY OF THE PERIOD}

An important question is the long-term stability of the period, since the companion stars are losing mass at high rates and tidally interact during the periastron passages. In addition, the primary star could be a fast rotator - as indicated by its dense polar wind (Smith et al. 2003; van Boeckel et al. 2005; Weigelt et al. 2007) - and the specific 
Table 3. Period derived from epochs of predicted and observed minima.

\begin{tabular}{llllc}
\hline Cycle & $\begin{array}{l}\text { Pred. } \\
\text { JD }\left({ }^{b}\right)\end{array}$ & $\begin{array}{l}\text { Predicted } \\
(\text { Date })\end{array}$ & $\begin{array}{l}\text { Observed } \\
(\text { Date })\end{array}$ & $\begin{array}{c}P \\
(\mathrm{~d})\end{array}$ \\
\hline$\# 1$ & 32592.8 & 1948 February 11 & 1948 April 19 & $>2015.9$ \\
$\# 2$ & 34615.5 & 1953 October 26 & 1953 June 28 & $<2029.3$ \\
$\# 2$ & $”$ & " & 1953 December 30 & $>2009$ \\
$\# 3$ & 36638.2 & 1959 March 11 & 1959 May 14 & $>2014.4$ \\
$\# 4$ & 38660.9 & 1964 September 23 & 1965 February 15 & $>2001.9$ \\
$\# 5$ & 40683.6 & 1970 April 07 & 1970 May 17 & $>2016.0$ \\
$\# 7$ & 44729.0 & 1981 May 04 & 1981 May 21 & $>2018.6$ \\
$\# 8$ & 46751.7 & 1986 November 17 & 1987 January 15 & $>2003.1$ \\
$\# 9$ & 48774.40 & 1992 June 01 & 1992 May 31 & - \\
$\# 10$ & 50797.10 & 1997 December 15 & 1997 December 12 & - \\
\hline
\end{tabular}

${ }^{a}$ Intermediate excitation. ${ }^{b} \mathrm{JD}+2400000$.

angular momentum may be changing continuously. The coupling of rotational and orbital angular momentum may lead to an increase in the orbital period. A period derived from data encompassing many cycles may be hiding such variations. The only way to tackle this question is by comparing the present-day period (measured from the last few events) with the average period $\left(P_{\text {avg }}\right)$, derived from the events recorded in the past $60 \mathrm{yr}$.

We looked at the events reported by Feast et al. (2001). In case the spectrum was in low-excitation state, we assumed that it had just reached the minimum and so was at phase 0 . As a matter of fact, phase 0 must have occurred already at some time before the observation, in order that a period based on that record would underestimate the period. The average period, or more precisely a lower limit to it, is obtained from the time-interval between that date and the last recorded minimum (2003.49) divided by the number of cycles. The derived average periods are presented in column 5 of Table 3. We excluded the last three events, since they were used to derive the present-day period. The dates of observed minima in Table 3 (column 4) were taken from Feast et al. (2001), except for the observation on 1970 May 17. This spectrum (taken at CTIO) was recorded by Virpi Niemela and indicates that phase 0 occurred at least $8 \mathrm{~d}$ before Thackeray's observation reported by Feast et al. (2001). The CTIO logbook reports that spectra were taken by Barry

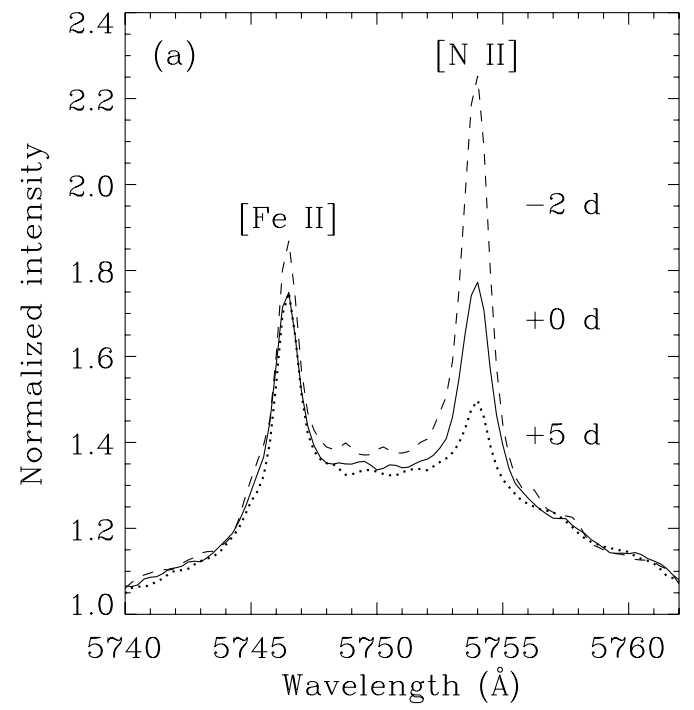

Lasker a day before phase 0 of the 1970 event (April 6), which could lead to a very tight constraint on the period, but unfortunately we were not able to locate that spectral plate.

The observation made on 1948 April 19 gives $P_{\text {avg }}>2015.9$ d and that of 1981 May 21 gives $P_{\text {avg }}>2018.6$ d. We can constrain the period length also from the other side. A maximum period may be derived when a particular observation was made before phase 0 . This is the case for the observation made on 1953 June 28, when the star was approaching the minimum, but was still in an intermediate phase, which gives $P_{\text {avg }}<2029.3$ d. The average period is thus constrained to

$2029.3>P_{\text {avg }}>2018.6 \mathrm{~d}$.

The stability of the period can be obtained from the difference between the present-day period and the average period, taking into account that $P_{\text {avg }}$ refers to half of the cycles involved. The spectrum taken on 1953 June 28 indicates that the period cannot have decreased by more than $1.4 \mathrm{~d} \mathrm{cycle}^{-1}$ and that of 1948 April 19 implies that it cannot have increased by more than $1.4 \mathrm{~d} \mathrm{cycle}^{-1}$.

We have another way to constrain the average period using quantitative information of the first event in 1948. Gaviola (1953) reported that $[\mathrm{N} \mathrm{II}] \lambda 5754$ was fainter than $[\mathrm{Fe}$ II] $\lambda 5746$, which places the date of the observation in a particular range inside the low-excitation event. An examination of recent events indicates that before phase $0,[\mathrm{~N} \mathrm{II}]$ is much stronger than the neighbouring [Fe II] line. The [N II] line decreases quickly, in contrast to [Fe II] which undergoes small and slow changes. Both features reach equal intensity $0.7 \mathrm{~d}$ after phase 0 , as can be seen in Fig, 4(a), where variations during event \#11 are displayed. The [N II] line remains fainter than [Fe II] for a subsequent $78 \mathrm{~d}$. This can be seen in Fig. 4(b), which combines measurements made in the last three events. The ratio of these two lines is not sensitive to the slit-width or to the spectral resolution, as long as they are kept $<4 \operatorname{arcsec}$ or $R>2000$, respectively. The fact that the 1948 observation was done $<78$ d later than phase 0 , combined with the epoch of the 2003.49 minimum results in

$P_{\text {avg }}=2020 \pm 4$ d.

This period is compatible with that derived in the present-day data. Taking into account that the average was taken between

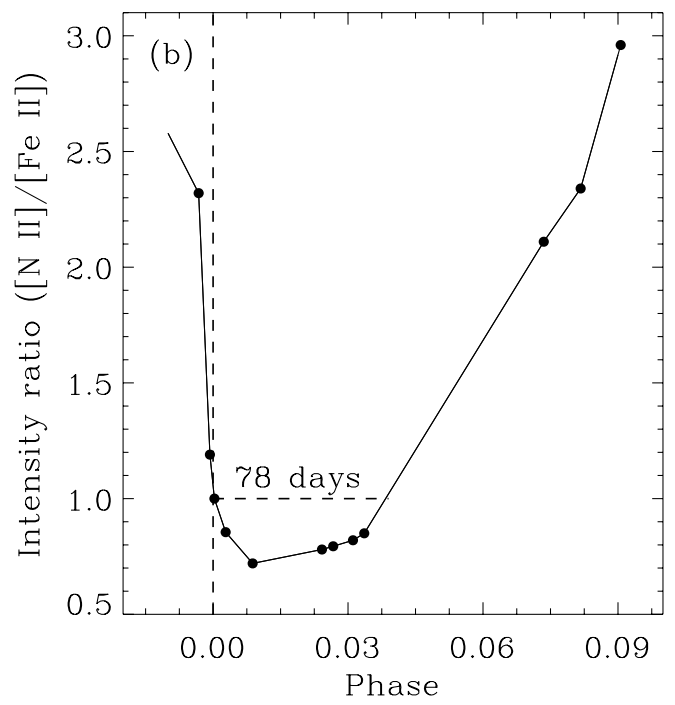

Figure 4. Relative intensities of [N II] $\lambda 5754$ and [Fe II] $\lambda 5746$ - (a) line profile variations. The labels on the right-hand side of the [N II] peak indicate days from phase 0 of the 2003.49 event. (b) Ratio between line peaks, indicating that $[\mathrm{N} \mathrm{II}] /[\mathrm{Fe} \mathrm{II}]<1.0$ starts at phase 0 and lasts for $78 \mathrm{~d}$ during the minimum. 
10 cycles, it could not have changed by more than $1.5 \mathrm{~d}_{\text {cycle }}{ }^{-1}$, in close agreement with $1.4 \mathrm{~d} \mathrm{cycle}^{-1}$ derived before. The constraint to the period change is

$-0.0007<\frac{\Delta P}{P}<+0.0007$.

This confirms previous claims of strict periodicity by Damineli (1996), Damineli et al. (2000) and Feast et al. (2001) implying that the low-excitation events are only understandable in the binary scenario. It is also consistent with the period change expected because of mass loss from the primary star. Simple considerations show that $\dot{P} / P=\alpha M / M$, where $\alpha$ is a constant of the order of unity (Khaliullin 1974). Ignoring changes in eccentricity, we find

$\dot{P}=0.11 \alpha\left(\frac{\dot{M}}{10^{-3} \mathrm{M}_{\odot} \mathrm{yr}^{-1}}\right)\left(\frac{100 \mathrm{M}_{\odot}}{M}\right) \mathrm{d} \mathrm{cycle}^{-1}$.

This is fully consistent with the observed upper limit.

\section{WERE THE PEAKS IN THE GIANT ERUPTION PRODUCED BY PERIASTRON PASSAGES?}

Damineli (1996) pointed out that the three most-pronounced peaks observed in 1827-43 were in close coincidence with the predicted times of phase 0 , when using the period $P=2014$ d. Frew (2004) also noted that the 'Lesser Eruption' which began on 1887.5 was within a few months of phase 0 . When using the new period, derived in this work $(P=2022.7 \mathrm{~d})$, the 1827.087 peak is now at phase 0.15 , that of 1837.967 is at phase 0.13 , and that of 1843.3 at phase 0.05 (Frew 2004), while the 1887.5 event corresponds to a phase of 0.96 . The correlation between peaks and the start of the spectroscopic events worsens with the new ephemeris. However, an exact correlation between the times of the peaks and phase 0 is not really relevant, since the time-sampling of the visual light curve was not very dense and the real maxima could have been missed by the observers. Moreover, if the mechanism that produced those peaks is the same as the one that produces the broad maxima observed presently in the near-infrared light curve, the lack of coincidence with phase 0 would not be a surprise. As reported by Whitelock et al. (2004), the $J H K$ light curves present maxima around phase 0 , but not in exact coincidence. These near-infrared peaks are quasiperiodic and may remain in high state for up to $3 \mathrm{yr}$, depending on the wavelength. Although the near-infrared light curve is anticorrelated with the radio flux, it still can be explained as free-free emission if optical depth effects are taken into account (Whitelock et al. 2004).

In the $V$ band, the maxima associated with the periastron are inconspicuous, as compared to those in the near-infrared. Could they have been more pronounced during the giant eruptions of the 19th century? There is no reason to believe so, as $\eta$ Carinae was much brighter in the optical than it is now, diminishing the contrast between the quasi-periodic maxima and the underlying stellar light. However, this is an unsafe terrain, as we do not know what mechanism produced the pronounced peaks during the giant eruption.

Recent estimates of the Homunculus mass suggest that more than $10 \mathrm{M}_{\odot}$ of material was ejected during the great eruption (Smith et al. 2003). Given the larger mass loss that occurred in the giant eruption, it is likely that the orbital parameters changed substantially during the great eruption, and thus it is not surprising that there is not a oneto-one correspondence between orbital phase and the pronounced peaks observed in 1827-43, even if they were a result of a binary interaction near periastron.

\section{DISCUSSION AND CONCLUSIONS}

We presented a homogeneous set of spectra covering events \#9 (1992.42), \#10 (1997.95) and \#11 (2003.49). We derived the period by measuring intensities of narrow lines (Weigelt blobs) and broad emission lines (stellar wind) and radial velocity variations from broad line components. These data, and others collected from the literature, enable an accurate determination of the period $P_{\text {pres }}=$ $2022.7 \pm 1.3 \mathrm{~d}$. An average period encompassing the past 11 cycles was found to be $P_{\text {avg }}=2020 \pm 4 \mathrm{~d}$, compatible with the present-day period. The period change is smaller than $1.5 \mathrm{~d} \mathrm{cycle}^{-1}$ along the last half century.

It is difficult to imagine any mechanism other than orbital motion which could maintain such a high stability, while allowing individual features to show the distinct light curves that are observed. No luminous unstable star is expected to follow such a precise clock. Even if it is conceivable that a shell ejection could be involved in the periodic events, it should be triggered by the periastron passage, when the secondary star approaches the primary to a few stellar radii. However, in a forthcoming paper, we show that the event starts when the secondary star is still near apastron.

We must expect that the period is drifting, since the stars are losing mass, they interact strongly as they get very close at periastron and the primary star appears to be a fast rotator. The period changes have been $\Delta P / P<1 / 1000$ along the last $60 \mathrm{yr}$, which is consistent with the observed mass-loss rate.

The situation is different for the eruptions of 1843 and 1890, when a considerable amount of matter was removed from the primary star in brief episodes. However, the relation between the pronounced peaks observed during the great eruption and periastron passages continues to be unknown. This is because the coincidence is not perfect, and because the peaks might not be strictly periodic but could still be associated with periastron passages, as seen presently in the near-infrared light curves.

From the disappearance of the He I $\lambda 6678$ narrow component, we determined the epoch of the start of the minimum to be $T_{0}=$ JD 245 2819.8. The procedure to define the minimum requires fitting and extrapolating the line-intensity variation along the descending part of the line-intensity curve, in the two weeks preceding the minimum intensity. Because of this definition, and since the starting time of the minimum is different from line to line, this definition is arbitrary and has no physical meaning. However, it is robust and demands only a few observations along $\sim 3$ weeks before the complete disappearance of the feature. Importantly, the time-delay for all other features to reach the minimum is well known.

The next minimum is predicted to start on 2009 January $11( \pm 2 \mathrm{~d})$. This will be the best event since 1948 for ground-based observations, since its central core fits entirely in the good observing season. The next favourable event will not occur before 2020. In order to improve the results presented in this work, daily observations should be made along a month starting on 2008 December 20.

\section{ACKNOWLEDGMENTS}

We thank J. E. Steiner and T. Gull for their comments on this draft. AD, JHG and MT thank FAPESP and CNPq for continuing support. Financial support from PIP-CONICET No. 5697 is acknowledged by JA. DJH acknowledges partial support from HST AR-10957. 


\section{REFERENCES}

Abraham Z., Falçeta-Gonçalves D., Dominici T. P., Nyman L.-Å D. P., McAulaife F., Caproni A., Jatenco-Pereira V., 2005, A\&A, 437, 977

Corcoran M. F., 2005, AJ, 129, 2018

Damineli A., 1996, ApJ, 460, L49

Damineli A., Conti P. S., Lopes D. F., 1997, New Astron., 2, 107

Damineli A., Stahl O., Kaufer A., Wolf B., Quast G., Lopes D. F., 1998, A\&AS, 133, 299

Damineli A., Kaufer A., Wolf B., Stahl O., Lopes D. F., de Araújo F. X., 2000, ApJ, 528, L101

Davidson K., Ebbets D., Weigelt G., Humphreys R. M., Hajian A. R., Walborn N. R., Rosa M., 1995, ApJ, 109, 1784

Davidson K. et al., 2005, AJ, 129, 900

Duncan R. A., White S. M., 2003, MNRAS, 338, 425

Feast M., Whitelock P., Marang F., 2001, MNRAS, 322, 741

Frew D. J., 2004, JAD, 10, 6

Gaviola E., 1953, ApJ, 118, 234

Groh J. H., Damineli A., 2004, Inf. Bull. Var. Stars 5492

Gull T. R., Kober G. V., Nielsen K. E., 2006, ApJS, 163, 173

Hamaguchi K. et al., 2007, ApJ, 663, 522

Hillier D. J., Allen D. A., 1992, A\&A, 262, 153

Khaliullin Kh. F., 1974, Astron. Zh., 51, 395 (1974, Sov. Astron., 18, 229)

Lajús E. F., Gamen R., Schwartz M., S alerno N., Llinares C., Fariña C., Amorín R., Niemela V., 2003, IBVS 5477
Martin J. C., Davidson K., Humphreys R. M., Hillier D. J., Ishibashi K., 2006, ApJ, 640, 474

Nielsen K. E., Corcoran M. F., Gull T. R., Hillier D. J., Hamaguchi K., Ivarsson S., Lindler D. J., 2007a, ApJ, 660, 669

Nielsen K. E., Ivarsson S., Gull T. R., 2007b, ApJS, 168, 289

Rodgers A. W., Searle L., 1967, MNRAS, 135, 99

Smith N., Gehrz R. D., Hinz P. M., Hoffmann W. F., Hora J. L., Mamajek E. E., Meyer M. R., 2003, AJ, 125, 1458

Steiner J. E., Damineli A., 2004, ApJ, 612, L133

Thackeray A. D., 1953, MNRAS, 113, 211

Thackeray A. D., 1967, MNRAS, 135, 51

van Boeckel R. et al., 2003, A\&A, 410, L37

van Genderen A. M., Sterken C., Allen W. H., Walker W. S. G., 2006, JAD, 12,3

Weigelt G., Ebersberger J., 1986, A\&A, 163, L5

Weigelt G. et al., 2007, A\&A, 464, 87

Whitelock P., Feast M. W., Koen C., Roberts G., Carter B. S., 1994, MNRAS, 270, 364

Whitelock P. A., Feast M. W., Marang F., Breedt E., 2004, MNRAS, 352, 447

Zanella R., Wolf B., Stahl O., 1984, A\&A, 137, 79

This paper has been typeset from a $\mathrm{T}_{\mathrm{E}} \mathrm{X} / \mathrm{LT} \mathrm{E} \mathrm{X}$ file prepared by the author 


\title{
A multispectral view of the periodic events in $\eta$ Carinae $^{\star} \dagger+\oint \Phi$
}

\author{
A. Damineli, ${ }^{1}$ | D. J. Hillier, ${ }^{2}$ M. F. Corcoran,,${ }^{3,4}$ O. Stahl, ${ }^{5}$ J. H. Groh, ${ }^{1}$ J. Arias, ${ }^{8}$ \\ M. Teodoro, ${ }^{1}$ N. Morrell, ${ }^{9}$ R. Gamen,${ }^{7}$ F. Gonzalez, ${ }^{7}$ N. V. Leister, ${ }^{1}$ H. Levato, ${ }^{7}$ \\ R. S. Levenhagen, ${ }^{1}$ M. Grosso, ${ }^{7}$ J. F. Albacete Colombo ${ }^{6}$ and G. Wallerstein ${ }^{10}$ \\ ${ }^{1}$ Instituto de Astronomia, Geofísica e Ciências Atmosféricas, Universidade de São Paulo, Rua do Matão 1226, \\ Cidade Universitária, São Paulo 05508-900, Brazil \\ ${ }^{2}$ Department of Physics and Astronomy, University of Pittsburgh, 3941 O'Hara Street, Pittsburgh, PA 15260, USA \\ ${ }^{3}$ CRESST and X-ray Astrophysics Laboratory, NASA/GSFC, Greenbelt, MD 20771, USA \\ ${ }^{4}$ Universities Space Research Association, 10211 Winconsin Circle, Suite 500 Columbia, MD 21044, USA \\ ${ }^{5}$ ZAH, Landessternwarte, Königstuhl 12, D-69117 Heidelberg, Germany \\ ${ }^{6}$ Facultad de Ciencias Astronomicas y Geofisicas de La Plata, Buenos Aires, Argentina \\ ${ }^{7}$ Complejo Astronomico El Leoncito, Casilla de Correo 467, San Juan, Argentina \\ ${ }^{8}$ Departamento de Fisica, Universidad de La Serena, Chile \\ ${ }^{9}$ Las Campanas Observatory, Carnegie Observatories, Casilla 601, La Serena, Chile \\ ${ }^{10}$ Department of Astronomy, University of Washington, Seattle, WA 98195, USA
}

Accepted 2008 March 10. Received 2008 February 28; in original form 2007 November 22

\begin{abstract}
A full description of the 5.5-yr low excitation events in $\eta$ Carinae is presented. We show that they are not as simple and brief as previously thought, but a combination of two components. The first, the slow variation component, is revealed by slow changes in the ionization level of circumstellar matter across the whole cycle and is caused by gradual changes in the windwind collision shock-cone orientation, angular opening and gaseous content. The second, the collapse component, is restricted to around the minimum, and is due to a temporary global collapse of the wind-wind collision shock. High-energy photons $(E>16 \mathrm{eV})$ from the companion star are strongly shielded, leaving the Weigelt objects at low-ionization state for more than six months. High-energy phenomena are sensitive only to the collapse, low energy only to the slow variation and intermediate energies to both components. Simple eclipses and mechanisms effective only near periastron (e.g. shell ejection or accretion on to the secondary star) cannot account for the whole 5.5-yr cycle.

We find anti-correlated changes in the intensity and the radial velocity of P Cygni absorption profiles in Fe II $\lambda 6455$ and He I $\lambda 7065$ lines, indicating that the former is associated to the primary and the latter to the secondary star. We present a set of light curves representative of the whole spectrum, useful for monitoring the next event (2009 January 11).
\end{abstract}

Key words: stars: general - stars: individual: $\eta$ Carinae.

\section{INTRODUCTION}

$\eta$ Carinae is one of the most-luminous and massive stars in the Milky Way. It underwent episodes of large mass ejections in recent centuries, one of them creating the Homunculus bipolar flow with $\sim 12 \mathrm{M}_{\odot}$ (Smith et al. 2003b). It continues to lose mass at a rate

\footnotetext{
${ }^{\star}$ Based partially on data collected at the OPD-LNA/MCT. $\dagger$ Based partially on data collected at ESO telescopes.

$\ddagger$ Based partially on data collected at Casleo Observatory.

$\S$ Based partially on data collected at Magellan Telescopes.

\Based partially on data collected at CTIO.

||E-mail: damineli@astro.iag.usp.br
}

of $\sim 10^{-3} \dot{\mathrm{M} \mathrm{yr}}{ }^{-1}$ through a stellar wind (Hillier et al. 2001), while intervening gas and dust precludes a clear view of the central source by ground-based observations.

Ground-based spectra show a mix of narrow, broad, permitted and forbidden emission lines (Hillier \& Allen 1992; Damineli et al. 1998), some of them displaying P Cygni absorption profiles. A comprehensive description of the spectrum is found in Damineli et al. (2008), hereafter Paper I, and in the references cited in that paper. The paradoxical aspect of the spectrum is the presence of lines from high- and low-energy states. On the basis of truly periodic variations in the lines, previous work was able to show that the central source is a binary star. The primary star is colder and more luminous and the invisible companion is hotter and fainter (Damineli et al. 2000). 
A tremendous wind-wind collision (WWC) was revealed from the X-ray light curve and spectra (Corcoran 2005; Ishibashi et al. 1999; Henley et al. 2008).

High-resolution images from the ground and from space showed the existence of condensations, named Weigelt objects (Weigelt \& Ebersberger 1986), that are the main source of narrow lines and of an extended stellar wind, from where broad lines are formed (Davidson et al. 1995).

Although we have a basic picture of the system, many details are not yet understood. This is because the spectrum is incredibly complex and variable. Moreover, the observational properties of variations in lines and continua have not been presented previously. Some key features, like the permitted broad emission-line He II $\lambda 4686$ (Steiner \& Damineli 2004) have just been discovered in this star, even if it is one of the most frequently observed in the entire sky. This line eluded detection for more than $50 \mathrm{yr}$, due to its faintness [equivalent width $(\mathrm{EW})<2 \AA$ ] and transient appearance just before minimum. In spite of being faint, it reveals a huge reservoir of high-energy photons. This line originates close to the central source, but the precise location and mechanism are unknown (Martin et al. 2006a; Soker \& Behar 2006). Temporal variations in the lines are an important tool to understand the system, but these have not been fully explored.

Extensive studies have also been made of the variability of $\mathrm{H} \alpha$. Davidson et al. (2005) examined the variability of HST STIS observations of $\mathrm{H} \alpha$ and showed that the profile did not repeat at the same phase. In particular, a flat topped $\mathrm{H} \alpha$ profile was observed during the 2003 event, but this was not seen during the 1998-99 event. Extensive UVES observations of the south-eastern lobe were also undertaken for the 2003 event (Stahl et al. 2005; Weis et al. 2005). As the light is reflected by the Homunculus, this allows the events to be observed from different directions. Reflected variability was seen, although the line profiles are different from what we see in the direction of the central star. This confirms that the event is not spherically symmetric, a property that could be interpreted as either a latitude dependent shell event or a consequence of the different viewing angles relative to the binary orbital plane. A consistent quantitative interpretation of these data set remains to be done.

In Paper I, we presented the fundamental parameters of the 5.5-yr cycle. They are the period length $P=2022.7 \pm 1.3 \mathrm{~d}$, the phase 0 on $T_{0}=\mathrm{JD} 2452819.8$ (defined by the disappearance of $\mathrm{He}$ I $\lambda 6678$ narrow component), and the high stability of the period during the last $60 \mathrm{yr}$, only understandable in a binary scenario. However, the events are not simple eclipses, and to decipher their nature we need to examine the temporal behaviour of the permitted and forbidden lines, and their associated features (broad, narrow and P Cygni components).

This paper is organized as follows. In Section 2, we present the source and quality of data; in Section 3, we present a general view where individual emission lines originate; in Section 4, we present the general framework of the binary model to interpret the data; in Section 5, we discuss the bimodal nature of the event; in Section 6, we discuss the peculiarities of the He I $\lambda 10830$ line; in Section 7, we present a multispectral view of the collapse component; and finally, in Section 8, we set forth a general discussion and our conclusions.

\section{DATA AND MEASUREMENTS}

In Paper I, we described the data acquisition and measurement, so only complimentary information is given here. Most of the data were taken at the Pico dos Dias Brazilian Observatory, with additional data taken at other South American Observatories in Argentina and
Chile. Spectra were normalized to the underlying stellar continuum and the measurements performed in the standard way with the IRAF package. Broad line emission profiles were separated from the narrow components and their EWs were measured by direct integration under the line profile, since their complexity prevented fitting by standard functions.

The lines reported here cover a wide range of excitation energy and lie in the optical and near-infrared (near-IR) windows. Except in the violet, the stellar continuum has signal-to-noise ratio of generally $\mathrm{S} / \mathrm{N}>100$. Close to $[\mathrm{Ne}$ III] $\lambda 3868 \AA$ the $\mathrm{S} / \mathrm{N}$ is smaller than near the other spectral lines, but this line is strong enough outside the minimum to produce accurate EWs. We do not present individual measurements and their associated errors, because this would require long tables and unnecessarily pollute the plots. Instead, we display average error bars in the figures. As a general rule, errors are $\sim 5$ per cent for $\mathrm{EW}>1 \AA$ and $\sim 50 \mathrm{~m} \AA$ for fainter lines. The best way to evaluate the statistical errors is by looking to the smoothness of the line intensity curves. As a matter of fact, the real uncertainties are dominated by systematic errors and these are difficult to assess. They are caused by the extreme richness of the spectrum, which makes it difficult to define the stellar continuum, and by line deblending procedures. Systematic errors are relatively unimportant in the present work, as we are looking for patterns in the temporal variability.

The spectral resolution varies from 15 to $50 \mathrm{~km} \mathrm{~s}^{-1}$ and, since the radial velocity is derived from integration over many pixels, the typical uncertainty is approximately one-tenth of the spectral resolution for a single pixel (better than $5 \mathrm{~km} \mathrm{~s}^{-1}$ ) Radial velocities are in the Heliocentric reference system.

\section{GENERAL INTERPRETATION OF THE SPECTRUM}

The ground-based spectra utilize a relatively large aperture, and thus sample both the central star, and different emitting regions in the circumstellar envelope (e.g. the equatorial disc, the Homunculus and the Little Homunculus). The different line contributions can be readily identified. First, there are the broad wind lines (H, Si II, Fe II), arising directly from the central star, which sample a large fraction of the wind. The broad line spectrum is similar to the P Cygni star HDE 316285 (Hillier \& Allen 1992; Hillier et al. 1998). Conversely, the P Cygni absorption components are only formed on our side of the wind, in the line-of-sight towards the primary star. Secondly, the broad components of He I emission lines, once thought to be related directly to the primary star, are now thought to be excited by the ultraviolet (UV) radiation of the companion (Hillier et al. 2006) and arise in the bow-shock/wind region between the two stars (Nielsen et al. 2007a). Thirdly, there are the narrow nebular lines which arise mainly in one of three Weigelt objects (Davidson et al. 1995). Forbidden lines display other components, in addition to the narrow ones, such as the blue displaced shoulders. They seem to come from an extended region around the central star. They peak at $-250 \mathrm{~km} \mathrm{~s}^{-1}$ in close coincidence with the speed of the gas in the radio spot at $\sim 1.1$ arcsec north-west from the central knot (Duncan, White \& Lim 1997; Teodoro et al. 2007) and both emissions could be physically connected. Fourthly, HST observations have revealed the existence of a 'Little Homunculus' which also has its own emission spectrum (Ishibashi et al. 2003). Fifthly, there is intrinsic emission from the Homunculus and equatorial disc, recognized by their radial velocity. Sixthly, the stellar spectrum can be seen in reflection off dust within the Homunculus. Unfortunately, in ground-based spectra, the relative contributions of these components to the ob- 
served spectrum may change with time, and in a manner not directly related to the binary orbit.

Hillier \& Allen (1992) showed that the nebular line emitting regions suffer significantly less extinction than does the central star. Indeed Hillier et al. (2001) estimated that the visual extinction to the central star was 7 mag in 1998 March, while Verner et al. (2002) and Verner, Brhuhweiler \& Gull (2005) used 0.5 mag for the visual extinction in their analysis of the Weigelt blob spectra observed in 1998 and 1999. It is this difference in visual extinction that causes the nebular spectra to be so bright, relative to the stellar spectrum, in ground-based spectra.

Recent HST observations have shown that the central star has brightened by a factor of 3 between 1998 and 2003.7 (Davidson et al. 1999; Martin \& Koppelman 2004), and has continued to brighten up to 2006.5 (Martin, Davidson \& Koppelman 2006b). Since the stellar spectrum has not undergone marked changes, the simplest explanation is that the circumstellar extinction has declined. Ground-based photometry also shows changes, although of smaller amplitude (van Genderen et al. 2006), due to dilution by 'Homunculus' emission. Because of the variable extinction and the scattered radiation in the Homunculus, the analysis of ground-based lines is complicated. During the last $25 \mathrm{yr}$, some lines in ground-based spectra have weakened. The observed changes could be due to intrinsic changes in the knot properties, changes in the primary or in the secondary star, or decreasing circumstellar extinction. The later would cause a weakening of the Weigelt nebular lines relative to the scattered stellar continuum.

In the case of He I $\lambda 10830$ (Damineli et al. 1999), the EW is decreasing faster than the stellar continuum is increasing, indicating that dust destruction/dissipation is not the only cause of the variations. This result is robust, in the sense that the flux calibration is straightforward in the near-IR; 90 per cent of the energy is in the stellar continuum and the line emission comes from a well-defined central knot. For lines in the optical range, the situation is less clear, since the contrast between the central knot and the nebula is lower. In any case, during an event, extinction variations appear to be relatively small. Further, line ratios of neighbouring nebular lines can be used, limiting the effects of circumstellar extinction.

Another issue of importance is the nature of the Weigelt objects which are believed to have been ejected sometime after 1890 - either in the smaller eruption that took place around 1890 (Smith et al. 2004) or perhaps as late as the 1930's (Dorland, Currie \& Hajian 2004). Given their recent origin, it would not be surprising if the Weigelt spectra were undergoing significant changes over the last 50-100 yr. The illuminating flux is decreasing as the blobs move further away from the ionizing source (ignoring possible changes in the primary and secondary stars), and the physical conditions (e.g. density and size) of the blobs is probably changing. The influence of internal dust extinction within the blobs may also be changing, as might be the differential extinction between the blobs and the central source.

The first known and convincing evidence for high-excitation lines in the spectrum of $\eta$ Carinae comes from spectra taken from 1944 to 1951 by Gaviola (1953). Spectra taken in 1938 March do not clearly show He I (Humphreys \& Koppelman 2005), and as discussed by Feast, Whitelock \& Marang (2001), spectra taken before 1920 do not show the high-excitation lines. This could be a confirmation of the later ejection date for the Weigelt objects, or simply reflect that their properties were very different from those today. It is even possible/probable that the gas giving rise to the narrow Fe II and [Fe II] lines in the early 1900's is not the same gas giving rise to the observed emission lines today. It should be recalled that the 'Little
Homunculus' was ejected around 1890 (Ishibashi et al. 2003), and presumably this ejected material had a substantial influence on the integrated observed spectrum for some time after it was ejected. In $1893 \eta$ Carinae showed an F-type absorption spectrum, with a significant blue shift $\left(-200 \mathrm{~km} \mathrm{~s}^{-1}\right)$ of the absorption lines, probably indicating a shell ejection (Whitney 1952). That author also notes that there were marked spectral changes until 1903, while the spectrum remained relatively unchanged between 1903 and 1930.

\section{THE BASIC BINARY SCENARIO}

The discovery of the strict periodicity (Damineli 1996) and binarity (Damineli, Conti \& Lopes 1997) did bring some order to explore the complex variations in lines and continuum. While the period length is unique, the behaviour of the light curve (time and duration of the minimum, shape of the descending and recovering branch) differs from one feature to another. Although the ultimate cause of the event is the eccentric orbit, every feature is governed by a specific mechanism with its own characteristic time-scale. In order to discuss the different possibilities, we use a binary model like the one presented by Henley et al. (2008), but only as a general framework, which is in good general agreement with the observations, although not completely accounting for all of them.

The system is composed of two massive and evolved stars in a highly eccentric orbit, the secondary companion being the main source of (hard) ionizing photons (Damineli et al. 1997). The secondary star is hotter and less luminous than the primary, and its wind is faster and less dense. The WWC generates X-rays in the walls of a shock-cone bent towards the secondary star (Ishibashi et al. 1999). Since it is more transparent than the wind of the primary star, most of the X-rays and ionizing photons escape through it. Some of the photons from the secondary star penetrate the wind of the primary star beyond the limits of the shock-cone, producing an ionized cavity to the side of the companion star. The shock-cone points almost radially away from the primary star around apastron, but it gets twisted as it approaches periastron, when the orbital speed becomes comparable to that of the primary star wind (Pittard \& Corcoran 2002). The sudden drop in the X-ray flux has been attributed to the huge increase in opacity when the shock-cone opening leaves our line-of-sight and we see the WWC through the dense wind of the primary star (Corcoran 2005). If this is the case, the wind of the primary star should be porous, since during the minimum we still see a hard X-ray component with the same temperature as in the high-excitation state (Hamaguchi et al. 2007). We will show in this work that, even if the orientation of the shock-cone opening is important, it is not the only or even the most important factor to control the variability.

The observer is placed to the side of the apastron, although not necessarily aligned to the main axis of the orbit. This is consistent with several observations: (i) the He I emissions are primarily blueshifted along most of the 5.5-yr cycle; (ii) the P Cygni absorptions, which must be formed on our side of the primary star, are weak for most of the cycle, indicating that this side is more ionized than the back side (Hillier et al. 2001, 2006; Nielsen et al. 2007a); and (iii) if periastron were on our side of the system, we should see a enhancement of $N_{\mathrm{H}}$ when the secondary star reaches the opposition, which would be coincident with the middle of the high-excitation state, but which is not observed. Further, the Weigelt objects are on our side of the system and the observation that maximum excitation occurs around $\phi=0.5$, when the column density $\left(N_{\mathrm{H}}\right)$ to $\mathrm{X}$-rays is low for us, indicates that the shock-cone is opened toward us during the high-excitation state. These facts exclude models in 
which the periastron is to our side of the system (Abraham et al. 2005; Kashi \& Soker 2007). Because of this fundamental disagreement, we will not comment on these works, even if they are in agreement with some particular aspect of the observations. In our adopted model, the secondary star is moving away from us prior to periastron passage (Damineli et al. 1997; Pittard \& Corcoran 2002). We assume, as usual, that the orbital plane is more or less perpendicular to the polar axis of the Homunculus, in order that we see the binary axis from an intermediate angle (neither parallel nor perpendicular), although there is no observational constraint to the orbital inclination.

\section{THE COMPOSITE MORPHOLOGY OF THE EVENT}

The variability of high-excitation lines is reasonably well known around the minimum. They show a collapse in a time-scale shorter than a few weeks, followed by a minimum a few months long. The same situation is seen in X-rays and in several broad-bands in the optical and near-IR. The event, however, covers different time-scales as we look at different spectral features.

\subsection{The slow variation component}

Damineli (1996) and Damineli et al. (1999) showed that He I $\lambda 10830$ varies continuously along the 5.5-yr cycle, between minimum and maximum, with no sharp transition. An even more extreme example, showing almost sinusoidal variability, was reported by Duncan \& White (2003) for the radio cm light curve. Although this is relevant to understand the mechanism of the event, since it is working all along the orbit and not confined to the periastron passage, it has not received enough attention.

In Fig. 1(a), we illustrate variations in the EW of [Ar III] $\lambda 7135$ (narrow component) with orbital phase for the event \#10 (phase 0 on 1997.95). Unfortunately, we do not have photometry with the same spatial and time resolution to derive the line flux from EWs. The asymmetry between the fading and recovering branches of the minimum is due, in part, to changes in the level of the continuum, but other effects are involved, since the light curve at radio wavelength is also asymmetric (Duncan \& White 2003). As apparent from the figure, $[\mathrm{Ar} \mathrm{III}] \lambda 7135$ changes through the entire cycle. In order to compensate for changes in the continuum level we measured a neighbouring line that suffers little variation along the event.
We refer to the narrow line components only. The companion line for [Ar III] $\lambda 7135$ is [Fe II] $\lambda 7155$, also displayed in Fig. 1(a). [Fe II] shows a small decrease at $\phi=0$, but otherwise has a smooth behaviour. We normalized all line intensities and ratios to unity at $\phi=0.4$ in order to visually compare intensity curves. The line ratio displays a much higher degree of asymmetry than before division by the neighbouring line, indicating that both lines were affected by substantial variability of the stellar continuum along cycle \#10 (which started in 1997.95 and finished in 2003.49).

If the Weigelt objects were fully ionized outside the minimum, the line intensity curve would be flat in the corresponding phases, unlike what we observe. [Ar III] shows a broad maximum in the range $(\phi=$ 0.4-0.7), whether we look to the direct EW measurements or to its ratio with the neighbouring $[\mathrm{Fe} \mathrm{II}]$ line. These lines are strong when excitation is high (EW $\sim 3 \AA$ for $[\mathrm{Ar} \mathrm{III}]$ and $\mathrm{EW} \sim 10 \AA$ for $[\mathrm{Fe} \mathrm{II}]$ ). It seems plausible that only a fraction of $\mathrm{Ar}$ and $\mathrm{Ne}$ in the Weigelt objects exposed to the ionizing source is ionized to the second stage. We need better data, defining a clear maximum in the line intensity curve, to make a strong point on the partial ionization. However, it is clear that we cannot no longer say that the events in $\eta$ Carinae are brief episodes. This seems to be in conflict with the fact that the event as seen in high-energy phenomena, like X-rays and He II, is confined to a narrow range of phases. This apparent contradiction is due to the existence of two regimes in the events, as shown below.

The radio light curve at $3 \mathrm{~cm}$ (Duncan $\&$ White 2003) shows many similarities with the [Ar III] line intensity curve for event \#10; continuous variability along the whole cycle, the centre of the minimum at $\sim 4.5$ months later than $\phi=0$ and the asymmetry of the minimum, and with the second branch recovering slower than the fading one. An important difference is that, around the minimum, the radio light curve is sinusoidal, but [Ar III] display a sudden drop followed by a flat minimum.

The other three doubly ionized lines: [Ne III] $\lambda 3868,[\mathrm{Fe} \mathrm{III]} \lambda 4701$ and $[\mathrm{S} \mathrm{III}] \lambda 6312$ behave in similar way to $[\mathrm{Ar}$ III] $\lambda 7135$. Since [S III] $\lambda 6312$ was as densely sampled in time as [Ar III] $\lambda 7135$, we combined the two to enhance the $S / N$. In the case of [S III] $\lambda 6312$, we divided its intensity by that of the neighbouring Fe II $\lambda 6318$ narrow line component. We then averaged the results for [Ar III] and [S III], after having normalized the curves to the unity at phase $\phi=0.4$. The combined line intensity curve is displayed as circles in Fig. 1(b).

In order to bring more clarity to our proposed double behaviour of the event, we modelled it by a Gaussian fit, excluding points deviating more than $3 \sigma$. We call the fit the slow variation component.
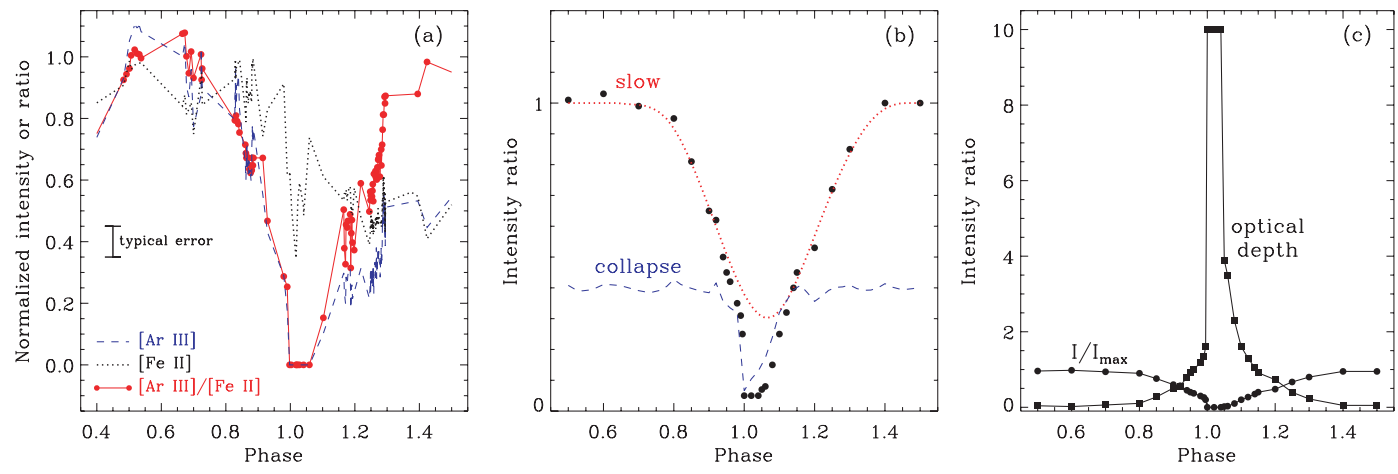

Figure 1. The slow variation and the collapse components seen in narrow lines. Panel (a): normalized EW of [Ar III] $\lambda 7135$ (dashed line); [Fe II] $\lambda 7155$ (dotted line); and the ratio between these two narrow line components (filled circles). A typical error bar is shown in the middle left-hand panel of the figure. Panel (b): observed intensities (circles); Gaussian fit to the 'slow' component (dotted line); and collapse component (dashed line) obtained by subtracting the Gaussian fit. Panel (c): EW ratios of [Ar III]/Fe II] $\lambda 7155$ and [S III]/Fe II $\lambda 6318$ normalized on phase $\phi=0.4$ and averaged $\left(I / I_{\max }\right)$ (circles); optical depth (squares, see the text). 
It is centred on phase $\phi=0.069,140 \mathrm{~d}$ after $\phi=0$ remarkably close to the radio $3-\mathrm{cm}$ minimum $(\sim 130 \mathrm{~d})$ and has a full width at halfmaximum $($ FWHM $)=649 \mathrm{~d}$. The Gaussian fit was subtracted from the data and the difference is represented by a dashed curve at the bottom of Fig. 1(b). We call it the collapse component, because of the fast drop just before $\phi=0$ and its relation with the minimum at high energies (X-rays and He II) as discussed in the next section.

What is the cause of the slow variation changes in the doubly ionized lines? The intensity of the doubly ionized narrow lines depends on the ionizing flux the Weigelt objects receives from the secondary star. Since the binary orbit is at least 10 times smaller than its distance to the Weigelt objects, the change in the distance to the secondary star plays only a minor role in the line intensities. To get insights into the causes of the variations in the Weigelt lines, we will first interpret the radio-cm light curve, which only has a pure slow component.

Radio continuum maps (Duncan \& White 2003) at 3-cm wavelengths show that the size of the radio source is maximum at $\phi=$ 0.5, filling the Little Homunculus (Teodoro et al. 2007), and then shrinking to a point source as the minimum approaches. If the minimum were produced by an eclipse, in which the ionizing source is hidden from us when passing behind the primary star, or behind its stellar wind, or when the opening of the shock-cone around the secondary star leaves our line-of-sight, there would always be gas being ionized in other directions, except ours. The net effect would be a change in the small scale structure of the radio map due to irregular density distribution, but not in its size and flux density. The facts that, during the minimum, the size of the radio map is reduced to almost a point source and that the flux density decreases indicate that the volume of ionized gas in the circumstellar medium also decreases. This indicates that a fraction of ionizing photons coming the secondary star are impeded from escaping to the circumstellar environment, which implies that the size of the shock-cone opening is decreasing toward periastron and/or the gas density inside its cavity is increasing. The shock-cone is not rotating as a rigid body around the centre of mass, especially in regions far from its apex. Far from this region, the gas flow may be disturbed and left behind, in a spiral-like pattern, increasing the opacity for escaping photons. The effect may be small for X-rays but high for UV radiation. In this scenario, the radio light curve is not expected to be symmetric with respect to the periastron passage, as is observed.

We can interpret the slow variation component of the double excited nebula lines in the same manner as the radio light curve. In this case, variations in the line intensity of doubly ionized lines represent changes in the optical depth toward the secondary star, as seen from the Weigelt objects. In order to explore the idea that the ionization in the Weigelt objects is controlled by opacity, let us define an optical depth, by assuming that it is zero at maximum line intensity and increases in proportion to the decrease in the line intensity. For example, at 90 per cent of the maximum intensity, the optical depth is $\tau=0.046$, and so on, as displayed in Table 1 .

Table 1. Parametrization of the event for [Ar III] and [S III].

\begin{tabular}{ccc}
\hline$I / I_{\max }$ & $\begin{array}{c}\text { Length }^{a} \\
(\mathrm{~d})\end{array}$ & $\begin{array}{c}\text { Optical depth } \\
\tau\end{array}$ \\
\hline 0.90 & 1214 & 0.046 \\
0.50 & 587 & 0.30 \\
0.10 & 182 & 1.0 \\
0.0 & 120 & $\gg 1$ \\
\hline
\end{tabular}

${ }^{a}$ Time to return to the same line intensity.
Fig. 1(c) illustrates the change in optical depth (squares) along the curve intensity of the doubly ionized lines $\left(I / I_{\max }\right)$. We see that the optical depth has a smooth behaviour along the 5.5-yr cycle, as expected from the slow variation component, suffering a sudden increase when the optical depth reaches $\sim 1$. The short-lived collapse component corresponds to points with $\tau>1$.

Another way to examine the evidence for two components in the 5.5-yr cycle is by looking for how long the line intensity curve stays above some intensity or above some optical depth. As seen in Table 1 , the optical depth remains at $\tau>1$ for approximately six months close to the minimum and at $\tau<1$ for the remaining $5 \mathrm{yr}$.

\subsection{The collapse component}

The collapse component derived by subtraction of the Gaussian fit is centred at $\phi=0.0299$ (60 d after $\phi=0)$, has FWHM = $189 \mathrm{~d}$ and covers 30 per cent of the area under the curve. It starts when the doubly ionized forbidden lines fall below $\sim 40$ per cent of their maximum intensity, and lasts for $\sim 15$ per cent of the 5.5-yr cycle. We reinforce that these values are specific to [Ar III] and $[\mathrm{S} \mathrm{III]}$ and other features may result in different values, since they are affected by different proportions of the collapse and the slow variation components. Moreover, these values were measured in the subtracted curve, which may be contaminated by defects in the deblending procedure.

What causes the crash in intensities in the collapse component? The optical depth rises steeply as $\phi=0$ approaches. It is unlikely due to a simple eclipse, since the wind of the primary star is optically thick up to many stellar radii (Hillier et al. 2001) and has a gradual radial density profile. At this epoch, the Weigelt objects are suddenly screened from high-energy $(E>16 \mathrm{eV})$ ionizing radiation. A possible explanation would be that, as the shock-cone opening changes direction around the orbit, the line-of-sight from the secondary star to the Weigelt objects crosses its walls, entering into the high-opacity region dominated by the primary's wind. Let us call it the 'cone eclipse'. Interestingly, all features that have the collapse component (e.g. X-rays, He II $\lambda 4686$, etc.) show such a fast drop. However, this does not necessarily mean that the same mechanism needs to be invoked to explain all features - instead we note that the time-scale for the collapse phase is ultimately driven by the short time the secondary spends near periastron.

The collapse in X-rays has been attributed to the 'cone eclipse' just mentioned, when our line-of-sight leaves the cone opening (Pittard \& Corcoran 2002). Since the Weigelt objects do not lay on our line-of-sight and both features (X-rays and doubly ionized lines) fade simultaneously, the same explanation cannot hold for the Weigelt lines. The 'cone eclipse' could be attributed to the collapse of He II $\lambda 4686$ seen directly in the central object. However, its image reflected by the dust near the Homunculus South Pole, $\sim 45^{\circ}$ from our line-of-sight, collpases at the same time - after correcting for the extra travel time to the 'Homunculus' South Pole, (Stahl et al. 2005). In this case too the 'cone eclipse' seems implausible.

Since there are many features, formed in different places of the system, which show a synchronized fading, we suggest a simple hypothesis: the WWC shock suffers a temporary global collapse when the stars are close enough to periastron. Previous work suggested that the events in $\eta$ Carinae (principally changes at the central minimum) are due to a global change in the WWC. Soker (2005), in order to explain the fast drop in the X-ray curve and the long time-scale of the minimum, advocates that near periastron the companion accretes from the primary's wind. Martin et al. (2006a) and (Davidson 2002) discussed difficulties for eclipse models to account for these 
two features in the $\mathrm{X}$-ray light curve, in the He II line intensity and in the radial velocity curves. These authors suggest that the radiative and tidal forces of the secondary companion star induce a major disturbance in the inner wind of the primary, resulting in a shell ejection. Alternatively, they suggest that WWC shock may become unstable because of the large density near periastron and suffer a general crash. Although our data are not useful to select any special mechanism, or a particular mechanism, we recognize that there is a sudden and simultaneous fading in many broad band light curves and spectral line intensities all over the spectrum. We call it the 'collapse' component.

\subsection{A detailed view of the collapse component for doubly ionized lines}

In this section, we explore the duration of the minimum for the doubly ionized forbidden lines and show that they disappear and re-appear in a defined sequence. Since we measured the EW of the narrow component separately, they represent the way the Weigelt objects experience the event.

During the monitoring campaign of the 2003.5 event, we noticed that when the narrow component of $\mathrm{He}$ I $\lambda 6678$ disappeared, [Fe III] $\lambda 4701$ was still detectable and that [Ne III] $\lambda 3868$ had disappeared a few days earlier. In Fig. 2, we display the behaviour of [S III], [Ne III], [Ar III], and [Fe III] narrow components, measured in milli-

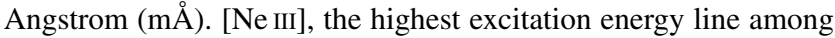
these four, is the first to disappear and the last to re-appear. [Fe III], with the lowest energy transition, fades later and recovers earlier. This could be expected naturally, without any complicated physics, if the line which fades earlier was intrinsically much fainter outside the minimum. However, this is not the case - [Ne III] is much stronger, having reached $\mathrm{EW} \sim 5500 \mathrm{~m} \AA$ in early 2001 (close to the middle of the high-excitation phase) as compared to [Fe III], which maximum was $\mathrm{EW} \sim 2800 \mathrm{~m} \AA$. The intermediate-excitation energy lines [S III] and [ $\mathrm{Ar} \mathrm{III}]$ fall in between the two extremes, indicating that the order of fading and recovering is strongly modulated by the ionization potential (IP).

Fig. 2 indicates that also [S III] and [Ar III] follow the order the line which fades earlier recovers later. This is reinforced by the fact that [S III] reaches the zero intensity $0.5 \mathrm{~d}$ before [Ar III], as seen in column 2 in Table 2. However, this is the opposite to the trend the higher the energy of the transition, the earlier the line fades, although we note that the IPs of the two species are very similar. We cannot be sure that the two lines behave anomalously, or if this is just due to the quality of our data. On the one hand, the determination of the time to reach the zero intensity has an uncertainty of $\sim 1 \mathrm{~d}$. On the other hand, the difference between the EWs of the two lines also is of the order of the errors. In addition, [S III] is seated on top of a variable broad Fe II line and the nearby stellar continuum is difficult to assess, and thus systematic effects may contaminate the measurements of this particular line.

Since the doubly ionized forbidden lines have different IPs and critical densities, we examined their correlation with the time to attain zero intensity (relative to $\phi=0$ ). The time of zero intensity was derived in the same way as in paper I for the narrow component of He I $\lambda 6678$ : a linear fit through the descending branch of the line intensity curve extrapolated to zero. In the second column of Table 2, we display the time delays for several spectral features, with have a typical uncertainty of $\sim 1 \mathrm{~d}$. We are focused on the first six lines in Table 1, formed in the Weigelt objects. Since the forbidden lines are collisionaly excited, we list the IPs to get the ion yielding the observed transition [i.e. IP $\left(\mathrm{Ne}^{+}\right)$for $\mathrm{Ne}$ III], but as lines from $\mathrm{He}$ I are generally formed by recombination we give its IP. We see in column 2 of Table 2 that the time delay for disappearance has a general trend with the IP in the sense the higher the energy earlier the line fades as seen in Fig. 2. As shown in that table (column 4), the time delay is not correlated with the critical density for line formation.

The narrow nebular lines are known to originate around the dense Weigelt objects. If the radiation ionizing these blobs is suddenly extinguished, the line intensities will decay on a recombination timescale. For He I, with $\alpha_{B}=2.73 \times 10^{-13}$ at $10000 \mathrm{~K}$ (Osterbrock 1989), the recombination time-scale is

$t_{\mathrm{rec}}=42.4\left(\frac{10^{6} \mathrm{~cm}^{-3}}{N_{\mathrm{e}}}\right) \mathrm{d}$,

where $N_{\mathrm{e}}$ is the electron density. Since He I decays on a time-scale of the order of 5-10 d, the density in Weigelt objects must, conservatively, exceed $10^{6} \mathrm{~cm}^{-3}$. Higher densities are possible, since it is likely that the line variations are also governed by the timescale associated with the reduction in ionizing flux, which in turn is

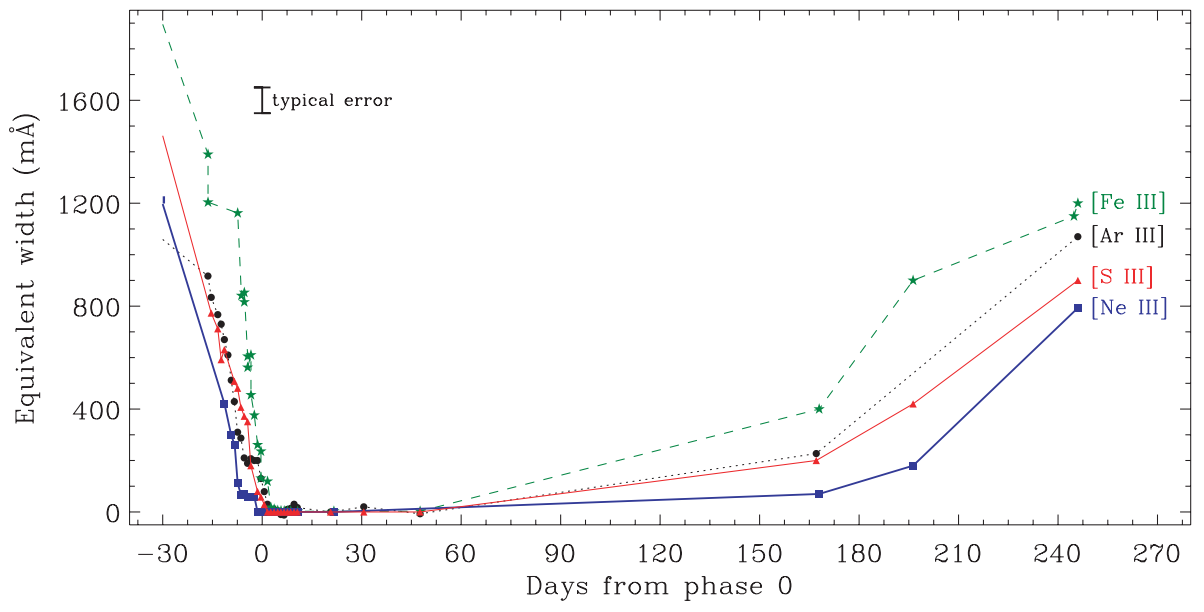

Figure 2. The central part of the minimum for the narrow components of the high-excitation lines. [Ne III] (squares), [Fe III] (stars), Ar III] (circles), [Si III] (triangles). [Ne III] has the highest transition energy, fading earlier and recovering later. [Fe III] has the lowest energy, fading later and recovering earlier. Ar III] and $[\mathrm{Si}$ III] have intermediate energy. The doubly ionized lines take at least nine months to recover the intensity they had a month before phase 0 . Typical error bar is shown at the upper left of the figure. 
Table 2. Time-delay to $\phi=0$ for several features.

\begin{tabular}{cccc}
\hline Feature pass-band & $\begin{array}{c}\text { Time-delay } \\
(\mathrm{d})\end{array}$ & $\begin{array}{c}\text { IP } \\
(\mathrm{eV})\end{array}$ & $\begin{array}{c}\rho_{\text {crit }} \\
\left(\mathrm{cm}^{-3}\right)\end{array}$ \\
\hline$[\mathrm{Ne} \mathrm{III]} \lambda 3868$ & -5 & 41.0 & $7.6 \times 10^{6}$ \\
{$[$ Ar III] $\lambda 7135$} & +2 & 27.6 & $5 \times 10^{6}$ \\
He I $\lambda 6678$ narrow line component & 0 & 24.6 & - \\
{$[\mathrm{S} \mathrm{III}] \lambda 6312$} & +1.5 & 23.3 & $15 \times 10^{6}$ \\
{$[\mathrm{Fe}$ III] $\lambda 4701$} & +3 & 16.2 & - \\
{$[\mathrm{N}$ II] $\lambda 5754$} & +3.5 & 14.5 & $8.6 \times 10^{3}$ \\
$\mathrm{X}$-rays & -1 & - & - \\
He II & +4 & 54.4 & - \\
$V$ band & +20 & - & - \\
$J$ band & +21 & - & - \\
$H$ band & +15 & - & - \\
$K$ band & +19 & - & - \\
$L$ band & +12 & - & - \\
Radio 7 mm & +29 & - & - \\
Pa $\gamma$ & $(+1)$ & 13.6 & - \\
\hline
\end{tabular}

associated with the orbital time-scale around $\phi=0$. The lower limit to the electron density is consistent with that given by Verner et al. (2005) who found $N_{\mathrm{e}} \sim 10^{7} \mathrm{~cm}^{-3}$ for the high-ionization region from an analysis of Weigelt line ratios. It is consistent also with the results reported by Hartman et al. (2005) for the H II zones of the Weigelt objects.

The variation in other line intensities could also be used to place constraints on the density in the Weigelt objects. Hydrogen has a similar recombination time-scale to He I, while elements, such as $\mathrm{N}$ have a time-scale a factor of a few shorter. On the other hand, elements such as $\mathrm{O}$ (whose IPs are nearly the same as $\mathrm{H}$ ), are coupled to the $\mathrm{H}$ by strong charge exchange reactions, and thus their recombination time-scale is determined by $\mathrm{H}$.

For a simple spherical ionization bounded nebula, the ionization time-scale is similar to the recombination time-scale (Spitzer 1978). As the observed recovery in line strengths takes considerably longer than the decline, the variation in the obscuration of the ionizing source by intervening gas must be the primary factor determining the recovery time.

\subsection{The collapse component in He I narrow emission lines}

In Fig. 3(a), we present the EWs of the He I $\lambda 6678$ narrow line component along the last three events. The label of the events are the same as in Paper I, in order that \#9 has phase 0 on 1992.42, \#10 on 1997.95 and \#11 on 2003.49. There are two remarkable features in the collapse component of this line: (i) it is asymmetric and (ii) the post-minimum branch has been recovering at slower pace as time goes by. Both behaviours could be due to changes intrinsic to the line emission region, or just to a temporal increase in the level of the stellar continuum. If we demonstrate that changes in the stellar continuum across the collapse component are not the cause of the asymmetry, then the secular weakening of the recovering branch is also not due to brightening of the central source. The collapse component is a local feature, insensitive to temporal variations in the stellar continuum flux, which occur on longer time-scales.

In order to correct for possible changes in the stellar continuum across the minimum, we used published photometry to derive line fluxes for the He I $\lambda 6678$ narrow line component along the event \#11. Here, we are not interested in the absolute fluxes, only in the relative variations across the core of the event (collapse component). In this way, we normalized all quantities to the value they had on JD 2452714 (represented by stars in Fig. 3b). The relative line flux is obtained by multiplying the relative flux nearby continuum by EW.

Variations in the continuum flux are easily derived from existing photometry, since we need only relative changes, avoiding complications involved in magnitude standardization. Color variations along the event are negligible in the optical window (at wavelengths longer than the Balmer jump), as indicated by the $B-V$ colour index (Lajús et al. 2003; van Genderen et al. 2003). The problem is that the amplitude of the variations depends on the aperture used to extract the magnitudes, and the ones of published photometry do not match the slit aperture used to record the spectra. The slit apertures encompass a few arcsecond (1.5-4 arcsec), as compared to $\sim 22$ arcsec used in ground-based photometry. Although spacebased photometry is available, the extraction apertures ( 0.3 arcsec) are much smaller than the slit widths. Since the slit width is intermediate to these two data sets, we can use them to constrain the flux variability.

The adoption of ground-based photometry would smear out the variations in the central star, since the extraction aperture
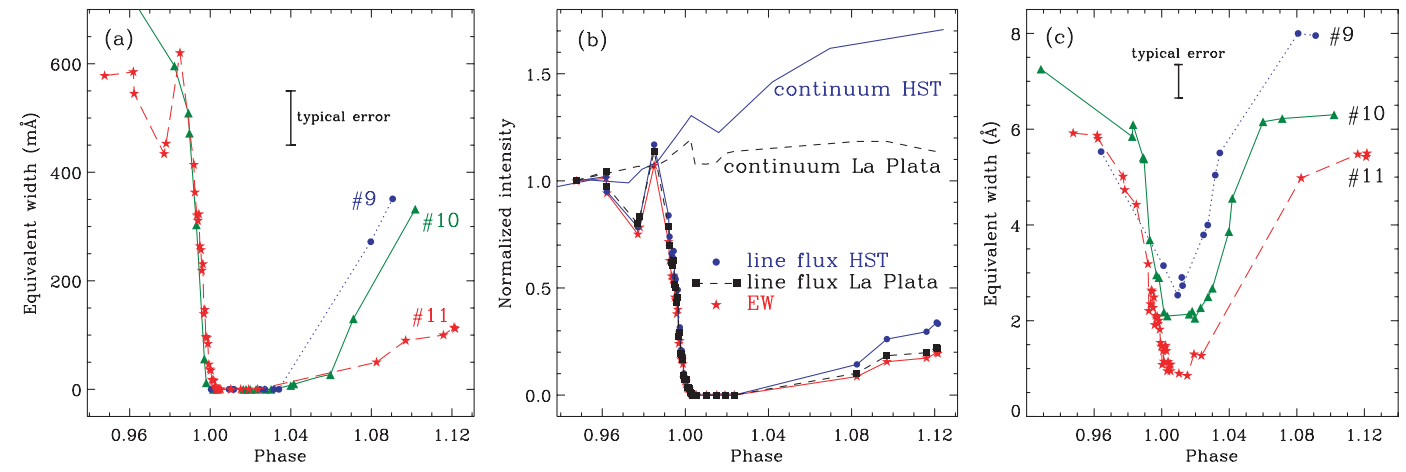

Figure 3. He I $\lambda 6678$ line. Panel (a): EW of the narrow component in the last three events \#9 (circles), \#10 (triangles) and \#11 (stars). Panel (b): normalized quantities for event \#11: continuum of the central star from the STIS/HST HRC F550M filter (upper solid curve); $V$-band continuum of the Homunculus plus central star from La Plata photometry (dashed curve); narrow component line flux normalized with the (HST) stellar continuum (circles); narrow line components normalized with the Homunculus continuum (squares); normalized EW of the narrow line component (stars). (c) The same as panel (a), but for the broad component. Typical error bars for the line measurements are shown in the upper middle part of panels (a) and (c). Photometric errors are smaller than the widths of the lines. 
encompasses the whole Homunculus nebula, which is bright in the optical region. The line flux variations obtained in this way are a lower limit to the one sampled by the slit width. In Fig. 3(b) (dashed line), we show flux variations derived from photometry taken at $\mathrm{La}$ Plata (Lajús et al. 2003). The magnitude is $V \sim 5$ and the errors are $\sim 0.005 \mathrm{mag}$, in order that they are a little larger than the width of the dashed line. We used the $V$-band measurements, since the $R$ band is contaminated by $\mathrm{H} \alpha$. The mismatch in wavelength between the line and the continuum is not important, since we are dealing with relative fluxes and the colour variations involving these two filters are very small. Relative fluxes in the $V$-band continuum, used to calibrate the line flux are presented by a dashed line at the upper part of the figure, are labelled as 'continuum La Plata'.

We can obtain an upper limit to the flux variations by using photometry from the central star, free from nebular contamination, as reported by Martin et al. (2006b) in their table 5. Those authors report synthetic photometry derived from HST STIS imaging through the medium-band HRC F550M filter. The magnitude for the event \#11 was $~ 6.5$ with errors smaller than $0.01 \mathrm{mag}$. Relative fluxes for the central star are presented as a solid line in the upper part of Fig. 3(b), labelled as 'continuum HST' and the corresponding line fluxes are displayed as the dots at the bottom of that figure. As in the case of ground-based photometry, errors are similar to the thickness of the line that represents the continuum flux. The real relative fluxes of the He I $\lambda 6678$ narrow line component are intermediate between the ones derived from ground- and space-based photometry. Taking into account the errors, the asymmetry between the descending and ascending branches appears to be real, and not an artefact of variations in the stellar continuum. On the other hand, allowing for the continuum variation does weaken the trend that the recovery phase is changing from cycle to cycle. Frequent observations during the recover phase of cycle 12 may help to clarify the cycle-to-cycle variations.

\subsection{The collapse component in the broad He Iemission lines}

In Fig. 3(c), we display the EW of the He I $\lambda 6678$ broad line component across cycles \#9, \#10 and \#11. This broad line component is thought to be formed in the inner regions of the system, since it requires a relatively high flux of energetic photons and high density. We do not know the exact location, but possible candidates are the walls of the WWC shock-cone and the inner wind of the primary star. We must keep in mind that the central object is seen under heavy circumstellar extinction $\left(A_{V} \sim 7 \mathrm{mag}\right)$ as compared to the Weigelt objects $\left(A_{V} \sim 0.5\right)$, which are primarily affected only by interstellar extinction (Hillier et al. 2001). Variability in these two components need not be correlated.

The central part of the minimum in this broad He I line component shares some similarities with the narrow component, but there are also important differences. Large variability is confined to a relatively short time interval $(\phi=0.99-1.035$ or $\sim 90 \mathrm{~d})$, very similar to the X-ray minimum. The centre of the minimum $(\phi=0.015$ or $\sim 30 \mathrm{~d}$ after $\phi=0$ ) is also coincident with that in X-rays and occurs much earlier than in the slow variation component $(\sim 140 \mathrm{~d})$. The minimum in the He I $\lambda 6678$ broad component is a little asymmetric, in the sense that the fading is faster than the recovering, but to a much smaller extent than for the narrow line formed in the Weigelt objects.

It is interesting to note that the broad emission never disappears, which could indicate that there is always some ionizing radiation from the secondary star illuminating the walls of the shock-cone. Alternatively, the residual broad emission could simply be 'intrinsic' emission from the primary wind. The fact that the broad He I component is formed near the centre of mass and never disappears, indicates that eclipses cannot be invoked to explain all phenomena. For this line the real cause of the fast drop is a crash in the structure of the WWC which may also affect the escape of high-energy photons. Observations by Stahl et al. (2005) show that the broad line components weaken simultaneously in the Homunculus South Pole (via reflected light). This rules out an eclipse (or 'cone eclipse') mechanism, since different directions are affected simultaneously. We thus favor a model in which there is a collapse and restoration of the wind shock-cone. A beautiful realization of this idea is shown in the 3D numerical simulation by (Okasaki 2008).

What is causing the changes in the WWC? The secondary star does not seem to be the culprit. The repeatability of the X-ray light curve (Corcoran 2005) is remarkable. Since the X-ray emission is dominated by its wind (with the primary wind playing the role of a wall) the companion must be a stable star. The change should be in the primary star. If its mass loss decreases, the WWC shock is shifted farther from the secondary star and the shock-cone aperture is enlarged. This would cause a decrease in the ionization and as a consequence a weakening of the $\mathrm{He}$ I broad line component.

The WWC should reorganize some time after periastron, and its signature could be present in our data. The fast recovery in the $\mathrm{X}$-ray light curve and the He I broad component line intensity at approximately three months after $\phi=0$ indicates that at that time, the WWC is already restored and that our line-of-sight is again inside the shock-cone opening. Three months thus provides an upper limit to the duration of the WWC crash since we cannot exclude the possibility that the recovery in the X-ray light curve and the $\mathrm{He} I$ broad component corresponds to the end of the 'cone eclipse' to our specific direction.

The 'collapse' component takes much longer to end for the Weigelt objects. The ionization/excitation in the Weigelt objects (narrow components in the high-ionization forbidden lines and in $\mathrm{He}$ I) takes more than nine months to reach the same level as it had a month before $\phi=0$. This is possible since they are at a line-of-sight different from ours. More importantly, they are far from the central source and the external parts of the shock-cone are distorted as it rotates around the orbit. After the collapse, additional gas may be trapped for some time inside the shock-cone. The slow recovery seen in the radio light curve may be due to the same cause.

\subsection{The collapse component in the $\mathbf{P}$ Cygni absorption lines}

P Cygni absorption lines are important because they sample the gas in a narrow beam to our side of the emitting region. They change as the source moves in the binary orbit and/or because the absorbing material suffers changes in the degree of excitation. Many lines display these components, which are strongly variable across the minimum. However, changes from cycle to cycle have also been observed.

The P Cygni absorption component, that is lost in He I $\lambda 6678$ due to a blend with [Ni II], appears clearly in He I $\lambda 7065$ line (Fig. 4a). ${ }^{1}$ It reaches $\mathrm{EW} \approx 0.5 \AA$ at approximately three months before $\phi=0$ and decreases with time. Three weeks before $\phi=0$ it starts increasing, reaching a new maximum around $\phi=0$ and then it decreases up to complete disappearance $\sim 20 \mathrm{~d}$ after. While the P Cygni absorption must be produced by material between us and the primary star there is still a debate whether it is directly related to material in the WWC cone, or produced by the wind of the primary

\footnotetext{
${ }^{1}$ The narrow and the broad emission components of He I $\lambda 7065$ display a behaviour very similar to $\mathrm{He}$ I $\lambda 6678$.
} 

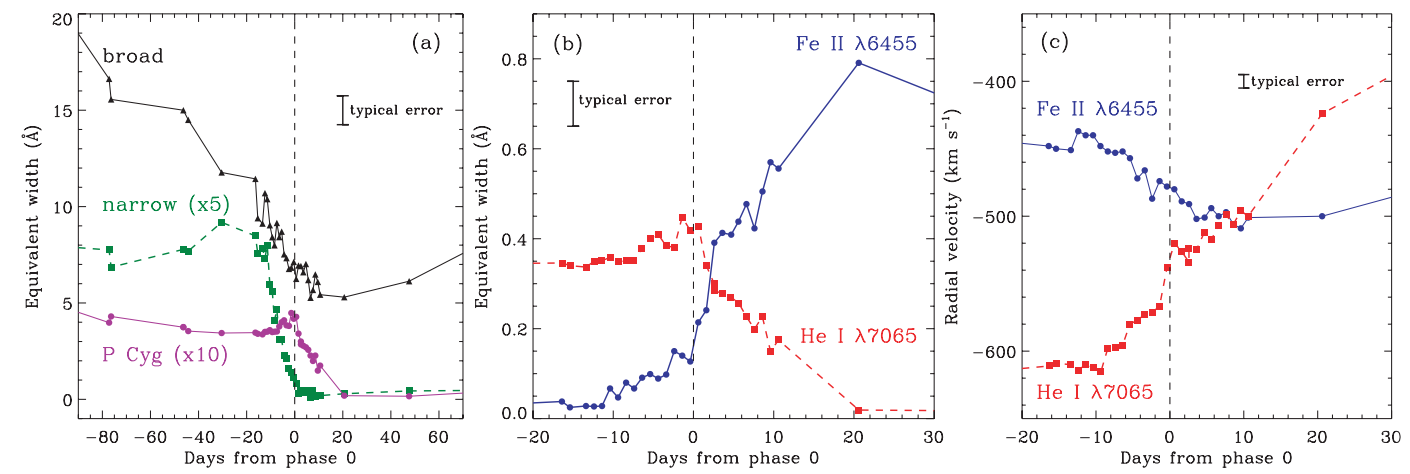

Figure 4. Panel (a): He I $\lambda 7065$ : EW of the broad emission (triangles); narrow emission component multiplied by 5 (squares); and the P Cygni absorption component multiplied by 10 (circles); panel (b): EW of He I $\lambda 7065$ (squares)and Fe II $\lambda 6455$ P Cygni absorption components (circles); panel (c): radial velocity of barycentre of $\mathrm{He}$ I $\lambda 7065$ (squares) and Fe II $\lambda 6455$ P Cygni absorption components (circles). Typical error bars are shown in the upper part of the panels.

(Nielsen, Ivarsson \& Gull 2007b). For either scenario, the absence of P Cygni absorption during the minimum indicates that the aperture of the WWC cone is pointing away from us, which coincides with the position of the secondary star 'behind' the primary. With this orientation, He along our line-of-sight to the primary cannot be ionized by energetic photons from the secondary star. This gives support to the idea that the collapse component is produced by an 'eclipse-like' phenomenon that it is centred at approximately three weeks after $\phi=0$.

The idea that the shock-cone is pointing away from us during the minimum is reinforced by comparing the P Cygni absorption component of $\mathrm{He}$ I $\lambda 7065$ with that of $\mathrm{Fe}$ II $\lambda 6455$. The large difference in excitation energy makes these two lines strategic to probe material at large and short distances from the ionizing source. In Fig. 4(b), we see that across the minimum, the absorption component in Fe II is rising while that of $\mathrm{He} \mathrm{I}$ is fading, a behaviour also observed by Nielsen et al. (2007b) in HST spectra of the central source. The observed behaviour is a consequence of $\mathrm{Fe}$ II recombining on our side of the primary star wind, that is located on the opposite side of the primary star relative to the ionizing companion star. Just after the collapse, the wind of the primary star has recombined at maximum extent. It is interesting to see that the re-ionization (intensity decrease) of Fe II starts soon, as compared with the long absence of P Cygni absorption in He I. This behaviour of the He I P Cygni absorption component is expected, since the opening of the shockcone takes time to point again to our direction. The re-ionization of Fe II in our side of the primary star wind, however, starts soon after the opposition of the secondary star, as its ionizing flux penetrates through the wind. The broad line component of $\mathrm{He} I \lambda 6678$ in Fig. 3(c) shows that the ionization recovers relatively quickly in the inner parts of the system, as compared to the slow recovery seen by the Weigelt objects.

The radial velocity of the P Cygni profile from these two lines provides an alternative way to analyze the situation just described. Fig. 4(c) shows the same opposite behaviour between He I $\lambda 7065$ and Fe II $\lambda 6455$ radial velocity as is shown by the line strengths. The Fe II $\lambda 6455$ P Cygni absorption component shifts to more blueward velocities across $\phi=0$, while the He I $\lambda 7065$ P Cygni absorption component shifts to less blueward velocities. The amplitude of velocity changes is smaller in Fe II $\lambda 6455$ because it is formed in regions where the wind is already reaching the terminal velocity as compared to He I that is formed in a zone subject to larger acceleration. The maximum speed of the He I $\lambda 7065 \mathrm{P}$ Cygni absorption component $\left(-610 \mathrm{~km} \mathrm{~s}^{-1}\right)$ is higher than that of the Fe II $\lambda 6455 \mathrm{P}$
Cygni absorption component $\left(-500 \mathrm{~km} \mathrm{~s}^{-1}\right)$. Since Fe II recombination occurs in regions where the primary star wind is reaching its terminal velocity, the He I line cannot be formed in the same stellar wind, as it requires higher excitation flux and gas density, only present close to the star. The only plausible formation regions for the He I broad line are the walls of the WWC shock-cone, not the primary's wind.

\section{HeI $\lambda 10830 \AA$ - A PECULIAR SPECTRAL LINE}

The He I $\lambda 10830$ line is particularly interesting: it is very strong, displays many components in the central knot and in the nebular region, and undergoes remarkable variations. Fig. 5(a) displays the variability of the emission profile. It changes in intensity and width along the cycle. At high resolution, two peaks are clearly defined +12 (the ' $R$ ' peak) and $-85 \mathrm{~km} \mathrm{~s}^{-1}$ (the ' $\mathrm{V}$ ' peak). The ' $\mathrm{R}$ ' peak is higher than the ' $\mathrm{V}$ ' peak $(\mathrm{R} / \mathrm{V}>1)$ during the high-excitation state. The intensity ratio changes to $\mathrm{R} / \mathrm{V}<1$ at $105 \mathrm{~d}$ before $\phi=0$ and again to $\mathrm{R} / \mathrm{V}>1$ at $4 \mathrm{~d}$ before $\phi=0$ (Paper I). There is a question if the $\mathrm{V}$ and $\mathrm{R}$ peaks are independent emissions, or just a broad emission split into two by a shell absorption feature, as claimed by Damineli et al. (1998). Our present high-resolution spectra show that the putative 'shell absorption' does fall below the continuum only during the minimum. This is a false continuum, due to the depression of the local stellar continuum by the P Cygni absorption. The pseudo absorption profile remains steady at $-35 \mathrm{~km} \mathrm{~s}^{-1}$, as also the $\mathrm{V}$ and $\mathrm{R}$ peaks do. Although the radial velocity of the narrow absorption feature agrees with the faint absorption in Balmer lines, the $\mathrm{R}$ and $\mathrm{V}$ peaks vary independently and are steady in radial velcoity indicating separate emitting regions. The Weigelt objects are natural candidates for these two components, but the large separation in radial velocity $\left(97 \mathrm{~km} \mathrm{~s}^{-1}\right)$ does not match that of the Weigelt objects. Moreover, when looking to long slit spectra, we see two narrow emission lines crossing all the field upt o the borders of the Homunculus. The two nebular lines are separated by $-127 \mathrm{~km} \mathrm{~s}^{-1}$, a little more than the $\mathrm{R}$ and $\mathrm{V}$ peaks. This happens because, in the central object, the nebular lines merge with the $\mathrm{R}$ and $\mathrm{V}$ peaks that are much broader and contaminated by the velocity field of the circumstellar gas.

Fig. 5(a) shows two additional emission peaks at -255 (V1 peak) and $-460 \mathrm{~km} \mathrm{~s}^{-1}$ (V2 peak). These two peaks are variable along the cycle and also from cycle to cycle. The absorption component at $-1060 \mathrm{~km} \mathrm{~s}^{-1}$ (interstellar medium) was once believed to be a 

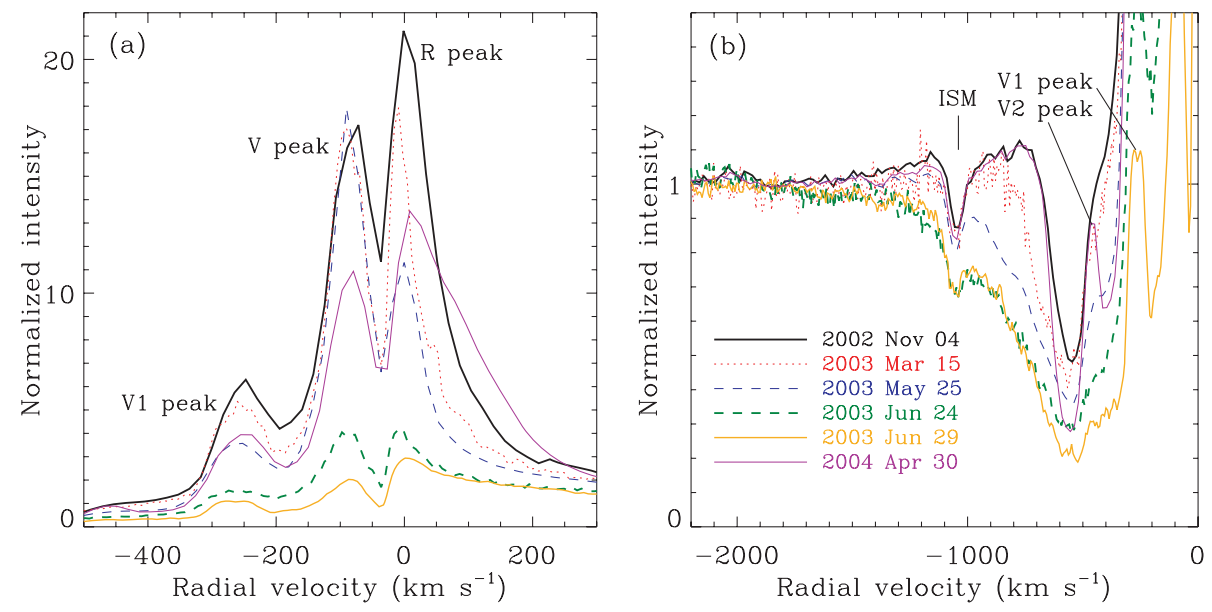

Figure 5. Line profile of $\mathrm{He}$ I $\lambda$ 10830. Panel (a): variability of the emission peaks (legend in panel b). Panel (b): zoom showing variations in the P Cygni absorption. Note the extension of the profile up to $-1700 \mathrm{~km} \mathrm{~s}^{-1}$ near $\phi=0$.

narrow absorption component in the stellar wind (Damineli et al. 1993), but Groh, Damineli \& Jablonski (2007) showed that it is an interstellar/circumstellar feature. The P Cygni absorption during the high-excitation phase is faint and placed at $-570 \mathrm{~km} \mathrm{~s}^{-1}$, in agreement with the lines emitted by the wind of the primary star. As the minimum approaches, this feature starts to get broader and deeper, the centroid shifts up to $-650 \mathrm{~km} \mathrm{~s}^{-1}$. This change in the centroid is due to the contribution from the absorption wings that increases, extending up to $-1400 \mathrm{~km} \mathrm{~s}^{-1}$. When plotting together the spectra at maximum and minimum excitation, it is possible to track the line wings up to $-1700 \mathrm{~km} \mathrm{~s}^{-1}$ While high velocities are generally not seen at our viewing angle, velocities of order $1000 \mathrm{~km} \mathrm{~s}^{-1}$ are seen from polar directions (Smith et al. 2003a). This led Smith et al. (2003a) to suggest that the wind of $\eta$ Carinae is asymmetric, and that during the event a shell event occurs leading to a situation in which the equatorial wind more closely resembles the polar wind.

The P Cygni absorption component in He I $\lambda 10830$ reaches its maximum strength ( $\mathrm{EW}=18 \AA$ ) $10 \mathrm{~d}$ after $\phi=0$, a time when the absorption components in the optical $\mathrm{He}$ I lines have already faded. This could indicate that different spatial locations contribute to the observed absorption, although all absorbing structures must occur in gas between us and the primary. Surprisingly, the variability of the P Cygni line is more similar to the low excitation line Fe II $\lambda 6455$ and that of $\mathrm{He}$ I $\lambda$ 7065. An alternative explanation for the distinct behaviour of the absorption component of He I $\lambda 10830$ is related to the stability of the $2 s^{3} \mathrm{~S}$ state. After the ionizing radiation field is switched off, the population of the metastable $2 \mathrm{~s}^{3} \mathrm{~S}$ state will persist longer than the $2 \mathrm{p}$ states, which are the lower levels for the observed optical He I lines.

The radial velocity of the P Cygni absorption component in He I $\lambda 10830$ has a behaviour similar to that of $\mathrm{He}$ I $\lambda 7065$, with the minimum (maximum negative) velocity occurring $\sim 10 \mathrm{~d}$ before $\phi=0$ and a maximum at $\sim 45 \mathrm{~d}$ after. The minimum speeds in He I $\lambda 10830$ and $\mathrm{He} \mathrm{I} \lambda 7065$ are -650 and $-610 \mathrm{~km} \mathrm{~s}^{-1}$ and the maximum is -450 and $-350 \mathrm{~km} \mathrm{~s}^{-1}$ respectively. The minimum (maximum negative) speed of the He I $\lambda 10830 \mathrm{P}$ Cygni line is also larger than that of Fe II $\lambda 6455$, indicating that it is not formed in the outer wind of the primary star. One possibility is that He I $\lambda 10830$ forms in gas from the secondary star that has passed through the shock-cone, forming a tail left behind in a spiral-like pattern, as the secondary star turns around the centre of mass. When such portion of high-velocity gas ceases to be ionized by its parent star, it recombines, producing the extended wings in the P Cygni absorption.

The observed behaviour of the He I $\lambda 10830$ emission profile is a combination of several effects. First, around the event, the Weigelt objects are shielded by the dense primary wind (and perhaps the star itself) from the ionizing radiation field, causing the narrow component to weaken, and disappear entirely during the state of minimum. Secondly, in order to explain the weakening of the broad component, the size of the He I emitting region must shrink near periastron. Since the number of ionizing photons emitted by the secondary star does not change during the event, why does the broad He I emission change? This must be due to the dense primary wind reprocessing the ionizing photons, and perhaps even the emitted He I photons. This in turn requires that the secondary star be deep within the primary wind at periastron. The residual broad He I emission, in both $\lambda 10830$ and optical lines, that is observed during the minimum is probably produced by the primary. One possible caveat with this explanation is the weakness of the P Cygni absorption after the minimum. The calculations of Hillier et al. (2001) show that it is relatively easy to alter the strength of the intrinsic He I emission without significantly affecting $\mathrm{H}$ and $\mathrm{Fe}$ II line strengths, and thus this residual He I emission is easily explainable for reasonable luminous blue variable (LBV) parameters. One final feature that requires explanation is the high-velocity absorption profile seen during the minimum.

At minimum, the observed profile closely resembles that of HD 151804, which is an O8Iape (Groh et al. 2007). This must occur simply by chance, and cannot be the secondary star, since Hillier et al. (2006) showed that we would not expect to see the companion spectrum in the optical/IR, since the primary's luminosity is at least a few times higher than the secondary.

\section{A MULTISPECTRAL VIEW OF THE MINIMUM}

The spectroscopic events are present at all wavelengths - radio, IR, optical, UV and X-ray - and in spectral features such as the doubly ionized forbidden lines, the narrow $\mathrm{He} \mathrm{I}$ lines, the broad $\mathrm{He} \mathrm{I}$ lines, and the broad emission lines from the wind of the primary star. While all show the event, the characteristic behaviour varies 

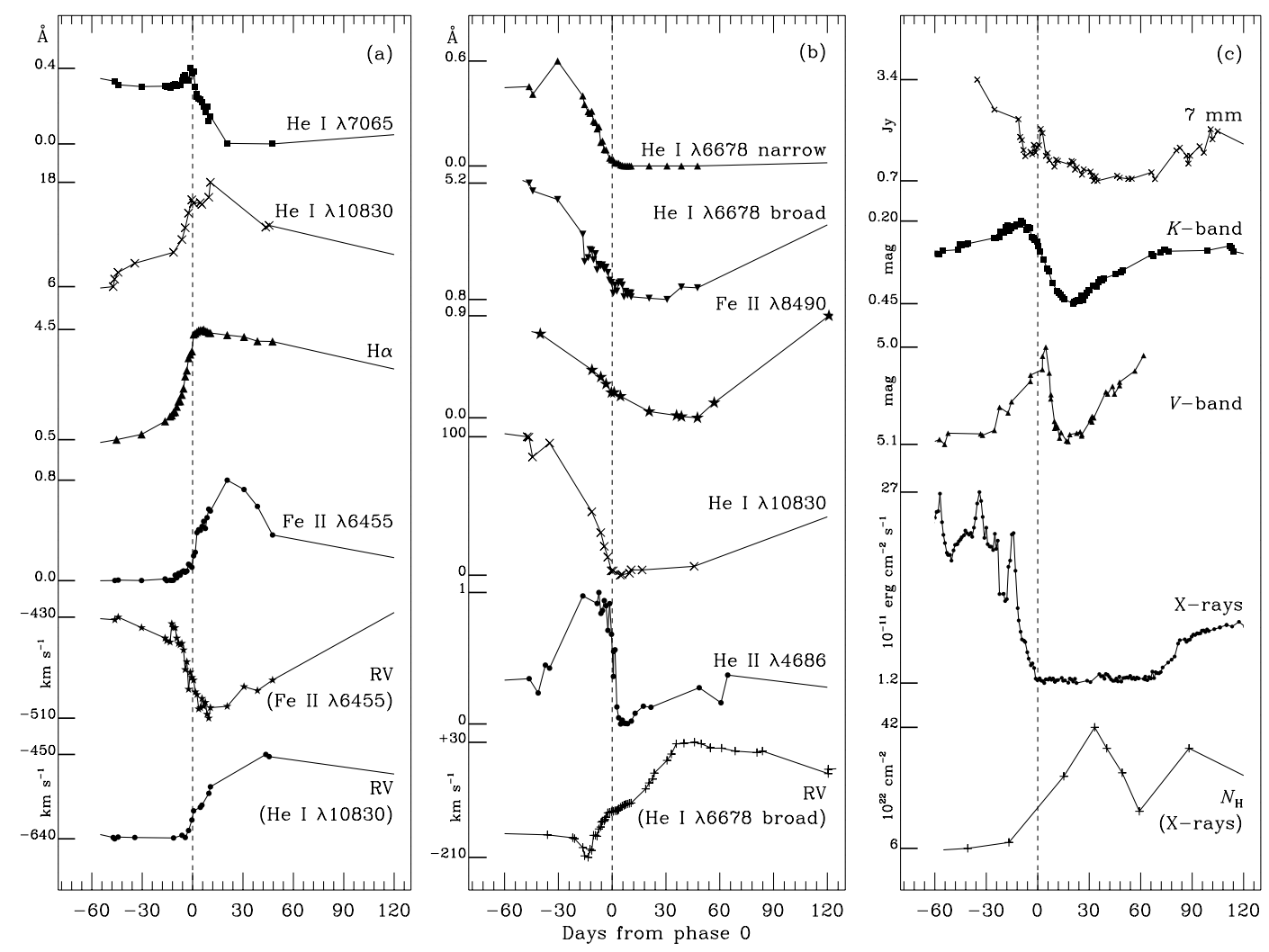

Figure 6. A panoramic view of variations in different features, and at different wavelengths, in the core of the event (collapse component). Panel (a): P Cyni absorption. EW in Å: He I $\lambda 7065 ; \mathrm{He}$ I $\lambda$ 10830; H $\alpha$ and Fe II $\lambda 6455$ plus radial velocity of Fe II $\lambda 6455$ and He I $\lambda 10830$ in km s ${ }^{-1}$. Panel (b): emission lines. EW in Å: He I $\lambda 6678$ narrow and broad component; Fe II $\lambda 8490$ (narrow) fluorescent line; He I $\lambda 10830$ total line profile; He II $\lambda 4686$ (Steiner \& Damineli 2004 ); and radial velocity of He I $\lambda 6678$ broad emission component in $\mathrm{km} \mathrm{s}^{-1}$. (c) Broad band. Radio 7-mm flux in Jansky (Abraham et al. 2005); $K$-band mag (Whitelock et al. 2004); $V$-band mag (Lajús et al. 2003); X-ray flux in $10^{22} \mathrm{erg} \mathrm{cm}^{-2} \mathrm{~s}^{-1}$ (Corcoran 2005); and X-ray column density $\left(N_{\mathrm{H}}\right)$ in $10^{22} \mathrm{~cm}^{-2}(\mathrm{Hamaguchi}$ et al. 2007).

dramatically. At one extreme, the radio 3-cm light curve shows only the slow variation and at the other extreme, He II and X-rays show only the collapse component. The observed behaviour rules out any mechanism for the event that works only close to periastron, such as a shell ejection around periastron (Martin et al. 2006a), accretion of the primary wind on to the secondary companion (Soker 2005) and eclipse of the shock-cone opening (Pittard \& Corcoran 2002). Models like these, in which the minimum is produced only by geometrical factors ('cone eclipses'), are ruled out by radio observations.

In Fig. 6, we present a panoramic view of emission, absorption, radial velocity, and continuum flux variations across the minimum (collapse component), and across the spectrum. In addition to the measurements made in our spectra, we reproduce curves by other authors, taken from the cited literature. Here, we are not aiming to present full data, just the light curves morphology, to show the time of their maxima/minima and the decline/recovery phases. Since the plots are compressed in the Y scale, the errors are of the order of the size of the symbols.

We want to warn the reader that radial velocities presented were derived from the position of the centroid of broad lines. The line profiles are complex, and thus radial velocity variations do not represent the movement of some specific region. Our aim, by measuring centroids, was to produce robust model independent measurements. Variable and extended line wings introduce shifts in the centroids, not only in proportion to the wing extension, but to its intensity.
In this work, we are not aiming to measure the full extent of the line wings, which is difficult because of their asymptotic merging with the stellar continuum. Such measurements would rely on subjective definition of the terminal speed, in addition to being limited by the $\mathrm{S} / \mathrm{N}$ of the stellar continuum. Centroids represent the bulk of the velocity field.

The top four curves of Fig. 6(a) display the EW variation of $\mathrm{P}$ Cygni absorption features for four lines - each line shows its own unique variability curve. The EW of $\mathrm{He}$ I $\lambda 7065 \mathrm{P}$ Cygni absorption is generally high along the $5.5-\mathrm{yr}$ cycle, reaching a peak $2 \mathrm{~d}$ before $\phi=0$. It then decreases with time, reaching the minimum $20 \mathrm{~d}$ after $\phi=0$. In contrast, the EWs of the P Cygni absorption components of $\mathrm{He}$ I $\lambda 10830, \mathrm{H} \alpha$ and Fe II $\lambda 6455$ are low before $\phi=0$, reach the maximum after that, and maintain a high intensity level for a relatively long time after $\phi=0 . \mathrm{H} \alpha$ reaches its maximum during the first week after $\phi=0$ and seems to be saturated, decreasing very slowly after that. He I $\lambda 10830$ reaches its maximum $10 \mathrm{~d}$ after $\phi=$ 0 , while Fe II $\lambda 6455$ takes $20 \mathrm{~d}$ to reach its maximum.

The radial velocity variations in the Fe II $\lambda 6455$ and He I $\lambda 10830$ P Cygni absorption components are presented at the bottom of Fig. 6(a). We measured the position of the line centroid, by integrating along the absorption line profile, and so it corresponds to the barycenter of the P Cygni absorption component. Starting approximately two months before $\phi=0, \mathrm{Fe}$ II $\lambda 6455$ radial velocity shifts to higher (negative) values, reaching a minimum $\sim 10 \mathrm{~d}$ after $\phi=0$ and returns to pre-minimum at a slower pace. The centroid of 
the P Cygni absorption component shifts by $\sim 80 \mathrm{~km} \mathrm{~s}^{-1}$ across $\phi=$ 0 , indicating that the bulk of the recombination shifts toward larger radii. We have already shown that $\mathrm{He}$ I $\lambda 7065 \mathrm{P}$ Cygni absorption moves in the opposite sense across $\phi=0$, changing by $250 \mathrm{~km} \mathrm{~s}^{-1}$ in the time frame starting $10 \mathrm{~d}$ before $\phi=0$ up to $50 \mathrm{~d}$ after it. The radial velocity of the He I $\lambda 10830 \mathrm{P}$ Cygni absorption component behaves like He I $\lambda 7065$. This seems confusing, since the intensity of this line behaves like Fe II $\lambda 6455$. This can be explained if the He I $\lambda 10830$ line has contributions from different regions, in the inner and outer parts of the system. The core of the P Cygni absorption in He I $\lambda 10830$ seems to be formed close to that of He I $\lambda 7065$, in the inner regions of the shock-cone and primary star wind. The wings of the P Cygni absorption, however, can be formed at larger distances, contributing substantially to the EW, but not too much to the radial velocity. We will discuss this point later in this paper.

We now turn our attention to emission-line strengths, displayed in Fig. 6(b). The He I $\lambda 6678$ narrow component emission behaves like the doubly ionized forbidden lines that are emitted in the Weigelt objects; there is an extended minimum after $\phi=0$ and a very slow recovery. The broad component of the same line shows a minimum at a later time and a faster recovery than the narrow component. A narrow fluorescent line, Fe II $\lambda 8490$, shows a minimum at an even later time, but the general appearance of the collapse component is very similar to that of the He I $\lambda 6678$ broad component. The EW of the complex He I $\lambda 10830$ line displays a behaviour intermediate between that of the narrow and the broad components of $\mathrm{He} I \lambda 6678$, indicating that its emission-line profile is composed of both narrow and broad components.

The He II $\lambda 4686$ line intensity curve is taken from Steiner \& Damineli (2004). This line remains absent from the spectrum most of the cycle (Steiner \& Damineli 2004; Martin et al. 2006a), rises quickly the month before $\phi=0$ and displays a very sharp decline after that. The same behaviour was reported by Stahl et al. (2005) in the central star and reflected by dust in the pole of the Homunculus south-eastern lobe: at 2.6 arcsec south and 2.8 arcsec east from the star. A narrowing of the shock-cone, as in the case of X-rays, could explain the disappearance of $\mathrm{He}$ II from our line-of-sight and simultaneously (after correcting for the light travel time) from the Homunculus south-eastern pole, as long as the cone opening is pointing away from us at periastron, in agreement with other observations. Steiner \& Damineli (2004) argued that He II $\lambda 4686$ was excited by X-rays from the WWC, but Martin et al. (2006a) argued that this mechanism was too inefficient, and instead invoked a mechanism related to UV radiation from the central source although the precise details are unclear. The simultaneous disappearance from multiple viewing angles plus the strongly asymmetrical light curve suggest that He II 4686 emission is not simply a result of UV excitation in the inner wind of the secondary star, but instead might somehow be coupled to the WWC whose shape is strongly affected around periastron.

At the bottom of Fig. 6(b) we present the radial velocity curve of the He I $\lambda 6678$ broad emission component. It shows a minimum of $\sim-210 \mathrm{~km} \mathrm{~s}^{-1}$ at approximately two weeks before $\phi=0$, a maximum $\left(30 \mathrm{~km} \mathrm{~s}^{-1}\right)$ in coincidence with the middle of the $\mathrm{X}$-ray minimum and then a slow decrease along the rest of the 5.5-yr cycle.

Fig. 6(c) shows measurements in the broad continuum bands. The light curve at 7-mm radio wavelength was made with data from Abraham et al. (2005). It is interesting, since the shape of the minimum is between that of long radio wavelength $(3 \mathrm{~cm})$, which varies slowly along the whole cycle and the of X-ray light curve, which has a very sharp minimum. The middle of the radio-mm minimum occurs approximately two weeks after that in X-rays.

The light curve in the $K$ band was taken from Whitelock et al. (2004) and the $V$ band from Lajús et al. (2003). The centre of the minimum in the $V$ and $K$ bands occur approximately two weeks before that in X-rays. Further, the duration of the minimum in these two photometric bands is the shortest among all the measured features. Both of them show a peak preceding the minimum, as discussed by Whitelock et al. (2004), and in both cases the variability amplitude is small $(\Delta V=0.1, \Delta K=0.25)$.

The variation of $N_{\mathrm{H}}$, in units of $10^{22} \mathrm{~cm}^{-2}$ and reported by Corcoran (2005), is presented at the bottom of panel 6c. It behaves similarly to the Fe II $\lambda 6455 \mathrm{P}$ Cygni absorption. It is important to notice that the time of maximum in these two features coincides with the middle of the X-ray minimum. We suggest that this time corresponds to the periastron passage. There is a secondary peak at approximately three months after $\phi=0$, but we do not know if it is real, or just an unreliable measurement. Hamaguchi et al. (2007) show that the temperature of the WWC remains constant through the minimum, in contrast to the behaviour expected if the shock cools and collapses. However, Corcoran (2005) and Hamaguchi et al. (2007) show that there is a reduction in the emission measure during the minimum, which means that almost all of the WWC is hidden behind a very thick absorber. There is also some indication from the X-ray line profiles for a significant change in the physical condition in the WWC. One possibility would be that the shock-cone narrows significantly, in order that X-rays escape only to some defined direction. In this way, the X-ray light curve is modulated by both intrinsic and extrinsic (geometrical) causes.

In Fig. 7, we present radial velocity curves for broad lines covering a wide range of excitation energy: the broad emission lines of Si XIII-XIV - taken form Henley et al. (2008), He II $\lambda 4686$ - taken from Steiner \& Damineli (2004), He I $\lambda 6678$ and H I $\lambda 10938$ and the He I $\lambda 7065$ absorption, measured by us. Si II $\lambda 6347$ broad emission

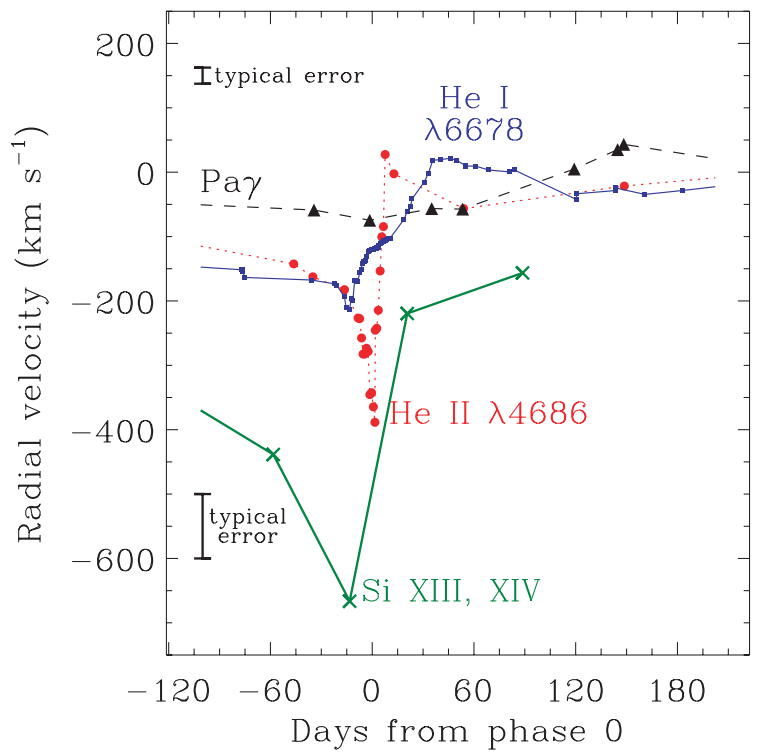

Figure 7. Radial velocity curves of broad emission lines close to $\phi=0$, covering a wide range of excitation energies. Si XIII-XIV lines were averaged from data reported by Henley et al. (2008) and He II $\lambda 4686$ was taken from Steiner \& Damineli (2004). Typical error bars for the optical/IR lines are in the upper part of the figure and for the combined X-ray lines at the bottom left-hand part. 
and P Cygni absorption behave like He I (not shown here). We see a common signature of a slow shift toward higher negative speeds when approaching $\phi=0$, then a sudden reversal to the positive side, followed by a new slow decrease towards the negative side. The extreme observed radial velocities are $-700 \mathrm{~km} \mathrm{~s}^{-1}$ for the X-ray Si XIII-XIV lines (Henley et al. 2008), $\sim-400 \mathrm{~km} \mathrm{~s}^{-1}$ for $\mathrm{He}$ II, $\sim-200 \mathrm{~km} \mathrm{~s}^{-1}$ for He I and $\sim-80 \mathrm{~km} \mathrm{~s}^{-1}$ for H I. The higher the excitation energy, the higher is the velocity jump at $\phi=0$. Although the radial velocity changes are due to binarity, they do not track the orbital motion of the companion stars. Henley et al. (2008) were able to fit the X-ray lines if they are formed in the WWC cone walls.

Could the lower excitation lines presented in Fig 7 be interpreted in the same way as X-ray lines, since they share similar properties? He II $\lambda 4686$, for example, is believed to be formed close to the X-ray emitting region (Steiner \& Damineli 2004; Martin et al. 2006a). However, it is formed at lower temperatures than X-ray lines, which means farther from the apex than X-ray lines. Since the gas speed increases as it flows away from the cone apex, the lower excitation lines should have higher speeds, contrary to that is observed. The fact that the P Cygni absorption in He I $\lambda 7065$ follows the same general pattern as very high energy emission lines is even more difficult to understand. One possibility is that, far from the apex, the conical surface does not exist anymore or it is dominated by large disturbed cells.

\section{DISCUSSION AND CONCLUSIONS}

From an analysis of the narrow components of forbidden emission lines we infer that the event is composed of two parts: the slow variation, and the collapse components. The former comprises almost the entire 5.5-yr cycle, is centred at a later time than the collapse component and the fading/recovering branches have a smaller degree of asymmetry. These lines are formed in the Weigelt objects and represent the way they 'see' the ionizing source, which is the radiation field of the secondary star that escapes through the shockcone opening. The gentle fading and recovery indicates that the cone is not completely transparent. The obscuration of the ionizing source, as seen from the Weigelt objects, increases and decreases as the secondary star travels around the orbit and deep into and out of the primary's wind. The slow variation component indicates that the shape and gas density inside the shock-cone change along the cycle. Models invoking a shell ejection, accretion on to the secondary companion, or a simple eclipse by the primary, are unable to explain the slow variation component.

The collapse component is seen in many spectral features X-rays, high-excitation Weigelt lines, He I P Cgyni absorption, and He I emission. It is likely that multiple processes are affecting the collapse phase, with its duration ultimately set by the amount of time the companion spends near periastron in its highly eccentric orbit. Eclipse-like effects ('cone eclipse') could produce a decrease in lines formed in the Weigelt objects, in the inner system and reflected in the dusty Homunculus and features. However, not all directions can be affected at the same time.

Due to uncertainties in the orbital and stellar parameters it is unclear how close the primary and secondary stars approach at periastron. However, because of the much higher densities near periastron, and the rapidly changing orbit, conditions in the shock-cone will change, and it is possible that instabilities will occur. The observed behaviour of many spectral features might be explained by a global disruption of the WWC shock. With this model it is also easy to explain the observed asymmetry seen in the collapse light curves around minimum. The bow shock is not symmetrically orientated around periastron and its structure is not identical either side of periastron. In addition to the Coriolis effect, the companion stars are approaching each other before periastron and receding after, changing the relative speeds at which the winds collide.

Although we could not identify unambiguously the signature of the WWC restoration, it must happen at most three months later than $\phi=0$. At three months, their is the sharp recovery in the intensity of X-rays and the He I broad emission lines. This is either due to the restoration of the WWC, or due to the end of the 'cone eclipse' (in which case the restoration of the shock must have occurred earlier).

The doubly ionized forbidden lines show a remarkable behaviour in the collapse component. There is a trend of the time delay of line fading with the IP, indicating that the Weigelt objects see an ionizing spectrum that becomes progressively softer as the minimum is approached, and progressively harder in the recovery phase. This must be caused by optical depth effects of intervening gas in between the ionizing source and the blobs. The slow re-ionization of the blobs (more than six months after the minimum for [Ne III]) is most likely due to obscuration effects. Since the line intensity curves of the high-energy forbidden lines do not flatten out in the high-excitation state, it is probable that only a fraction of the gas in the Weigelt objects is ionized to $\mathrm{Ne}^{++}, \mathrm{S}^{++}$and $\mathrm{Ar}^{++}$.

Very high energy features, such as X-rays and He II $\lambda 4686$, display almost only the collapse component. Conversely, at radio $\mathrm{cm}$ wavelengths the light curve is dominated by the slow variation component. At millimetre wavelengths, the collapse component is present at a modest level.

The minimum of the radio 7-mm light curve is centred at $\sim 42 \mathrm{~d}$ after $\phi=0$. Although the WWC shock may be responsible for a fraction of the radio emission at these energies, most of the emission comes from ionization in the gas outside the binary system. Some effects, such as the light travel time from the source and recombination time of the gas, can represent a delay to the centre of the minimum in order that this epoch is compatible with the centre of minimum in X-rays.

He I P Cygni absorption (and broad emission) lines cannot be formed in the wind of the primary star, since its speed reaches values larger than those of P Cygni absorption in Fe II $\lambda 6455$, which is formed in the external layers of the primary's wind.

As the P Cygni absorption component of Fe II $\lambda 6455$ reaches the maximum intensity and maximum negative velocity approximately three weeks after $\phi=0$. the wind of the primary star is recombined to a maximum extent at that time. It must occur when the (ionizing) secondary star is at opposition. This interpretation is corroborated by the fact that around $\phi=0$ the velocity of the P Cygni absorption component of $\mathrm{Fe}$ II $\lambda 6455$ is shifting to the negative side, and that of He I $\lambda 7065$ P Cygni absorption to the opposite direction. Other features associated with the shock-cone of the secondary star support this scenario, such as the He I $\lambda 6678$ broad emission component that also is shifting to the positive side of radial velocities and reaches the minimum at $\phi=0.01$. The $\mathrm{X}$-ray flux reaches a minimum and the column density $\left(N_{\mathrm{H}}\right)$ reaches a peak $30 \mathrm{~d}$ after $\phi=0$. Moreover, the fluorescent (narrow) line Fe II $\lambda 8490$ also reaches a minimum around $\phi=0.015$. These data, taken together, indicate that the opposition of the secondary star occurs 20-30 d after $\phi=0$. We do not claim that this is an eclipse in a classical sense, neither from the primary stellar disc nor from its wind.

The HeI $\lambda 10830$ line indicates that material along our line-of-sight latitude reaches much higher negative velocities $\left(-1400 \mathrm{~km} \mathrm{~s}^{-1}\right)$ than the typical velocities we see in the 
high-excitation phases $\left(-550 \mathrm{~km} \mathrm{~s}^{-1}\right)$. Most likely the P Cygni absorption is due to secondary gas that flows through the walls of the shock-cone and is left behind as the secondary star turns around the centre of mass at periastron. Variations in the $\mathrm{V}$ and $\mathrm{R}$ line peaks indicate that there are other emitting regions for this spectral line, in addition to the Weigelt objects and the winds of the companion stars.

Although the observations reported here are compatible with the generic binary scenario presented in Section 4, none of the existing models describes the whole data set. A numerical 3D simulation of two-colliding winds for parameters appropriate to the $\eta$ Carinae system will be needed to assist in understanding the complex variability that is observed. Work in progress (Okasaki 2008) is very promising, having been able to reproduce the near-periastron collapse, compatible with data we presented here.

If we are to understand $\eta$ Carinae and its evolutionary state, the identification of genuine Keplerian velocity-shifts, and the determination of the masses and spectral types of both stars, is a crucial goal. The intensive efforts applied to understand $\eta$ Carinae, which is a difficult system because of extreme conditions (masses, mass-loss, orbital eccentricity), bring benefits to the field of colliding wind binaries. Binarity in $\eta$ Carinae may not have been responsible for the 1843 giant eruption, and so does not explain the other examples of extreme LBVs, like P Cygni, V1 in N2363, etc. However, the secondary star in $\eta$ Carinae probes different regions of the primary's wind and, hopefully, will enable the determination of its mass. This is helpful in understanding the parameters of evolved massive stars, which are difficult to diagnose when in isolation.

The next minimum is predicted to start on 2009 January 11 ( \pm 2 d). Fig. 6 is useful to plan monitoring campaigns through the collapse component. The time frame starts in early 2008 November and extends through 2009 July. This is the best event since 1948 for ground-based observations, since its central core fits entirely in the good observing season. The next favorable event will not occur before 2020. The critical time for narrow components of the highexcitation lines and He I encompasses the time interval December 15 to January 20 . The P Cygni absorption and the $N_{\mathrm{H}}$ to the X-ray source will reach the maximum around February 10. In order to improve significantly the observations made in the 2003.49 event, it is necessary to monitor this critical time interval more frequently than one observation per day.

Since we now have a better picture of the events, we can plan for the next critical observations focused on a few representative lines. Major gains, relative to the present knowledge, will come from higher spatial resolution and $\mathrm{S} / \mathrm{N}$ observations. Signatures from high-energy phenomena, like X-rays, He II $\lambda 4686$ and the Balmer jump are especially important.

\section{ACKNOWLEDGMENTS}

We thank J. E. Steiner, T. Gull and N. Soker for their comments on this draft. AD, JHG and MT thank FAPESP and CNPq for continuing support. JA is supported by Fondo ALMA para el desarrollo de la Astronomía, CONICYT No. 31050004.

\section{REFERENCES}

Abraham Z., Falçeta-Gonçalves D., Dominici T. P., Nyman L.-Å., Dourouchoux P., McAulaife F., Caproni A., Jatenco-Pereira V., 2005, A\&A, 437, 977

Corcoran M. F., 2005, AJ, 129, 2018

Damineli A., 1996, ApJ, 460, L49
Damineli A., Viotti R., Baratta G. B., de Araújo F. X., 1993, A\&A, 268, 183

Damineli A., Conti P. S., Lopes D. F., 1997, New Astron., 2, 107

Damineli A., Stahl O., Kaufer A., Wolf B., Quast G., Lopes D. F., 1998, A\&AS, 133, 299

Damineli A., Stahl O., Wolf B., Kaufer A., Jablosnki F. J., 1999, in Morse J. A., Humphreys R., Damineli A., eds, ASP Conf. Ser. Vol. 179, eta Carinae at the Millennium. Astron. Soc. Pac., San Francisco, p. 221

Damineli A., Kaufer A., Wolf B., Stahl O., Lopes D. F., de Araújo F. X., 2000, ApJ, 528, L101

Damineli A. et al. 2008, MNRAS, 384, 1649 (Paper I)

Davidson K., 2002, in Schlegel E. M., Vrtilek S. D., eds, ASP Conf. Ser. Vol. 262, The High Energy Universe at Sharp Focus. Astron. Soc. Pac., San Francisco, p. 267

Davidson K., Ebbets D., Weigelt G., Humphreys R. M., Hajian A. R., Walborn N. R., Rosa M., 1995, ApJ, 109, 1784

Davidson K. et al., 1999, AJ, 118, 1777

Davidson K. et al., 2005, AJ, 129, 900

Dorland B. N., Currie D. G., Hajian A. R., 2004, AJ, 127, 1052

Duncan R. A., White S. M., 2003, MNRAS, 338, 425

Duncan R. A., White S. M., Lim J., 1997, MNRAS, 290, 680

Feast M., Whitelock P., Marang F., 2001, MNRAS, 322, 741

Gaviola E., 1953, ApJ, 118, 234

Groh J. H., Damineli A., 2004, IBVS 5492

Groh J. H., Damineli A., Jablonski F. J., 2007, A\&A 465, 993

Hamaguchi K. et al., 2007, ApJ, 663, 522

Hartman H., Damineli A., Johansson S., Letokhov V. S., 2005, A\&A, 436, 945

Henley D. B., Corcoran M. F., Pittard J. M., Stevens I. R., Hamaguchi K., Gull T. R., 2008, preprint (arXiv:0801.4779)

Hillier D. J., Allen D. A., 1992, A\&A, 262, 153

Hillier D. J., Crowther P. A., Najarro F., Fullerton A. W., 1998, A\&A, 340, 483

Hillier D. J., Davidson K., Ishibashi K., Gull T., 2001, ApJ, 553, 837

Hillier D. J. et al., 2006, ApJ, 642, 1098

Humphreys R. M., Koppelman M., 2005, in Humphreys R. M., Stankek K. Z., eds, ASP Conf. Ser. Vol. 332, The Fate of the Most Massive Stars. Astron. Soc. Pac., San Francisco, p. 159

Ishibashi K., Corcoran M. F., Davidson K., Swank J. H., Peter R., Drake S. A., Damineli A., Whithe S., 1999, ApJ, 524, 983

Ishibashi K., Gull T. R., Davidson K. et al., 2003, AJ, 125, 3222

Kashi A., Soker N., 2007, New Astron., 12, 590

Lajús E. F., Gamen R., Schwartz M., Salerno N., Llinares C., Fariña C., Amorín R., Niemela V., 2003, IBVS 5477

Martin J. C., Koppelman M. D., 2004, AJ, 127, 2352

Martin J. C., Davidson K., Humphreys R. M., Hillier J. D., Ishibashi K., 2006a, ApJ, 640, 474

Martin J. C., Davidson K., Koppelman M. D., 2006b, AJ, 132, 2717

Nielsen K. E., Corcoran M. F., Gull T. R., Hillier D. J., Hamaguchi K. Ivarsson S., Lindler D. J., 2007a, ApJ, 660, 669

Nielsen K. E., Ivarsson S., Gull T. R., 2007b, ApJS, 168, 289

Okasaki A., 2008, http://www.arc.hokkai-s-u.ac.jp/okazaki/index-e.html

Osterbrock D., Ferland G. J., 2006, Astrophysics of Gaseous Nebulae. University Science Books, Mill Valley, CA

Pittard J. M., Corcoran M. F., 2002, A\&A, 383, 636

Smith N., Davidson K., Gull T. R., Kazunori I., Hilier J. D., 2003a, AJ, 586, 432

Smith N., Gehrz R. D., Hinz P. M., Hoffmann W. F., Hora J. L., Mamajek E. E., Meyer M. R., 2003b, AJ, 125, 1458

Smith N. et al., 2004, ApJ, 605, 405

Soker N., 2005, ApJ, 635, 540

Soker N., Behar E., 2006, ApJ, 652, 1563

Spitzer L., Jr, 1998, Physical Processes in the Interstellar Medium. Wiley$\mathrm{VCH}$, Berlin

Stahl O., Weis K., Bomans D. J., Davidson K., Gull T. R., Humphreys R. M., 2005, A\&A, 435, 303

Steiner J. E., Damineli A., 2004, ApJ, 612, L133 
Teodoro M., Damineli A., Sharp R. G., Groh J. H., Barbosa C. L. 2007, MNRAS, in press (arXiv:0804.0240)

van Genderen A. M., Sterken C., Allen W. H., Liller W., 2003, A\&A, 412, L25

van Genderen A. M., Sterken C., Allen W. H., Walker W. S. G., 2006, JAD, 12,3

Verner E. M., Gull T. R., Bruhweiler F., Johansson S., Ishibashi K., Davidson K., 2002, ApJ, 581, 1154

Verner E., Brhuhweiler F. B., Gull T. R., 2005, ApJ, 624, 973
Weigelt G., Ebersberger J., 1986, A\&A, 163, L5

Weis K., Stahl O., Bomans D. J., Davidson K., Gull T. R., Humphreys R. M., 2005, AJ, 129, 1694

Whitelock P. A., Feast M. W., Marang F., Breedt E., 2004, MNRAS, 352, 447

Whitney C. A., 1952, Harvard College Observatory Bulletin No. 921, 8

This paper has been typeset from a $\mathrm{TE}_{\mathrm{E}} \mathrm{X} / \mathrm{LT} \mathrm{E} \mathrm{X}$ file prepared by the author 


\title{
Near-infrared integral field spectroscopy of the Homunculus nebula around $\eta$ Carinae using Gemini/CIRPASS
}

\author{
M. Teodoro, ${ }^{1 \star}$ A. Damineli, ${ }^{1}$ R. G. Sharp, ${ }^{2}$ J. H. Groh $^{3}$ and C. L. Barbosa ${ }^{4}$ \\ ${ }^{1}$ Instituto de Astronomia, Geofísica e Ciências Atmosféricas, Universidade de São Paulo, \\ Rua do Matão 1226, Cidade Universitária, São Paulo 05508-900, Brazil \\ ${ }^{2}$ Anglo-Australian Observatory, PO Box 296, Epping, NSW 1710, Australia \\ ${ }^{3}$ Max-Planck-Institute für Radioastronomie, Auf dem Hügel 69, D-53121 Bonn, Germany \\ ${ }^{4} I P \& D$, Universidade do Vale do Paraíba, Av. Shihima Hifumi 2911, São José dos Campos, 12244-000 SP, Brazil
}

Accepted 2008 March 28. Received 2008 March 20; in original form 2007 May 8

\begin{abstract}
This work presents the first integral field spectroscopy of the Homunculus nebula around $\eta$ Carinae in the near-infrared spectral region $(J$ band). We confirmed the presence of a hole on the polar region of each lobe, as indicated by previous near-IR long-slit spectra and mid-IR images. The holes can be described as a cylinder of height (i.e. the thickness of the lobe) and diameter of 6.5 and $6.0 \times 10^{16} \mathrm{~cm}$, respectively. We also mapped the blue-shifted component of He I $\lambda 10830$ seen towards the NW lobe. Contrary to previous works, we suggested that this blue-shifted component is not related to the Paddle but it is indeed in the equatorial disc.

We confirmed the claim of N. Smith and showed that the spatial extent of the Little Homunculus matches remarkably well the radio continuum emission at $3 \mathrm{~cm}$, indicating that the Little Homunculus can be regarded as a small $\mathrm{H}$ II region. Therefore, we used the optically thin $1.3 \mathrm{~mm}$ radio flux to derive a lower limit for the number of Lyman-continuum photons of the central source in $\eta$ Car. In the context of a binary system, and assuming that the ionizing flux comes entirely from the hot companion star, the lower limit for its spectral type and luminosity class ranges from $05.5 \mathrm{III}$ to $\mathrm{O} 7 \mathrm{I}$. Moreover, we showed that the radio peak at $1.7 \mathrm{arcsec} \mathrm{NW}$ from the central star is in the same line-of-sight of the 'Sr-filament' but they are obviously spatially separated, while the blue-shifted component of He I $\lambda 10830$ may be related to the radio peak and can be explained by the ultraviolet radiation from the companion star.
\end{abstract}

Key words: stars: general - stars: individual: $\eta$ Carinae - circumstellar matter - reflection nebulae.

\section{INTRODUCTION}

The Homunculus nebula around the massive luminous blue variable $\eta$ Carinae is the result of an eruptive mass-loss event that took place around 1843, throwing out more than $10 \mathrm{M}_{\odot}$ in a bipolar outflow (Gaviola 1950; Ringuelet 1958; Currie et al. 1996; Smith \& Gehrz 1998; Smith, Gehrz \& Krautter 1998; Smith et al. 2003; Morse et al. 2001; Smith 2006). Hillier \& Allen (1992) suggested that the lobes of the Homunculus are essentially hollow shells with most of the mass concentrated in two polar caps and thin side walls (see also Meaburn, Walsh \& Wolstencroft 1993; Davidson et al. 2001; Smith 2002). In addition, a ragged equatorial disc also formed, which makes the Homunculus unique among bipolar nebulae (Duschl et al. 1995). The Homunculus shows a complex mottled surface with lanes of dust condensation and holes in the lobes (Morse et al. 1998). Although

^E-mail: mairan@astro.iag.usp.br (MT) the Homunculus is mainly a reflection nebula, it also has associated intrinsic emission lines due to shocks or photo-excitation (Allen \& Hillier 1991, 1993; Hillier \& Allen 1992; Davidson et al. 2001; Smith 2002, 2004, 2005, 2006). Such studies showed that the observed velocity pattern of a spectral line along the Homunculus can be used to determine the origin of each component of the emission.

Surprisingly, another bipolar structure lying inside the Homunculus was discovered by Ishibashi et al. (2003) using long-slit spectroscopy obtained with the Space Telescope Imaging Spectrograph (STIS) aboard the Hubble Space Telescope (HST). The so-called Little Homunculus was detected in more than 30 optical lines of [Fe II] and [Ni II] (such as [Fe II] $\lambda 4891, \lambda 4907, \lambda 4975$ and [Ni II] 27380) as well as in He I and H I lines (Ishibashi et al. 2003), and is particularly bright in the near-IR [Fe II] lines (Smith 2002). The proper motion and radial velocities analysis are consistent with the Little Homunculus forming in a smaller mass-ejection event that occurred around 1890 (Ishibashi et al. 2003; Smith 2005). Smith (2005) estimated an ejected mass and kinetic energy for the Little 
Homunculus of $0.1-0.2 \mathrm{M}_{\odot}$ and roughly $10^{47} \mathrm{erg}$, respectively values which are at least two orders of magnitude lower than those for the Great Eruption that created the larger Homunculus (Smith et al. 2003). Although Smith (2005) mapped the basic structure of the Little Homunculus using five slits oriented parallel to the major axis and separated by $\approx 1$ arcsec, the spatial distribution of the Little Homunculus with a higher angular resolution in the near-infrared has not been done so far.

$\eta$ Car is also surrounded by a broken toroidal ring structure (Morris et al. 1999; Smith \& Gehrz 2000; Smith et al. 2002; Ishibashi et al. 2003), which absorbs part of the ultraviolet radiation, while allowing the rest to escape through holes and excite/ionize the surrounding gas at large distances from the central source (Smith 2006). An excellent example of this effect is given by the blue-shifted component of the He I $\lambda 10830$ line projected on to the NW lobe (Smith 2002).

This work presents the results of the first integral-field spectroscopy mapping of the Homunculus nebula. The paper is organized as follows. The observations and data reduction are described in Section 2. A discussion about the line-formation mechanism throughout the nebula around $\eta$ Carinae is presented in Section 3, while the results are shown in Section 4. In Section 5 is a comparison of the continuum radio-emission and our results as well as our estimates about the properties of the hot-companion star. Finally, our conclusions are summarized in Section 6.

\section{OBSERVATIONS AND DATA REDUCTION}

The integral field observations of $\eta$ Car were recorded on 2003 March 14, 15 and 18 at the $8 \mathrm{~m}$ Gemini South telescope using the visitor instrument CIRPASS, ${ }^{1}$ a spectrograph developed by the Cambridge instrumentation team (Parry et al. 2004). CIRPASS has 490 hexagonal lens placed at the integral field unit with a spatial sampling interval of 0.25 arcsec per lens. It provides a wavelength coverage of $\lambda \lambda 10620-12960$, with a resolving power $\left(\frac{\lambda}{\Delta \lambda}\right)$ of 3200 .

The observations were originally planned for two epochs, one at the high- (2003 March) and other at the low-excitation state (2003 July) of the $5.5 \mathrm{yr}$ cycle (Damineli 1996; Damineli et al. 2000). Unfortunately, the observing run during the low excitation state was lost due to poor weather conditions.

The following strategy was adopted to map the whole Homunculus: two images were taken at a given position of the nebula, and then the IFU was shifted by 0.88 arcsec along the north-south axis to take the next two images. The final dataset comprised two images from 44 IFU positions, which corresponds to a final mosaic of 6299 spectra and covers the whole Homunculus.

The data were reduced using standard near-infrared techniques. First, any spurious features were removed by the $\operatorname{IRAF}^{2} /$ COSMICRAYS task. After that, the spectra were flat-fielded, and an optimal spectral extraction was performed in order to account for the overlapping wings among neighbouring spectra. The wavelength calibration was done using an argon lamp spectra and a polynomial interpolation ( $\mathrm{rms} \sim 0.1 \AA$ ). The telluric lines were removed dividing the Homunculus spectra by the spectrum of a hot early-type star observed

\footnotetext{
${ }^{1}$ www.ast.cam.ac.uk/ optics/cirpass/cirpass_index.html

${ }^{2}$ IRAF - Image Reduction and Analysis Facility - is written and supported by the IRAF programming group at the National Optical Astronomy Observatories (NOAO) in Tucson, Arizona. NOAO is operated by the Association of Universities for Research in Astronomy (AURA), Inc. under cooperative agreement with the National Science Foundation
}

just after the science observation. The photospheric lines of the telluric standard was removed previously through an interpolation of the adjacent continuum. The FWHM of the point-spread function of our data is 0.4 arcsec, which was measured using the intensity profile of the standard star. Finally, a full data cube was constructed from the individual spectra using our own tasks written in IDL. The signal-to-noise ratio $(\mathrm{S} / \mathrm{N})$ is quite variable along the entire mosaic: within the region where the Homunculus nebula is located, the average $\mathrm{S} / \mathrm{N}$ in the continuum is $\approx 25$, while throughout the outer ejecta it is roughly 10 .

\section{MECHANISMS OF EXCITATION AND/OR IONIZATION IN THE CIRCUMSTELLAR EJECTA OF $\eta$ CAR}

In this paper, we focus on two emission lines found throughout the Homunculus, namely, [Fe II] $\lambda 12567$ and $\mathrm{He}$ I $\lambda 10830$. As usual in the spectra of the Homunculus, these lines show many components of intrinsic and reflected emission, which can be used to map the spatial distribution of structures lying inside or outside the Homunculus. Hence, it is very important to know about the mechanisms of lineformation in order to better understand the physical conditions of the emitting and reflecting regions.

In this section, we will discuss about the process of line-formation inside and outside the Homunculus nebula. We must stress that throughout this paper, we refer to 'photo-excitation' as the process by which a photon of the radiation field is absorbed by an atom or ion of the gas with the promotion of one electron to a higher energy level without ionization (bound-bound transition). If the incident photon has an energy greater than the ionization potential of the atom or ion, then one electron will be stripped out of it. This process is called 'photo-ionization' and is responsible for bound-free transitions.

On the other hand, if the gas is hot enough to keep most of the atoms ionized, as usually found around massive stars, then the electronic density will be high and probably the electrons will collide with the ions and excite their electron to an upper level (more energetic). This process is called 'collisional-excitation' or 'collisionalionization', depending on the capability of the incident electron in removing or not one electron from the target ion.

The return of the electron to the ground state of the ion - known as recombination - will be followed by the emission of many photons with different energy, which gives rise to the emission-line spectrum of some stars.

\subsection{The Homunculus nebula}

Many studies have shown that in the lobes of the Homunculus nebula, photo-excitation is the predominant mechanism for populating the atomic levels of the ions (Gull et al. 2005; Verner, Bruhweiler \& Gull 2005; Smith 2006). This is because the strong stellar radiation is absorbed by dust in the nebula which, in turn, is heated to a few hundreds degrees Kelvin and starts to emit a reprocessed radiation field responsible for keeping the observed ionization structure inside the walls (Smith \& Ferland 2007). However, this is not ionizing radiation since the central source has a dense stellar wind which absorbs nearly all of the Lyman-continuum photons. The few photons that escape the stellar wind are absorbed either by the toroidal structure at the equator or by the Little Homunculus, which causes strong variability in the radio continuum (Duncan, White \& Lim 1997).

On the other hand, the stellar wind shows a latitude-dependent profile, being more dense and fast in the polar regions than in the equatorial region (Smith et al. 2003). The expansion velocity of the 
Homunculus is about $600 \mathrm{~km} \mathrm{~s}^{-1}$ while the stellar wind reaches terminal velocities in the range of $600-1000 \mathrm{~km} \mathrm{~s}^{-1}$. Thus, inside the lobes it is expected to detect collisionally excited emission lines as well. Indeed, the strength of IR [Fe II] and $\mathrm{H}_{2}$ lines in the NW lobe relative to SE suggest that there is a combination of slow shocks and photo-excitation inside the lobes. The shocks are needed to explain the observed value $\gtrsim 35$ for the ratio of [Fe II] $\lambda 16435$ to $\mathrm{Br} \gamma$ (Smith \& Davidson 2001), though it should not exceed the threshold velocity either for dissociation of $\mathrm{H}_{2}$ - detected by Smith \& Davidson 2001 - or to emit any hard X-ray photon as noted by Weis, Duschl \& Bomans 2001. Therefore, the walls of the nebula must be composed of dense, small neutral/molecular knots or clumps (Morse et al. 1998) so that the fast bi-polar wind could escape into the outer ejecta without strong interaction with the Homunculus (similar to the well-known Rayleigh-Taylor instabilities).

Therefore, in the lobes of the Homunculus nebula, there is a competition between photo-excitation and collisions as the main line-formation mechanism, the former being the most significant excitation/ionization process.

\subsection{The equatorial region}

In the equatorial region, however, the stellar wind is slower than in the polar regions. It also presents a lower density and consequently, the emission due to collisions is weak. Therefore, the equatorial region is largely dominated by photo-excitation. This is because of both the proximity to the central source and the high ionization flux from the equatorial region of the central star (Smith et al. 2003). The presence of a torus around the system is revealed by narrow-band IR images and confirmed at radio wavelengths (Duncan, White \& Lim 1997; Smith, Gehrz \& Krautter 1998) as well as in emission lines. Nevertheless, this structure is not continuous but shows either dense clumps (where low-ionization ions are detected) and holes (through where radiation can escape). Examples of these structures are the so-called 'Sr-filament' (Zethson et al. 1999; Gull et al. 2000, 2001; Zethson et al. 2001; Bautista et al. 2002; Hartman et al. 2004; Bautista et al. 2006) and the He I $\lambda 10830$ emission columns (Smith et al. 2002).

\subsection{The outer ejecta}

The picture drastically changes when considering the line-formation process outside the Homunculus nebula, namely, in the outer ejecta. This region is nitrogen-rich (Smith \& Morse 2004) and responsible for practically all of the observed X-ray flux up to $1.5 \mathrm{keV}$, which implies shock velocities in excess of $1500 \mathrm{~km} \mathrm{~s}^{-1}$ (Weis et al. 2004). These shocks are sufficient to excite (and even ionize) ions to higher energy levels than those observed in the Homunculus. This is supported by the observation of N VI/VII, Si XIII/XIV, Mg XII in the X-ray part of a thermal-emission spectrum and strong $\mathrm{N}$ II, [OIII], [S III] and Si II and many other lines of high-ionization energy ions in the optical range (Smith et al. 2004; Weis et al. 2004; Hamaguchi et al. 2007).

Thus, throughout the Homunculus nebula the process of lineformation is mainly via photo-excitation with a little contribution from slow shocks inside the lobes at high stellar latitudes, while in the outer ejecta the predominant process is excitation/ionization via collisions, with little contribution from photo-excitation.

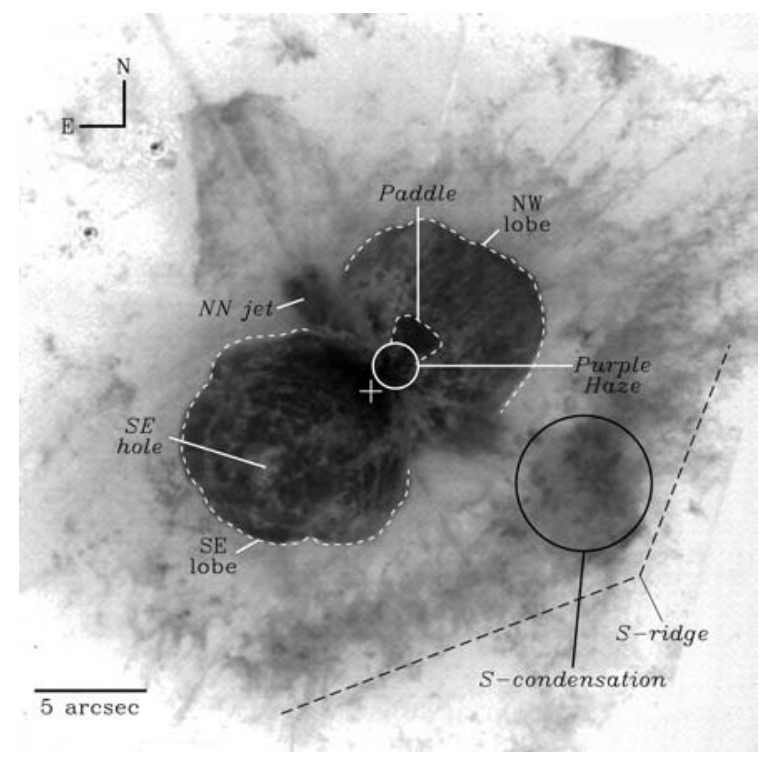

Figure 1. Optical HST/ACS image of the ejecta around $\eta$ Car (Morse et al. 1998). This image shows the adopted nomenclature of some of the most important regions around $\eta$ Car.

\section{RESULTS: J-BAND SPATIAL MAPS OF THE NEBULA AROUND $\eta$ CAR}

\subsection{Structures in the $[\mathrm{Fe} \mathrm{II}] \lambda \mathbf{1 2 5 6 7}$ line}

This section presents the spatial structure and kinematics of the photo-excited regions found in the Homunculus. For the first time, a complete spatial map of such photo-excited regions is presented in the near-infrared. Although velocity maps were already made using forbidden lines in the optical with higher spatial resolution using HST (Ishibashi et al. 2003), the use of the near-infrared region in this work allows the observer to peer through the circumstellar dust and probe the environment around $\eta$ Car.

Extensive work has been done in the near-infrared by Smith (2002, 2004, 2005, 2006) to established the overall kinematics of the regions around $\eta \mathrm{Car}$, in special the Little Homunculus (Smith 2005). However, a complete spatial map has not been done so far in near-infrared. The IFU observations presented here should therefore be interpreted as complementary information to what has been presented by previous works using long-slit spectroscopy.

Fig. 1 is an image of the circumstellar environment of $\eta$ Car obtained with the HST Advanced Camera for Survey (ACS). This image is referred to throughout this paper for the location and standard nomenclature of specific regions in the ejecta of $\eta$ Car.

\subsubsection{Identifying line components in the Homunculus spectrum}

We used the kinematic model of the Homunculus proposed by Davidson et al. (2001) to identify reflected and intrinsic emission components. This model was built using long slit observations of forbidden spectral lines in the optical, mapping the emission coming from inside the Homunculus with spatial and spectral resolution of 0.1 arcsec and $\approx 90 \mathrm{~km} \mathrm{~s}^{-1}$, respectively. Thus, as a first approximation, the Davidson et al. (2001) model is accurate enough (for our objectives) to classify the observed components of a given line as intrinsic or reflected. 

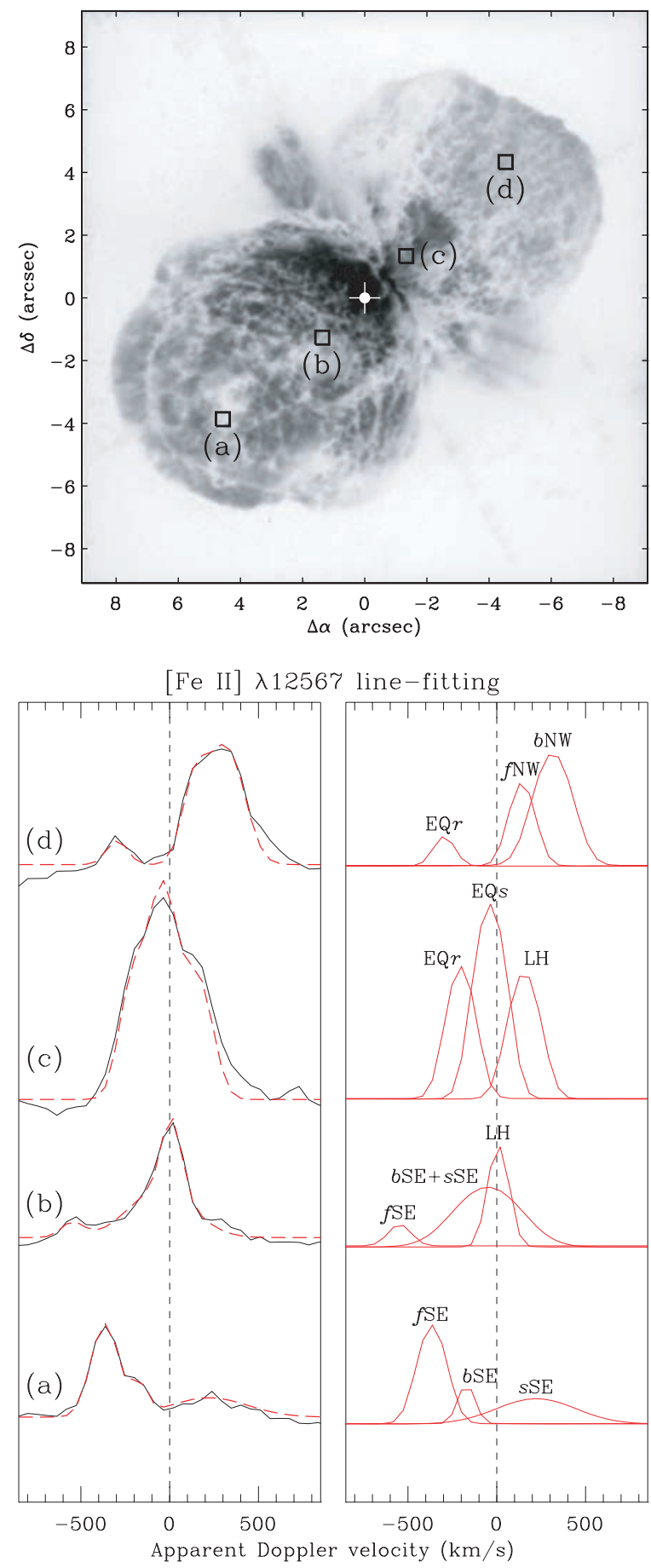

Figure 2. The upper panel shows the position where we extracted the spectra shown in the lower panel. Although the boxes in the upper panel have approximately the dimension of one lens $(0.25 \mathrm{arcsec})$, each spectrum in the lower panel is a median-combined of four adjacent lens in order to improve the signal to noise ratio. The abbreviations is described in Section 4.1.1.

Typical spectra from the Homunculus are presented in Fig. 2. The adopted abbreviations are as follows: $f(b)$ means intrinsic emission coming from the front (back) wall of the SE or NW lobe and $s$ means scattered emission reflected in the SE or NW lobe. As usual, we refer to front (back) wall as the near (far) side of each lobe of the Homunculus. Emission associated with the equatorial ejecta is labelled as either EQ $s$ or $\mathrm{EQ} r$, where $s$, in this case, means slowand $r$, rapid-moving gas.
We identified all of the [Fe II] $\lambda 12567$ components in order to map the emission structures of the Homunculus. The Doppler velocity of each component mentioned hereafter is heliocentric and was obtained by a multi-Gaussian line fitting procedure. The components are as follows:

(i) $f \mathrm{SE}\left(\approx-400 \mathrm{~km} \mathrm{~s}^{-1}\right)$ is an intrinsic emission due to Balmer excitation to an upper level followed by recombination to a lower level (bound-bound transition) or recombination of $\mathrm{Fe}^{++}$to $\mathrm{Fe}^{+}$ (free-bound transition) inside the SE lobe;

(ii) $b \mathrm{SE}\left(\approx-200 \mathrm{~km} \mathrm{~s}^{-1}\right)$ is intrinsic emission coming from the back wall of the SE lobe and is due to recombination of $\mathrm{Fe}^{++}$to $\mathrm{Fe}^{+}$as well;

(iii) $s \mathrm{SE}\left(\approx+200 \mathrm{~km} \mathrm{~s}^{-1}\right)$ is emission from the stellar wind scattered in the front wall of the SE lobe;

(iv) $\mathrm{EQ} s\left(\approx-100 \mathrm{~km} \mathrm{~s}^{-1}\right)$ is due to intrinsic emission from slowmoving material located in the equatorial plane, which intercepts our line-of-sight towards the NW lobe. This component was also detected in [Ni II] $\lambda 7380$ by Davidson et al. (2001) and in many low-ionization emission lines such as [Mn II], [Cr II] and [Ti II]. It is due to the 'Sr-filament' discussed in Section 5.1;

(v) $\mathrm{EQ} r\left(\approx-250 \mathrm{~km} \mathrm{~s}^{-1}\right)$ is due to equatorial ejecta illuminated directly by ionizing radiation from the central source. This component comes from a region known by its strong continuum radio emission and variability. We will discuss this feature in Section 5.1;

(vi) $\mathrm{fNW}\left(\approx+100 \mathrm{~km} \mathrm{~s}^{-1}\right)$ is an intrinsic emission associated with the near wall of the NW lobe. It is due to the same mechanism as $f$ SE;

(vii) $b \mathrm{NW}\left(\approx+300 \mathrm{~km} \mathrm{~s}^{-1}\right)$ is also intrinsic emission related to recombination at the polar region of the NW lobe;

(viii) LH is emission associated with the Little Homunculus.

\subsubsection{The hole at the pole of lobes}

We detected two regions where emission due to recombinant $\mathrm{Fe}^{++}$ is nearly absent. These regions can be seen in Fig. 3, which shows velocity maps of [Fe II] $\lambda 12567$ from -525 to $+510 \mathrm{~km} \mathrm{~s}^{-1}$. On both lobes, a small polar region with extremely reduced emission in this line can be identified (circular contour in each lobe in Fig. 3). The flux from these holes are typically $\sim 50$ per cent lower than its immediate surroundings. Moreover, such deficit of [Fe II] and $\mathrm{H}_{2}$ emission at these locations was also reported by Smith et al. (1998) and Smith (2006).

It is tempting to associate the hole seen in the [Fe II] $\lambda 12567$ velocity maps with the structure known as $S E$ hole (see Fig. 1), observed in optical and near-infrared wavelengths (Smith et al. 1998). To investigate that hypothesis, we compared the relative position between the SE hole and the SE region with low emission of [Fe II] $\lambda 12567$. Besides, we also compared the position of those regions with the location of the lobe's pole. ${ }^{3}$ To do so, we assumed the kinematic model of the Homunculus of Smith (2006), which was obtained by tracing the $\mathrm{H}_{2}$ emission along the nebula and gives a more accurate position for the location of the pole.

Our results give strong support to the idea that there indeed is a hole at the pole of each lobe. The facts that led us to this conclusion are mainly two:

(i) the location of the $\mathrm{SE}$ region with lower emission of [Fe II] $\lambda 12567$ does not match neither the position of the SE hole nor

\footnotetext{
${ }^{3}$ By the word 'pole' we mean to say the location in the lobe where the stellar latitude is $90^{\circ}$. Obviously, this position is model-dependent.
} 


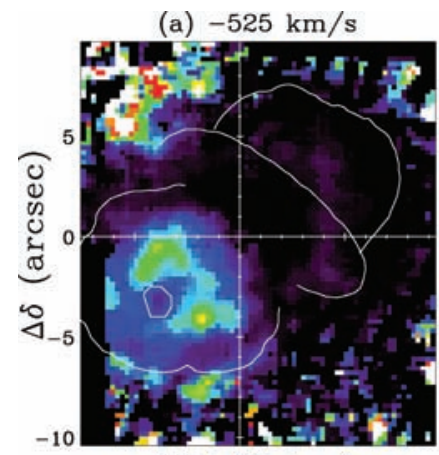

(d) $+401 \mathrm{~km} / \mathrm{s}$

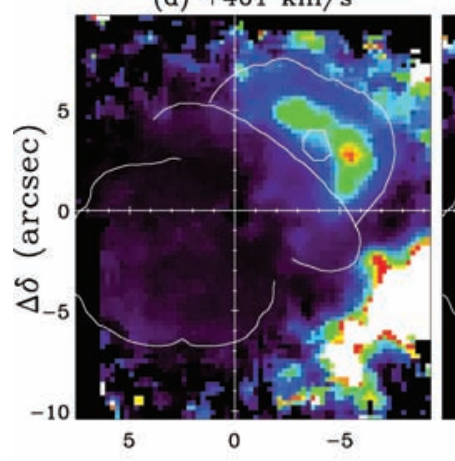

(b) $-471 \mathrm{~km} / \mathrm{s}$

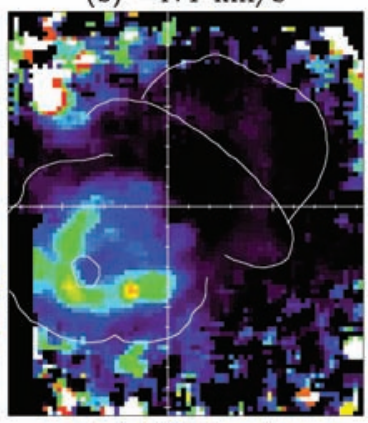

(e) $+455 \mathrm{~km} / \mathrm{s}$

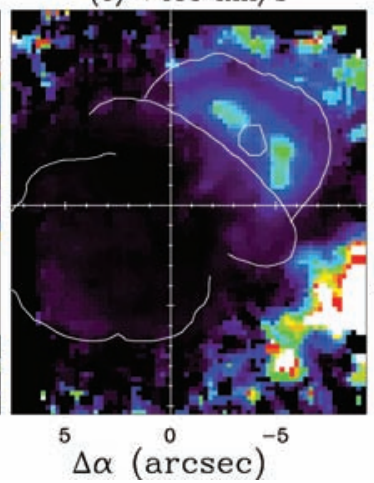

(c) $-416 \mathrm{~km} / \mathrm{s}$

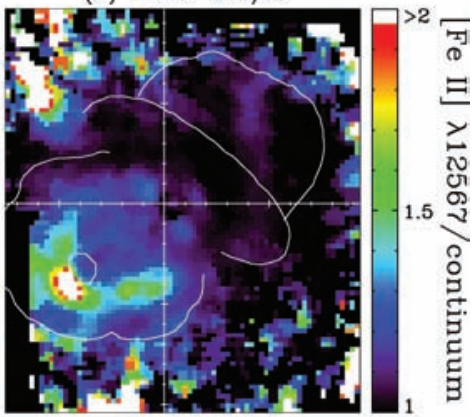

(f) $+510 \mathrm{~km} / \mathrm{s}$

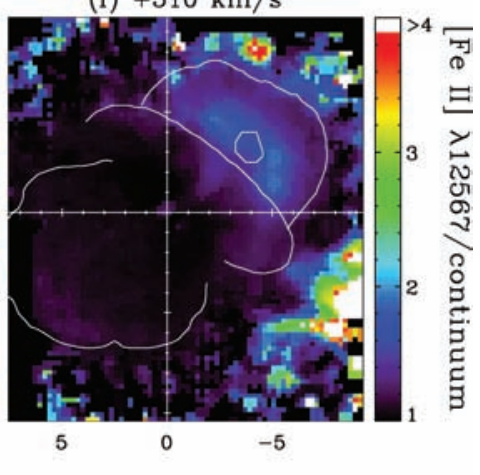

Figure 3. Velocity maps of the [Fe II] $\lambda 12567$ line showing a hole both in the SE and NW lobe (Smith et al. 1998). The coordinates of the NW hole are the same as the SE hole but rotated by $180^{\circ}$ around the centre of the axis. Notice the change in the colour scale to bring up weaker emissions in each lobe. The emission from the surrounding of the hole is almost 50 per cent greater than that coming from the hole itself. The system velocity is $8.1 \mathrm{~km} \mathrm{~s}^{-1}$ heliocentric (Smith 2006).

the pole of the lobe. Instead, they are shifted from one another by $\approx 0.7$ arcsec along the major axis of the Homunculus, that is, the $S E$ hole is half-way between the pole of the lobe and the region with weak emission of $\left[\mathrm{Fe}\right.$ II] $\lambda 12567$. Hence, the lack of $\mathrm{Fe}^{+}$emission is not associated with either the $S E$ hole or the pole.

(ii) the absence of thermal infrared emission from dust reported by Smith et al. (1998) is also a strong indication that those polar holes are indeed lower-density regions, and not shadows.

[Fe II] $\lambda 12567$ is most likely to arise from a warm, low-density region inside the lobe because when the stellar radiation field penetrates the wall of the lobes - which has a hydrogen density of about $10^{7} \mathrm{~cm}^{-3}-$ it gets more attenuated and then $\mathrm{Fe}^{+}$recombines to $\mathrm{Fe}^{0}$ and we see no more emission from Fe II (Smith \& Ferland 2007). Thus, the spatial distribution of this line represents the emission coming from the inner part of the lobes. Together with the fact that molecular hydrogen emission comes from a region of the lobe that is shielded from strong radiation - that is, just outside it - we could get a rough estimate of the lobes' thickness.

A first approximation of the geometry of the hole is to consider it as a cylinder with linear diameter ${ }^{4} d-$ the diameter of the [Fe II] non-emitting region - and height $\Delta R_{0}$ - the distance between the SE pole of the Homunculus and the [Fe II] non-emitting region. Hence, considering an inclination angle of $i=41^{\circ}$ from the line-of-sight (Davidson et al. 2001; Smith 2006), we obtained for the height and diameter of the cylinder, respectively, a linear size of $6.5 \pm 0.4 \times$ $10^{16}$ and $6.0 \pm 0.3 \times 10^{16} \mathrm{~cm}$. The errors quoted here are due only to our uncertainty in position and do not include the uncertainty in

\footnotetext{
${ }^{4}$ To conversion between apparent and linear size, we adopted a distance of $2.25 \mathrm{kpc}$ to $\eta$ Car (Davidson et al. 2001)
}

distance, which is in the range of $0.1-2 \times 10^{16} \mathrm{~cm}$ for most studies (Davidson et al. 2001; Smith 2006).

The right-hand panel of Fig. 4 shows the adopted model for the height and radius of the hole in the lobes of the Homunculus. The coordinates of the non-emitting region in the NW lobe were obtained by considering the position of the same region in the SE lobe, mirrored relatively to the central star by $180^{\circ}$.

We also estimated the thickness of the lobes at lower latitudes by measuring the 'limb-darkening' profile seen in our velocity maps (cf. Fig. 3). Indeed, there is a clear separation between the [Fe II] $\lambda 12567$ emission and the optical limit of the Homunculus' lobes because of the high-density medium inside the wall of the lobes. The observed mean separation in both lobes is $1.3 \mathrm{arcsec}$, which corresponds to a linear thickness of $4.4 \pm 0.5 \times 10^{16} \mathrm{~cm}$ (here, the errors are due to the irregularity of the $[\mathrm{Fe} \mathrm{II}] \lambda 12567$ emission region). This result suggests that the thickness of the lobes also presents a latitudedependent effect, which makes it almost 50 per cent thicker at polar regions than at lower latitudes.

Both holes - SE and NW - define an axis with position angle (P.A.) of $-50^{\circ}$, which coincides with that found by Smith (2002) based on symmetry arguments. We suggest that these holes must form a fundamental axis of the Homunculus, which could be created because of a low (or even inhibited) mass-loss rate within $\approx 5^{\circ}$ of the poles. Since about 75 per cent of the mass of the Homunculus is located at high stellar latitudes (Smith 2006), when the lobes expand they might appear as two rings in the future, similar to those seen around other blue supergiants, such as HD168625 or Sher 25 (Smith 2007).

An alternative explanation is that the central star has had a major blowout in the polar region, creating the holes. In this scenario, this 'blowout' would have been a greater manifestation of 


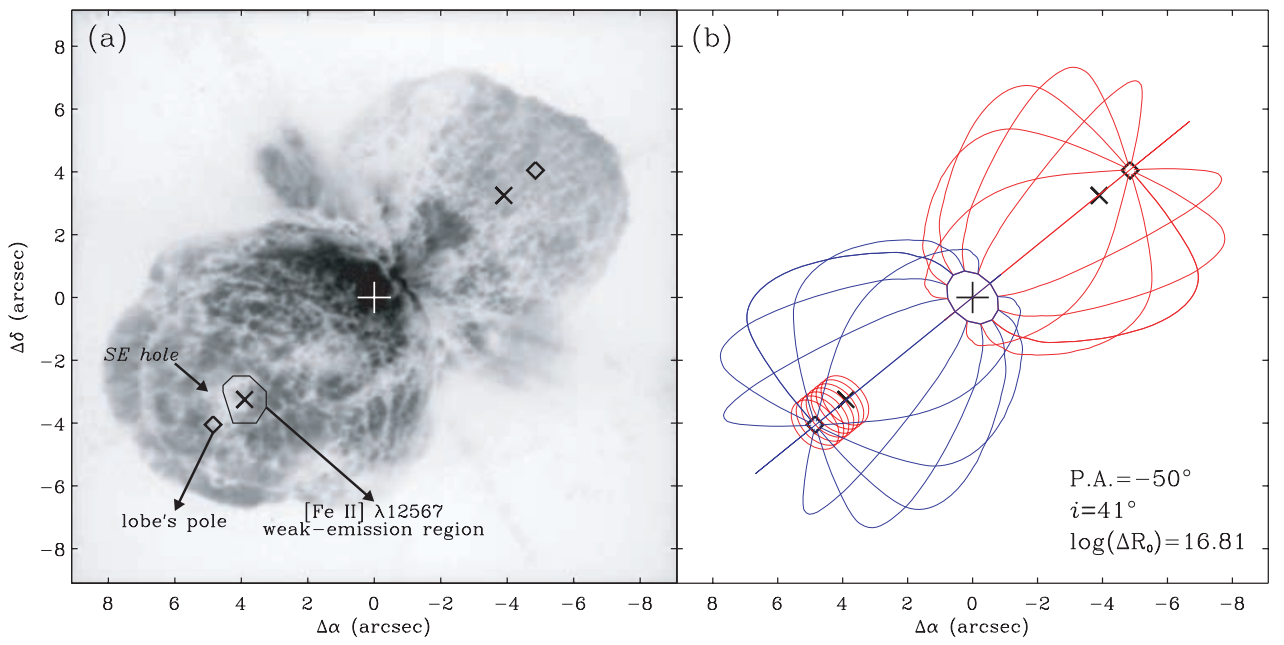

Figure 4. (a) Position of the features used to estimating the thickness of the lobes: $\diamond$ marks the location of the pole of the lobe (as in Smith 2006), while $\times$ indicates the centre of the [Fe II] $\lambda 12567$ weak-emission region (circular contour). (b) A cylinder in the SE lobe superimposed on the Homunculus model. From the $\times$ mark to the $\diamond$ symbol, the linear height of the cylinder is roughly $6.5 \times 10^{16} \mathrm{~cm}\left[\log \left(\Delta R_{0}\right)=16.81\right]$, which we assumed as the thickness of the polar region of the lobes. The diameter of the cylinder is assumed to be the same as that observed for the [Fe II] $\lambda 12567$ weak-emission region, which has a linear size of $6.0 \times 10^{16} \mathrm{~cm}$. The adopted values for the inclination and position angle of the Homunculus model are also given (the same parameters are applied to the cylinder as well).

the same mechanism that produced the many fast-moving structures dubbed 'strings' or 'whiskers' or even 'spikes' (Meaburn et al. 1996; Morse et al. 1998; Weis, Duschl \& Chu 1999). These high-density $\left(n_{\mathrm{e}} \sim 10^{4} \mathrm{~cm}^{-3}\right.$; Weis 2002) filamentar structures lie outside the Homunculus and are moving at nearly $1000 \mathrm{~km} \mathrm{~s}^{-1}$ but even so, they do not emit hard X-rays most likely because of its very small crosssection. Interestingly, they are only seen at high stellar latitudes (in the polar directions). One of the explanations for the observed velocity profile (a Hubble law) of these structures is that they could be formed in a presumably stellar explosion (Weis et al. 1999). Thus, if this scenario is correct, this explosion could be responsible for the formation of the hole in pole as well.

We also note that an explosion at the surface of the primary star was the physical mechanism used by Smith \& Townsend (2007) in a simulation that creates, simultaneously, a bipolar nebula and an equatorial disc (as observed in the Homunculus). However, the physical mechanism that could start such stellar explosion remains unclear, and encourages further studies.

\subsubsection{Spatial mapping of the Little Homunculus}

Due to the long-slit spectroscopic technique employed by Smith (2005), the determination of the spatial extent and distribution of the Little Homunculus (hereafter $\mathrm{LH}$ ) was restricted to the interpolation between the points where the emission associated with the LH was detected in the slit. In the present work, we show the 3-D kinematics in the form of slices in velocity space, rather than slices along the major axis as in Smith (2005), but the results of the two independent methods are in agreement. Our velocity channel images may provide a better way to evaluate images from simulations of the formation of the LH (González et al. 2004), as we provide a complete, modelindependent spatial map of the LH.

Our analysis of the velocity maps (Fig. 5) showed that the emission of the SE lobe of the LH begins at $\approx-250 \mathrm{~km} \mathrm{~s}^{-1}$ and goes up to $+100 \mathrm{~km} \mathrm{~s}^{-1}$. The emission associated to the LH is seen blueshifted near the centre in the SE lobe as indicated in Figs 5(a) and (b), in line with the results of Smith (2005). Starting from negative and moving toward positive velocities, it is possible to see the emission from the equatorial disc (EQ in Fig. 5a) in the same line-of-sight of the NW lobe of the LH. However, based on geometric arguments, the components of the equatorial disc can only have negative velocities (Davidson et al. 1997). Thus, the component associated to the NW lobe of the LH was identified as the structure lying near the central region with velocities ranging from $\approx+20$ up to about $+235 \mathrm{~km} \mathrm{~s}^{-1}$ (see Figs 5d-f).

\subsection{The He I $\lambda 10830$ emission column}

The He I $\lambda 10830$ line has a very complex velocity structure in the spectrum of the Homunculus (Smith 2002). It is a combination of absorption, emission and reflection from different regions inside and outside the nebula and is, presumably, formed near the central source.

We detected an intrinsic emission component which appears restricted to a narrow azimuthal region in the line-of-sight to the NW lobe (Smith 2002). It is labelled as 1 in Fig. 6, and is likely photoexcited by energetic photons (at least $16.2 \mathrm{eV}$ ), since [Fe II] $\lambda 12567$ does not show any component at the same velocity. Component 2 is associated with emission from the slow-moving equatorial ejecta, ${ }^{5}$ and component 3 is reflected emission from the central source in the NW lobe (see also figs 12 and 13 of Smith 2002).

This narrow intrinsic emission of He I $\lambda 10830$ (hereafter He emission column) is likely formed when the UV radiation from the central source passes through the holes in the torus (Smith 2002; Smith et al. 2002) and are free to excite He atoms at large radii from the central source. The apparent Doppler velocity of the He emission column changes, respectively, from $\approx-250$ to $\approx-500 \mathrm{~km} \mathrm{~s}^{-1}$ when moving from a projected distance of 2-10.5 arcsec from the central source (see Fig. 7), suggesting that the emitting region has a Hubble-flow motion, that is, $v \propto d$. Note that such high projected velocity would suggest that the equatorial disc has ejecta moving as fast as the polar cap of the Homunculus. However, as will be

\footnotetext{
${ }^{5}$ Note, however, that component 2 may also be associated with diffuse emission due to the $\mathrm{H}$ II region in which $\eta$ Carinae is immersed.
} 


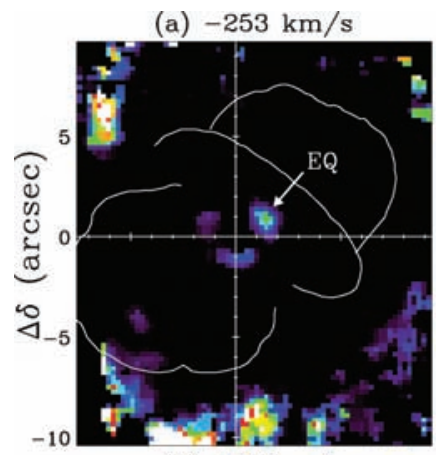

(d) $+19 \mathrm{~km} / \mathrm{s}$

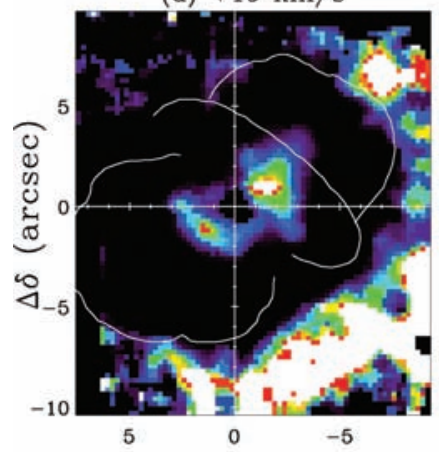

(b) $-198 \mathrm{~km} / \mathrm{s}$

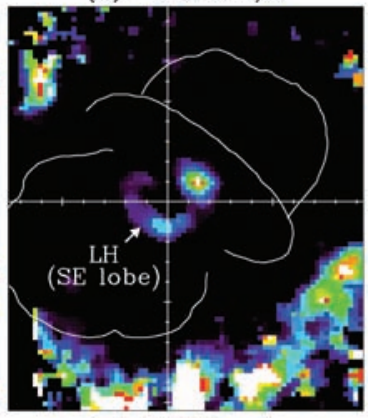

(e) $+183 \mathrm{~km} / \mathrm{s}$

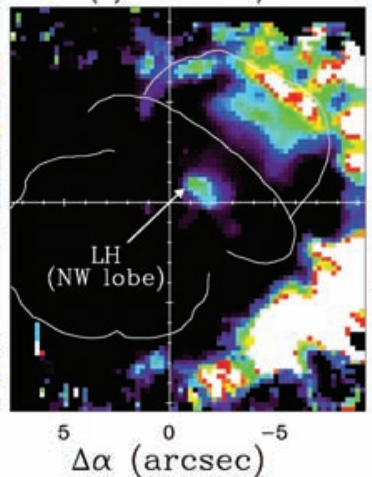

(c) $-89 \mathrm{~km} / \mathrm{s}$

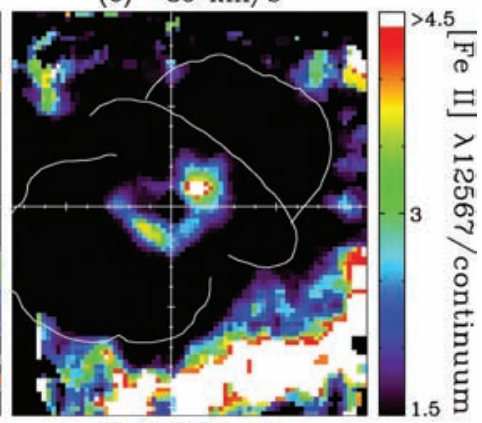

(f) $+237 \mathrm{~km} / \mathrm{s}$

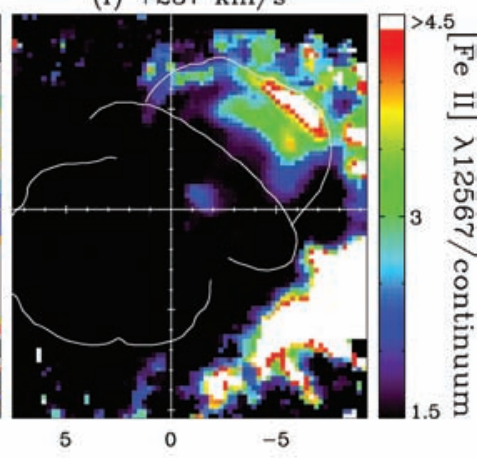

Figure 5. Velocity maps of the [Fe II] $\lambda 12567$ line showing the observed structures and its identification. LH means emission associated to the Little Homunculus while $\mathrm{EQ}$ is due to the equatorial disc. A fully animated version of this figure is available at www.astro.iag.usp.br/ $\sim$ damineli/feii.gif.

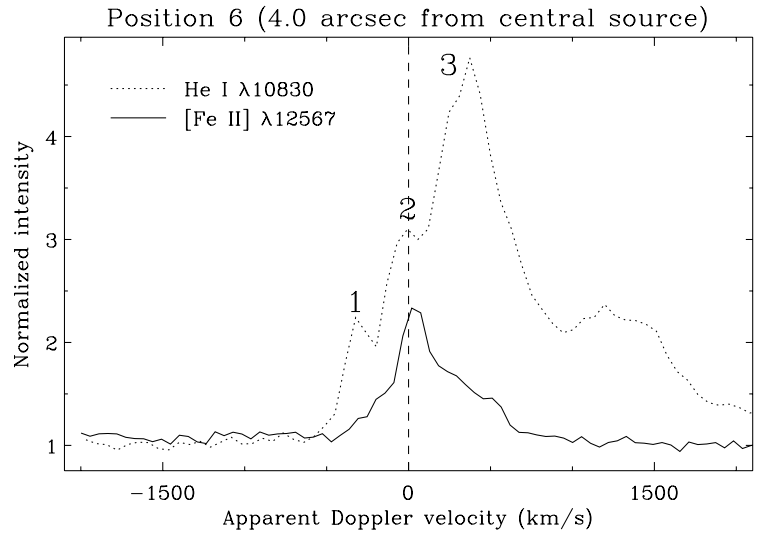

Figure 6. Comparison between $\mathrm{He}_{\mathrm{I}} \lambda 10830$ and $[\mathrm{Fe}$ II] $\lambda 12567$. The components labelled 1 and 2 are intrinsic emission from the equatorial region while 3 is formed in the winds of the central source and then scattered by the dust in the background NW lobe. Both spectra were extracted from the point labelled 6 in Fig. 7. The broad line at $\approx 1200 \mathrm{~km} \mathrm{~s}^{-1}$ is a blend between Fe II $\lambda 10863$ and Fe II $\lambda 10872$.

discussed in the next section, given the errors associated to the determination of the inclination angle of the helium emission column (which indicates whether or not it is in the equatorial disc), it may be comfortably associated with the Great Eruption, which lasted about 20 yr with peak between 1843 and 1851 (Currie et al. 1996; Currie \& Dowling 1999; Morse et al. 2001).

\subsubsection{Characteristics of the helium emission column and the detection of its twin brother}

It is known that the Paddle is a dust-free region located at the equatorial disc (Smith et al. 1998). Its shape is well defined and seems

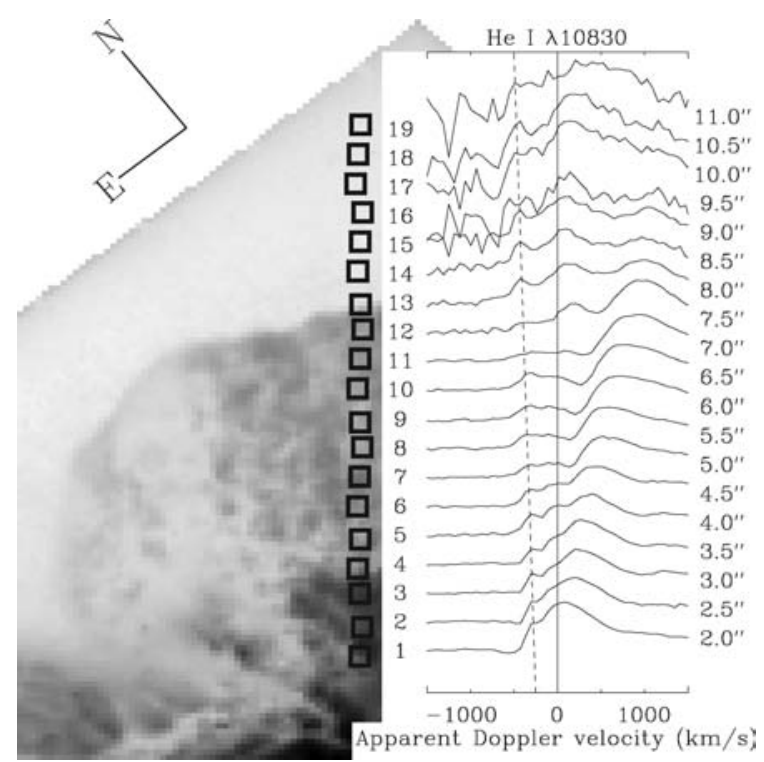

Figure 7. He I $\lambda 10830$ line profile along position angle $-41^{\circ}$. Notice the detection of the He I $\lambda 10830$ emission column along this position angle (vertical dashed line). In order to improve the signal-to-noise ratio, each spectrum was median-combined from four adjacent lens. The background image of the Homunculus was rotated by $41^{\circ}$ counter-clockwise.

symmetric regarding the major axis of the Homunculus ${ }^{6}$ (see Fig. 1). Therefore, the Paddle would be a suitable candidate to be blamed for the escape of radiation. Indeed, free of any interaction, it is expected

\footnotetext{
${ }^{6}$ Although it is likely that this alignment occurs by chance.
} 


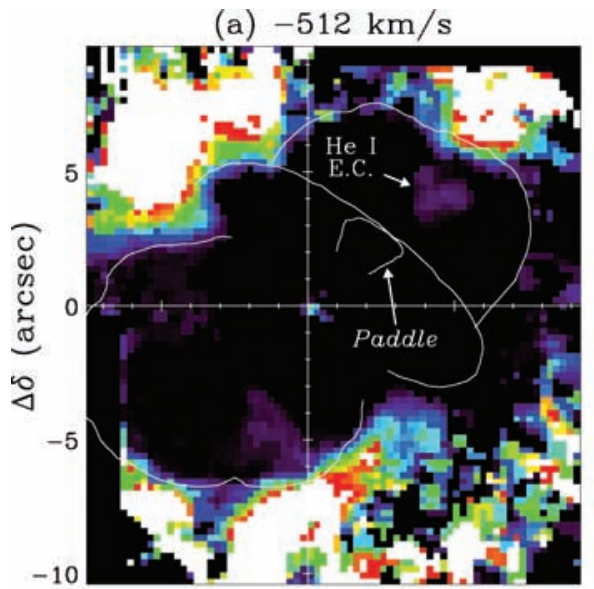

(c) $-386 \mathrm{~km} / \mathrm{s}$

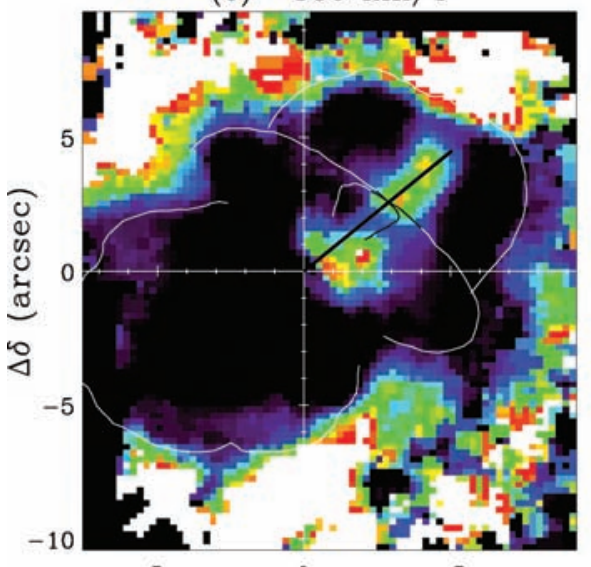

$0 \quad-5$

\section{$\Delta \alpha(\operatorname{arcsec})$}

(b) $-449 \mathrm{~km} / \mathrm{s}$

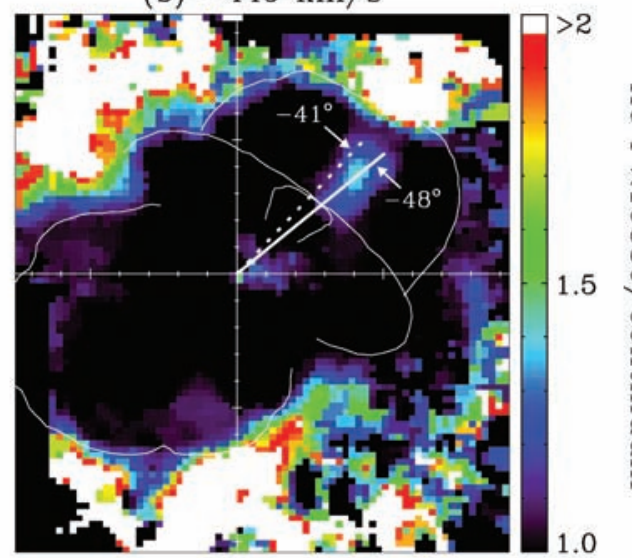

(d) $-322 \mathrm{~km} / \mathrm{s}$

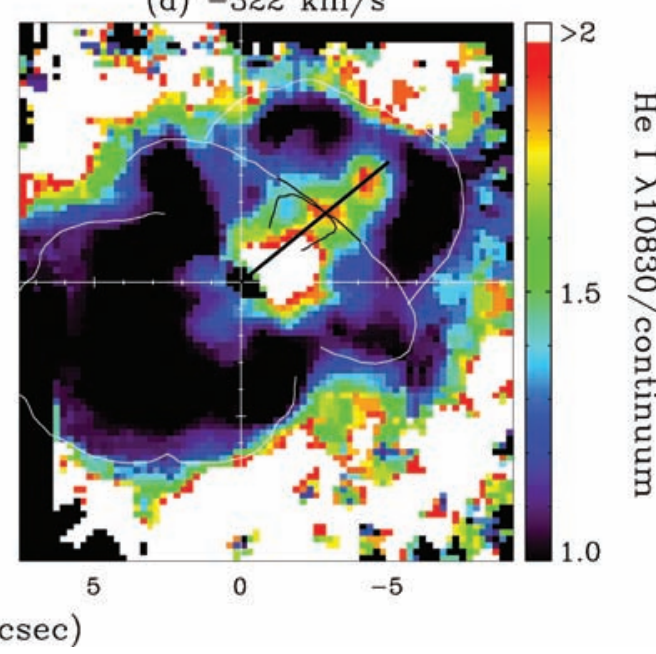

Figure 8. Velocity maps for the He I $\lambda 10830$ line showing the location of the He emission column (He I E.C. in the figure) and the Paddle. The misalignment between the P.A. of the Paddle and that of the helium emission column is clearly seen in (b). Also, note the strong emission (white region) near the centre in (d), which is associated to the Purple Haze. A full animated version of this figure is available at www.astro.iag.usp.br/ damineli/hei.gif.

that radiation flowing through that region would follow a linear path centred on P.A. $=-41^{\circ}-$ the position angle of the Paddle. However, the observed P.A. of the He I emission column is different of the Paddle, namely the He emission is at $-48^{\circ}$ (see Fig. 8). We must stress that even with this discrepancy, the $\mathrm{He} \mathrm{I} \lambda 10830$ emission column can be weakly detected along P.A. $=-41^{\circ}$ because of its roughly 3 arcsec wide but the bulk of emission comes indeed from P.A. $=$ $-48^{\circ}$.

In order to analyse the kinematic structure of the He I $\lambda 10830$, we adopted the same convention as in Davidson et al. (2001) and calculated the inclination angle ${ }^{7}$ of the He emission column using the following equation

$\tan \left(i_{\mathrm{He}}\right)=\frac{t}{4.74 D} \frac{V}{\omega}$,

where $t$ is the age, in years, of the equatorial gas, $D$ is the heliocentric distance to $\eta$ Car measured in pc, $V$ is the apparent Doppler velocity $\left(\mathrm{km} \mathrm{s}^{-1}\right)$ measured at position $\omega(\operatorname{arcsec})$. Note that regarding the age of the equatorial disc, there is no consensus. Based on kinematics

\footnotetext{
${ }^{7}$ The inclination angle is defined such that $i=0^{\circ}$ means that the equatorial disc is seen face-on, while $i=90^{\circ}$ corresponds to a edge-on view.
}

studies, Morse et al. (2001) suggested that the equatorial disc is coeval with the Homunculus lobes, although some material appears to be even younger presumably associated with posterior eruptions (Davidson et al. 1997, 2001; Smith \& Gehrz 1998; Dorland, Currie $\&$ Hajian 2004). In the present work, we assumed an age of $160 \mathrm{yr}$ for the equatorial disc. We also assumed that it is perpendicular to the major axis of the Homunculus (Davidson et al. 2001; Smith \& Townsend 2007).

From our data, the average value of $|V / \omega|$ was $67.9 \pm 6.3 \mathrm{~km} \mathrm{~s}^{-1}$ $\operatorname{arcsec}^{-1}$, corresponding to tan $\left(i_{\mathrm{He}}\right)=0.95 \pm 0.13$, which in turn results an inclination angle of approximately $44^{\circ}$ from the plane of the sky toward us. Though the error in our result $\left( \pm 3^{\circ}\right)$ is larger than that obtained with long-slit observations - typically less than $1^{\circ}-$, the lower end is consistent with $i=41^{\circ}$, which is the assumed inclination angle of the equatorial disc obtained using long-slit observations. Even so, our range of values for the inclination angle of the helium emission column is coherent with the Great Eruption, which takes place between 1837 and 1860, with the peak occuring around 1843 and 1851 (Currie et al. 1996; Currie \& Dowling 1999; Morse et al. 2001).

Hence, we concluded that, if the He I $\lambda 10830$ emission column is indeed in the equatorial disc and is caused by UV escaping through 

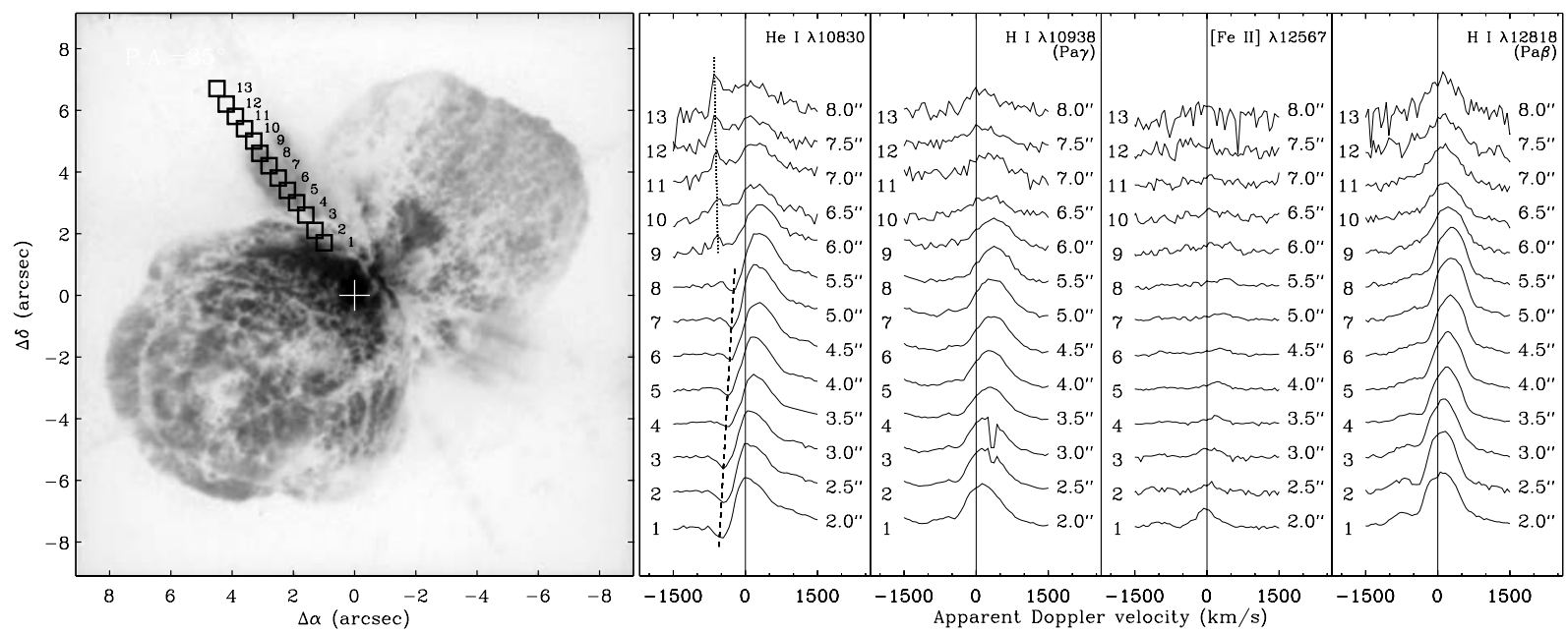

Figure 9. Tracing of line profiles toward the $N N$ jet. Notice the changes in the P Cygni absorption component in the helium line (dashed line), which moves from approximately -500 to $-220 \mathrm{~km} \mathrm{~s}^{-1}$ from position 1 to 9 , respectively. Beyond position 9 , we detected another He I $\lambda 10830$ emission column (dotted line). At position 2 and 3, Pa $\gamma$ shows an artifact in the red side of the line that is caused by a cosmetic defect in the detector.

a hole in the torus, we should detect this same effect in other places, since it is known that there are many holes in the equatorial torus.

In fact, we also detected intrinsic emission of He I $\lambda 10830$ at the end of the $N N$ jet (Fig. 9). With a P.A. of $+35^{\circ}$, the spectrum extracted from 2 to 6 arcsec from the central source is likely reflected by dust in the $N N$ jet, since they show a red-shifted velocity profile where it is expected to find only blue-shifted velocities (if they were due to intrinsic emission). Furthermore, He I $\lambda 10830$ shows a velocityvariable P Cyg profile in that region (shown by the dashed line from position 1 to 8 in Fig. 9), which is also a strong suggestion of reflection. However, beyond 6 arcsec from the central source, the reflected profile disappears and a blue-shifted emission begins to raise at approximately $-570 \mathrm{~km} \mathrm{~s}^{-1}$ going up to $-650 \mathrm{~km} \mathrm{~s}^{-1}$ at 8 arcsec (see Fig. 9). Therefore, our results suggest that there are at least two regions where radiation is escaping to excite/ionize gas lying in the equatorial disc.
In a binary context, these regions could be produced by the high-energy radiation coming direct from the hot source of the system, which spends most of its orbital period near apastron, in a highly elliptical orbit. Thus, if the plane of the orbit is the same as the equatorial disc, then one would expect the UV from the secondary to escape through the holes in the torus and excite/ionize helium atoms along its way. It would be very interesting to observe these regions along the period of $5.52 \mathrm{yr}$ to see their behavior near the minimum, when the hot companion gets into the dense wind of the primary. Hence, if our assumption is correct, the He I $\lambda 10830$ emission column would fade and then return.

We also noted that to the SW direction - toward the $S$-condensation - we only detected reflected components as well as intrisic emission associated with the equatorial disc but no signal of another He I $\lambda 10830$ emission column (see Fig. 10).
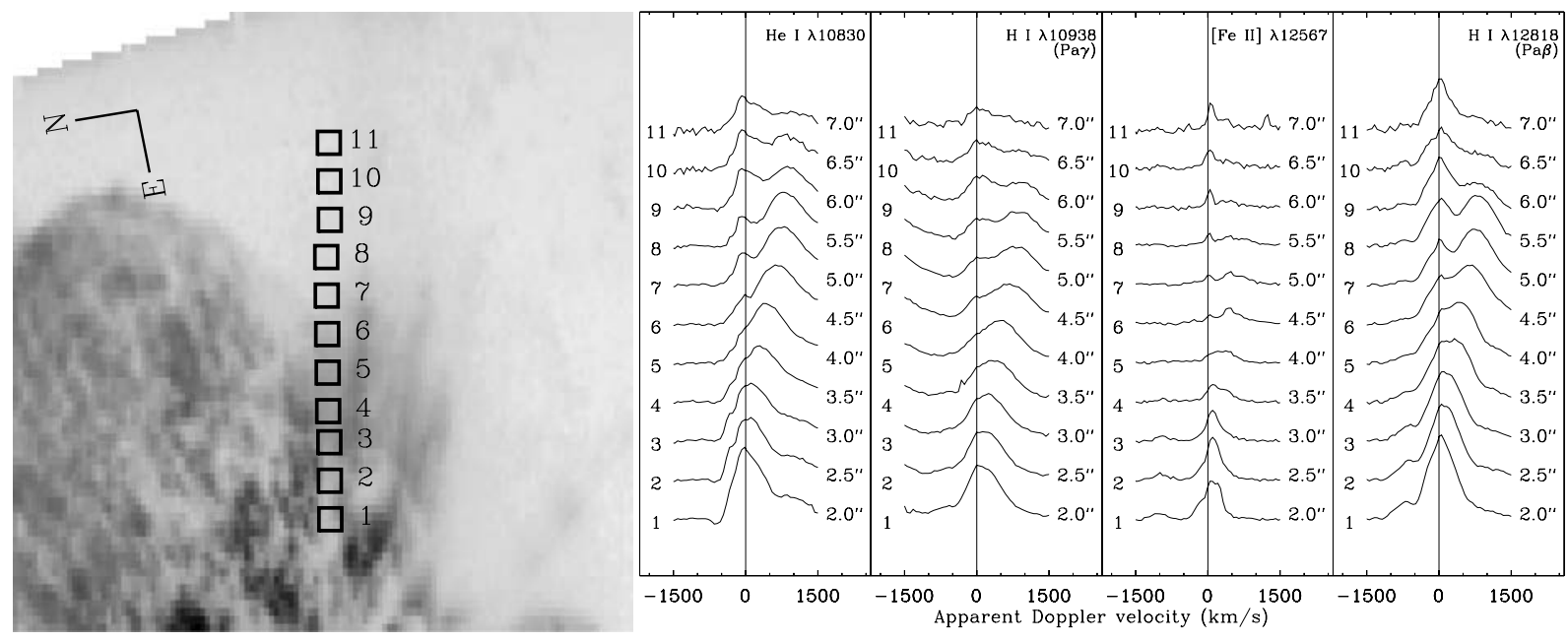

Figure 10. Same as Fig. 9 but extracted towards the S-condensation. At this position angle, we did not detected any component in the helium line that could be due to high-energy photons (far-UV from the secondary) escaping through holes in the equatorial torus. We only detected intrinsic emission due to the equatorial disc as well as reflected components. Notice that all of the lines show a component near $0 \mathrm{~km} \mathrm{~s}^{-1}$, which remains with practically the same apparent Doppler velocity at all of the positions. This component may be associated to the $\mathrm{H}$ II region in which $\eta \mathrm{Car}$ is immersed. To better visualization, the image of the Homunculus was rotated by $-100^{\circ}$. 


\section{DISCUSSION}

\subsection{The 3-cm radio emission}

The radio monitoring performed by Duncan \& White (2003) revealed that during the low-excitation phases (when the highexcitation lines weaken or vanish - Gaviola 1953; Rodgers \& Searle 1967; Thackeray 1967; Zanella, Wolf \& Stahl 1984) the free-free emission is concentrated in a small region of $\sim 1.5$ arcsec in diameter. However, during the 'normal' state, a more extended 3-cm radio emission region of about 4 arcsec is present, which can be seen by the contours in Fig. 11.

It is often assumed that the structure seen at $3-\mathrm{cm}$ radio continuum is the equatorial torus. In this context, during the high-excitation state, the surrounding torus absorbs the UV radiation and then is kept ionized throughout the most part of the orbital period. However, when the secondary star is at periastron, the ionizing flux is rapidly absorbed by the dense wind of the primary star and thus the previously ionized 4 arcsec-wide region - namely, the torus - is allowed to recombine and therefore, the radio-continuum flux is reduced to a point-like source, that is, restricted to a small Strömgren sphere around the hot companion.

On the other hand, the ionizing flux could also be absorbed in the lobes of the LH. Duncan et al. (1997) showed that the H91 $\alpha$ flux is composed of mainly two components: one bright and narrow feature $\left(\mathrm{FWHM} \approx 250 \mathrm{~km} \mathrm{~s}^{-1}\right.$ ) with peak at $-250 \mathrm{~km} \mathrm{~s}^{-1}$ and a broad $\left(\mathrm{FWHM} \approx 600 \mathrm{~km} \mathrm{~s}^{-1}\right)$, fainter emission with peak at approximately $-115 \mathrm{~km} \mathrm{~s}^{-1}$ (Duncan et al. 1997). The brightest component is presumably equatorial emission due to a turbulent gas cloud located at 1.6 arcsec NW of the central source. This cloud must be colder than the rest of the torus because of its high ratio of spectral-line to continuum, which is an indicator of the temperature of the emitting region (Duncan et al. 1997, and references therein).

Although the projected position of this cold cloud (which we refer to as the radio spot) is the same as the 'Sr-filament' (see Fig. 12),

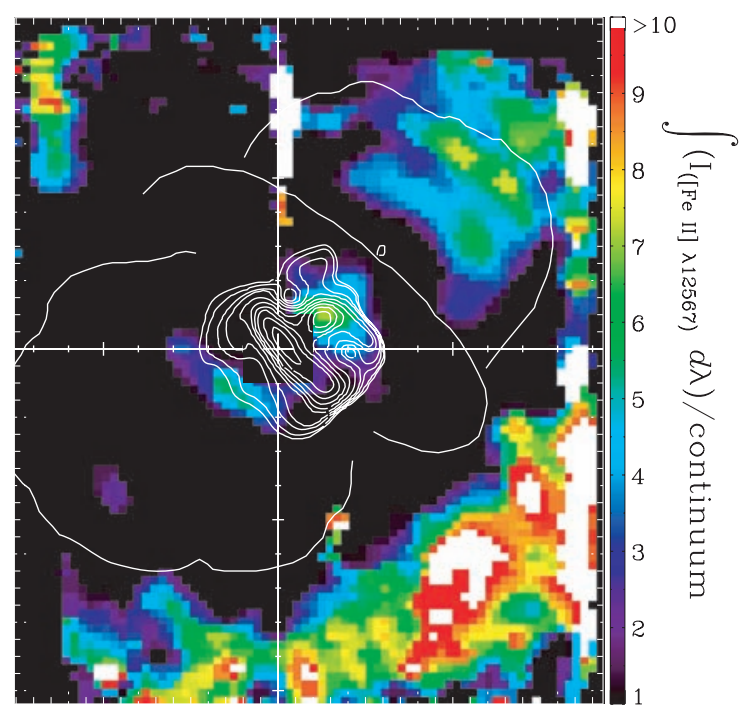

Figure 11. The background image represents the integral of the [Fe II] $\lambda 12567$ line flux from -1000 to $+1000 \mathrm{~km} \mathrm{~s}^{-1}$ normalized by the adjacent continuum. The continuum radio-emission at $3 \mathrm{~cm}$ (from Duncan et al. 1997) is superimposed to show that the low levels match the spatial extent of the Little Homunculus, as claimed by Smith (2005). Also, note the spatial coincidence between the NW radio peak and and the emission from the equatorial region (see discussion in Section 5.1).
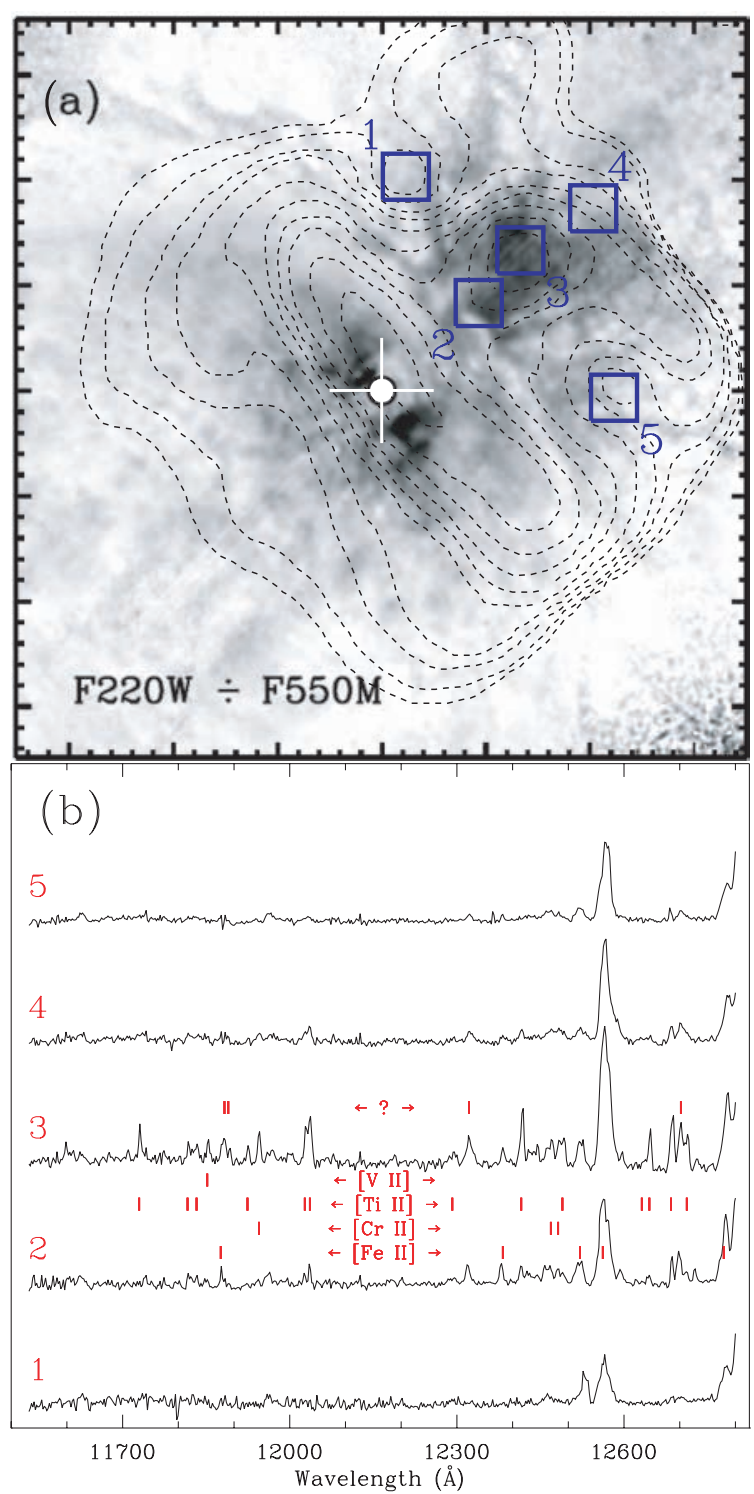

Figure 12. (a) 3-cm radio contours from Duncan et al. (1997) superimposed on an image of the ratio of F220W to F550M from Smith et al. (2004) (reproduced with permission). In the background image, dark areas indicate stronger UV emission. The radio contours were scaled to take into account an expansion due to the 7-year delay between the radio and optical observations. (b) The spectrum taken from the regions indicated in (a) shows the presence of several low-ionization lines at positions 2 and 3, which have stronger intensity as compared to 1,4 and 5 .

they obviously do not occupy the same spatial region, since the radio spot must be ionized to be seen in radio frequencies while the 'Sr-filament' shows many lines of low-ionization ions such as [Sr II], [Ti II], etc. (Zethson et al. 1999; Hartman et al. 2001, 2004). Lines of these same ions were also present in our data, as shown in Fig. 12 and listed in Table 1. In addition, the kinematics of the 'Sr-filament' $\left(\approx-100 \mathrm{~km} \mathrm{~s}^{-1}\right)$ does not match the observed velocity of the peak of the bright $\mathrm{H} 91 \alpha$ component $\left(\approx-250 \mathrm{~km} \mathrm{~s}^{-1}\right)$. We noted, though, that the He I $\lambda 10830$ emission column does match the velocity of the radio peak. Moreover, they are located at roughly the same projected position, suggesting that they may be related to each other. There is no doubt that this relationship deserves fur- 
Table 1. Emission lines observed in the region of the 'Sr-filament'. The unidentified lines are listed with a '?' symbol. Note that $[\mathrm{Fe}$ II] $\lambda 12567$ has three components (shown in bold font).

\begin{tabular}{|c|c|c|}
\hline$\lambda_{\text {obs }}(\AA)$ & Ion & Velocity $\left(\mathrm{km} \mathrm{s}^{-1}\right)$ \\
\hline 11730.8 & [Ti II] $\lambda 11736$ & -130 \\
\hline 11817.7 & [Ti II] $\lambda 11823$ & -142 \\
\hline 11833.8 & [Ti II] $\lambda 11838$ & -132 \\
\hline 11853.0 & [V II] $\lambda 11857$ & -110 \\
\hline 11877.2 & {$[\mathrm{Fe} \mathrm{II}] \lambda 11882$} & -110 \\
\hline 11883.9 & $?$ & \\
\hline 11890.8 & $?$ & \\
\hline 11925.2 & [Ti II] $\lambda 11930$ & -130 \\
\hline 11945.8 & {$[\mathrm{Cr}$ II $] \lambda 11950$} & -115 \\
\hline 12028.1 & [Ti II] $\lambda 12033$ & -115 \\
\hline 12037.1 & [Ti II] $\lambda 12042$ & -115 \\
\hline 12292.8 & [Ti II] $\lambda 12298$ & -115 \\
\hline 12322.9 & $?$ & \\
\hline 12383.5 & {$[\mathrm{Fe} \mathrm{II}] \lambda 12388$} & -100 \\
\hline 12416.6 & [Ti II] $\lambda 12422$ & -120 \\
\hline 12469.7 & {$[\mathrm{Cr}$ II $] \lambda 12476$} & -140 \\
\hline 12482.8 & {$[\mathrm{Cr}$ II $] \lambda 12488$} & -135 \\
\hline 12490.5 & [Ti II] $\lambda 12496$ & -140 \\
\hline 12521.8 & {$[\mathrm{Fe} \mathrm{II}] \lambda 12521$} & +10 \\
\hline 12556.3 & & -250 \\
\hline 12563.2 & {$[\mathrm{Fe}$ II] $\lambda 12567$} & -85 \\
\hline 12573.1 & & +150 \\
\hline 12633.0 & [Ti II] $\lambda 12638$ & -120 \\
\hline 12646.5 & [Ti II] $\lambda 12651$ & -105 \\
\hline 12685.5 & [Ti II] $\lambda 12692$ & -145 \\
\hline 12703.1 & $?$ & \\
\hline 12713.7 & {$[\mathrm{Ti}$ II]/[Mn II] $\lambda 12719$} & -115 \\
\hline \multirow[t]{2}{*}{12787.3} & {$[\mathrm{Fe}$ II] $\lambda 12787$} & +10 \\
\hline & Mean velocity & $-109 \pm 9$ \\
\hline
\end{tabular}

ther studies, since it could give important clues about the ionizing source.

Regarding the faint component of the $\mathrm{H} 91 \alpha$ emission, it could arise from both the torus and the LH because of the spatial coincidence that exists between the low-level contours of the broad radio-emission and the extent of the $\mathrm{LH}$ (see Fig. 11). Moreover, the FWHM of this component is similar to the range of velocities observed in the $\mathrm{LH}\left(\approx \pm 250 \mathrm{~km} \mathrm{~s}^{-1}\right.$; Smith 2005).

\subsection{On the nature of $\eta$ Car B}

Independently of where the radio emission is formed and assuming that the free-free emission discussed in Section 5.1 is caused mainly by the UV radiation field of $\eta \mathrm{Car} \mathrm{B}$, we estimated the number of Lyman continuum photons using the following relation (Mezger, Smith \& Churchwell 1974; Carpenter, Snell \& Schloerb 1990; Filipovic, Jones \& White 2003; Morgan et al. 2004)

$N_{\mathrm{Ly}}=\phi a\left(v, T_{\mathrm{e}}\right)^{-1}\left[\frac{v}{\mathrm{GHz}}\right]^{0.1}\left[\frac{T_{\mathrm{e}}}{\mathrm{K}}\right]^{-0.45}\left[\frac{S_{v}}{\mathrm{Jy}}\right]\left[\frac{D}{\mathrm{kpc}}\right]^{2}$,

where $N_{\text {Ly }}$ is the number of photons per second in the Lyman continuum, $\phi$ is a numeric constant $\left(=4.76 \times 10^{48}\right), a\left(v, T_{\mathrm{e}}\right)$ is a slowly varying function tabulated by Mezger \& Henderson (1967), $v$ is the frequency at which the observation is made, $T_{\mathrm{e}}$ is the electronic temperature, $S_{v}$ is the flux density, and $D$ is the distance to the source.
Using the observed radio continuum flux at $1.3 \mathrm{~mm}^{8}$ when the system is at high-excitation state (i.e. when $\eta \mathrm{Car} \mathrm{B}$ is out of dense wind of the primary star) $S_{v} \approx 39$ Jy (Abraham, Z., private communication) and a value of $a\left(v, T_{\mathrm{e}}\right) \sim 1$ for $T_{\mathrm{e}} \sim 10^{4} \mathrm{~K}$ (Mezger \& Henderson 1967), the ionising flux is $\log \left(N_{\text {Ly }}\right) \approx 49.4$. This corresponds to a star with the minimum spectral type of O5.5 III to O7 I star (Martins, Schaerer \& Hillier 2005). As we can only put a lower limit to the number of Lyman continuum photons and to the spectral type, we can not rule out a late-type Wolf-Rayet companion, which also has $\log \left(N_{\text {Ly }}\right)>49.4$ (Crowther 2007).

An O7 I presents stellar parameters compatible with other other works. The effective temperature for such a star is about $35000 \mathrm{~K}$ (Martins et al. 2005), which is well within the range of 34000 $38000 \mathrm{~K}$ determined by Verner et al. (2005) based on the observed ratio of [Ar III] $\lambda 7136$ to [Ne III] $\lambda 3869$ in the Weigelt blobs. Iping et al. (2005) also indicates an effective temperature near $35000 \mathrm{~K}$ using spectra obtained with the Far Ultraviolet Spectroscopic Explorer (FUSE). Altough the flux of $\eta$ Car B is expected to dominate the spectra at wavelengths shortward of $1200 \AA$ (Hillier et al. 2006), the quantitative analysis is rather complex (Hillier et al. 2006). An O5.5 III star presents stellar parameters that are also similar to those assumed for $\eta$ Car B. Following Martins et al. (2005), an O5.5 III star has an effective temperature of about $39250 \mathrm{~K}$, which is higher than the upper limit of Verner et al. (2005). Nevertheless, this effective temperature is rather acceptable since, there may be gas between the ionizing source and the Weigelt blobs responsible for absorbing the high energy part of the spectrum, and thus decreasing the estimating of the effective temperature.

It is worthwhile to note that Prinja, Barlow \& Howarth (1990) showed that early-type stars in the range from O5.5 $\left(T_{\text {eff }} \approx\right.$ $39250 \mathrm{~K})$ to $\mathrm{O} 7\left(T_{\mathrm{eff}} \approx 35000 \mathrm{~K}\right)$ present terminal velocities in the range from 1100 up to $3000 \mathrm{~km} \mathrm{~s}^{-1}$, which agrees with the values proposed for $\eta$ Car B by (Davidson 1999; Pittard \& Corcoran 2003) based on hydrodynamic calculations.

\section{SUMMARY AND CONCLUSIONS}

Near-infrared integral field spectroscopy has revealed additional details of the circumstellar ejecta around $\eta$ Car. The main results and conclusions are summarized below:

(i) We determined the dimensions and geometry of the hole present in both lobes of the Homunculus using our [Fe II] $\lambda 12567$ velocity maps and the model of Smith (2006) for the Homunculus. The holes have a diameter of $\approx 6.0 \times 10^{16} \mathrm{~cm}$ and is $\approx 6.5 \times$ $10^{16} \mathrm{~cm}$-thick at the polar region. They are located within $5^{\circ}$ from the pole, suggesting an inhibited mass loss at stellar latitudes $\gtrsim 85^{\circ}$ during the Great Eruption. These holes are seen in the $\mathrm{H}_{2}$ and [Fe II] $\lambda 16435$ lines as well Smith (2006);

(ii) The feature known as the $S E$ hole in optical images is a region with a local minimum column density towards the SE lobe caused by the fact that we are looking through the borders of the hole;

(iii) We confirmed the claim of Smith (2005) and also suggested that the broad component of the $3-\mathrm{cm}$ continuum radio-emission originates both in the torus and the LH because of the spatial coincidence between the low-level contours of the radio emission and the extent of the LH, though the bulk of emission is due to the torus. Moreover, the width of the broad radio-emission is also consistent with the kinematics of the LH.

\footnotetext{
${ }^{8}$ At this wavelength the free-free emission is optically thin (Abraham et al. 2005).
} 
(iv) The He I $\lambda 10830$ emission column presents a Hubble flow from $-250 \mathrm{~km} \mathrm{~s}^{-1}$ (at 2 arcsec from the central source) to $\approx-500 \mathrm{~km} \mathrm{~s}^{-1}$ (at 10.5 arcsec). Its position angle is $-48^{\circ}$ and based on symmetry and kinematic arguments, we suggested that the He I $\lambda 10830$ emission column is not related to the Paddle, which shows P.A. $=-41^{\circ}$. None the less, our results suggest that it is indeed in the equatorial disc (with inclination angle of $i_{\mathrm{He}}=44^{\circ}$ ) and is most likely related to the radio spot (the narrow component of the 3-cm continuum radio-emission reported by Duncan et al. 1997).

(v) We also detected another He I $\lambda 10830$ emission column at P.A. $=+35^{\circ}$, confirming the suggestion that such structure is indeed caused by high-energy photons (far-UV from $\eta$ Car B) escaping through holes in the equatorial disc.

(vi) The radio spot and the 'Sr-filament' are in the same lineof-sight but disconnected spatially. While the former is an ionized region with peak at $-250 \mathrm{~km} \mathrm{~s}^{-1}$, the latter is characterized by lowionization lines with typically $-110 \mathrm{~km} \mathrm{~s}^{-1}$, presumably shielded from high-energy radiation by $\mathrm{H}^{0}$ and a forest of $\mathrm{Fe}^{+}$(Bautista et al. 2002, 2006)

(vii) From the observed 1.3-mm radio flux we estimated that the ionising flux, which comes from $\eta$ Car B, is consistent with an O-type star hotter than O5.5 III to O7 I, though we can not rule out a Wolf-Rayet nature to the companion at this point.

\section{ACKNOWLEDGMENTS}

MT, AD, JHG and CLB are grateful to the Brazilian agencies CNPq and FAPESP for continuous financial support. We would like to thank Dr Nathan Smith for his extensive comments and suggestions on the earlier versions of this manuscript, as well as Dr Jon Morse for kindly granting the permission to use the HST/WFPC 2 images of the Homunculus shown in this paper. We are grateful to the referee Dr Theodore Gull for his fruitful comments that have improved the content and presentation of our results. MT also would like to thank Michelle Doherty for her efforts in obtaining all the calibration data. MT is supported by FAPESP through grant 05/00190-8. Based on observations obtained at the Gemini Observatory, which is operated by the Association of Universities for Research in Astronomy, Inc., under a cooperative agreement with the NSF on behalf of the Gemini partnership: the National Science Foundation (United States), the Particle Physics and Astronomy Research Council (United Kingdom), the National Research Council (Canada), CONICYT (Chile), the Australian Research Council (Australia), CNPq (Brazil) and CONICET (Argentina).

\section{REFERENCES}

Abraham Z., Falceta-Gonçalves D., Dominici T., Caproni A., JatencoPereira V., 2005, MNRAS, 364, 922

Allen D., Hillier J., 1991, Proc. Astron. Soc. Aust., 9, 120

Allen D. A., Hillier D. J., 1993, Proc. Astron. Soc. Aust., 10, 338

Bautista M. A., Gull T. R., Ishibashi K., Hartman H., Davidson K., 2002, MNRAS, 331, 875

Bautista M. A., Hartman H., Gull T. R., Smith N., Lodders K., 2006, MNRAS, 370, 1991

Carpenter J. M., Snell R. L., Schloerb F. P., 1990, ApJ, 362, 147

Crowther P. A., 2007, ARA\&A, 45, 177

Currie D. G., Dowling D. M., 1999, in Morse J. A., Humphreys R. M., Damineli A., eds, AsP Conf. Ser. Vol. 179, Eta Carinae at The Millennium. Astron. Soc. Pac., San Francisco, p. 72

Currie D. G., Dowling D. M., Shaya E. J., Hester J., Scowen P., Groth E. J., Lynds R., O’Neil E. J., Jr., 1996, AJ, 112, 1115

Damineli A., 1996, ApJ, 460, L49
Damineli A., Kaufer A., Wolf B., Stahl O., Lopes D. F., de Araújo F. X., 2000, ApJ, 528, L101

Davidson K., 1999, in Morse J. A., Humphreys R. M., Damineli A., eds, ASP Conf. Ser. Vol. 179, Eta Carinae at The Millennium. Astron. Soc. Pac., San Francisco, p. 304

Davidson K., Ebbets D., Johansson S., Morse J. A., Hamann F. W., 1997, AJ, 113,335

Davidson K., Zethson T., Johansson S., Ishibashi K., Ebbets D., 1997, BAAS 29,1261

Davidson K., Smith N., Gull T. R., Ishibashi K., Hillier D. J., 2001, AJ, 121, 1569

Dorland B. N., Currie D. G., Hajian A. R., 2004, AJ, 127, 1052

Duncan R. A., White S. M., 2003, MNRAS, 338, 425

Duncan R. A., White S. M., Lim J., 1997, MNRAS, 290, 680

Duschl W. J., Hofmann K.-H., Rigaut F., Weigelt G., 1995, in Niemela V., Morrell N., Feinstein A., eds, Rev. Mex. Astron. Astrofis. Ser. Conf. Vol. 2, Morphology and Kinematics of Eta Carinae. UNAM, Mexico, p. 17

Filipovic M. D., Jones P. A., White G. L., 2003, Serbian Astron. J., 166, 31

Gaviola E., 1950, ApJ, 111, 408

Gaviola E., 1953, ApJ, 118, 234

González R. F., de Gouveia Dal Pino E. M., Raga A. C., Velazquez P. F., 2004, ApJ, 600, L59

Gull T., Zethson T., Hartman H., Johansson S., Davidson K., Ishibashi K., 2000, BAAS, 32, 682

Gull T. R., Hartman H., Zethson T., Johansson S., Ishibashi K., Davidson K., 2001, BAAS, 33, 1505

Gull T. R., Vieira G., Bruhweiler F., Nielsen K. E., Verner E., Danks A., 2005, ApJ, 620, 442

Hamaguchi K. et al., 2007, ApJ, 663, 522

Hartman H., Zethson T., Johansson S., Gull T., Ishibashi K., Davidson K., Smith N., 2001, in Gull T. R., Johannson S., Davidson K., eds, ASP Conf. Ser. Vol. 242, Eta Carinae and Other Mysterious Stars: The Hidden Opportunities of Emission Spectroscopy. Astron. Soc. Pac., San Francisco, p. 107

Hartman H., Gull T., Johansson S., Smith N., HST Eta Carinae Treasury Project Team, 2004, A\&A, 419, 215

Hillier D. J., Allen D. A., 1992, A\&A, 262, 153

Hillier D. J. et al., 2006, ApJ, 642, 1098

Iping R. C., Sonneborn G., Gull T. R., Massa D. L., Hillier D. J., 2005, ApJ, 633, L37

Ishibashi K. et al., 2003, AJ, 125, 3222

Martins F., Schaerer D., Hillier D. J., 2005, A\&A, 436, 1049

Meaburn J., Boumis P., Walsh J. R., Steffen W., Holloway A. J., Williams R. J. R., Bryce M., 1996, MNRAS, 282, 1313

Meaburn J., Walsh J. R., Wolstencroft R. D., 1993, A\&A, 268, 283

Mezger P. G., Henderson A. P., 1967, ApJ, 147, 471

Mezger P. G., Smith L. F., Churchwell E., 1974, A\&A, 32, 269

Morgan L. K., Thompson M. A., Urquhart J. S., White G. J., Miao J., 2004, A\&A, 426, 535

Morris P. W. et al., 1999, Nat, 402, 502

Morse J. A., Kellogg J. R., Bally J., Davidson K., Balick B., Ebbets D., 2001, ApJ, 548, L207

Morse J. A., Davidson K., Bally J., Ebbets D., Balick B., Frank A., 1998, AJ, 116, 2443

Parry I. et al., 2004, in Moorwood A. F. M., Iye M., eds, Proc. SPIE Vol. 5492, Ground-based Instrumentation for Astronomy. SPIE, Bellingham WA, p. 1135

Pittard J. M., Corcoran M. F., 2003, in Arthur J., Henney W. J., eds, Rev. Mex. Astron. Astrofis. Ser. Conf. Vol. 15, The Wind Properties of Eta Carinae. UNAM, Mexico, p. 81

Prinja R. K., Barlow M. J., Howarth I. D., 1990, ApJ, 361, 607

Ringuelet A. E., 1958, Zeitschrift fur Astrophysik, 46, 276

Rodgers A. W., Searle L., 1967, MNRAS, 135, 99

Smith N., 2002, MNRAS, 337, 1252

Smith N., 2004, MNRAS, 351, L15

Smith N., 2005, MNRAS, 357, 1330 
Smith N., 2006, ApJ, 644, 1151

Smith N., 2007, AJ, 133, 1034

Smith N., Davidson K., 2001, ApJ, 551, L101

Smith N., Ferland G. J., 2007, ApJ, 655, 911

Smith N., Gehrz R. D., 1998, AJ, 116, 823

Smith N., Gehrz R. D., 2000, ApJ, 529, L99

Smith N., Townsend R. H. D., 2007, ApJ, 666, 967

Smith N., Gehrz R. D., Krautter J., 1998, AJ, 116, 1332

Smith N., Gehrz R. D., Hinz P. M., Hoffmann W. F., Mamajek E. E., Meyer M. R., Hora J. L., 2002, ApJ, 567, L77

Smith N., Davidson K., Gull T. R., Ishibashi K., Hillier D. J., 2003, ApJ, 586,432

Smith N., Gehrz R. D., Hinz P. M., Hoffmann W. F., Hora J. L., Mamajek E. E., Meyer M. R., 2003, AJ, 125, 1458

Smith N., Morse J. A., 2004, ApJ, 605, 854

Smith N. et al., 2004, ApJ, 605, 405

Thackeray A. D., 1967, MNRAS, 135, 51

Verner E., Bruhweiler F., Gull T., 2005, ApJ, 624, 973

Weis K., 2002, preprint (astro-ph/0208493)

Weis K., Duschl W. J., Chu Y.-H., 1999, A\&A, 349, 467

Weis K., Duschl W. J., Bomans D. J., 2001, A\&A, 367, 566

Weis K., Corcoran M. F., Bomans D. J., Davidson K., 2004, A\&A, 415, 595

Zanella R., Wolf B., Stahl O., 1984, A\&A, 137, 79

Zethson T., Johansson S., Davidson K., Humphreys R. M., Ishibashi K., Ebbets D., 1999, A\&A, 344, 211

Zethson T., Gull T. R., Hartman H., Johansson S., Davidson K., Ishibashi K., 2001, AJ, 122, 322

\section{SUPPLEMENTARY MATERIAL}

The following supplementary material is available for this article:

Fig. 3. Animated version. Velocity maps of the $[\mathrm{Fe} I I] \lambda 12567$ line showing a hole both in the SE and NW lobe (Smith et al. 1998).
The coordinates of the NW hole are the same as the SE hole but rotated by $180^{\circ}$ around the centre of the axis. Notice the change in the colour scale to bring up weaker emissions in each lobe. The emission from the surrounding of the hole is almost 50 per cent greater than that coming from the hole itself. The system velocity is $8.1 \mathrm{~km} \mathrm{~s}^{-1}$ heliocentric (Smith 2006).

Fig. 5. Animated version. Velocity maps of the [Fe II] $\lambda 12567$ line showing the observed structures and its identification. LH means emission associated to the Little Homunculus while EQ is due to the equatorial disc.

Fig. 8. Animated version. Velocity maps for the He I $\lambda 10830$ line showing the location of the He emission column (He I E.C. in the figure) and the Paddle. The misalignment between the P.A. of the Paddle and that of the helium emission column is clearly seen in (b). Also, note the strong emission (white region) near the centre in (d), which is associated to the Purple Haze.

This material is available as part of the online paper from: http://www.blackwell-synergy.com/doi/abs/10.1111/ j.1365-2966.2008.13264.x (this link will take you to the article abstract).

Please note: Blackwell Publishing are not responsible for the content or functionality of any supplementary materials supplied by the authors. Any queries (other than missing material) should be directed to the corresponding author for the article.

This paper has been typeset from a $\mathrm{T}_{\mathrm{E}} \mathrm{X} / \mathrm{L} \mathrm{T} \mathrm{T}_{\mathrm{E}} \mathrm{X}$ file prepared by the author. 


\title{
The Goodman/SOAR optical monitoring of the 2009.0 spectroscopic event of $\eta$ Carinae: (I) The He II $\lambda 4686$ light curve
}

\author{
M. Teodoro \\ and \\ A. Damineli \\ Instituto de Astronomia, Geofísica e Ciências Atmosféricas, Universidade de São Paulo, \\ Rua do Matão 1226, Cidade Universitária, São Paulo, 05508-900, Brazil \\ mairan@astro.iag.usp.br \\ J. E. Steiner \\ Instituto de Astronomia, Geofísica e Ciências Atmosféricas, Universidade de São Paulo, \\ Rua do Matão 1226, Cidade Universitária, São Paulo, 05508-900, Brazil \\ J. H. Groh \\ Max-Planck-Institute für Radioastronomie, Auf dem Hügel 69, D-53121 Bonn, Germany \\ et al... \\ et al...
}

\begin{abstract}
We present the first well-sampled (day-by-day) monitoring of He II $\lambda 4686$ during a spectroscopic event. Our results show that before the spectroscopic minimum there are 2 peaks in the equivalent width of this line and short after the minimum, another one occurs, which was never seen before because of poor time sampling. We also, measured the peak and centroid velocities through the event and found that they follow an inverted S-wave, usually seen in close binaries, with stable and periodic behavior, as well as smaller velocity amplitude than predicted by some theoretical models. Our main result is that the light curve is extremely stable and periodic. The interpretation and modelling of the results shown in this paper can put several important constraints on the orbital and dinamical parameters.
\end{abstract}

Subject headings: KEYWORDS

\section{Introduction}

The first detection of He II $\lambda 4686$ was done by Steiner and Damineli (2004), using data obtained during the events of 1992.5, 1998.0 and 2003.5, collected at the Observatório Pico dos Dias, Brazil.

Apart from the discover itself, the main result shown by those authors was the detection of a peak of about $1 \AA$ in the equivalent width of the line occurring previously to the spectroscopic min- imum. Since then, many works have tried to explain the observed behavior of this line based on the light curve and line profile shown by those authors (Abraham et al. 2005; Soker and Behar 2006). At that time, the only event with a good time-sampling was that of 2003.5, which covered from 10 days before the minimum up to 20 days after.

Obviously, a better monitoring was necessary and the golden opportunity came with the 2009 
event, which was predicted to occur on mid January, which coincides with the epoch when $\eta$ Car is crossing the meridian and therefore, the entire spectroscopic event would then fit the best observational window in the last 20 year.

Therefore, an observational campaign was planned by us to monitor the optical spectrum of $\eta$ Car with as many facilities as possible. The results are shown in the present paper, which is divided as follows. In section 2, we comment on the observations, while in section 3 , we describe how we measured the equivalent width and velocities of the He II $\lambda 4686$ line and in section 4 we show our results. Finally, the discussion and main conclusions are shown in section 5 .

\section{Observations}

\subsection{The 2009.0 monitoring campaigns}

We carried out a day-by-day spectroscopic monitoring of the optical spectrum of $\eta$ Car at SOAR from 2008 December to 2009 January. After the spectroscopic minimum, the data was obtained at a rate of one observation per month until 2009 May. We used the Goodman optical spectrograph to obtain blue and red spectra with spectral resolution, $R=\lambda / \Delta \lambda$, of about 3000 (3 pixels) in the range from 4150 to $6850 \AA$.

The FEROS data was obtained exclusively before the event, on late December. It delivers spectra with high-resolution $(R \approx 24000$ with 2 pixels $)$ and wide spectral range (from 3500 to $9200 \AA$ ) in one single observation.

We also collected data at the Coudé focus of the $1.60 \mathrm{~m}$ telescope of the Pico dos Dias Observatory (OPD-LNA/Brazil), during 2008 December and on 2009 January and February. With our chosen set-up, we obtained spectra with $R \approx 10000$ (2 pixels) from 4430 to $4930 \AA$.

\subsection{Past events: $1992.5,1998.0,2003.5$}

The data from past events shown in the present paper were obtained at OPD (1992.5 and 2003.5) and FEROS (1992.5), both with with the same set-up as described before. We also have spectra taken on 1997 November and December and on 2009 February and March, at the Coudé focus of the $1.9 \mathrm{~m}$ telescope of the Mount Stromlo and Siding Spring Observatory (MSSSO), which have spectral resolution of about 60000 from 4346 to $4935 \AA$.

\section{Methodology of measurements}

In order to have an homogeneous dataset and reduce systematic errors, we aplied the same region for the continuum and line integration for all of the data. The blue continuum was set at $4605 \AA$ and the red, at $4742 \AA$. Thus, we normalized the spectrum using these regions and measured the equivalent width by direct integration of the line profile in the range from 4675 to $4694 \AA$.

Regarding the velocity measurements, the peak velocity was measured directly as the velocity where the normalized intensity reaches its maximum value. On the other hand, the centroid wavelenght was calculated using the following relation

$$
\lambda_{c e n t}=\frac{\sum_{\lambda=\lambda_{1}}^{\lambda_{2}} \lambda\left(I_{\lambda}-C_{\lambda}\right)^{3 / 2}}{\sum_{\lambda=\lambda_{1}}^{\lambda_{2}}\left(I_{\lambda}-C_{\lambda}\right)^{3 / 2}},
$$

where $\lambda_{\text {cent }}$ is the centroid wavelenght, $I_{\lambda}$ and $C_{\lambda}$ are the line and continuum intensity at wavelenght $\lambda$, and the summation is done over the line integration range, with $\lambda_{1}=4675 \AA$ and $\lambda_{2}=47694 \AA$. Thus, the centroid velocity is obtained using the well-known relation

$$
v_{c e n t}=\left(\frac{\lambda_{c e n t}-\lambda_{0}}{\lambda_{0}}\right) c,
$$

where $c$ and $\lambda_{0}=4685.7 \AA$ are, respectively, the speed of light and the air rest wavelenght of a photon emitted by the $\mathrm{He}^{+}$ion in the transition of an electron from level 4 to 3 .

The main source of errors in our methodology for measure the equivalent width is the normalization of the spectrum continuum, which was done using a second order Chebyshev polynomy through the regions defined by the blue and red continuum. Specifically, those data obtained with échelle grating suffers from order overlapping and a good correction for this is crucial to have a spectrum without jumps or wobbles. Thus, in the present paper we only used those data with a good rectified continuum, which results in an average dispersion of $150 \mathrm{~m} \AA$.

Regarding the wavelength calibration, it was obtained with the observation of arc lamps before or after the observation of $\eta$ Car and the 
residual in the dispersion solution was kept below $0.01 \AA$, on average, for the SOAR and OPD data. Evidently, it is difficult to ascribe only one error representative of the full observational dataset, because each instrument has its own characteristics, reduction procedure and calibration.

\section{Results}

\subsection{The 15-years light curve}

The observed raw light curve of He II 4686 is shown in the top panel of Fig. 1. That figure was made using data from the last four events (1992.5, 1998.0, 2003.5 and 2009.0) and shifted according to a period of 2022.7 days, as found by Damineli et al. (2008b). We used the well time-sampled observations of 2009.0 along with sparse observations near the minimum of the past four events to show that the He II $\lambda 4686$ emission line has been quite stable and cyclic at least through the last 15 years.

\subsubsection{Period length}

Combining data from the last four events, we found that the period of the event in the He II $\lambda 4686$ line is different, yet consistent, from that determined with other features (e.g. Corcoran 2005; Damineli et al. 2008b,a).

To determine the period, we restricted our data to the phase of linear decreasing of the equivalent line width, which begins about 15 days before minimum. Then, we shifted the data using different trial periods, and for each one we determined the residuals of a fitting line through the data. Using this simple, yet robust approach, similar to the well-known phase dispersion method, the most favored period for the HeII line was 2021.5 days, with an estimated error of about 1.5 days over 15 years. The result is shown in the bottom panel of Fig. 1, where we applied the derived period to the entire curve.

\subsubsection{Stability}

Even though the entire light curve was never seen before so complete as shown in the present paper, sparse historical data show strong evidence that its behavior is quite cyclic, as shown in Fig. 1. For example, the 1998.0 data was already following a trend that indicated the existence of a third peak after the minimum. The same can be said
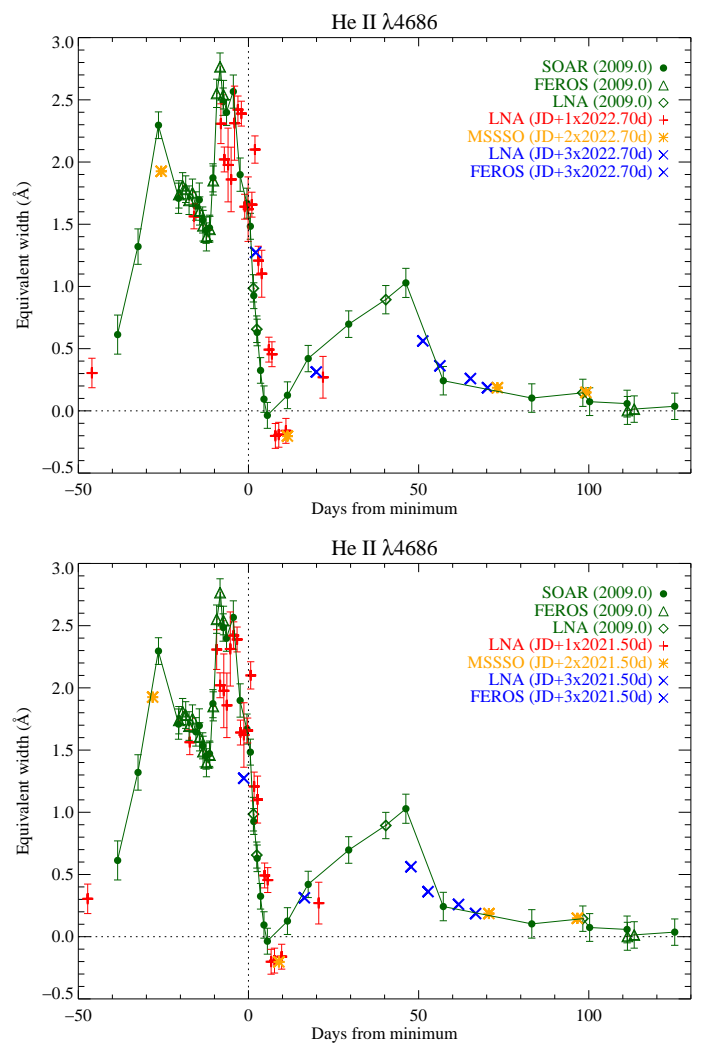

Fig. 1.- Top panel: equivalent width of He II $\lambda 4686$ for the last 4 events: 1992.4 (blue), 1998.0 (yellow), 2003.5 (red) and 2009.0 (green). The data were shifted using a period of 2022.7 days. Bottom panel: same as in top panel but shifted using a period of 2021.5 days. This period gives the least residuals.

for the 1992.5 data, which already hinted at the existence of a peak preceding the last peak before the minimum (which was actually detected in the work of Steiner and Damineli 2004).

\subsection{A detailed comparison between the 2003.5 and 2009.0 events}

\subsubsection{Kinematics}

We measured the radial velocity of both the peak and centroid of the He II 4686 line and the results are shown in Fig 2. Obviously, we do not show the data inside the minimum because they are not reliable.

The peak of this line shows a clear inverted S-wave pattern for both events: it reaches up 

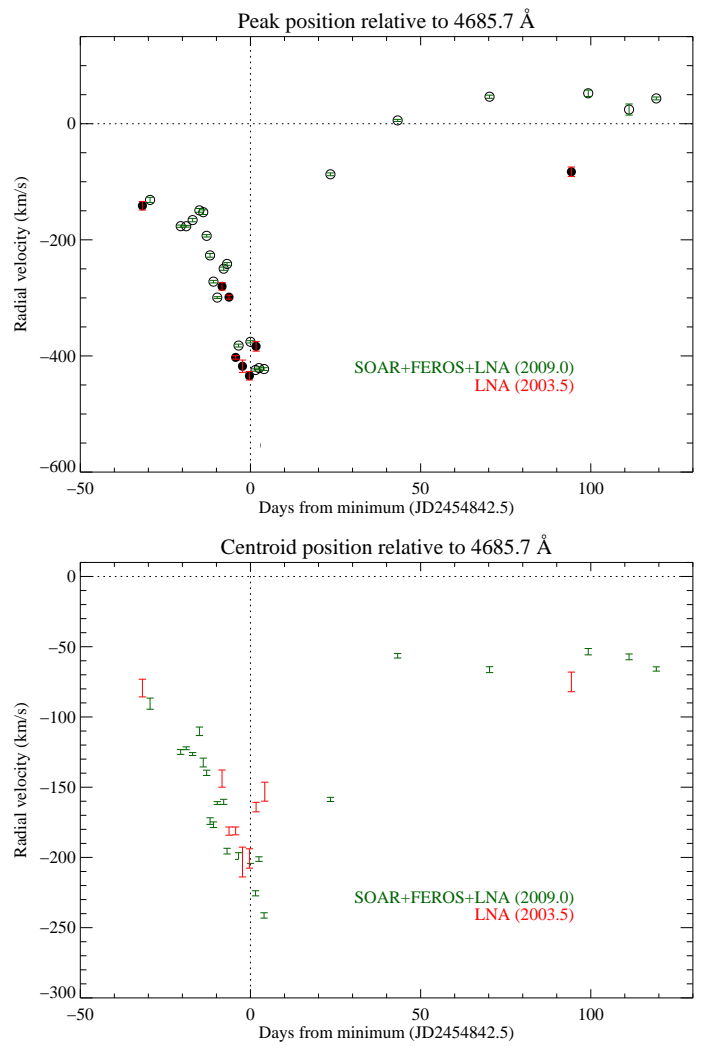

Fig. 2.- Radial velocity curve of the He II $\lambda 4686$. Top panel: velocity of the line peak. Bottom panel: velocity of the line centroid.

to $-450 \mathrm{~km} \mathrm{~s}^{-1}$ just before the minimum, and then vanishes completely during a few days and reappears near $-100 \mathrm{~km} \mathrm{~s}^{-1}$ keeping going up to $+50 \mathrm{~km} \mathrm{~s}^{-1}$, where it seems to remain constant.

We noted that the centroid velocity also shows the same inverted $\mathrm{S}$-wave pattern as the peak. However, with an amplitude almost half of the value observed for the latter. Just before minimum, the line centroid was at $\approx-250 \mathrm{~km} \mathrm{~s}^{-1}$ while short after, it was at $-150 \mathrm{~km} \mathrm{~s}^{-1}$ and stabilized around $-50 \mathrm{~km} \mathrm{~s}^{-1} 30$ days after the minimum. Interestingly, this velocity seems to be observed throughout the cycle, because even when the peak is absent from the spectrum, some line flux $(\lesssim 100 \mathrm{~m} \AA)$ in the range from 4675 to $4695 \AA$ As still present.

\subsubsection{Intrinsic line flux}

To determine the intrinsic flux of any optical line in $\eta$ Car, the main effort must be employed in the determination of the corrections for the extinction law toward $\eta$ Car, which is known to be quite unusual. In the line of sight to the central source in $\eta$ Car is has at least 2 mag of gray extinction associated with large grains around the central source (Hillier et al. 2001; van Genderen et al. 2006).

In the present paper, to determine the observed intrinsic line flux of the He II 4686 line, we based our calculations on the quoted value of $A_{V}=7$ from Hillier et al. (2001), obtained by modelling spectra obtained with HST on 1998. This value corresponds to the total extinction on early 1998 due to the circumstellar and interstellar components.

Since 1950 the central source has been showing an increasing in brightness at irregular rates as discussed by van Genderen et al. (2006). Thus, one cannot simply use the same $A_{V}$ to all of the events but, instead, it is mandatory to apply a specific value for the the total extinction for each epoch. However, this is only possible if $A_{V}$ is known for a given epoch.

van Genderen et al. (2006) showed that on early $2006 A_{V}=5.7$ (for $R_{V}=4.9$ ), assuming that the value of $A_{V}=7\left(R_{V}=5\right)$ estimated by Hillier et al. (2001) for early 1998 was correct. Taking this value as our zero point, and using the light curve of Fernandez Lajus et al. (2003) in the $V$ band, we see that back to 2003.5 the effective change in brightness was of 0.2 magnitudes in $V$. Therefore, $A_{V}$ was about 5.9 on 2003.5.

From 2006.0 to 2009.4, there was no net change in the central source brightness, which results in $A_{V}=5.7$ on early 2009 . This is because between 2006.5 and 2007.25, the central source passed through a phase of brightness decrease and after that did not changed until late 2008. On the other hand, between 2008.9 and 2009.4, the brightness of the central source increased again at the same rate as observed in the previous decreasing phase, resulting in no net changes between 2006.0 and 2009.4 .

It is important to notice that we have calculated the value for the total extinction in the $V$ band for the central source but to flux-calibrate 


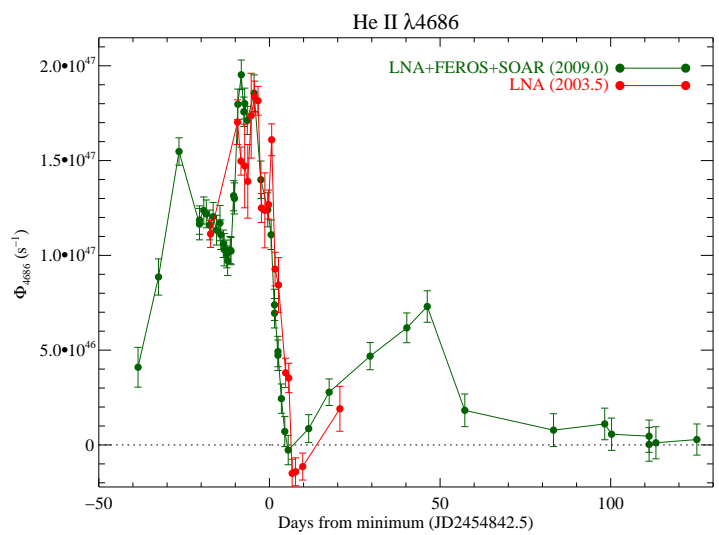

Fig. 3.- Derredened flux of the He II 4686 line for the two last events shifted by a period of 2021.5 days.

the He II line emission we need the brightness near $4686 \AA$ ( $B$ band). Another issue is that the light curves from Fernandez Lajus et al. (2003) were made by summing up the flux from an aperture with a radius of 22 arcsec, which obviously includes the entire Homunculus nebula, an important source of scattered light that needs to be accounted for in the $B$ band. Indeed, constraining the aperture to a smaller radius ( 1 arcsec?), we found that the nebula contributes with about 1.6 magnitudes in $B$. Thus, we added this value to the observed $B$-band photometry from Fernandez Lajus et al. (2003).

For each epoch, we separated $A_{V}$ into two components (interstellar and circumstellar) and applied the formalism of Cardelli et al. (1989, eq. 1) to the interstellar part (with $R_{V}=4.9$ ) in order to transform from $A_{V}$ to $A_{4686}$. We thus used the light curve from Fernandez Lajus et al. (2003) in the $B$ band (derredened and corrected for reflected light) to flux calibrate our data. The result is shown in Fig. 3.

\section{Discussion and conclusions}

In this paper we have shown for the first time a complete (day-by-day) light curve of the He II $\lambda 4686$ through a spectroscopic event (from entering to recovering phase). With such fantastic time sampling, we were able to detect 3 line peaks: 2 before and 1 after the minimum. The first peak and the after-minimum peak were a surprise to us because they were never seen before in any previous work. However, relying on data of the last 4 events, we found that, in spite of their poor timesampling, the equivalent width observed back then do match the 2009.0 ligth curve, suggesting that the after-minimum peak is indeed recurrent, as the rest of the light curve. In fact, we found strong evidence to belive that the He II $\lambda 4686$ emission has been quite stable and cyclic throughout the last 15 years, which gives support to the binary scenario.

We also found that both the light curve and line flux do not changed through the last 2 well time-sampled events (2003.5/2009.0). This result shows that the mechanism behind the production of He II $\lambda 4686$ photons must be stable and cyclic, with an estimated period of 2021.5 days. Also, based on the last 2 events, the dinamics also seems to be quite stable and periodic. Until now, there is no model able to reproduce the smooth transition observed for both the peak and the centroid velocities, as well as its small amplitude. We also noted that in the last two events, namely 2003.5 and 2009.0, the last peak seen before the minimum in the X-ray curves occurs about 16 days before the last peak before the minimum in the He II $\lambda 4686$. This relationship, if confirmed, may give important clues about the nature of the events.

Whatever the mechanism behind the formation of the He II $\lambda 4686$ might be, it must have an energy supply high enough to account for a peak in line flux of about $10^{47.3} \mathrm{~s}^{-1}$. It is worth to notice that Teodoro et al. (2008), based on the radio emission, found a value two orders of magnitudes greater for the ionizing flux coming from the secondary and Parkin et al. (2009), based on 3D modelling, showed that radiative braking and radiative inhibition may play a significant role on the $\mathrm{X}$-ray emission, increasing considerably the flux in the UV/soft X-rays, which could be used to produce the observed He II $\lambda 4686$ flux. Indeed, their model predicts a flux of $10^{48.1} \mathrm{~s}^{-1}$ in the range from 0.054 to $5 \mathrm{keV}$ (Parkin, private communication) and Cloudy simulations showed that in a nebula with $10 \%$ of $\mathrm{He}$, the flux of $4686 \AA$ photons produced by X-rays is about $15 \%$ for any density below $n_{e}=10^{10} \mathrm{~cm}^{-3}$, which results in $10^{47.3} \mathrm{~s}^{-1}$. However, we must stress that these are not the only one models that can produce the observed He II $\lambda 4686$ peak flux. In fact, there are 
many other different models for the origin of this line and each one is valid in some way, but discuss each of them goes well beyond of the scope of this paper and will be the subject of a forthcoming paper.

Finally, we stress the importance of the present He II $\lambda 4686$ light curve in adding much more information about the spectroscopic event than ever before. We showed that it is extremely periodic and stable by comparing the two last well timesampled events (2003.5 and 2009.0) and we have strong reasons to belive it has been so over the last 15 years. With such a detailed light curve, theoretical models will certainly be greatly improved if they could reproduce the results shown in this paper. Furthermore, modelling it would bring important clues about binary interactions and dinamics. Ultimately, it would give us better understanding on the true nature of the events, as this line seems to be the heart-beating of $\eta$ Car.

MT, AD and JES are grateful to the brazilian agencies FAPESP and $\mathrm{CNPq}$ for continuous financial support. MT is supported through grant FAPESP 05/00190-8.

Facilities: SOAR, OPD, FEROS, MSSSO.

\section{REFERENCES}

Abraham, Z., Falceta-Gonçalves, D., Dominici, T., Caproni, A., and Jatenco-Pereira, V.: 2005, MNRAS 364, 922

Cardelli, J. A., Clayton, G. C., and Mathis, J. S.: 1989, АpJ 345, 245

Corcoran, M. F.: 2005, AJ 129, 2018

Damineli, A., Hillier, D. J., Corcoran, M. F., Stahl, O., Groh, J. H., Arias, J., Teodoro, M., Morrell, N., Gamen, R., Gonzalez, F., Leister, N. V., Levato, H., Levenhagen, R. S., Grosso, M., Colombo, J. F. A., and Wallerstein, G.: 2008a, MNRAS 386, 2330

Damineli, A., Hillier, D. J., Corcoran, M. F., Stahl, O., Levenhagen, R. S., Leister, N. V., Groh, J. H., Teodoro, M., Albacete Colombo, J. F., Gonzalez, F., Arias, J., Levato, H., Grosso, M., Morrell, N., Gamen, R., Wallerstein, G., and Niemela, V.: 2008b, MNRAS 384, 1649
Fernandez Lajus, E., Gamen, R., Schwartz, M., Salerno, N., Llinares, C., Farina, C., Amorín, R., and Niemela, V.: 2003, Information Bulletin on Variable Stars 5477, 1

Hillier, D. J., Davidson, K., Ishibashi, K., and Gull, T.: 2001, ApJ 553, 837

Parkin, E. R., Pittard, J. M., Corcoran, M. F., Hamaguchi, K., and Stevens, I. R.: 2009, $M N$ $R A S$ 394, 1758

Soker, N. and Behar, E.: 2006, ApJ 652, 1563

Steiner, J. E. and Damineli, A.: 2004, ApJL 612, L133

Teodoro, M., Damineli, A., Sharp, R. G., Groh, J. H., and Barbosa, C. L.: 2008, MNRAS 387, 564

van Genderen, A. M., Sterken, C., Allen, W. H., and Walker, W. S. G.: 2006, Journal of Astronomical Data 12, 3

This 2-column preprint was prepared with the AAS LATEX macros $\mathrm{v} 5.2$. 